NAT'L INST OF STAND \& TECH 






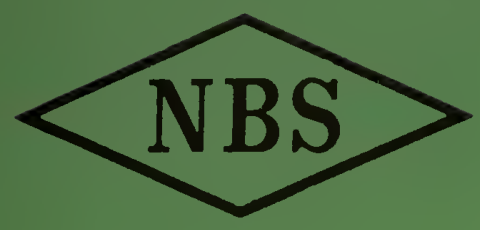

MAR 61973

: $: 0 \Xi 9$

Eechnical Note

$n_{0.326}$

\title{
AN ATLAS OF SOLAR FLARE EFFECTS IN THE IONOSPHERE OBSERVED WITH A HIGH-FREQUENCY DOPPLER TECHNIQUE
}

\author{
September 1960 - December 1962
}

$B Y$

DONALD M. BAKER 


\section{THE NATIONAL BUREAU OF STANDARDS}

The National Bureau of Standards is a principal focal point in the Federal Government for assuring maximum application of the physical and engineering sciences to the advancement of technology in industry and commerce. Its responsibilities include development and maintenance of the national standards of measurement, and the provisions of means for making measurements consistent with those standards; determination of physical constants and properties of materials; development of methods for testing materials, mechanisms, and structures, and making such tests as may be necessary, particularly for government agencies; cooperation in the establishment of standard practices for incorporation in codes and specifications; advisory service to goverument agencies on scientific and technical problems; invention and development of devices to serve special needs of the Government; assistance to industry, business, and consumers in the development and acceptance of commercial standards and simplified trade practice recommendations; administration of programs in cooperation with United States business groups and standards organizations for the development of international standards of practice; and maintenance of a clearinghouse for the collection and dissemination of scientific, technical, and engineering information. The scope of the Bureau's activities is suggested in the following listing of its four Institutes and their organizational units.

Institute for Basic Standards. Applied Mathematics. Electricity. Metrology. Mechanics. Heat. Atomic Physics. Physical Chemistry. Laboratory Astrophysics. ${ }^{*}$ Radiation Physics. Radio Standards Laboratory:* Radio Standards Physics; Radio Standards Engineering. Office of Standard Reference Data.

Institute for Materials Research. Analytical Chemistry. Polymers. Metallurgy. Inorganic Materials. Reactor Radiations. Cryogenics.* Materials Evaluation Laboratory. Office of Standard Reference Materials.

Institute for Applied Technology. Building Research. Information Technology. Performance Test Development. Electronic Instrumentation. Textile and Apparel Technology Center. Technical Analysis. Office of Weights and Measures. Office of Engineering Standards. Office of Invention and Innovation. Office of Technical Resources. Clearinghouse for Federal Scientific and Technical Information. **

Central Radio Propagation Laboratory.* Ionospheric Telecommunications. Tropospheric Telecommunications. Space Environment Forecasting. Aeronomy.

* Located at Boulder, Colorado 80301.

** Located at 5285 Port Royal Road, Springfield, Virginia 22171. 


\title{
NATIONAL BUREAU OF STANDARDS \\ Eechnical Mote. 326
}

ISSUED December 1, 1965

\author{
An Atlas of Solar Flare Effets in the lonosphere \\ Observed with a High - Frequency Doppler Technique \\ September 1960 - December 1962
}

\author{
Donald M. Baker \\ Institute for Telecommunication Science and Aeronomy * \\ Environmental Science Services Administration \\ Boulder, Colorado.
}

NBS Technical Notes are designed to supplement the Bureau's regular publications program. They provide a means for making available scientific data that are of transient or limited interest. Technical Notes may be listed or referred to in the open literature.

* Formerly designated the Central Radio Propagation Laboratory of the National Bureau of Standards.

For sale by the Superintendent of Documents, U.S. Government Printing Office

Washington D.C. 20402

Price: $60 \%$ 

Abstract. ..................... I

1. Introduction. . . . . . . . . . . . . . 1

2. Characteristics of Sudden Frequency Deviations. . . . . 2

3. Description of Records. . . . . . . . . . 6

4. Acknowledgement .................... 10

5. References.................... II

6. Index of Events ............... 12

7. Atlas ...................... 14 

AN ATLAS OF SOLAR FLARE EFFECTS IN THE IONOSPHERE OBSERVED WITH A HIGH-FREQUENCY DOPPIER TECHNIQUE SEPTEMBER 1960 - DECEMBER 1962

Donald M. Baker

Records of selected solar flare effects (sudden frequency deviations) in the ionosphere detected by a high frequency Doppler technique from September 1960 through December 1962 are presented. When available, records of short wave fadeouts (SWF) are also given.

Key Words: solar flare effects in the ionosphere, shortwave fadeouts, sudden frequency deviations, Doppler technique.

\section{Introduction}

1 The purpose of this atlas is to present a selection of the records of sudden frequency deviations (SFD) which have been observed from september 1960 through December 1962. Where available, records of the received signal strength have been included to show whether or not a sudden frequency deviation was accompanied by a short wave fadeout (SWF). Sudden frequency deviations are associated with solar flares, and the temporal variations of the SFD are thought to reflect the corresponding fluctuations in the solar ionizing radiation responsible for the enhanced production of electrons in the $\mathrm{E}$ and $\mathrm{F}$ regions of the ionosphere. Some flares produce both SWF and SFD, some SWF without SFD, and others SFD without SWF. These records (both SWF and SFD) should be of value in helping to distinguish between ionospheric disturbances of natural origin and those resulting from nuclear explosions. The records will also be of value for studies of the ionosphere, for comparison with other sudden ionospheric disturbance data and solar radio emission records, and for detailed comparison with optical observations of the solar flares. 
Sudden frequency deviations are detected by means of the highfrequency Doppler technique described by Watts and Davies [1960]. The frequency of an ionospherically propagated radio signal is monitored by comparing the received frequency with the signal from a stable local oscillator and recording the resultant beat signal on magnetic tape. Changes in the propagation medium cause variations in the received frequency which are detected as variations in the recorded beat frequency. The local oscillator is set a few cycles per second below the transmitted frequency to permit the sense of a frequency variation (positive or negative) to be determined. The solar-flare-induced disturbances detected by the technique have been given the name "sudden frequency deviations", abbreviated SFD, by Chan and Villard [1963].

The radio signals used in this technique (2-20 Mc/s) are usually reflected from the $F$ region of the ionosphere, and, therefore, the signals are subject to changes in the $D, E$, and $F$ regions. Our present knowledge indicates that the changes which cause sudden frequency deviations occur chiefly in the $E$ and $F$ regions (i.e. above the $100 \mathrm{~km}$ level). Thus, SFDs provide information on solar-flare-induced disturbances not provided by short wave fadeouts (SWF), sudden phase anomalies (SPA), sudden cosmic noise absorption (SCNA), or sudden enhancements of atmospherics (SEA)--all of which detect changes in the $D$ region.

The events in this atlas were selected on the basis of size, prospective usefulness, quality of the records, and uniqueness. An index of the events included is given on pages 12 to 13. The paths, frequencies, and path lengths used, and the period of operation of each path-frequency combination are given in Table 1 .

\section{Characteristics of Sudden Frequency Deviations}

A sudden frequency deviation is, by definition, associated with a solar flare. However, all solar flares do not produce sudden frequency deviations. Table 2 gives the percentage of the solar flares reported from October 1960 through December 1962 which were accompanied by SFD's. 
Paths and Frequencies in Operation from September 1960 thru December 1962

\begin{tabular}{|c|c|c|c|}
\hline $\begin{array}{c}\text { Path } \\
\text { Transmitter - Receiver }\end{array}$ & $\begin{array}{l}\text { Path Length } \\
(\mathrm{km})\end{array}$ & $\begin{array}{l}\text { Frequency } \\
(\mathrm{Mc} / \mathrm{s})\end{array}$ & $\begin{array}{l}\text { Effective Period of Operation } \\
(1960-1962)\end{array}$ \\
\hline \multirow[t]{3}{*}{ WWV to Boulder } & 2430 & 20 & $\begin{array}{l}1 \text { September } 1960 \text { - } 2 \text { June } 1961 \\
8 \text { September } 1961 \text { - } 17 \text { January } 1962\end{array}$ \\
\hline & & $15 *$ & $\begin{array}{l}21 \text { December } 1960 \text { - } 30 \text { January } 1961 \\
17 \text { January } 1962 \text { - } 31 \text { December } 1962\end{array}$ \\
\hline & & $10 *$ & 30 January 1961 - 31 December 1962 \\
\hline WWV to Shickley & 1780 & $10 *$ & 12 August 1961 - 18 April 1962 \\
\hline Sunset to Boulder & 25 & $\begin{array}{l}5.054 \\
4.000\end{array}$ & $\begin{array}{l}4 \text { August } 1961 \text { - } 31 \text { December } 1962 \\
30 \text { July } 1961 \text { - } 31 \text { December } 1962\end{array}$ \\
\hline WWVH to Anchorage & 4480 & $15 * *$ & 8 June 1962 - 3 December 1962 \\
\hline WwVH to Midway & 2200 & $\begin{array}{r}15 * * \\
10 * * \\
5 * *\end{array}$ & $\begin{array}{l}\text { 31 May } 1962 \text { - } 10 \text { July } 1962 \\
\text { 31 May } 1962 \text { - } 10 \text { July } 1962 \\
31 \text { May } 1962 \text { - } 10 \text { July } 1962\end{array}$ \\
\hline WWVH to Wake & 3900 & $10 * *$ & 26 May 1962 - 29 July 1962 \\
\hline \multicolumn{4}{|c|}{$\begin{array}{l}\text { * Subject to interference from WWVH } \\
\text { ** Subject to interference from JJY (Tokyo) }\end{array}$} \\
\hline \multicolumn{4}{|l|}{$\begin{array}{l}\text { Transmitter locations: } \\
\text { WWV (Beltsville, Md.) } \\
\text { Sunset, Colorado } \\
\text { WWVH (Maui, Hawaii) } \\
\text { JJY (Tokyo, Japan) }\end{array}$} \\
\hline $\begin{array}{l}\text { Receiver locations: } \\
\text { Shickley, Nebraska } \\
\text { Boulder, Colorado } \\
\text { Anchorage, Alaska } \\
\text { Midway Island } \\
\text { Wake Island }\end{array}$ & $\begin{array}{lll}40^{\circ} 26^{\prime} & \mathrm{N}, & 97 \\
40^{\circ} 03^{\prime} & \mathrm{N}, 10 \\
61^{\circ} 10^{\prime} & \mathrm{N}, 15 \\
28^{\circ} 15^{\prime} & \mathrm{N}, 17 \\
19^{\circ} 18^{\prime} & \mathrm{N}, 16\end{array}$ & 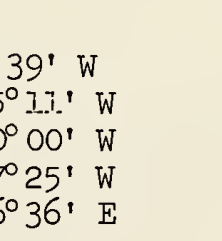 & \\
\hline
\end{tabular}


Table 2

Percentage of flares reported from October 1, 1960 through December 31, 1962 which were accompanied by SFD's.

Flare $\mathrm{H} \alpha$

Importance

$1-$

1

2

3

$1,2,3$

$1-, 1,2,3$
Number of

Flares

2994

648

55

10

713

3707
Percentage

with SFD

10

21

49

80

24

13 
Sudden frequency deviations show great variation in shape, size, and duration. The most distinctive characteristic of an SFD is a rapid increase in the received frequency. This positive frequency deviation is usually followed by a smaller negative deviation and a gradual recovery to the pre-flare frequency. However, some SFD's show only a positive deviation followed by a return to the pre-flare frequency. Some SFDs have only one peak while others are complex events with mltiple peaks of varying sizes. The time variation of the frequency during the positive phase of an SFD is thought to be closely related to the time variation of the ionizing radiation which causes the SFD.

The size of an SFD is dependent on the frequency, path length, and the solar zenith angle as well as the. size and rate of change of the flare-produced burst of ionizing radiation. The maximum positive frequency deviations observed on WWV-10 Mc/s received at Boulder have ranged from a few tenths of a cycle per second to over 50 cycles per second. Most SFD's are less than 1 cycle per second; an SFD of over 1 cycle per second is considered to be a large event. Large SFD's are observed during both large and small optical flares, but a large flare (importance 2 or 3 ) is more likely to be accompanied by a large SFD than is a small flare.

The duration of SFD's has been observed to range from less than one minute up to more than 15 minutes. The most frequent duration is of the order of 4 minutes, and the most frequent time taken to rise to the peak is from 1 to 2 minutes. Sudden frequency deviations almost always occur between the start and maximum phase of the optical flare as seen in $\mathrm{H} \alpha$ $(6563 \AA)$ with the peak of the SFD usually preceding the Ho peak by 1 or 2 minutes.

More complete discussions of the characteristics and interpretation of sudden frequency deviations and the statistics of their occurrence have been given by Kanellakos, Chan, and Villard [1962]; Kanellakos [1963]; Chan and Villard [1963]; Knecht and Davies [1961 a,b]; Davies [1962, 1963]; Davies, Watts, and Zacharisen [1962]; and Agy, Baker, and Jones [1965]. A catalog of SFD's detected at Boulder from October 1960 through December 1962 has been given by Agy, Baker, and Jones [1965]. 


\section{Description of Records}

The Doppler records (figure 2) show the variation of the received frequency (in cycles per second) as a function of time; time increases from left to right, frequency increases upward. Universal Time (UT) is used throughout. The timing accuracy of the records included in this atlas is \pm 1 minute; more accurate times can be obtained from the original records, but the labor involved prohibits obtaining such accuracy on a routine basis. The WWV transmission is interrupted for approximately 4 minutes each hour beginning at 45 minutes past the hour. All WWV records were originally timed from the beginning of a transmission break, and some records include either a complete transmission break (figure 11) or the start of a break (figure $41 \mathrm{c}, d, e$ ). The Sunset, Colorado transmitters were keyed every 10 minutes for purposes of identification, and these keying breaks often show up on the records (figure 28; 1430 and $1440 \mathrm{UT}$ ).

Many records have more than one trace. On the Sunset to Boulder records the existence of two traces usually means that both ground wave and sky wave were being received (figure $28 \mathrm{a}$ ); the steady, undeviated trace is the ground wave while the deviated trace is the sky wave. During some flares the increase of ionospheric absorption is so great that only the ground wave is received (figure $57 \mathrm{a}, \mathrm{b}$ ). The existence of multiple traces on the WWV to Boulder and WWV to Shickley records can be due either to the reception of more than one propagation mode or to an interfering signal. When two traces are observed during an SFD (figure 18), the one which undergoes the larger deviation is usually due to a signal reflected from the F region while that with the smaller, or no, deviation is the result of a reflection from the $E$ layer. In most cases the existence of three or more traces is caused by the reception of several transmission modes (one-hop, two-hop, etc., and possibly ordinary and extraordinary rays) which are affected differently by the flare-induced ionization. Traces due to an E-layer (undeviated) and three different F-layer modes can be seen in figure $67 \mathrm{~d}$. Traces due to two E-layer modes and single F-layer mode are present in figure $35 \mathrm{c}$. 
Several countries have standard frequency stations on 10 and/or $15 \mathrm{Mc} / \mathrm{s}$. Consequently, signals from two or more transmitters are occasionally received at these frequencies. The daily and hourly transmission schedules of the possible sources of interference on 10 and $15 \mathrm{Mc} / \mathrm{s}$ are shown in figure 1. At Boulder both WWV and WWVH are frequently received simultaneously, and occasionally a signal of unknown origin has appeared on the records at a time when both WWV and WWVH were off the air. An example of the simultaneous reception of WWV and WWV is shown in figure 23; the presence of WWVH is indicated by the additional transmission breaks at 1515 and 1530. An example of the reception of a strong signal of unknown origin is shown in figure $45 \mathrm{~d}$; a clean transmission break from 1445 to 1449 is seen on $15 \mathrm{Mc} / \mathrm{s}$ (figure $44 \mathrm{e}$ ) indicating the reception of WWV only; however, no such break is observed on $10 \mathrm{Mc} / \mathrm{s}$, and it is impossible to be sure that the signal after 1449 is WWV. The presence of non-WWV transmission breaks, or the absence of WWV breaks at the expected times, usually provides the only available indication of the presence of an unwanted signal. When signals from two or more transmitters are present, the only way to separate them, when possible, is by a close inspection of the original records for several hours before and after the period of interest. In the cases where more than one transmission was received, the usefulness of the records for detailed study of the ionosphere is severely restricted; however, the records are still useful for time comparisons with other SID data, with solar radio emission records, and with optical flare observations. Lack of space has often prohibited the inclusion of time breaks on the records in this atlas. During the day the signal received on 10 and $15 \mathrm{Mc} / \mathrm{s}$ is predominantly WWV, but there will be instances where interference from WWVH (and occasionally from other stations) is present. There are usually no interference problems on $4.000,5.054$, or $20 \mathrm{Mc} / \mathrm{s}$. An exceptional case of severe interference on $4 \mathrm{Mc} / \mathrm{s}$ can be seen in figure $37 \mathrm{a}$.

A third source of mutiple traces, on any of the frequencies, is equipment. At times the records show one or more harmonics of the fundamental trace (figure $33 \mathrm{c} ; \mathrm{d}$ ). These multiple traces are easily 


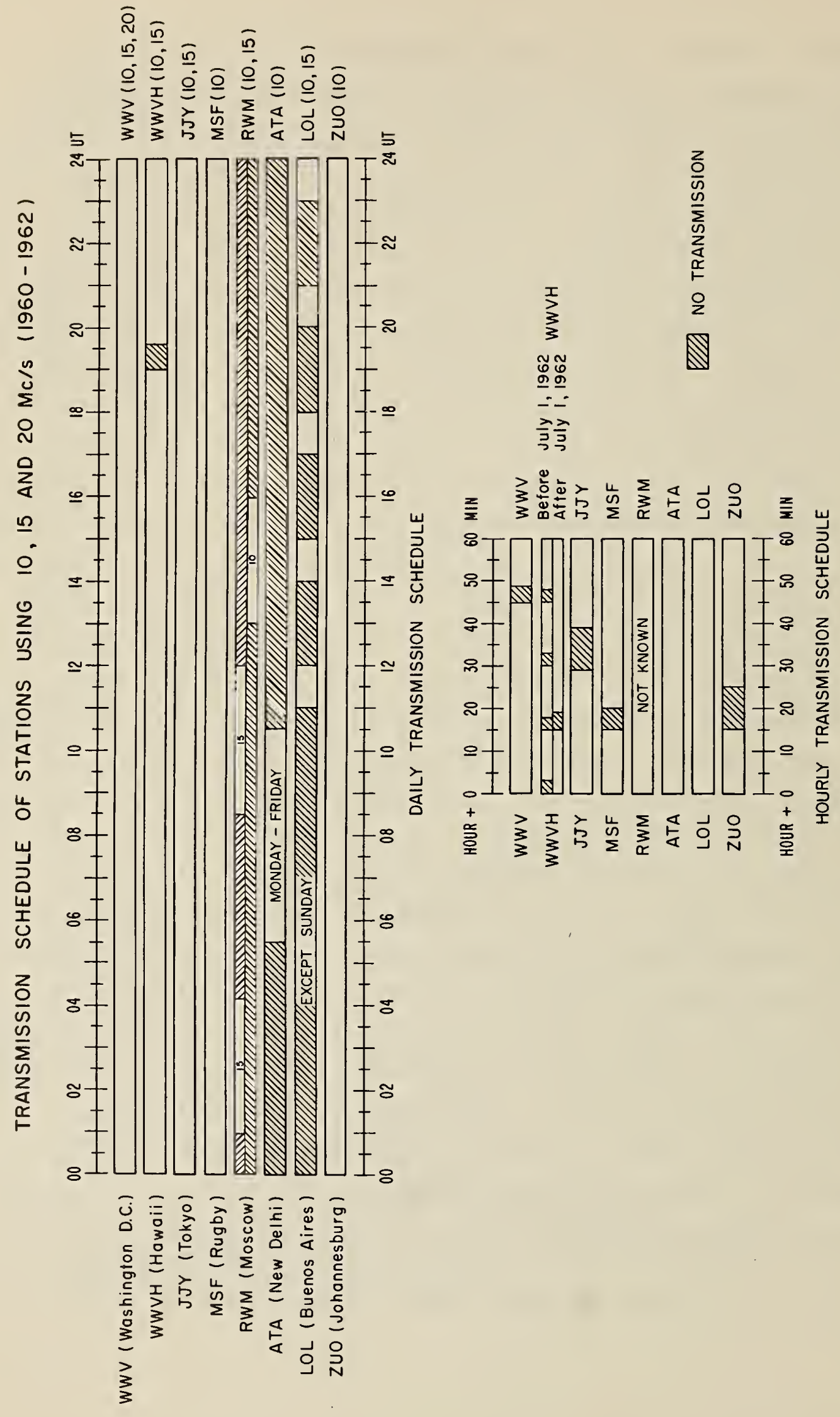


distinguished from those of other sources and usually create no problems; however, during some large SFD effects (figure $67 \mathrm{c}$ ) the fundamental and harmonics do get mixed together so that it becomes difficult to determine the magnitude of the frequency deviation.

A second type of instrumental effect occurs when a negative frequency deviation becomes larger than the frequency offset between the transmitted frequency and the reference oscillator. In such a case, the negative deviation is mirrored in the zero frequency axis so that it looks like a positive deviation on the records. An example of this effect is shown in figure $55 \mathrm{c}$; what appears to be a positive deviation between 1936:00 and 1936:20 is probably a negative phase.

The signal strength records (figure $34 \mathrm{c}$ ) were derived from the feedback voltage of the automatic gain controls of the receivers. They show the relative signal strength (in decibels above 1 microvolt) as a function of time; signal strength increases upward and time increases from right to left. Although a time scale is printed on the chart paper, the recorders often deviate from this scale. In using these records, the times indicated at the bottom should be used. On the WWV to Boulder records, the transmission breaks at 45 minutes past the hour serve to establish the time scale. On the Sunset to Boulder records, the keying breaks repeat at approximately 10 minute intervals, but the exact times at which they begin vary from day to day.

The signal strength records show whether an SFD was accompanied by an appreciable increase in absorption (a short wave fadeout or SWF) and give an order of magnitude estimate of the increase in absorption. These records show no measurable increase of absorption during many SFD's (figures 51 and 52 for example), whereas during some flares there is a large increase in absorption but no sudden frequency deviation (figures 33 and 34 ).

The signal strength of WWV shows regular fluctuations with a period of 5 minutes. These fluctuations are caused by the modulation schedule of WWV. Any features on the signal strength records which are of equipmental origin are marked by the letter $C$. All signal strength records 
included in the atlas are either reproductions of the original records or tracings from the original records. All tracings are identified as such in the figures.

$$
\text { 4. Acknowledgement }
$$

The preparation and publication of this atlas were supported by the Advanced Research Projects Agency, Nuclear Test Detection Office under Contract No. 183 . 


\section{References}

Agy, V., D. M. Baker, and R. M. Jones (1965), Studies of solar flare effects and other ionospheric disturbances with a high frequency Doppler technique, NBS Technical Note No. 306, U.S. Government Printing Office, Washington, D.C.

Chan, K. L., and O. G. Villard, Jr. (1963), Sudden frequency deviations induced by solar flares, J. Geophys. Res. 68, No. 10, 3197-3224. Davies, K. (1962), Ionospheric effects associated with the solar flare of September 28, 1961, Nature, 193, No. 4817, 763-764.

Davies, K. (1963), Doppler studies of the ionospheric effects of solar flares, Proceedings of the International Conference on the Ionosphere, London, 1962, Institute of Physics and the Physical Society, $76-83$.

Davies, K., J. M. Watts, and D. H. Zacharisen (1962), A study of F2 layer effects as observed with a Doppler technique, J. Geophys. Res. 67, No. 2, 601-609.

Kanellakos, D. P. (1963), Origin and location of ionospheric perturbations affecting the instantaneous frequency and azimuthal angle of arrival of HF waves, Radio Astronomical and Satellite Studies of the Atmosphere, ed. Aarons, North-Holland, Amsterdam, 525-559.

Kanellakos, D. P., K. L. Chan, and O. G. Villard, Jr. (1962), On the altitude at which some solar flare ionization is released, J. Geophys. Res. 67, No. 5, 1795-1804.

Knecht, R. W. and K. Davies (196la), Solar flare effects in the F region of the ionosphere, Nature 190, No. 4778, 797-798.

Knecht, R. W. and K. Davies (196lb), reply to Possible solar flare effects in the $F$ region of the ionosphere by G. H. Nunro, Nature 192, No. 4800,348 .

Watts, J. M, and K. Davies (1960), Rapid frequency analysis of fading radio signals, J. Geophys. Res. 65, No. 8, 2295-2301. 
6. Index of Events

Date

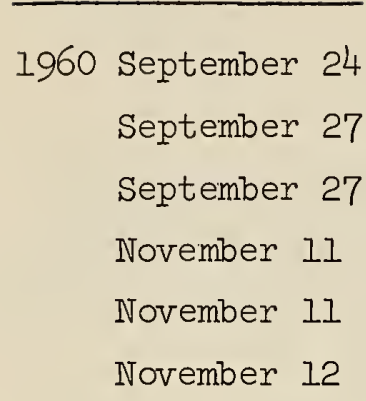

1961 January 30

January 30

January 31

January 31

April 3

April 5

April 26

May 4

May 10

May 28

June 15

June 29

July 1

July 10

July 13

July 15

July 16

July 17

July 19

July 21

September 4

September 4

September 4
Start Time

UT

2115

1702

2058

1512

1709

1324

1423

2003

1512

2133

1710

1621

1650

2204

1858

1906

1718

2108

2132

1732

2212

1508

1557

1913

2055

1715

1431

1513

1902
SFD Records

15
16
17
18
19
20

21

22

23

24

25

26

27

28

29

30

31

32

33

34

35

36

37

38

39

40

42,43

46,47

48,49
Signal Strength

Records 
Date

1961 September 4

September 10

September 27

September 28

November 22

1962 February 21

February 23

February 28

March 1

March 13

April 14

April 14

April 15

April 17

April 19

April 20

April 27

May 1

July 5

August 13

October 13
Start Time

UT

1914

1950

1952

2213

2015

1829

1830, 1842

1936

1635

1449

1257

1916

2050

2253

1935

1959

1411

1914

1937

2039

1805
SFD Records

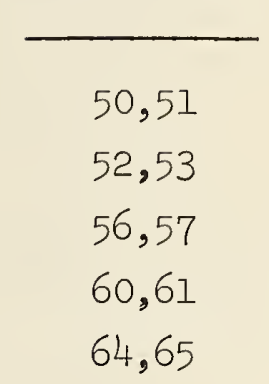

Signal Strength

Records

44

54,55

58,59

62,63

66,67

68,69

70,71

72,73

74,75

76,77

78

80,81

82,83

84,85

86,87

88,89

90,91

92,93

94,95

96,97

98,99

100,101

104

102,103

105

106

107

$108,109,110$

111

112

113

114,115

116 
7.

A T L A S

$-14-$ 


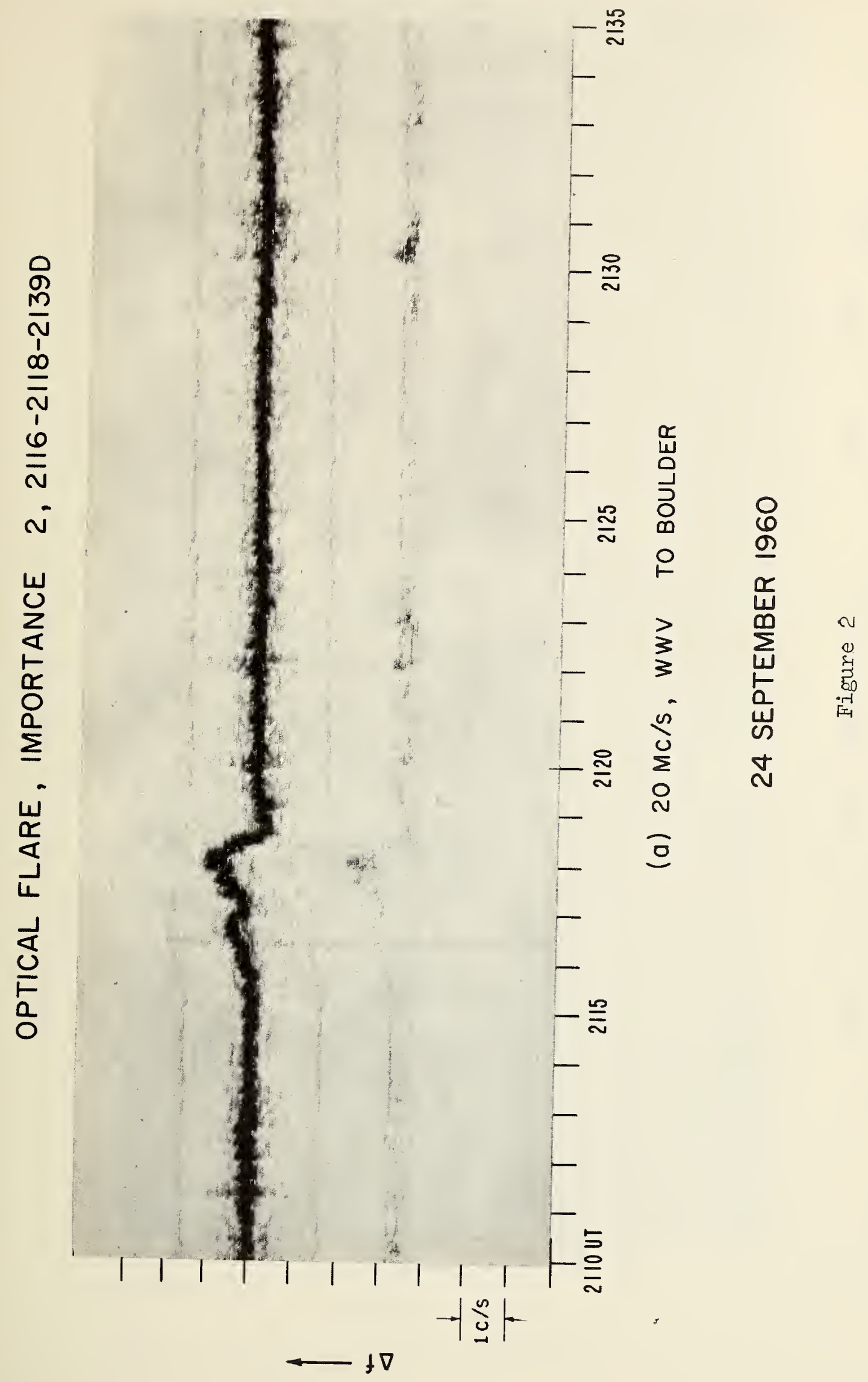




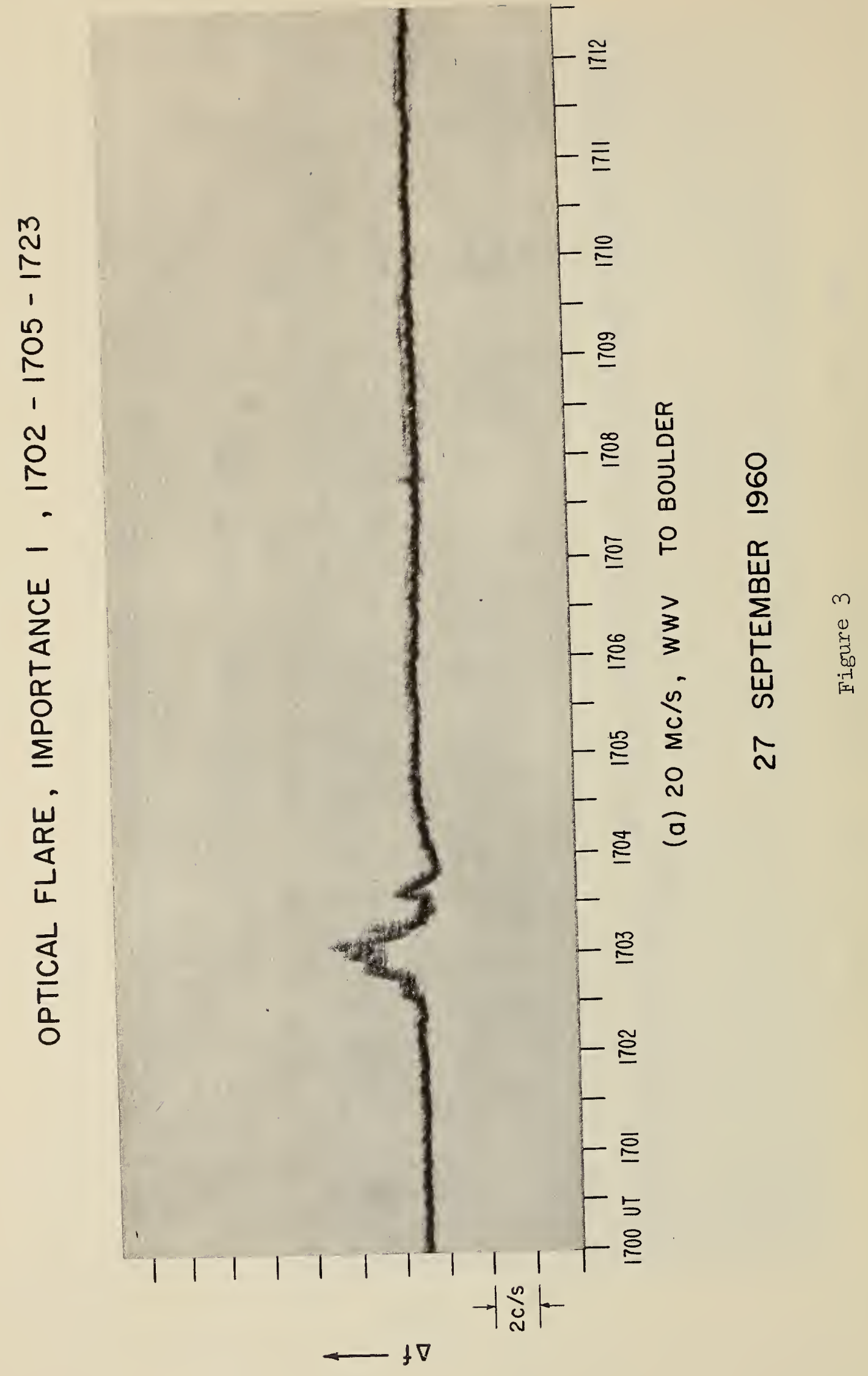




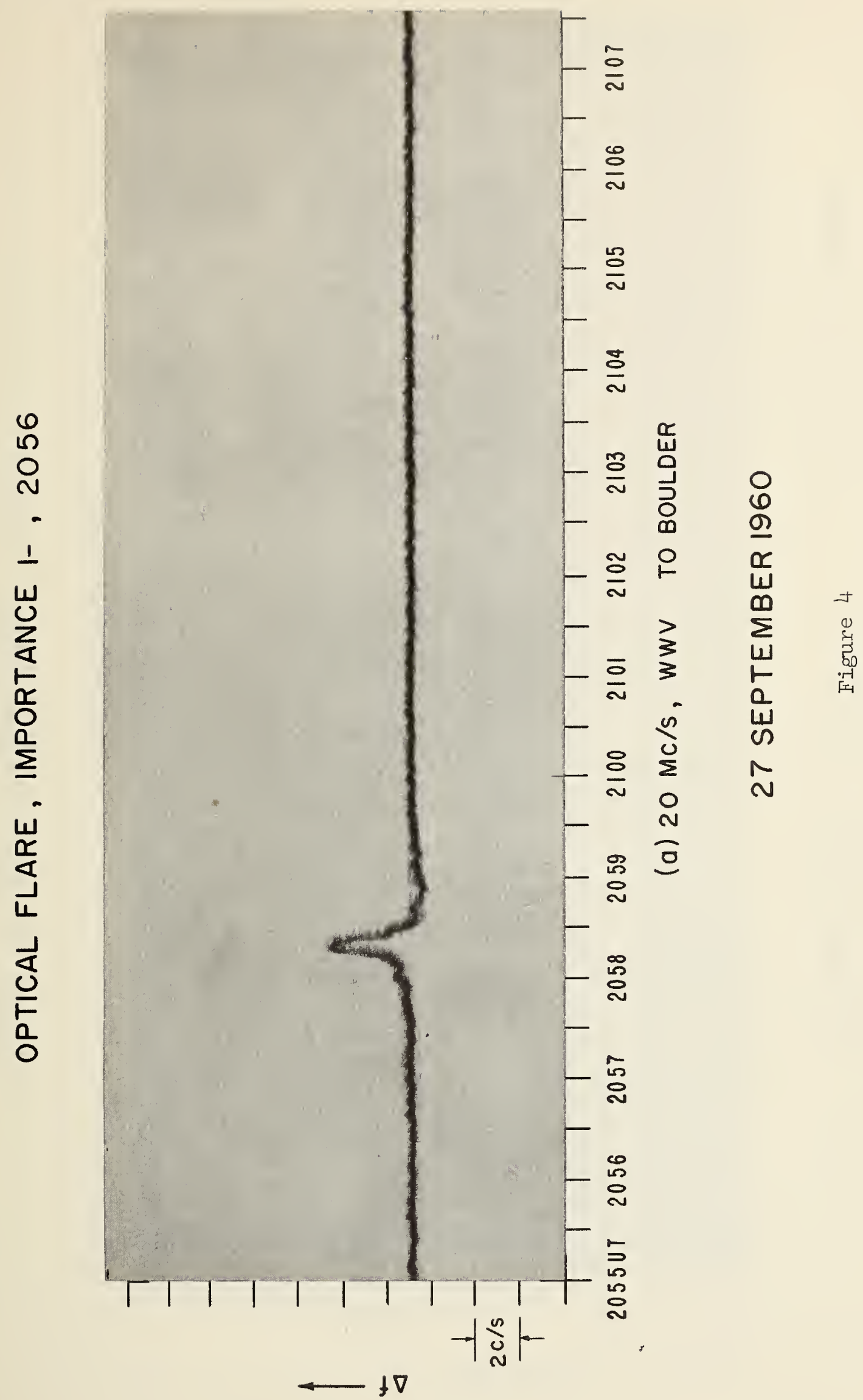




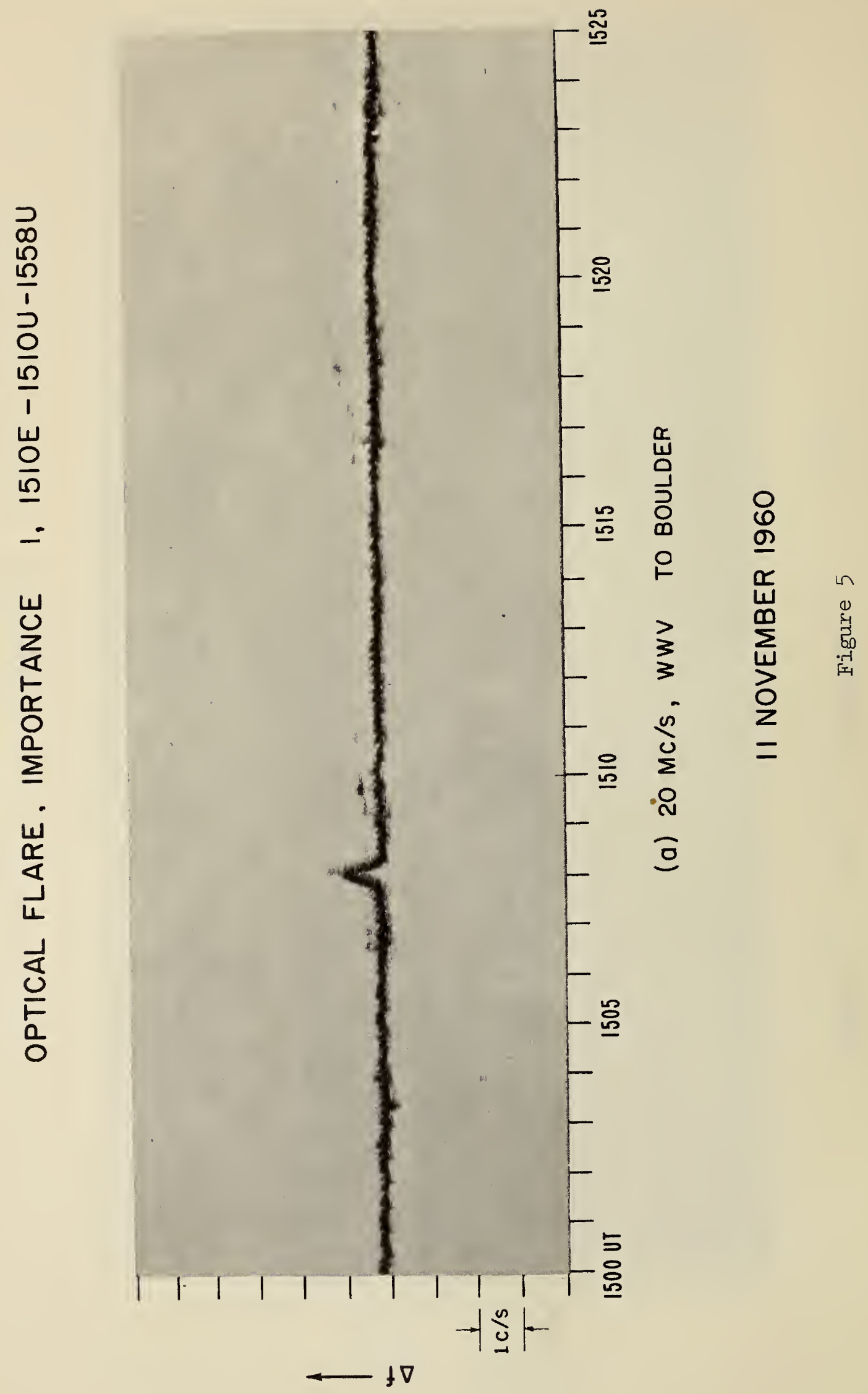




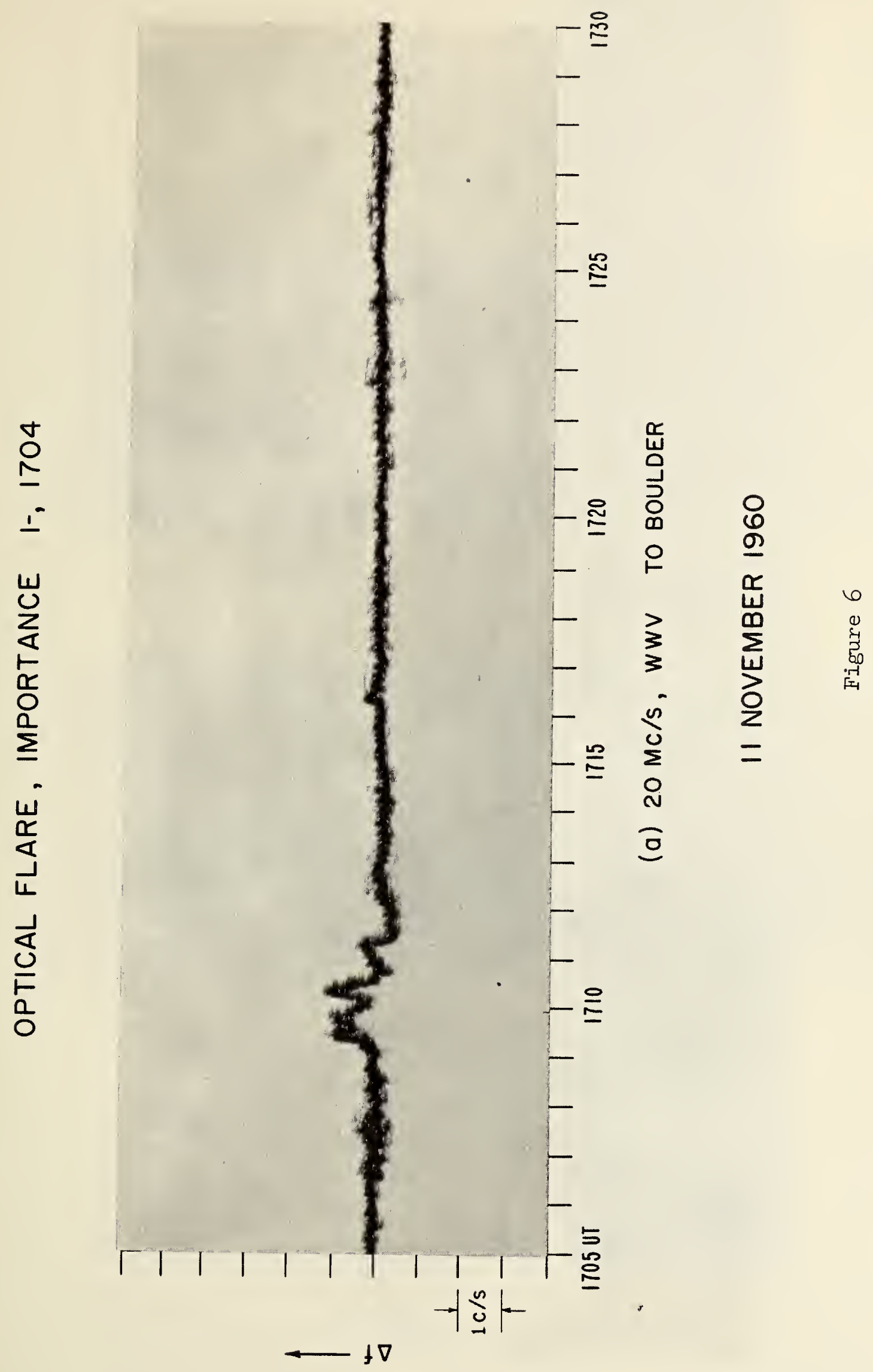




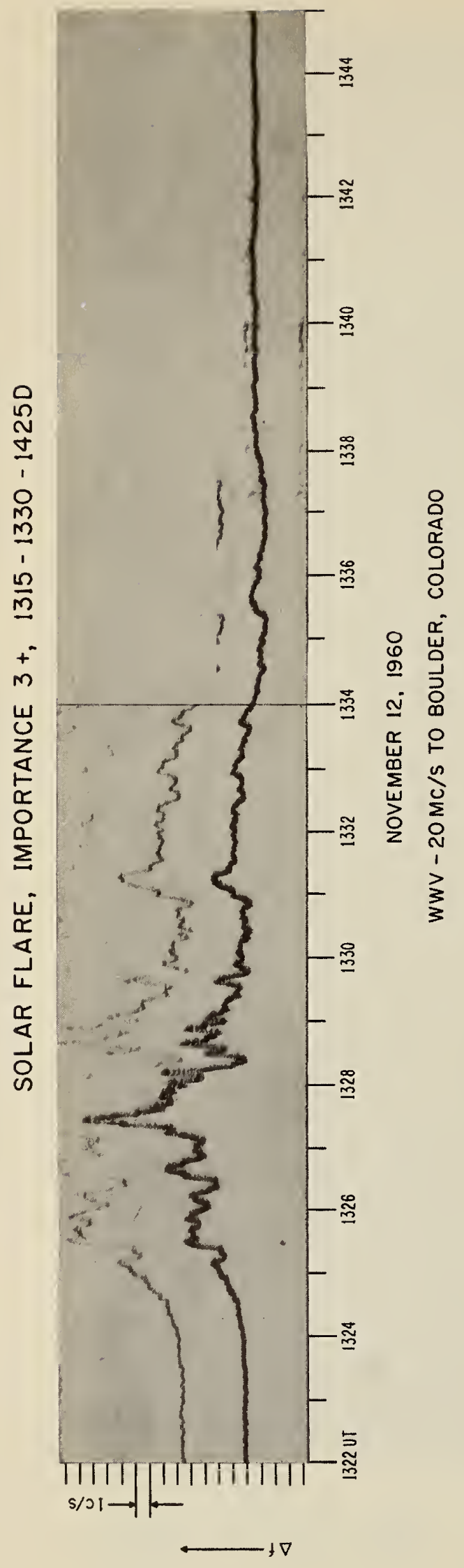

-
0
5
5
50
$0-1$
$\cdot-1$
II 
OPTICAL FLARE, IMPORTANCE I, 1420-1425-1440

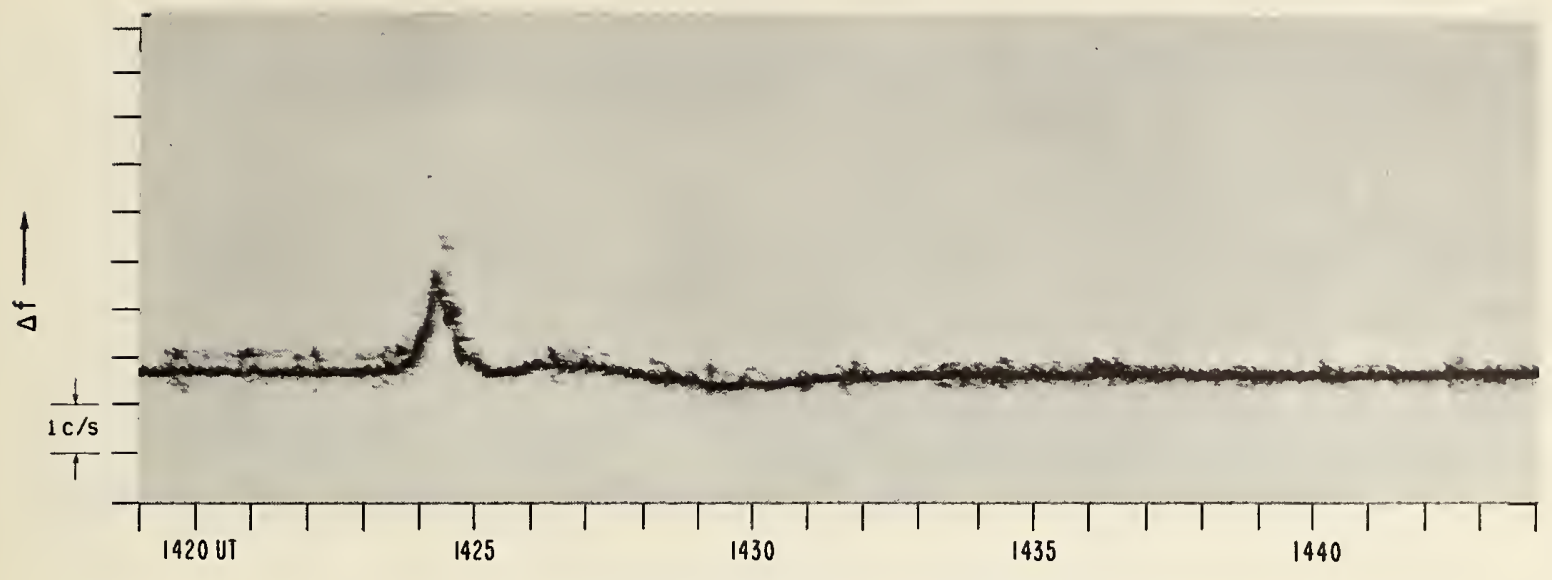

(a) $15 \mathrm{mc} / \mathrm{s}$, WWV TO BOULDER

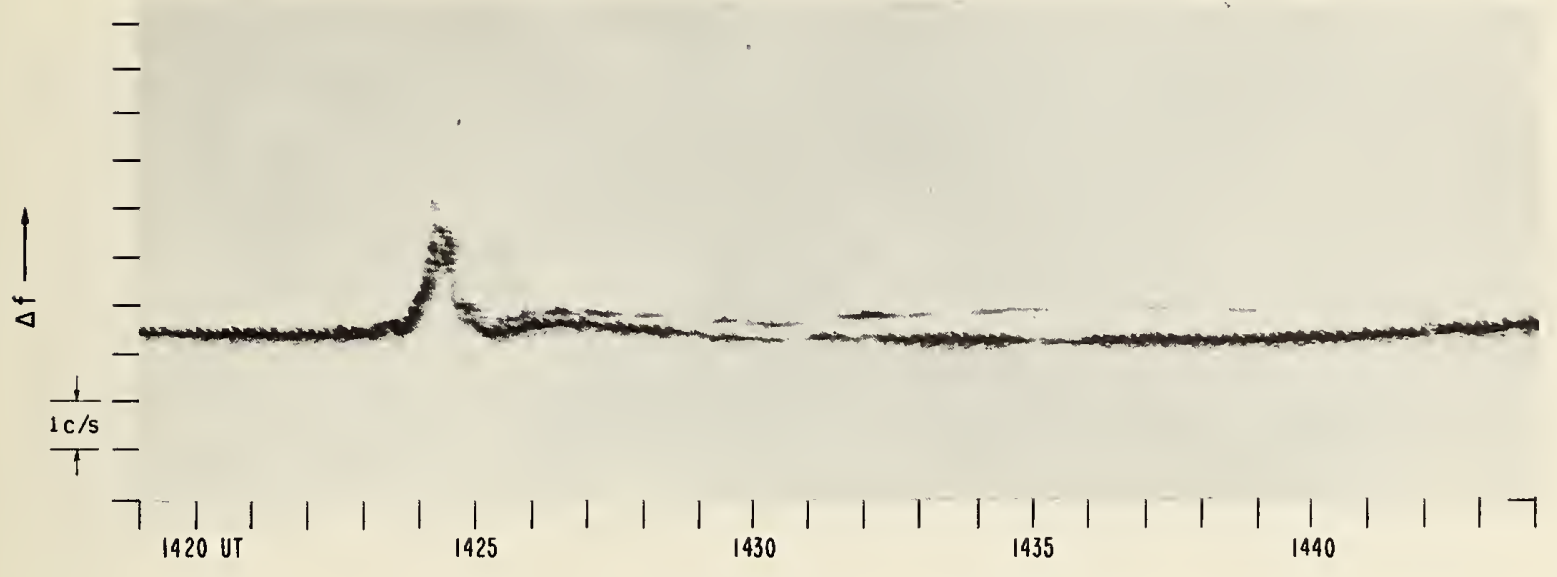

(b) $20 \mathrm{Mc} / \mathrm{s}$, WWV TO BOULDER

30 JANUARY 1961

Figure 8 
OPTICAL FLARE, IMPORTANCE I, 2000-2004-2013

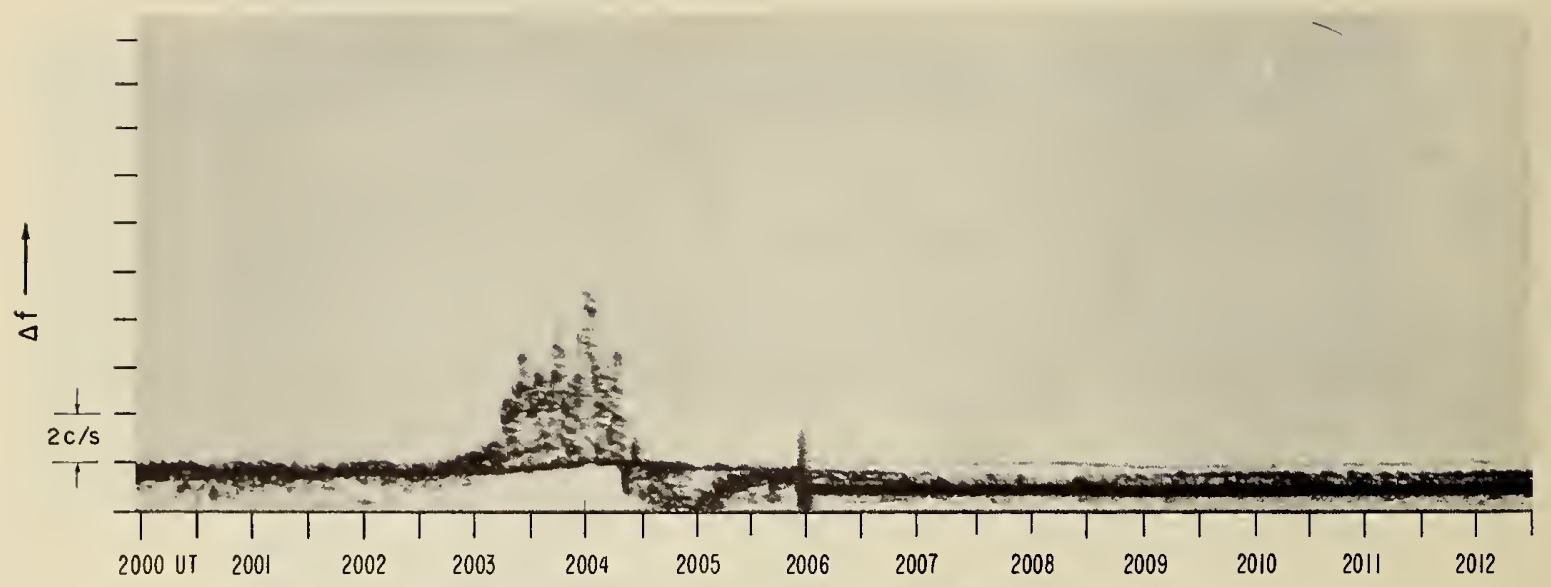

(a) $10 \mathrm{mc} / \mathrm{s}$, WWV TO BOULDER

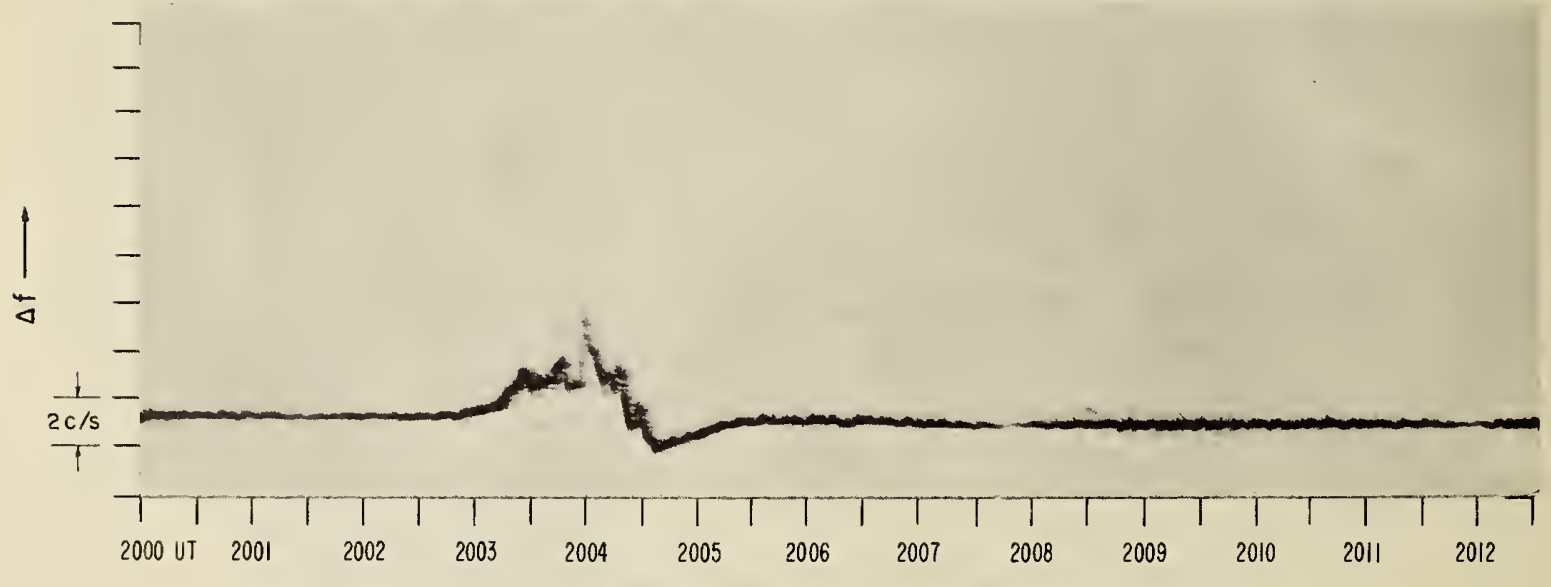

(b) $20 \mathrm{MC} / \mathrm{s}$, WWV TO BOULDER

30 JANUARY 1961

Figure 9 
OPTICAL FLARE, IMPORTANCE I-, 1509-15/4-1535

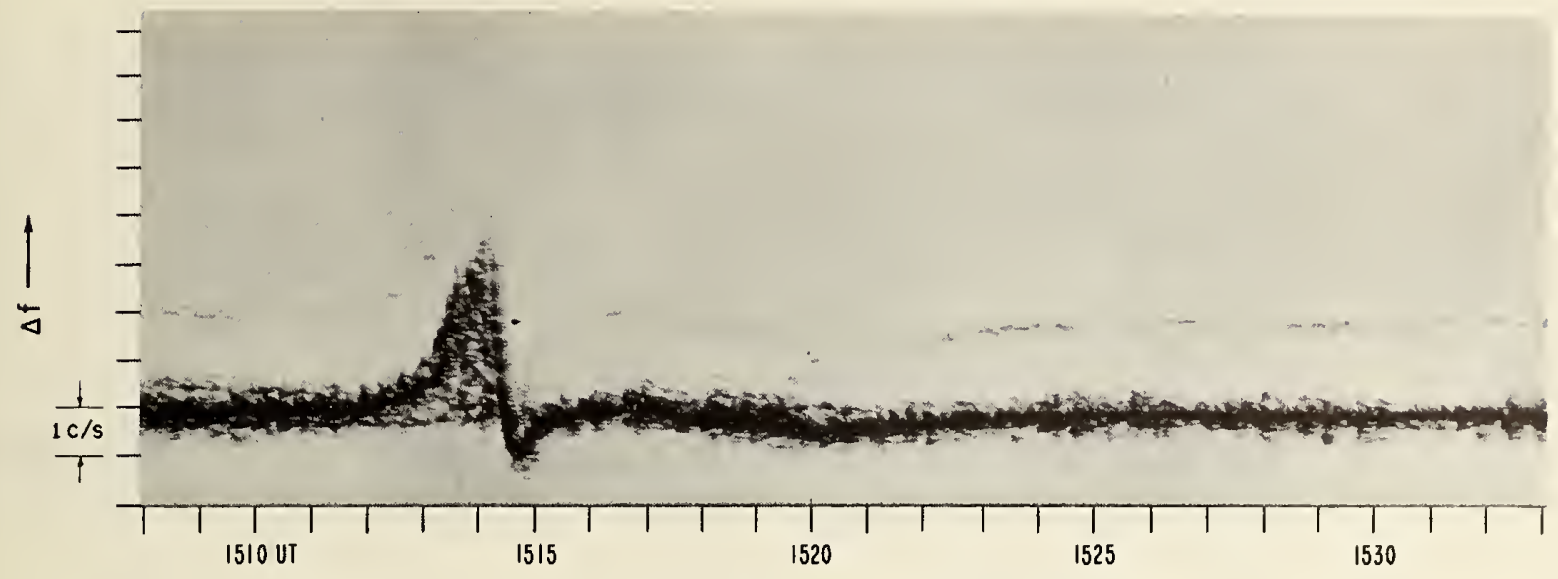

(a) $10 \mathrm{MC} / \mathrm{s}$, WWV TO BOULDER

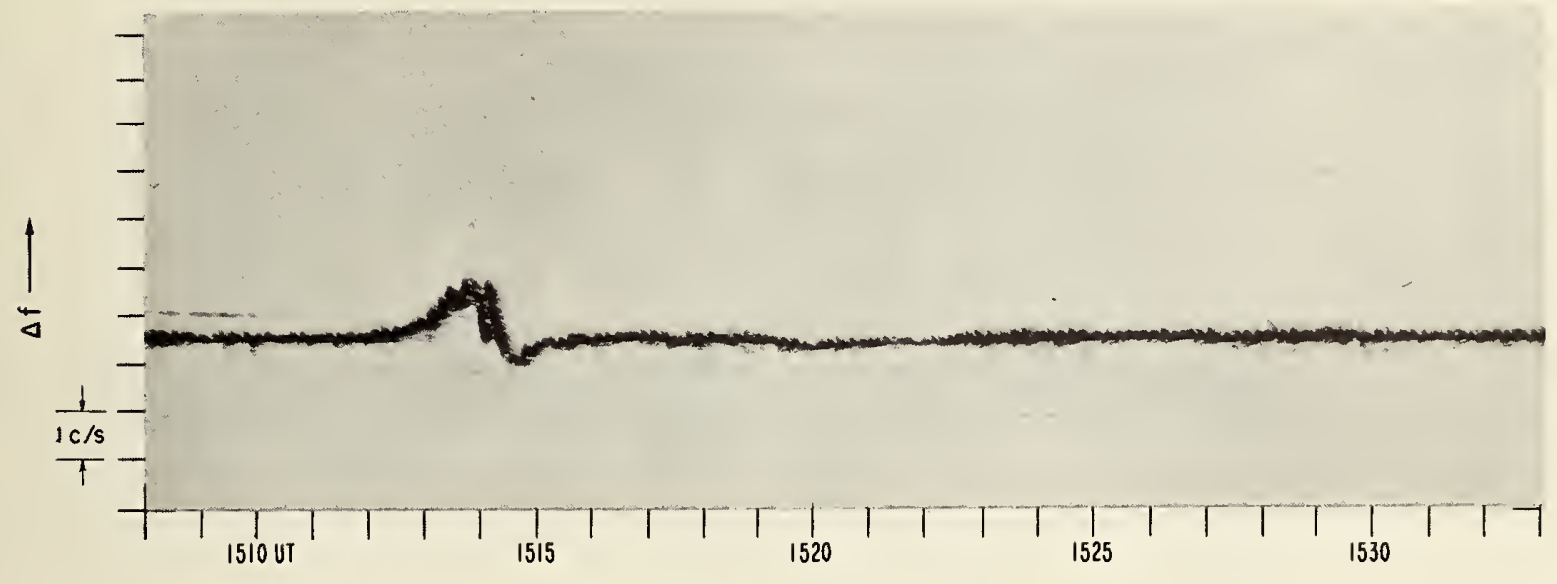

(b) $20 \mathrm{MC} / \mathrm{s}, W W V$ TO BOULDER

31 JANUARY 1961

Figure 10 
OPTICAL FLARE, IMPORTANCE I, 2131-2137-2155

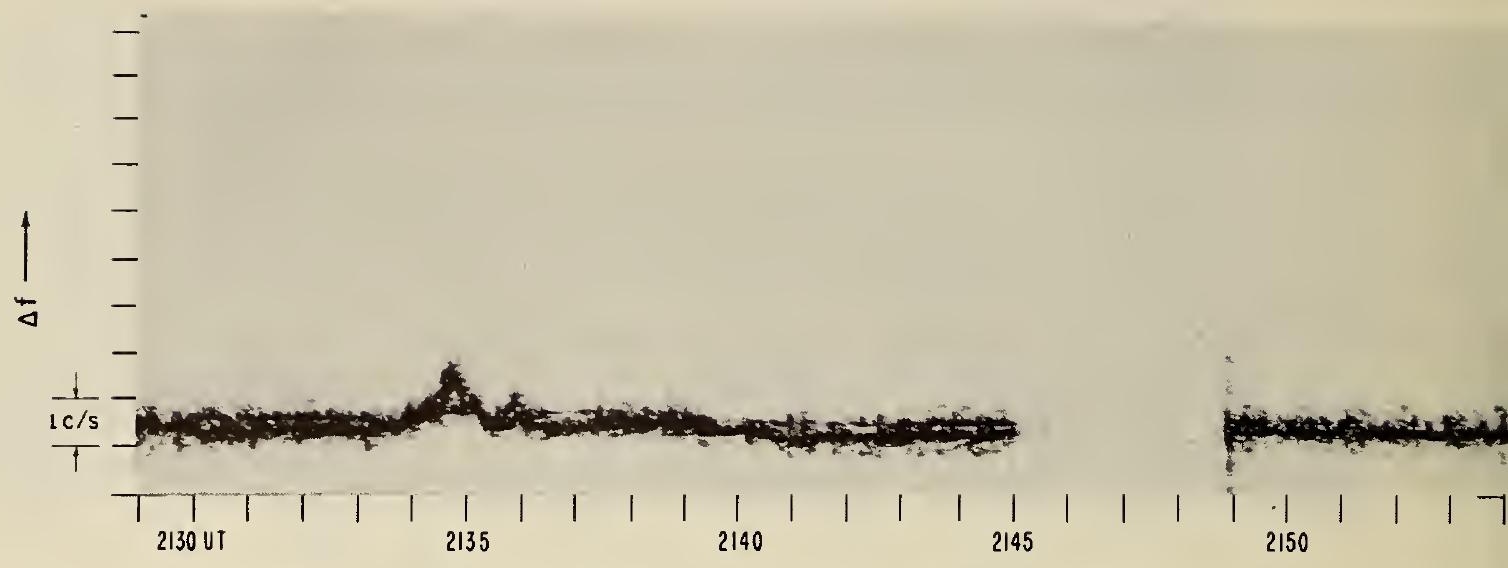

(a) $10 \mathrm{mc} / \mathrm{s}$, WWV TO BOULDER

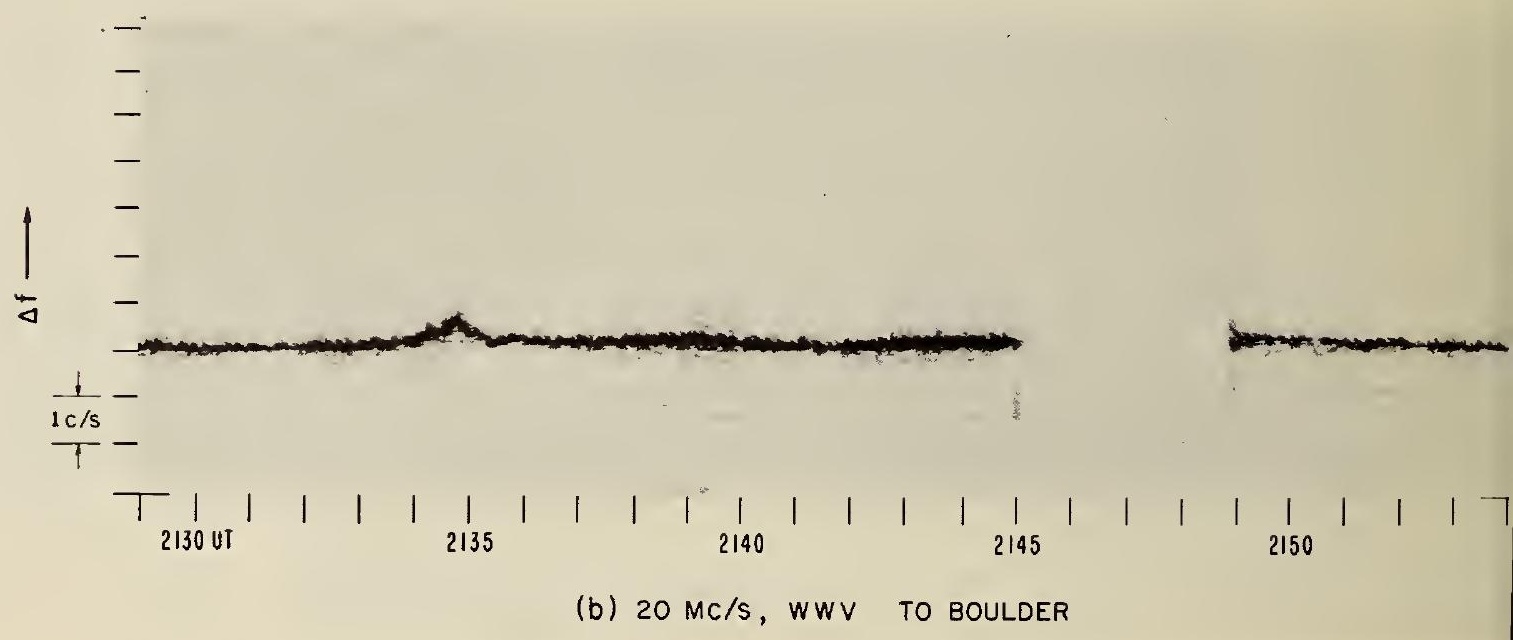

31 JANUARY 1961

Figure 11

$-24-$ 


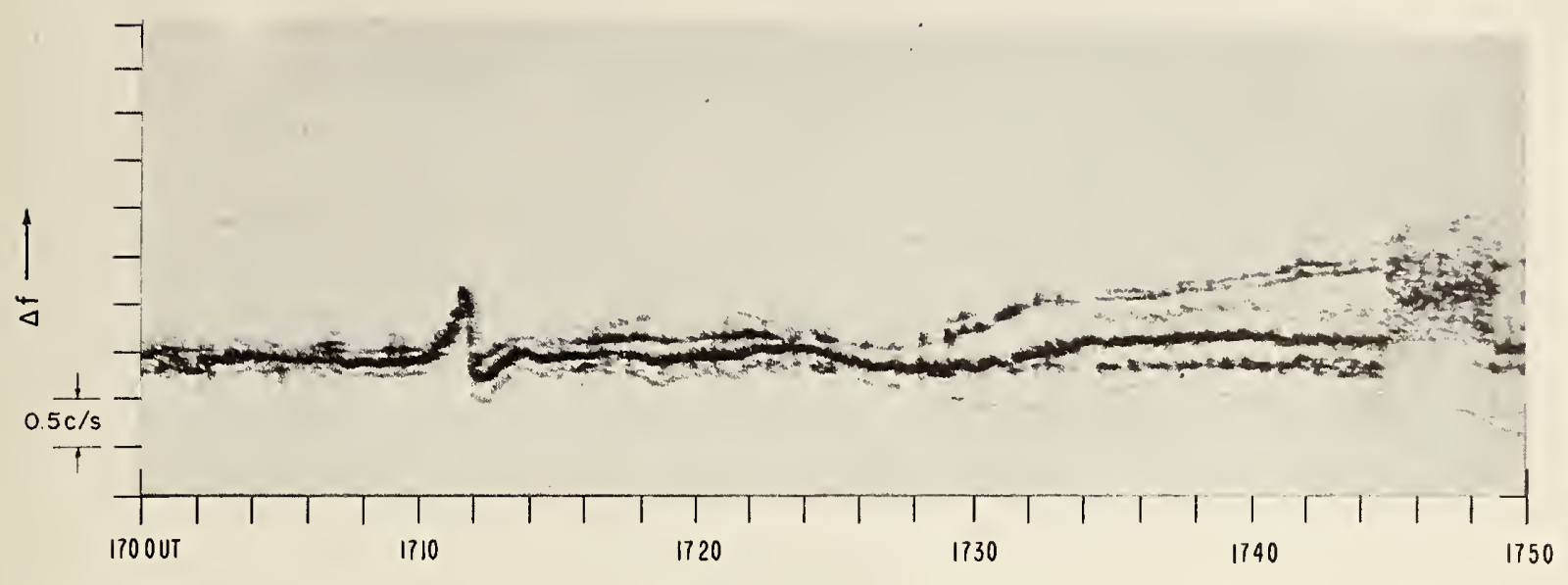

(a) $10 \mathrm{Mc} / \mathrm{s}$, WWV TO BOULDER

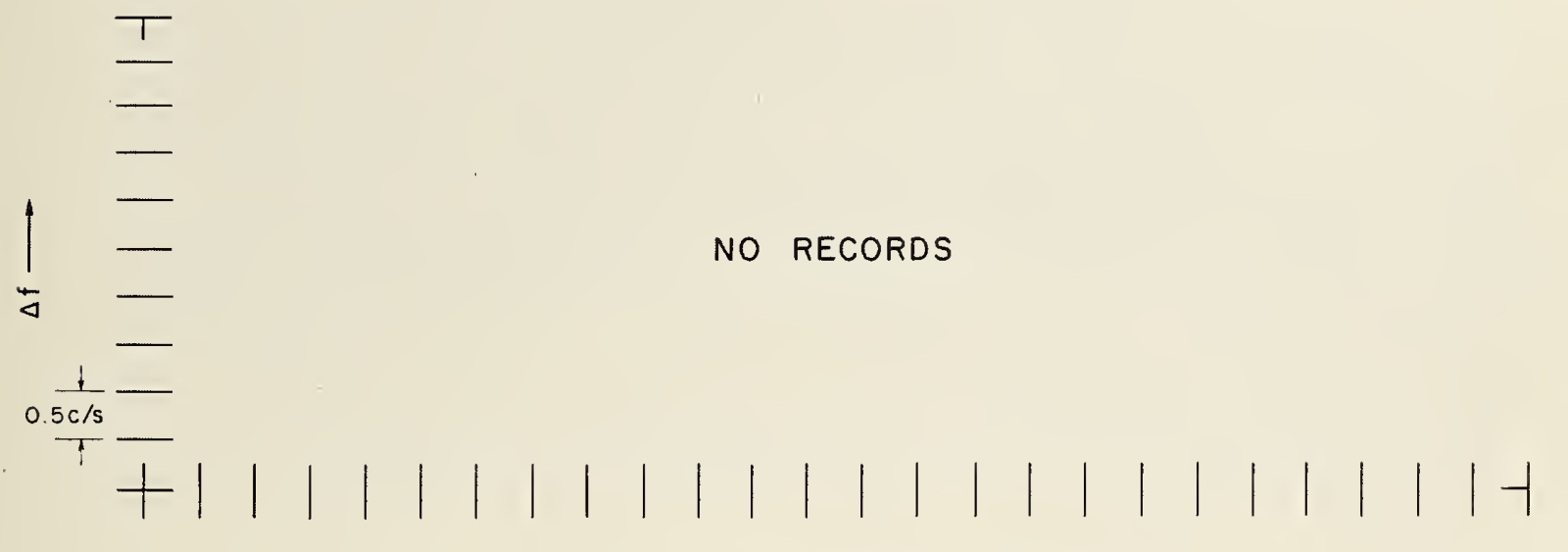

(b) $20 \mathrm{Mc} / \mathrm{s}$, WWV TO BOULDER

3 APRIL 1961

Figure 12 


\section{OPTICAL FLARE, IMPORTANCE I, 1555-1629-1647}

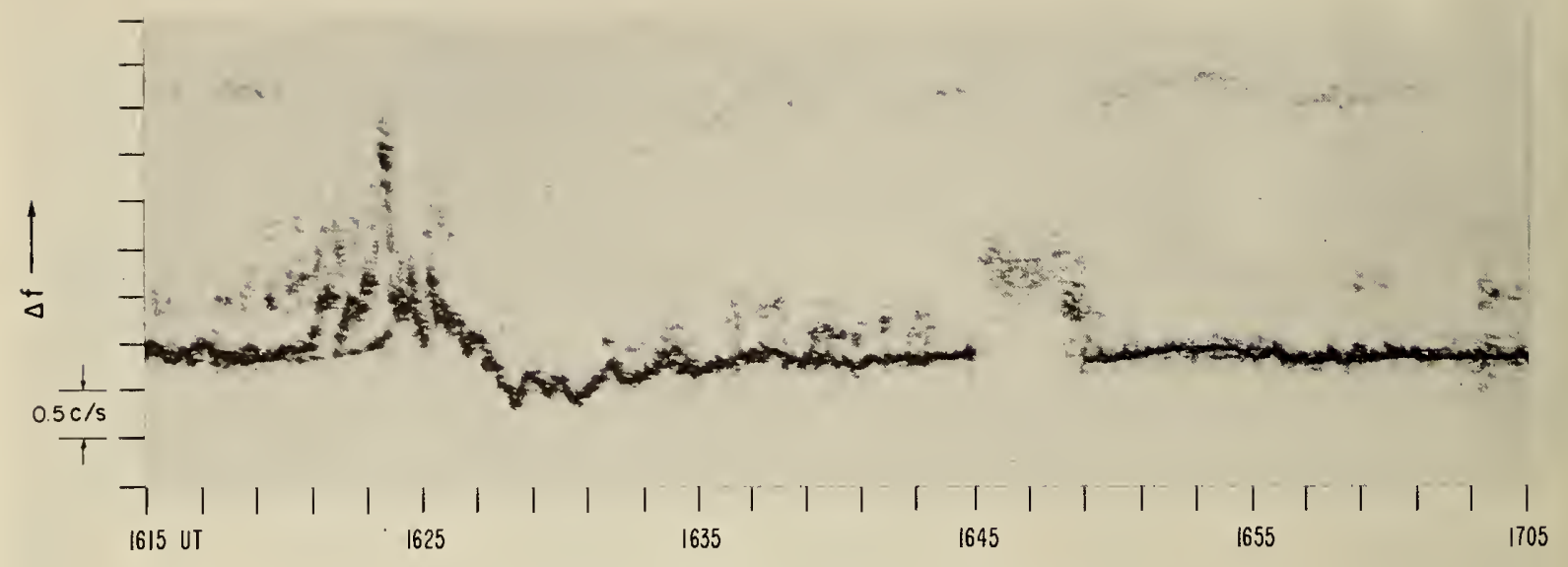

(a) $10 \mathrm{mc} / \mathrm{s}$, WWV TO BOULDER

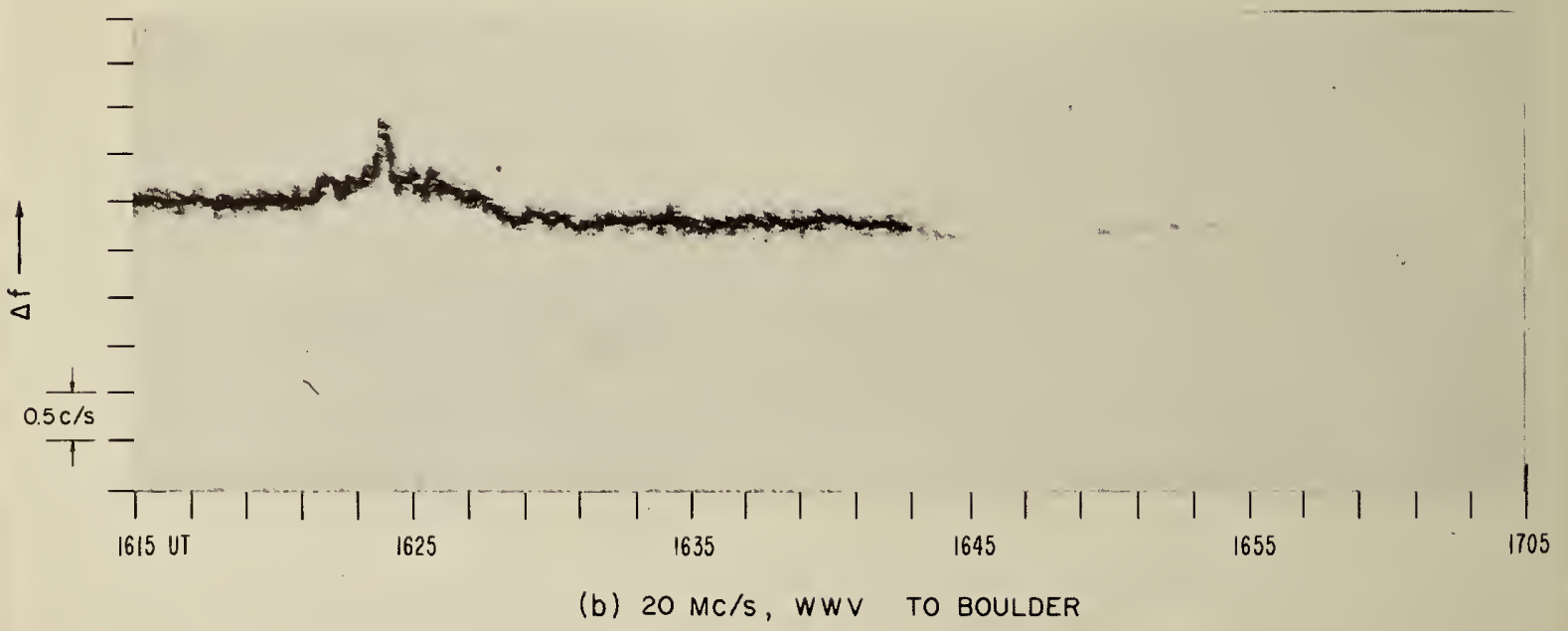

5 APRIL $|96|$

Figure 13 
OPTICAL FLARE, IMPORTANCE $3,1648-1718-1945$

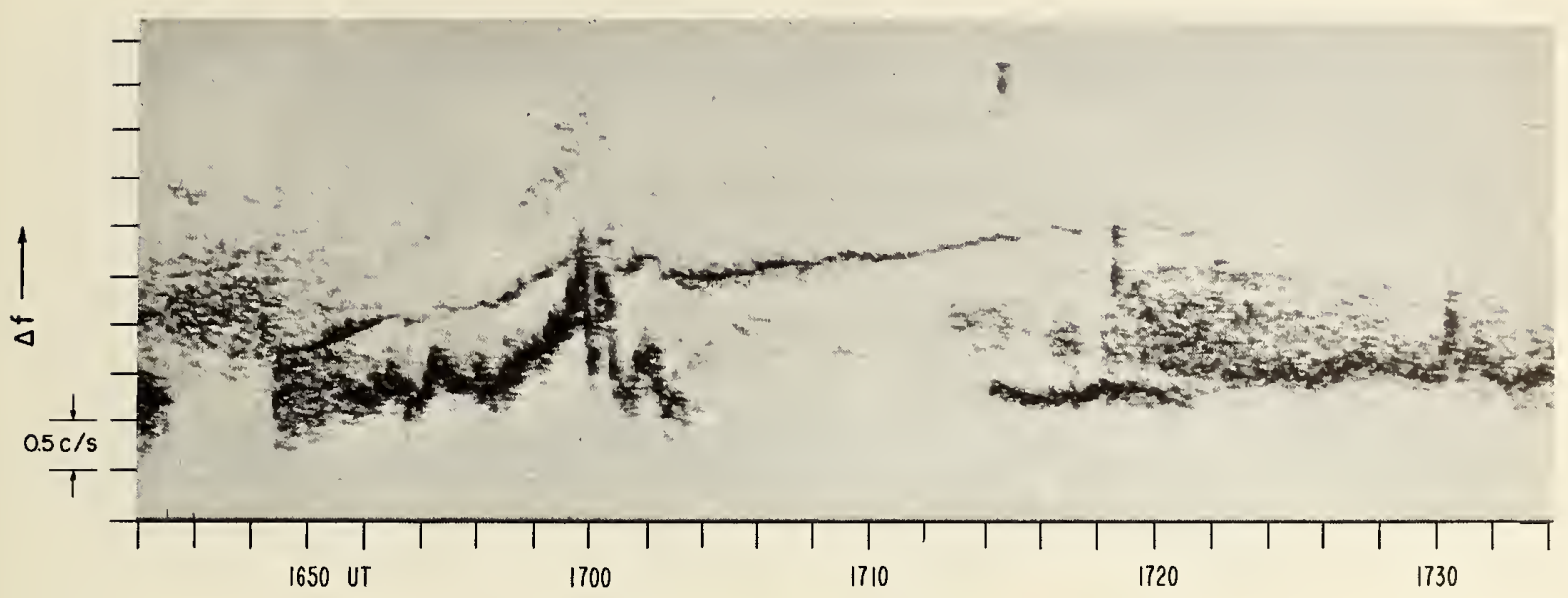

(a) $10 \mathrm{mc} / \mathrm{s}$, WWV TO BOULDER

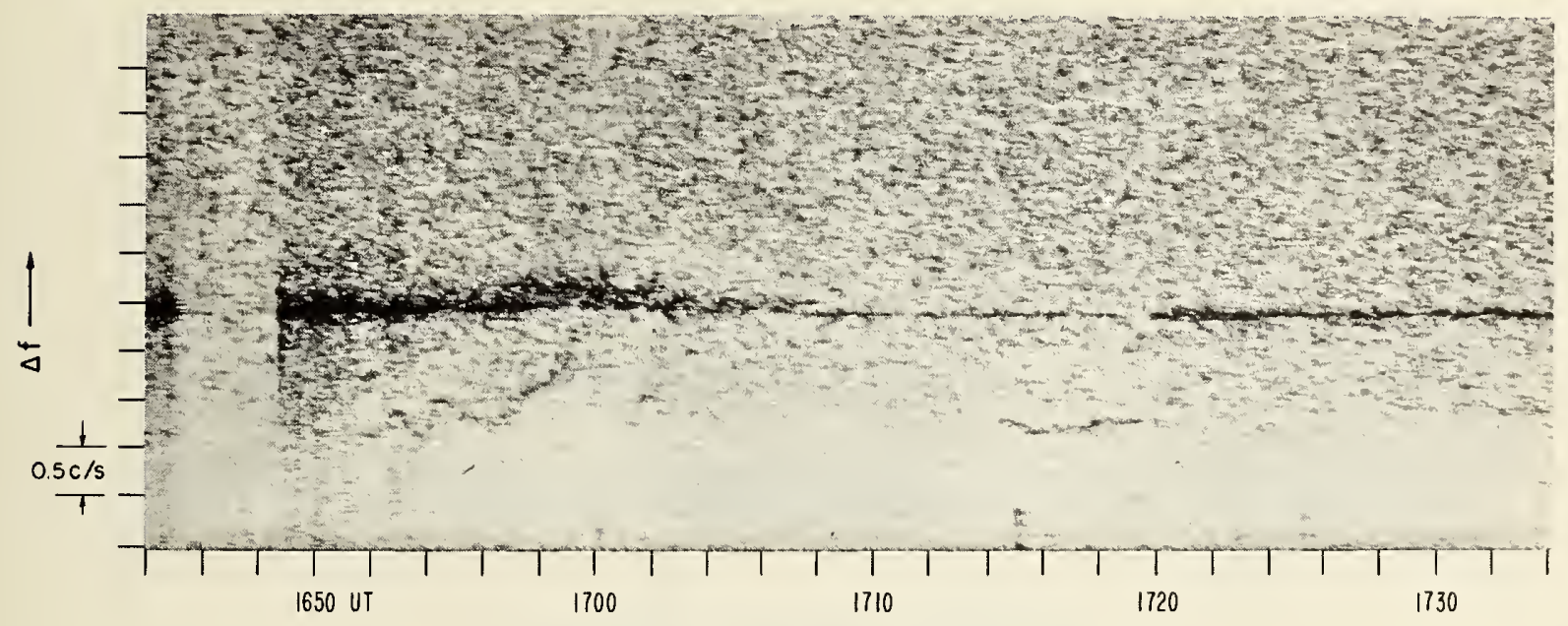

(b) $20 \mathrm{Mc} / \mathrm{s}$, WWV TO BOULDER

26 APRIL 1961

Figure 14 
OPTICAL FLARE, IMPORTANCE 3,2145-2212-2333D

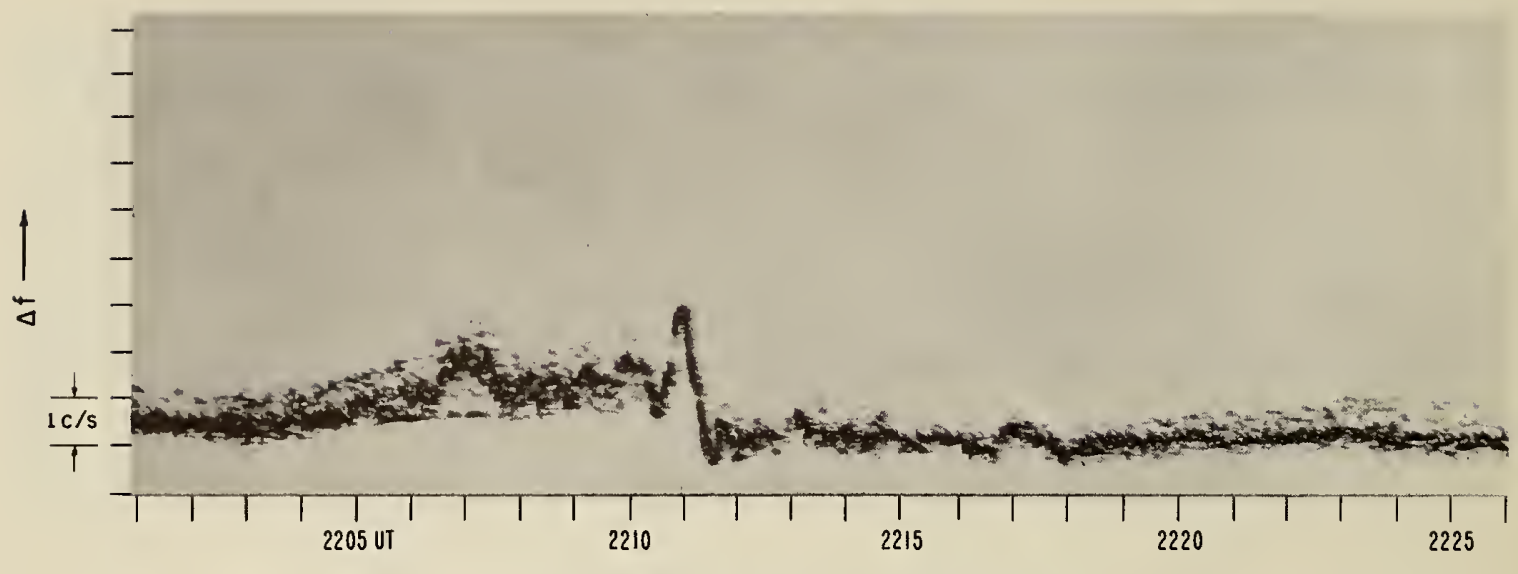

(a) $10 \mathrm{mc} / \mathrm{s}$, WWV TO BOULDER

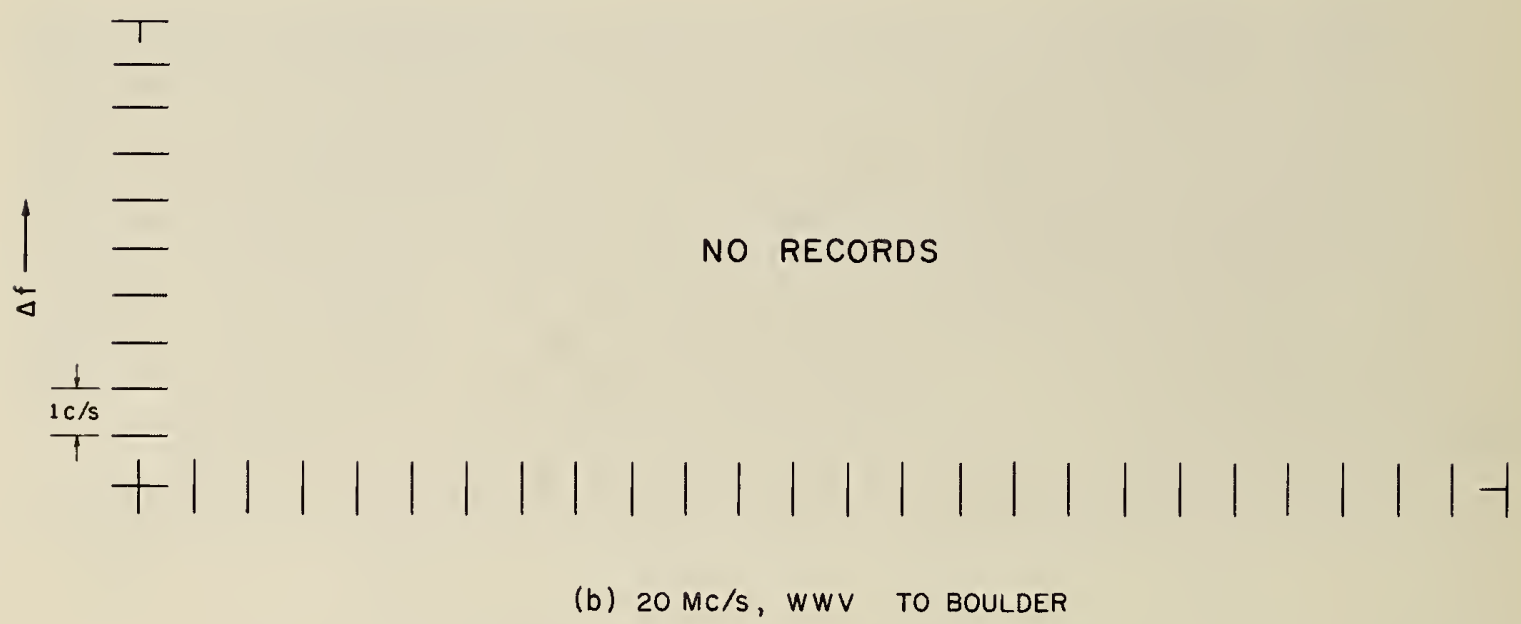

4 MAY 1961

Figure 15 
OPTICAL FLARE, IMPORTANCE 1-, 1858

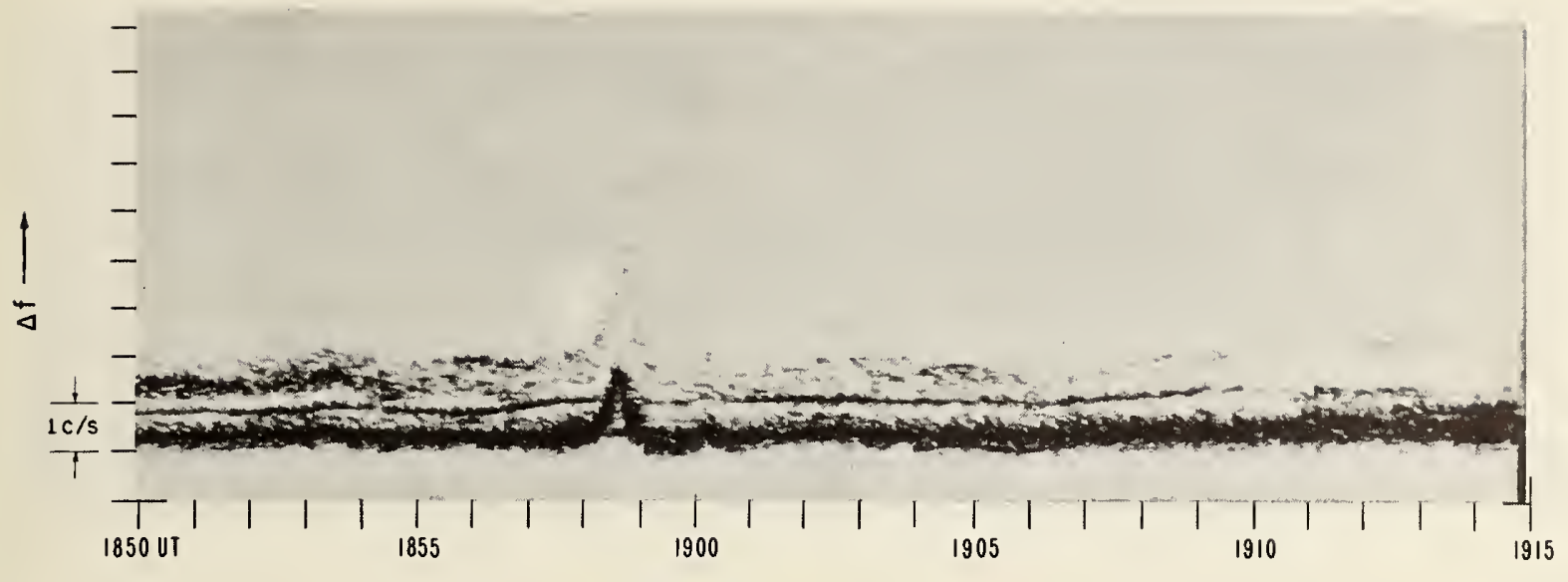

(a) $10 \mathrm{mc} / \mathrm{s}$, WWV TO BOULDER

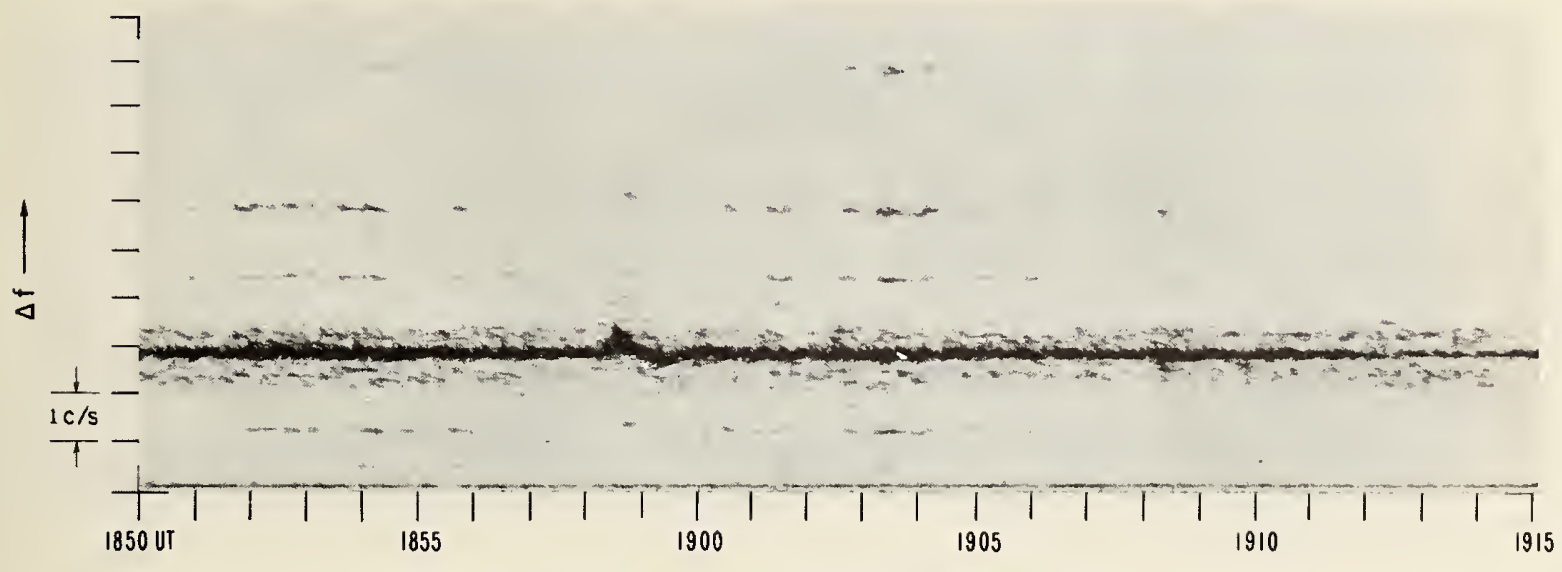

(b) $20 \mathrm{mc} / \mathrm{s}$, WWV TO BOULDER

IO MAY 1961

Figure 16 
OPTICAL FLARE, IMPORTANCE I-, 1904

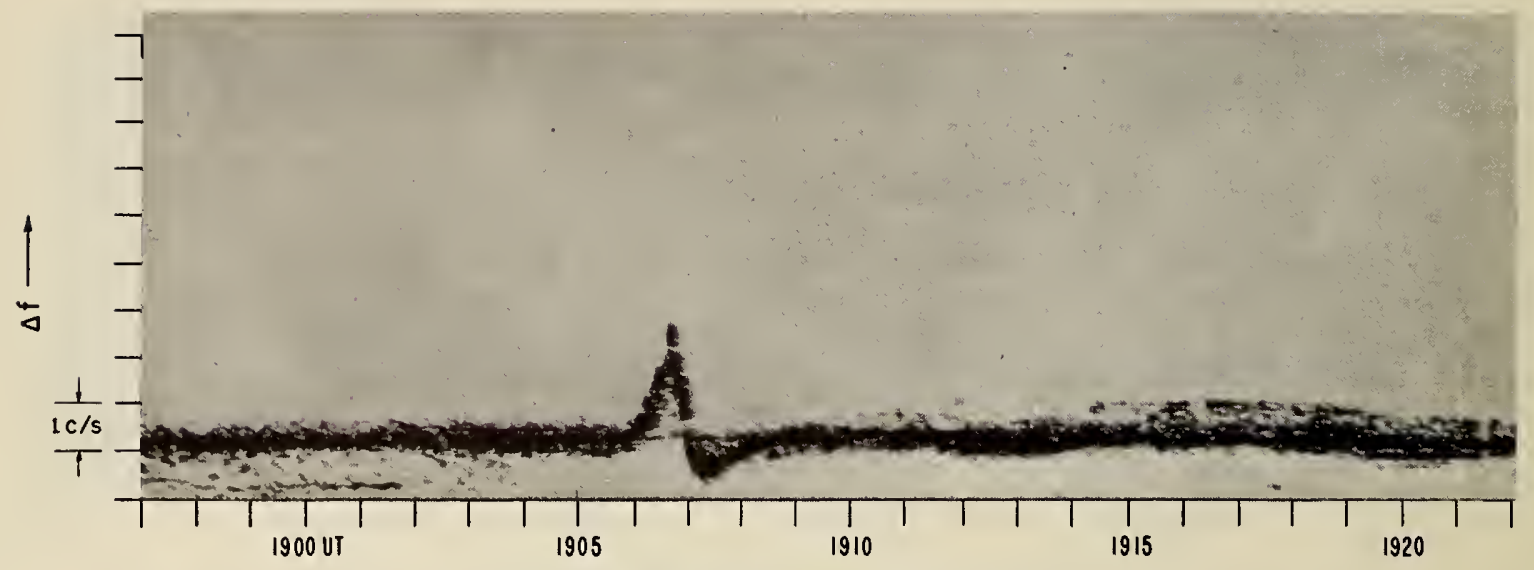

(a) $10 \mathrm{mc} / \mathrm{s}$, WWV TO BOULDER

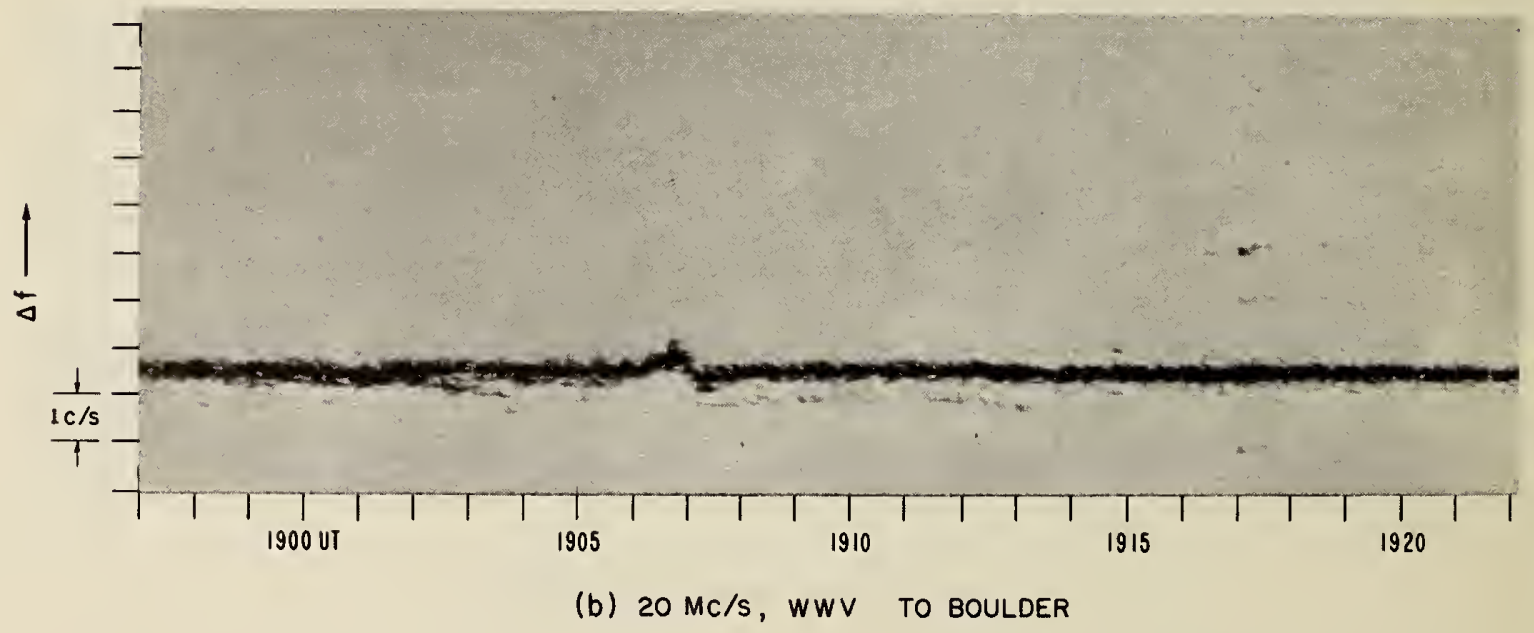

28 MAY 1961 
OPTICAL FLARE, IMPORTANCE I, I7I8E-1720U-1728U

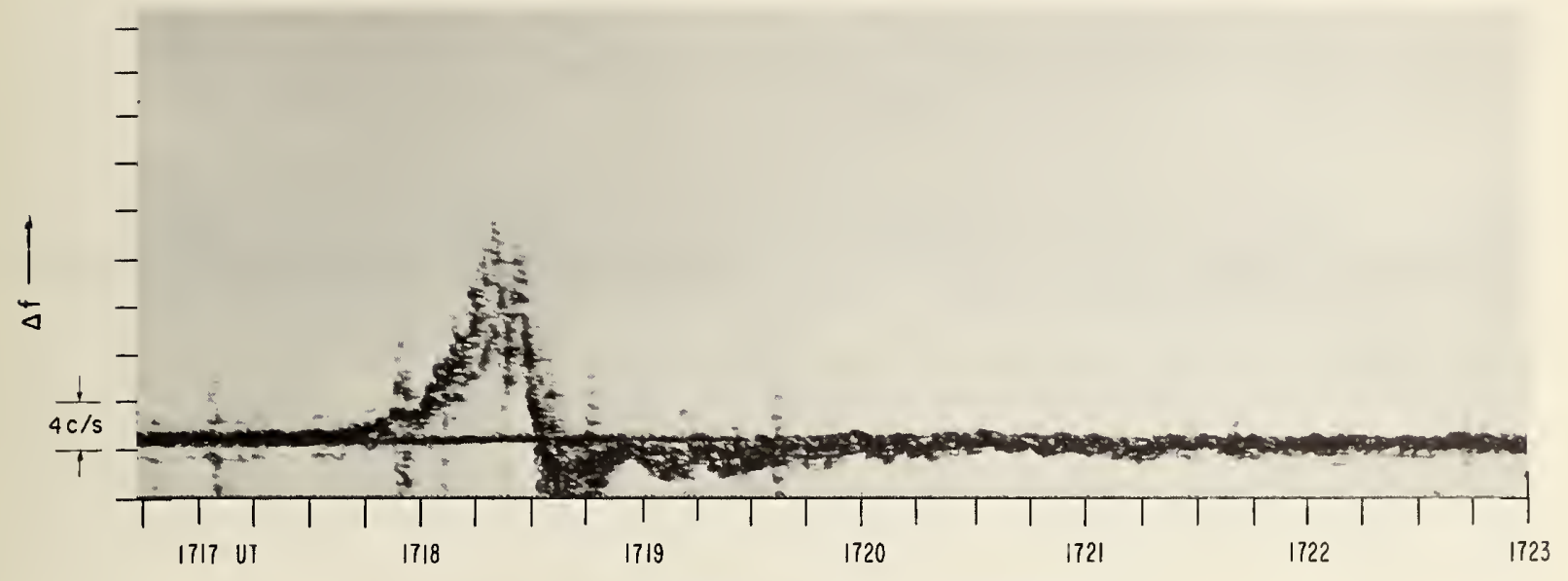

(a) $10 \mathrm{MC} / \mathrm{s}$, WWV TO BOULDER

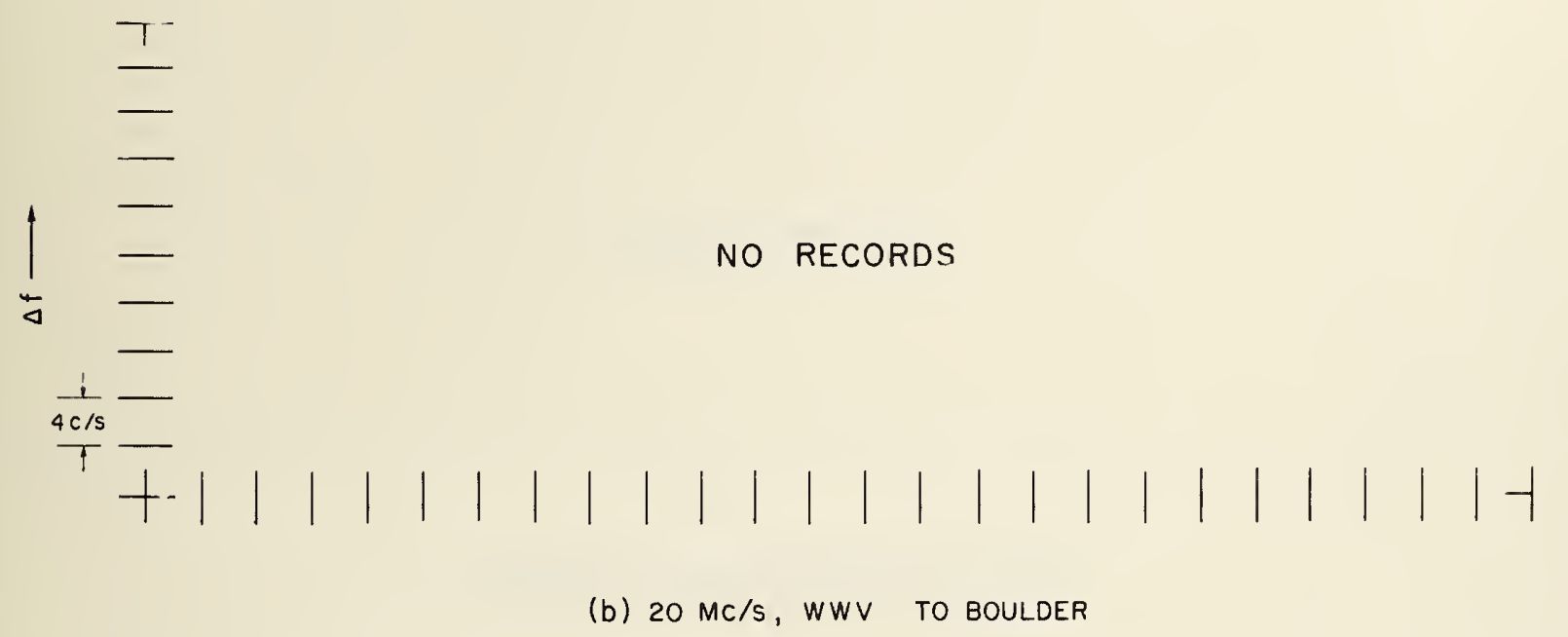

15 JUNE 1961

Figure 18 
OPTICAL FLARE, IMPORTANCE 1-, 2057
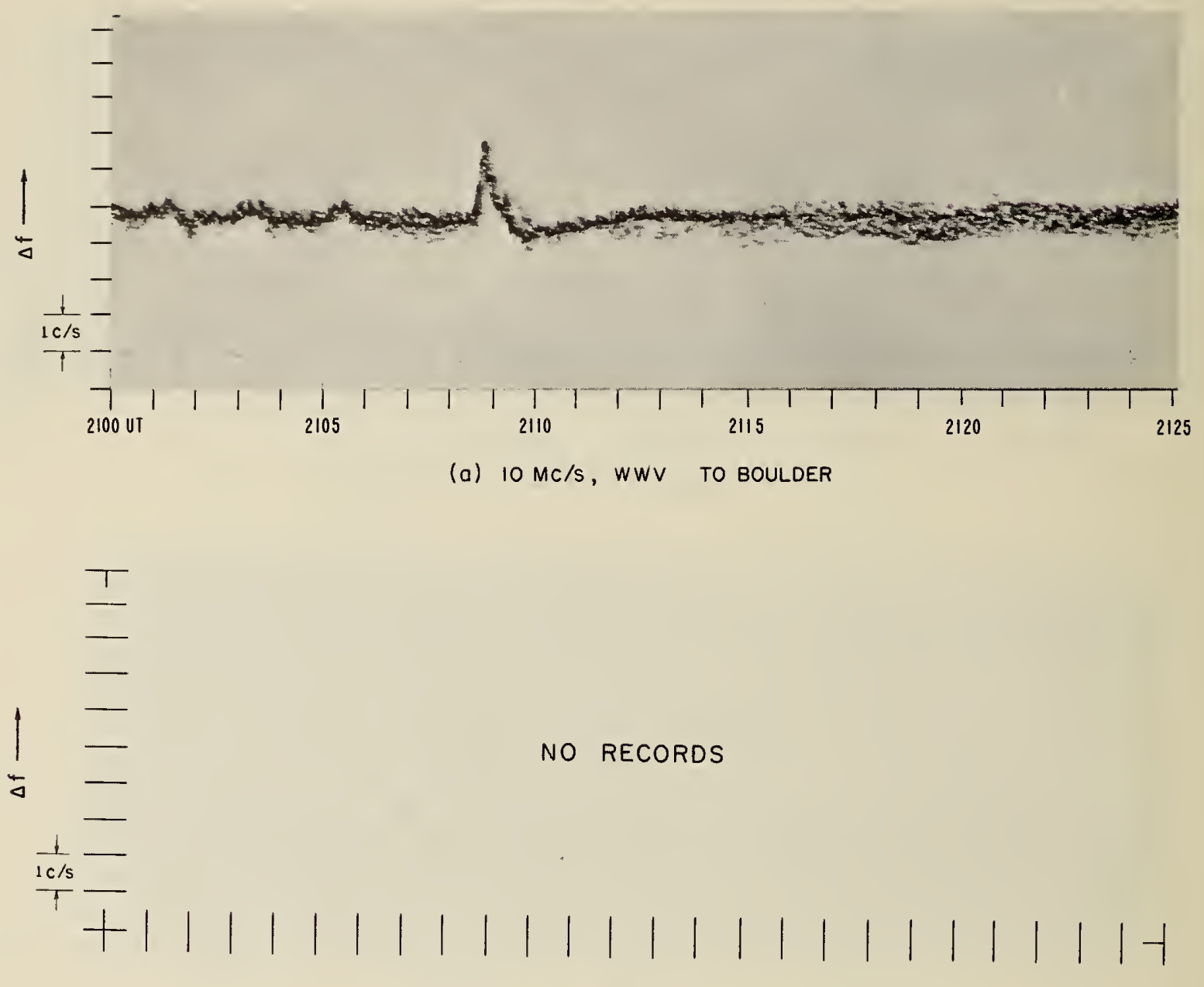

(b) $20 \mathrm{mc} / \mathrm{s}$, WWV TO BOULDER

29 JUNE 1961

Figure 19 


\section{OPTICAL FLARE, IMPORTANCE 1-, 2132}

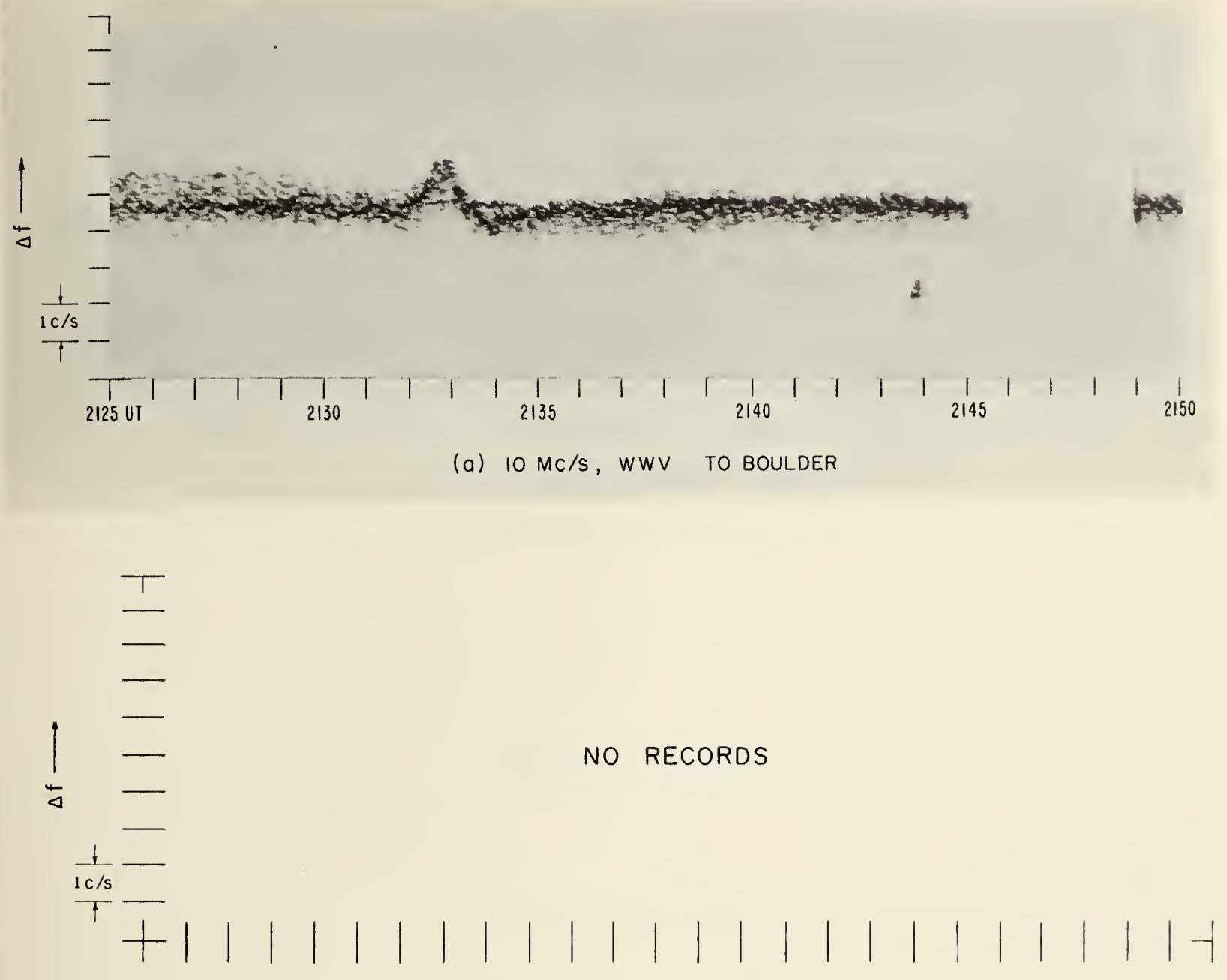

(b) $20 \mathrm{mc} / \mathrm{s}$, WWV TO BOULDER

| JULY $196 \mid$

Figure 20 
OPTICAL FLARE, IMPORTANCE $1,1741-1753-1800$

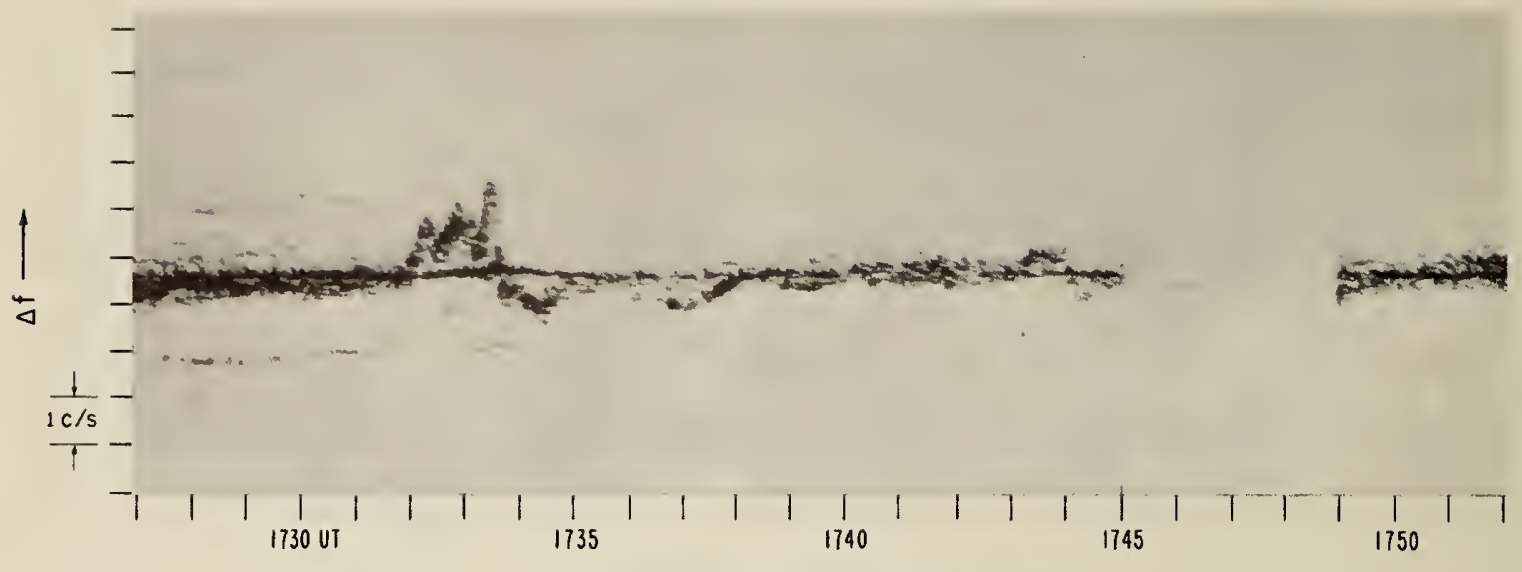

(a) $10 \mathrm{Mc} / \mathrm{s}$, WWV TO BOULDER

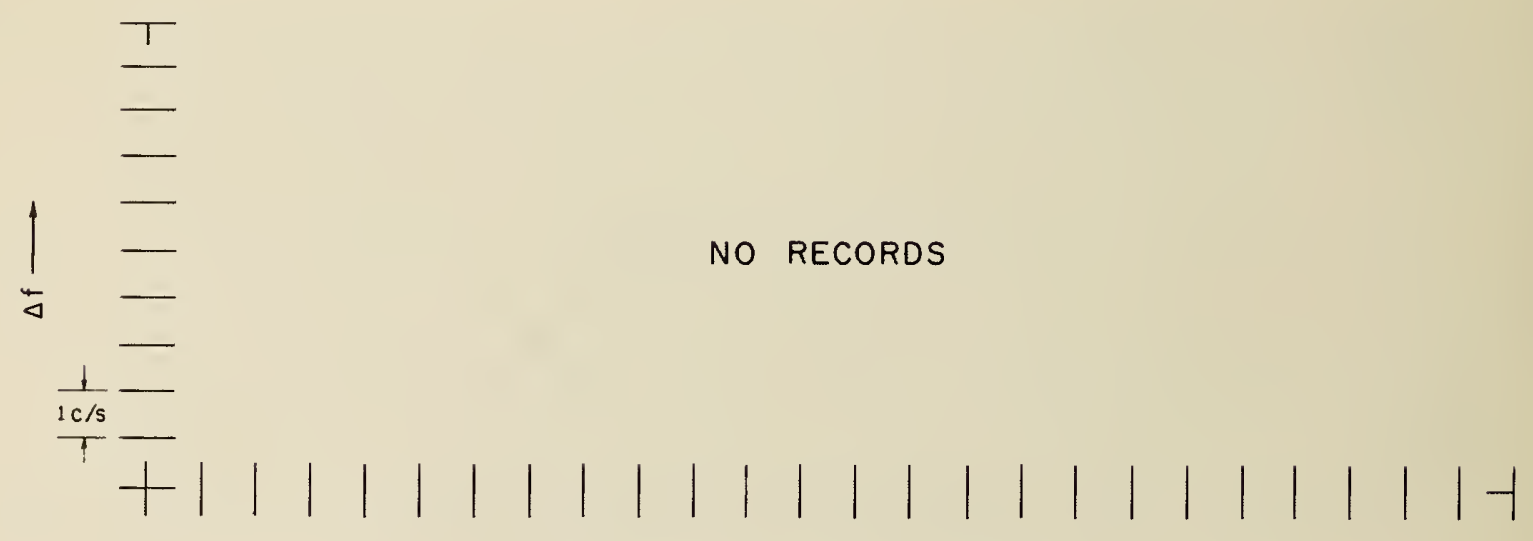

(b) $20 \mathrm{MC} / \mathrm{s}$, WWV TO BOULDER

10 JULY 1961

Figure 21

$-34-$ 
OPTICAL FLARE, IMPORTANCE I-, 2211

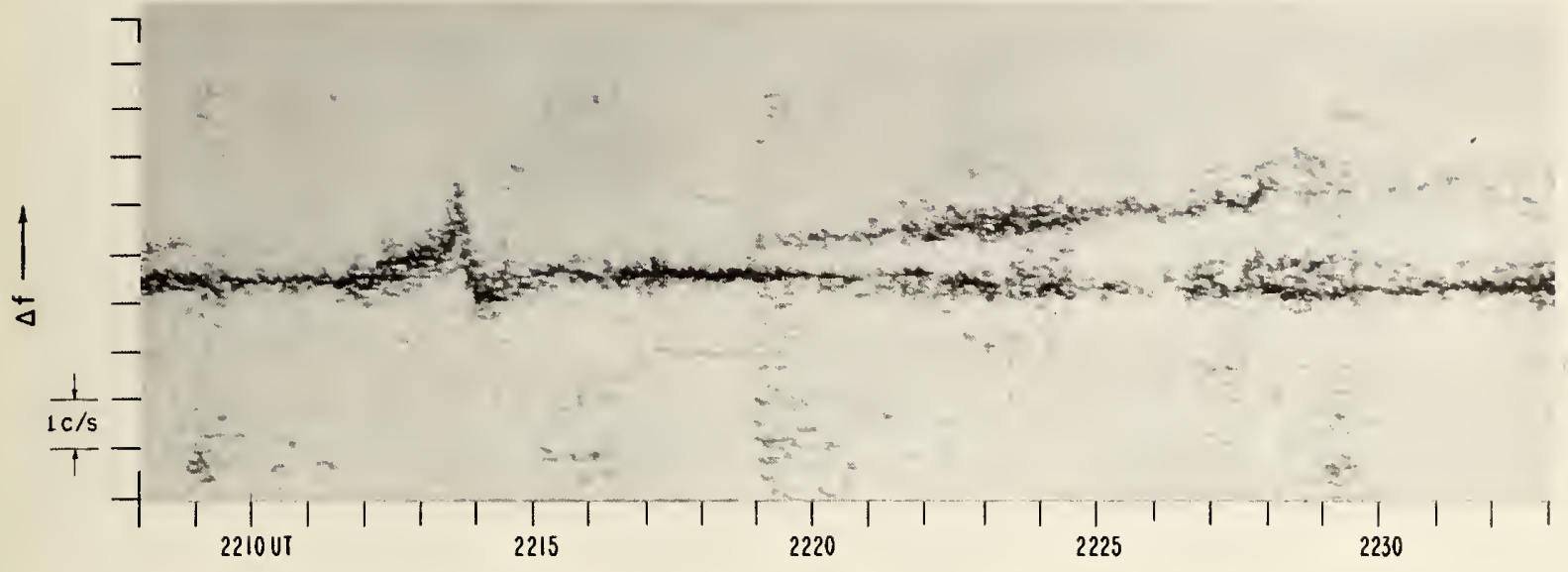

(a) $10 \mathrm{MC} / \mathrm{s}$, WWV TO BOULDER

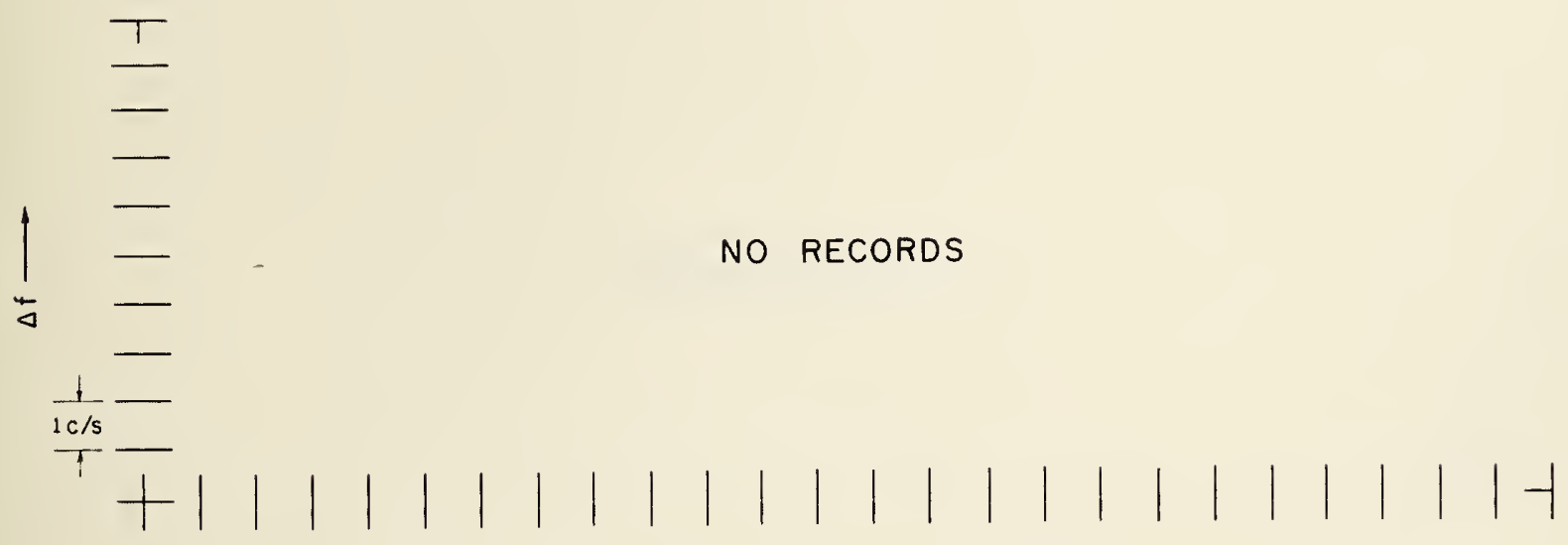

(b) $20 \mathrm{Mc} / \mathrm{s}$, WWV TO BOULDER

13 JULY 1961

Figure 22 


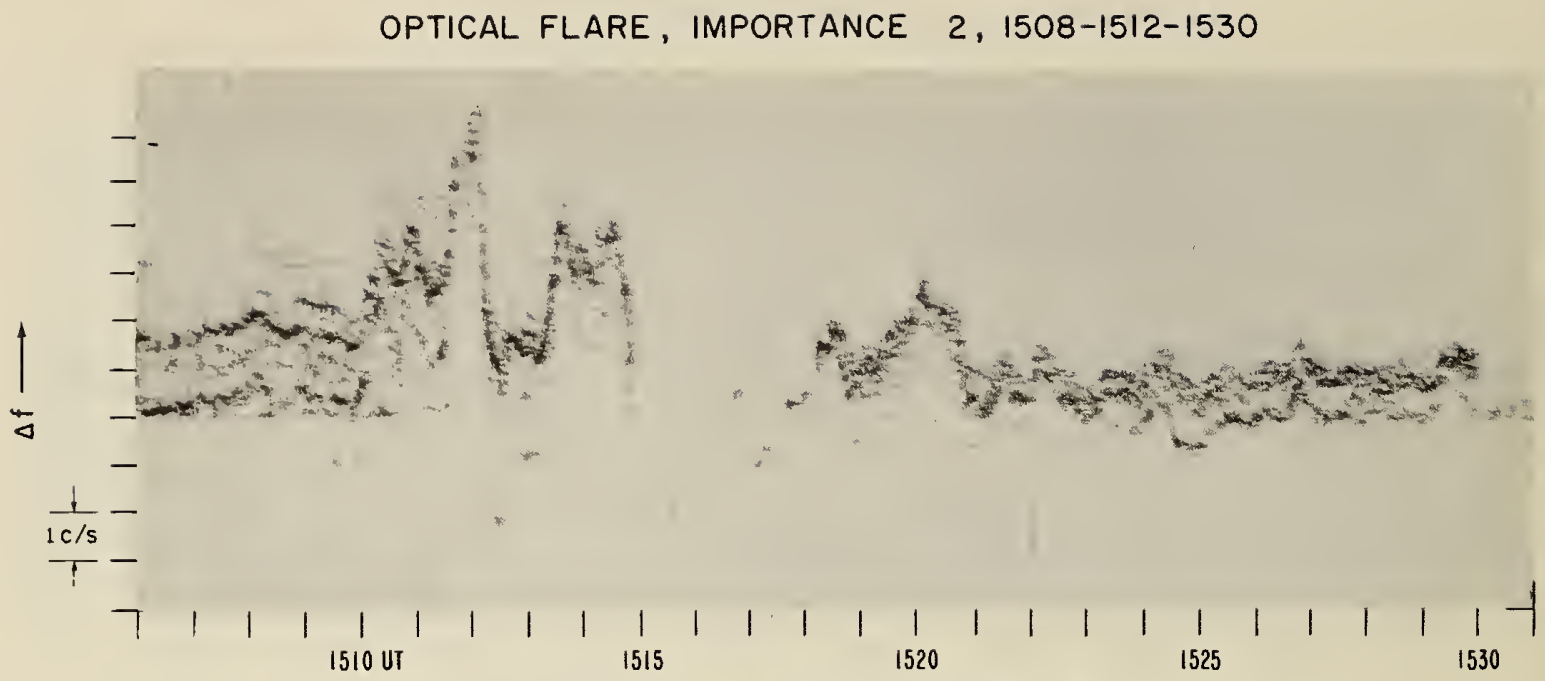

(a) $10 \mathrm{mc} / \mathrm{s}$, WWV TO BOULDER

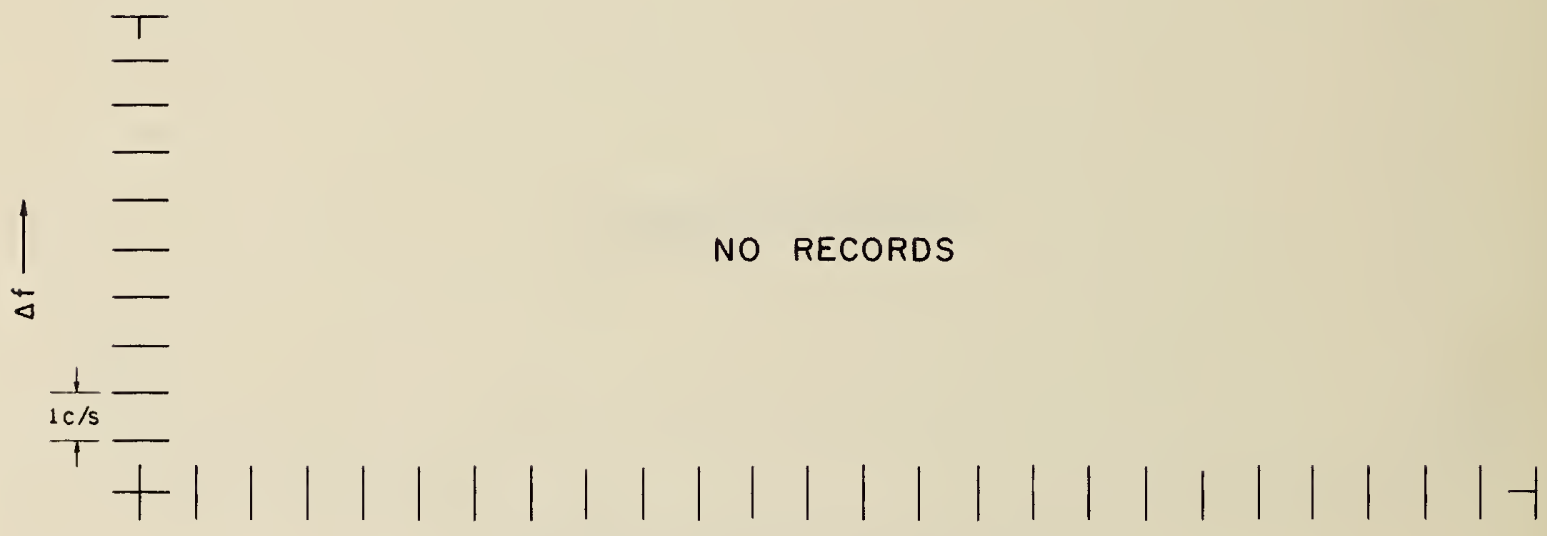

(b) $20 \mathrm{mc} / \mathrm{s}, W W V$ TO BOULDER

15 JULY 1961

Figure 23

$-36-$ 
OPTICAL FLARE, IMPORTANCE I-, 1556

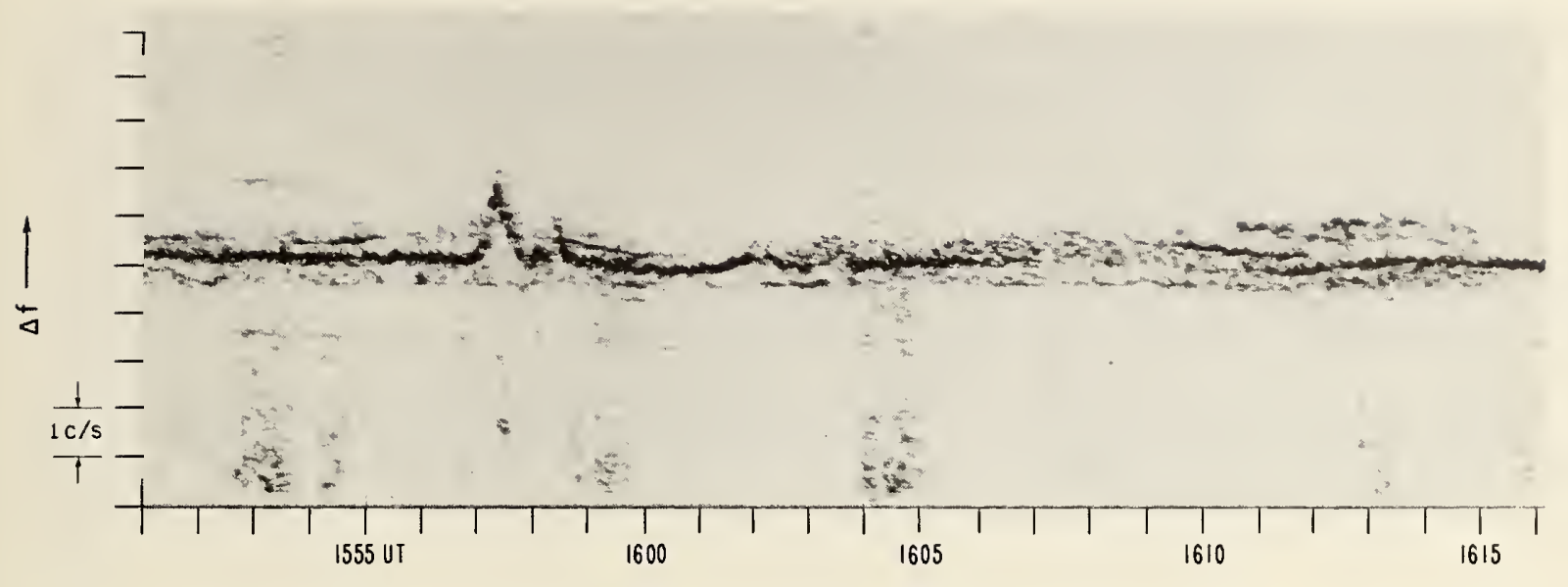

(a) $10 \mathrm{Mc} / \mathrm{s}$, WWV TO BOULDER

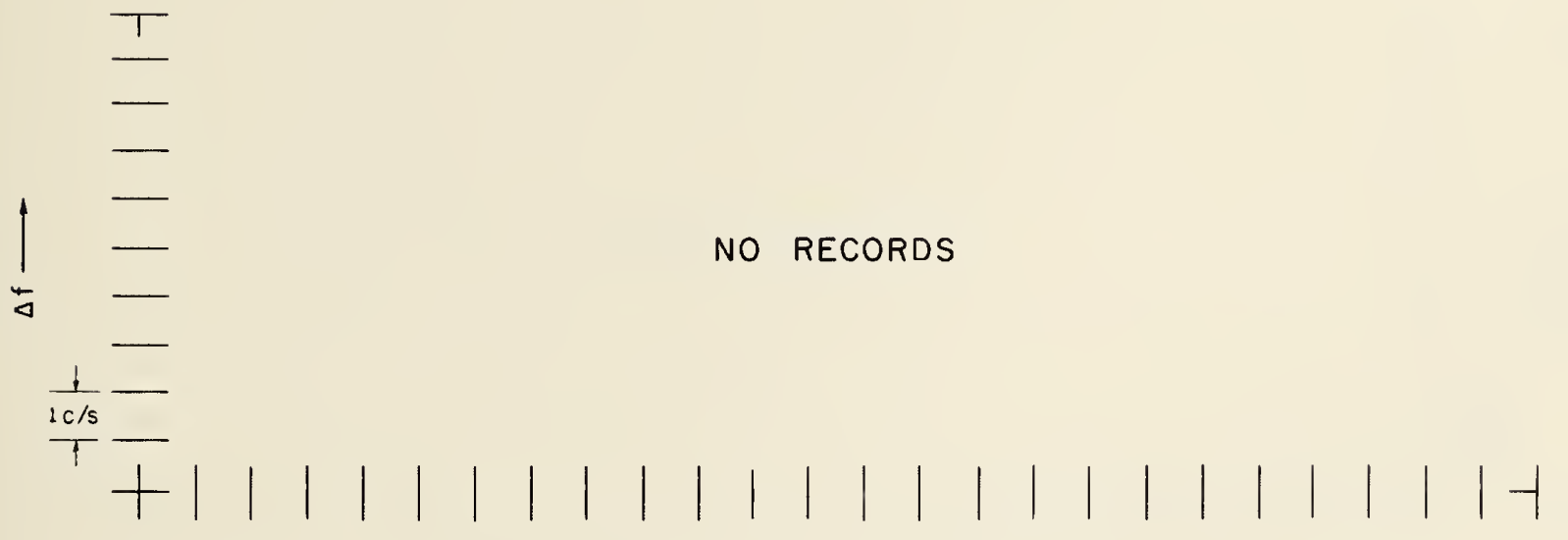

(b) $20 \mathrm{Mc} / \mathrm{s}$, WWV TO BOULDER

16 JULY 1961

Figure 24 
OPTICAL FLARE, IMPORTANCE I, 1907 - 1916-1935

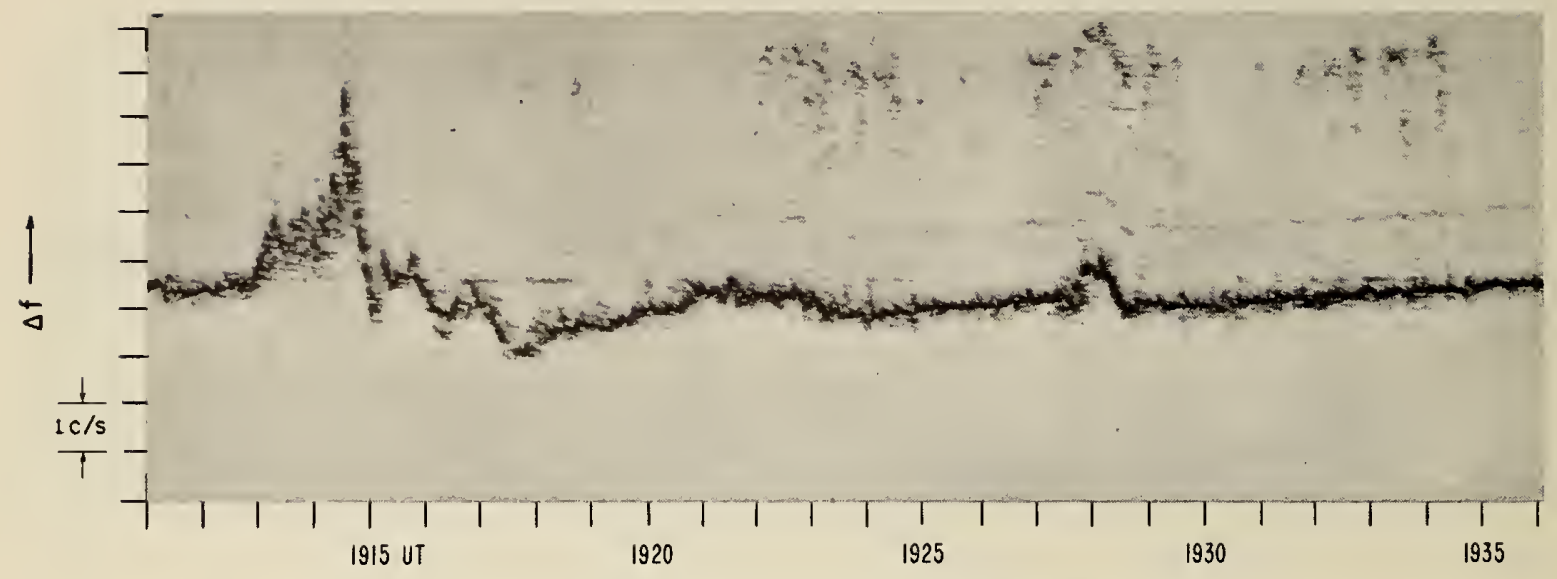

(a) $10 \mathrm{mc} / \mathrm{s}$, WWV TO BOULDER

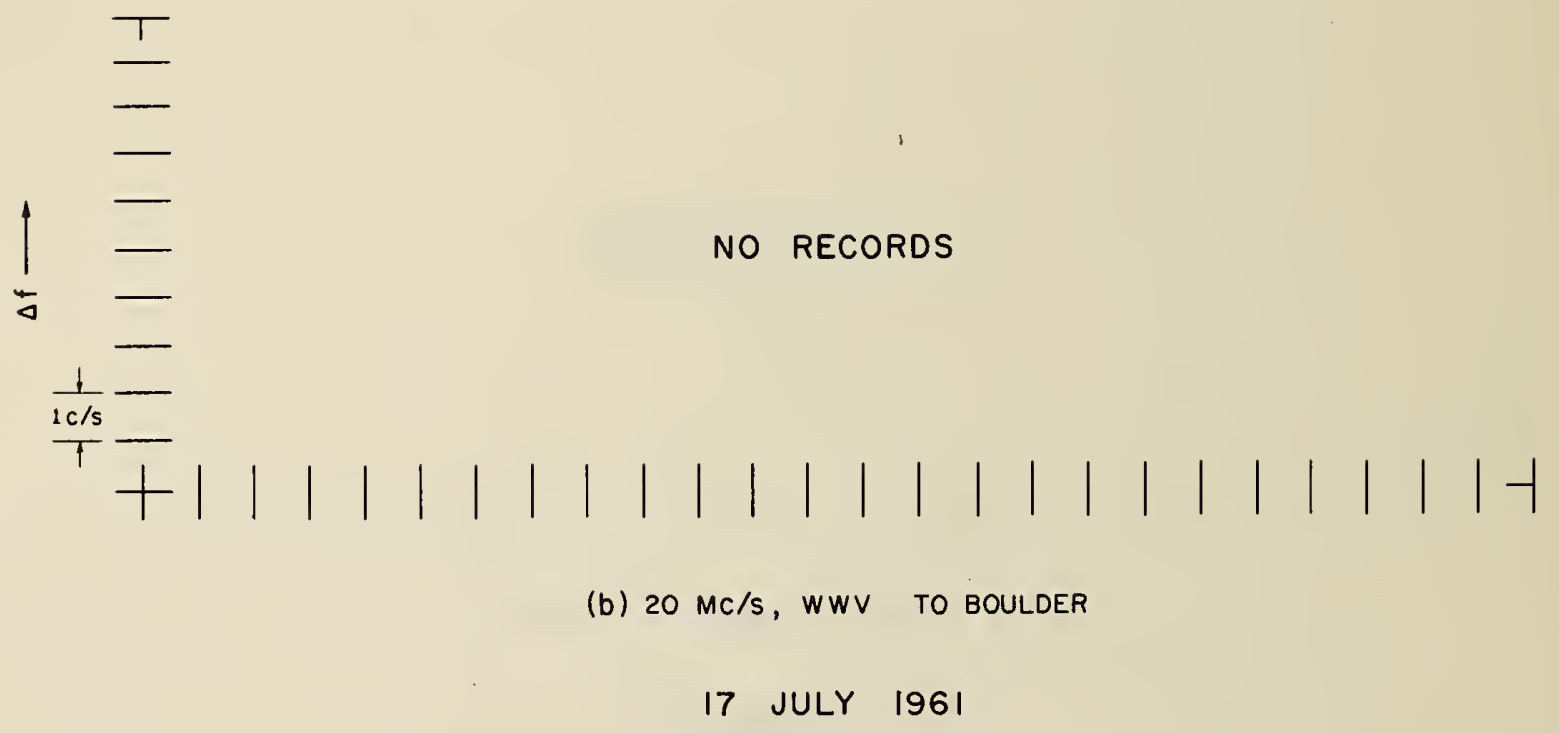

Figure 25 
OPTICAL FLARE, IMPORTANCE I, 2051-2102-2120

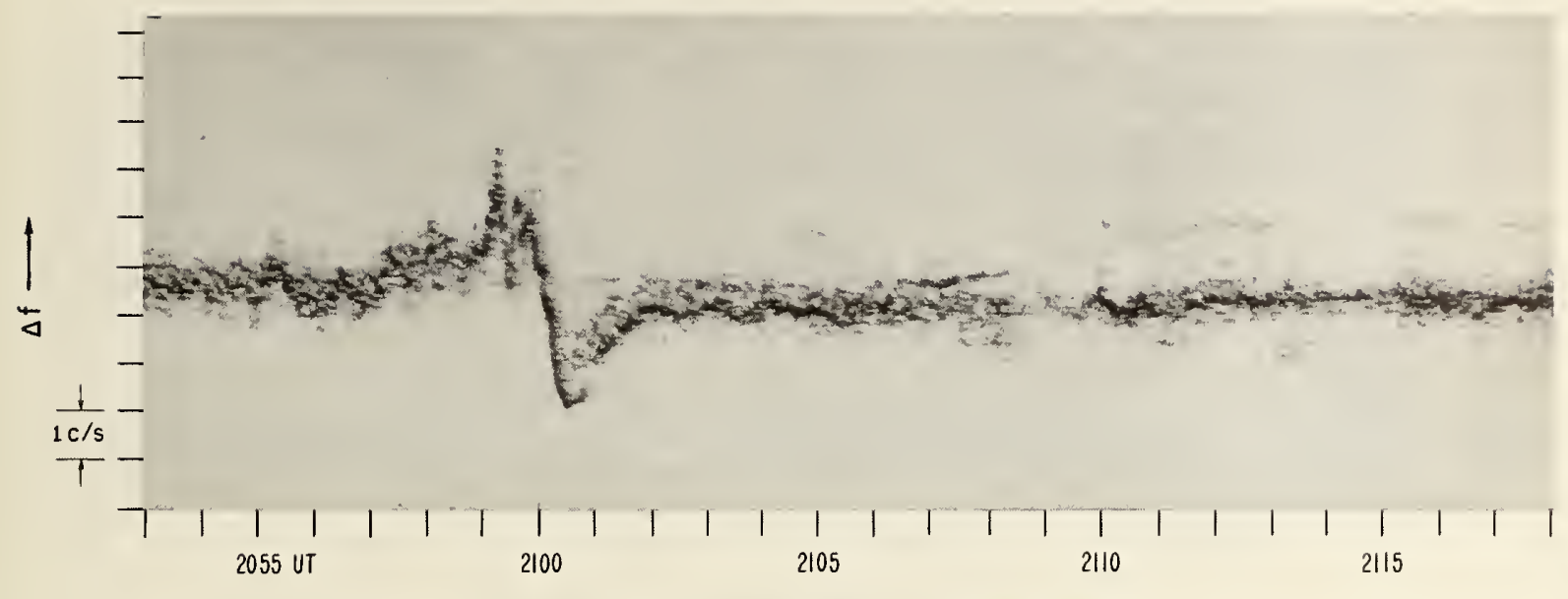

(a) $10 \mathrm{Mc} / \mathrm{s}$, WWV TO BOULDER

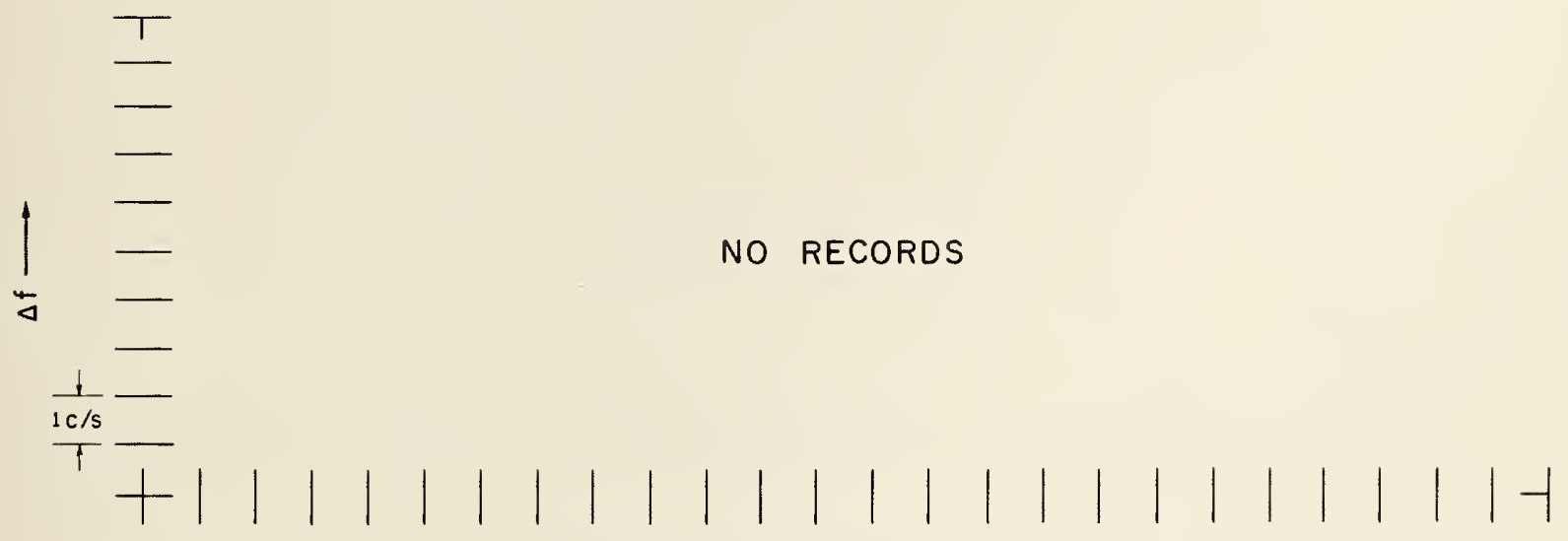

(b) $20 \mathrm{Mc} / \mathrm{s}$, WWV TO BOULDER

19 JULY 1961

Figure 26 
OPTICAL FLARE, IMPORTANCE 2, 1714-1718-1734

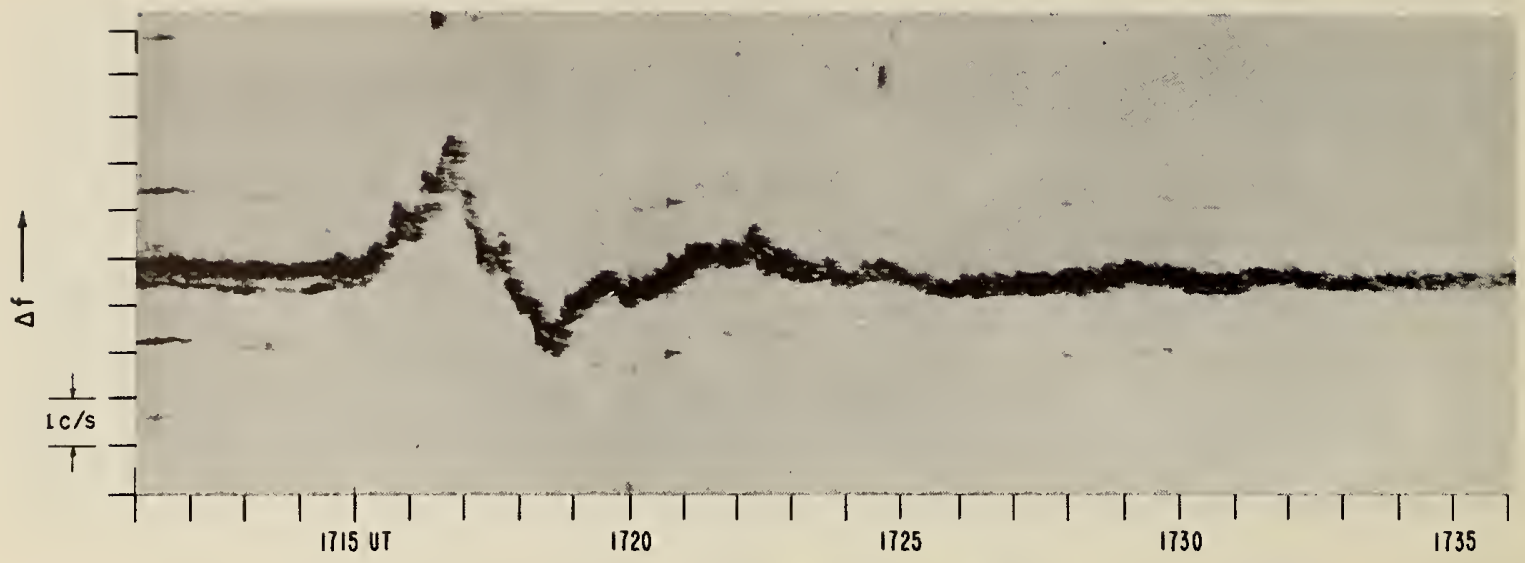

(a) $10 \mathrm{mc} / \mathrm{s}$, WWV TO BOULDER

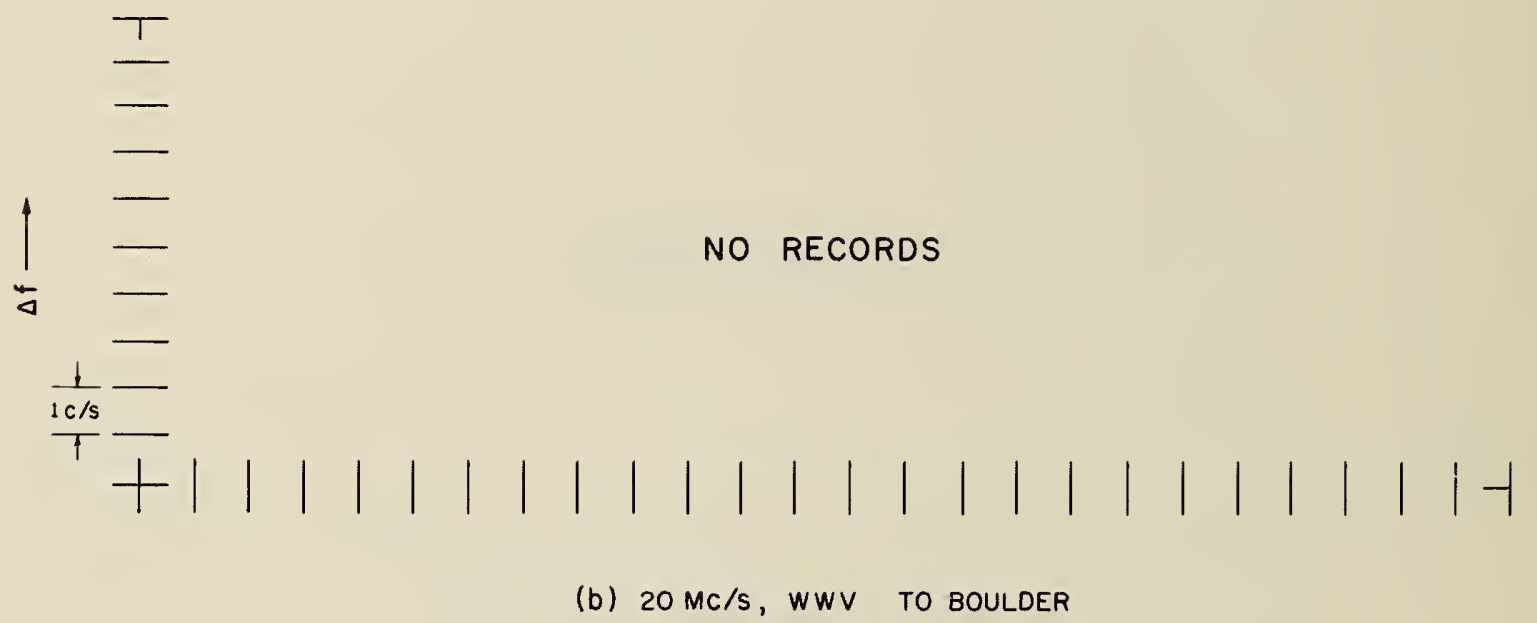

21 JULY 1961

Figure 27 

OPTICAL FLARE, IMPORTANCE I, 1425-1435-1512

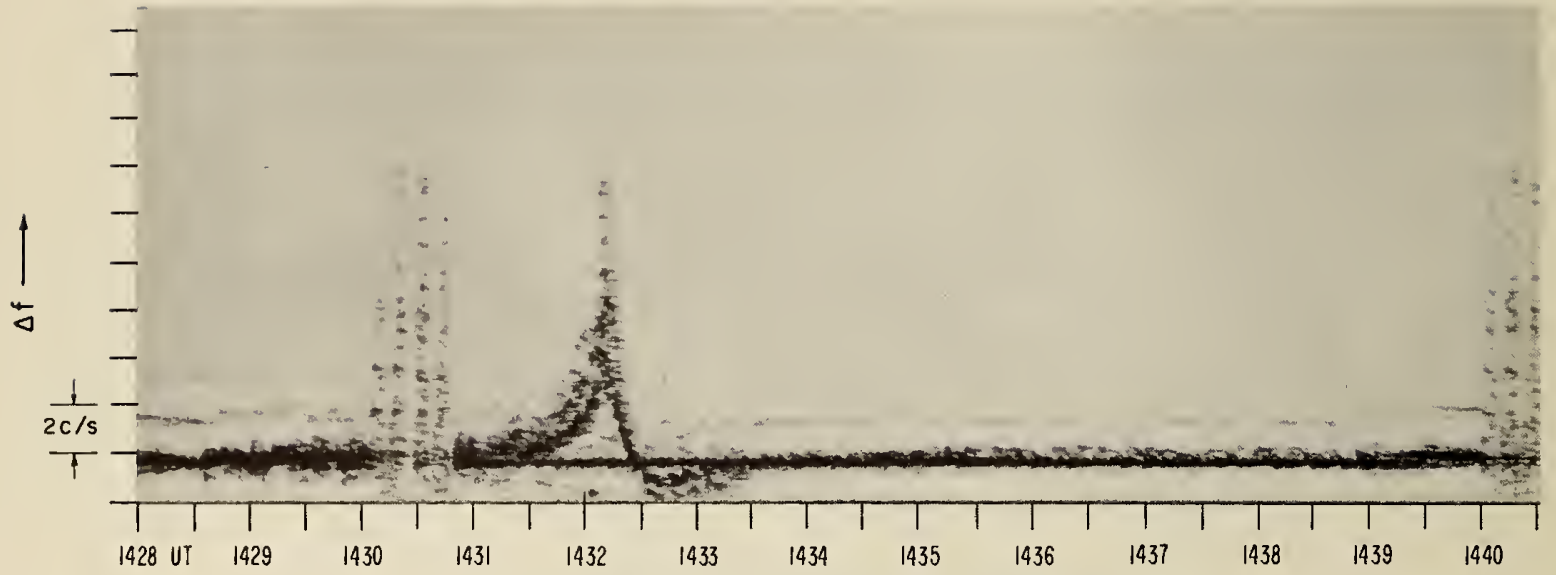

(a) $4.000 \mathrm{mC} / \mathrm{s}$, SUNSET TO BOULDER

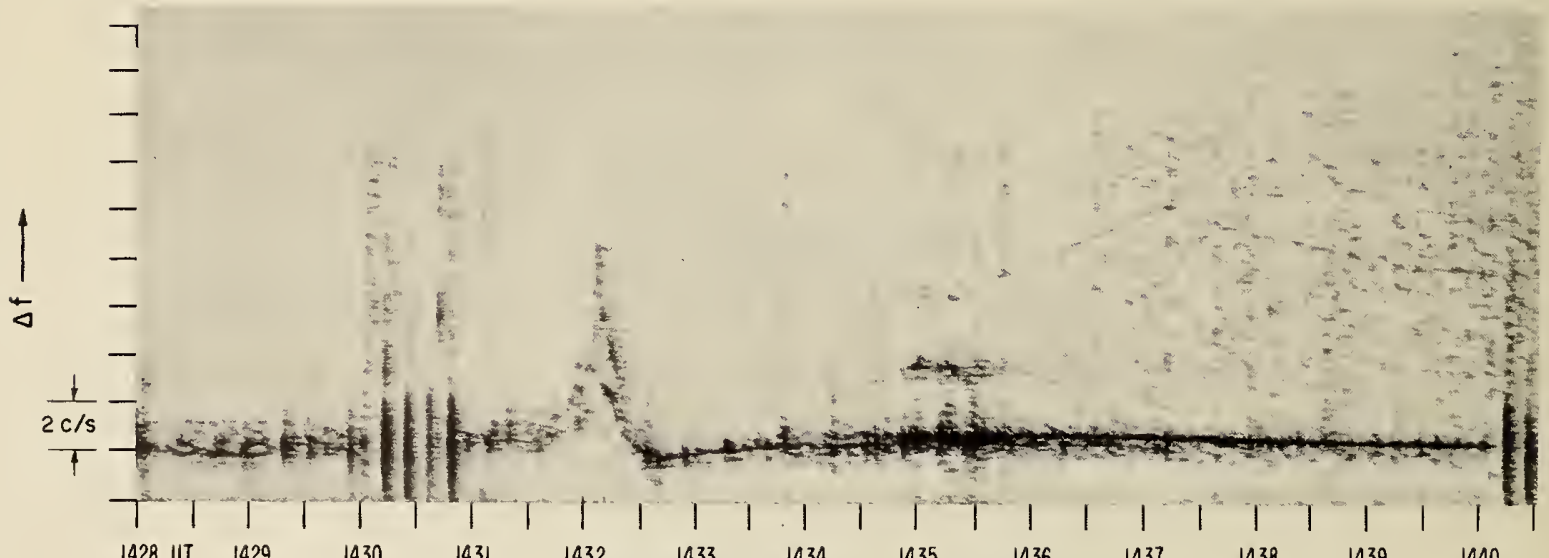

(b) $5.054 \mathrm{MC} / \mathrm{s}$, SUNSET TO BOULDER

4 SEPTEMBER 1961

Figure 28 


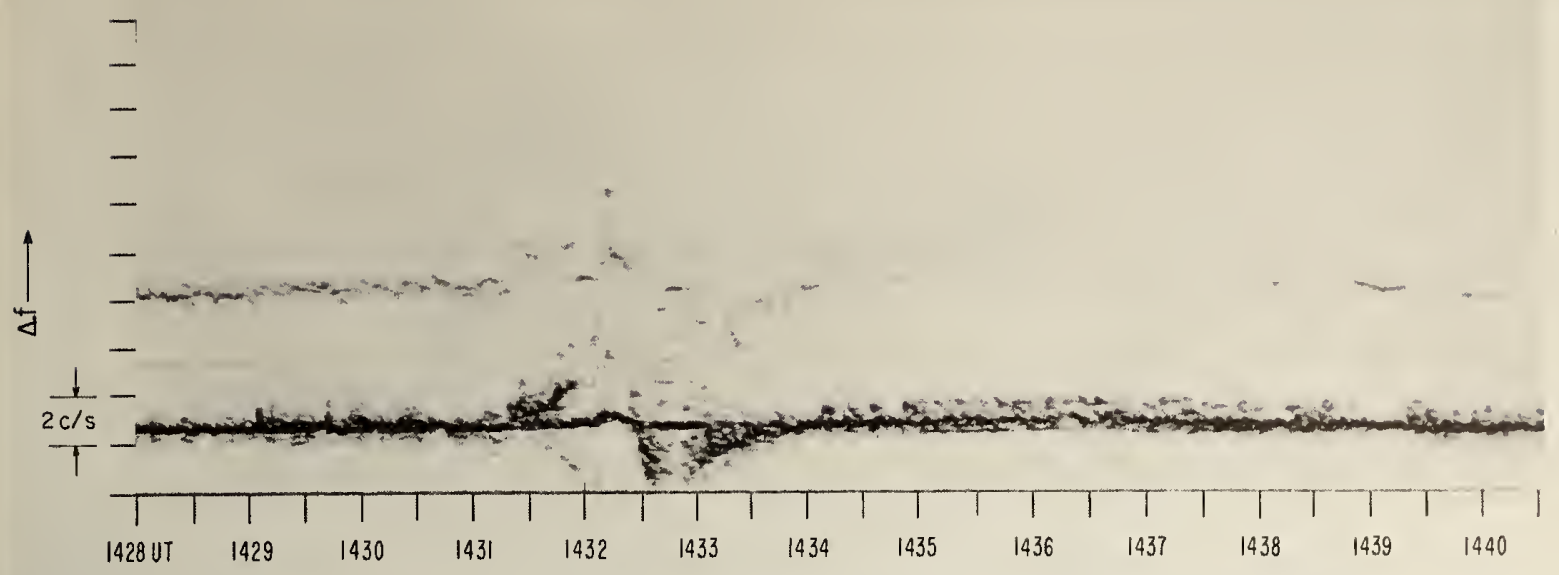

(c) $10 \mathrm{Mc} / \mathrm{s}$, WWV TO SHICKLEY

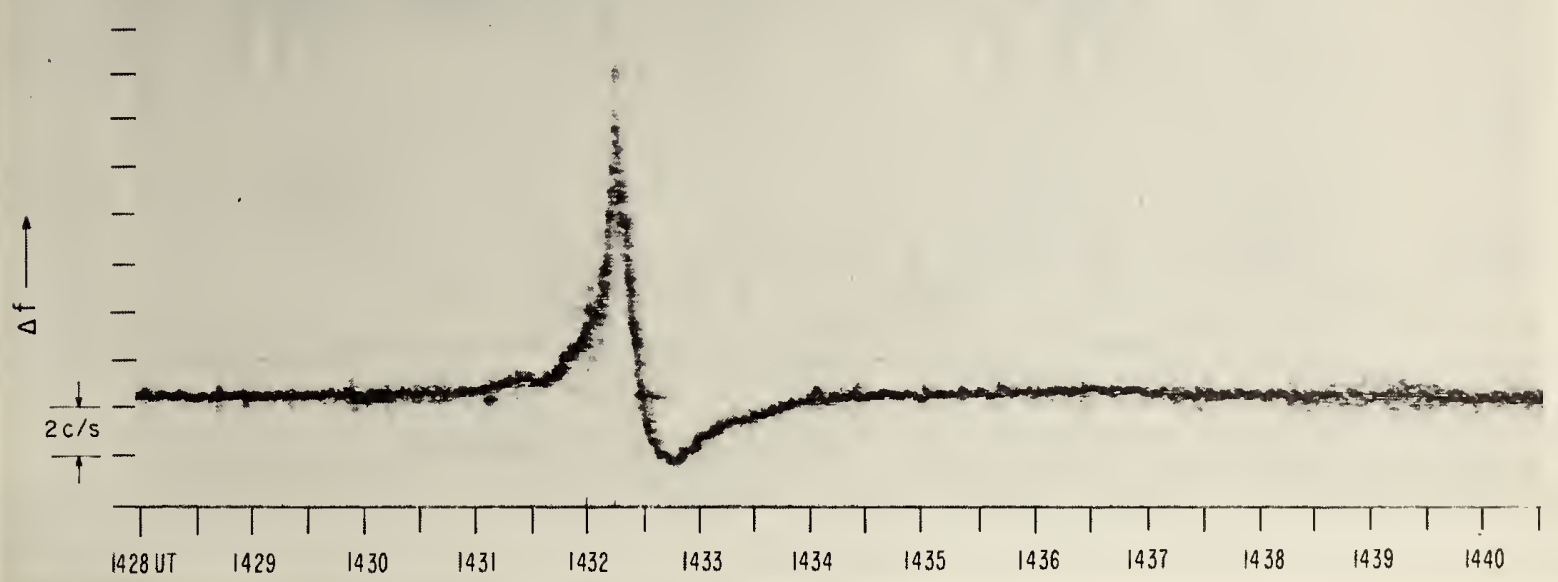

(d) $10 \mathrm{Mc} / \mathrm{s}$, WWV TO BOULDER

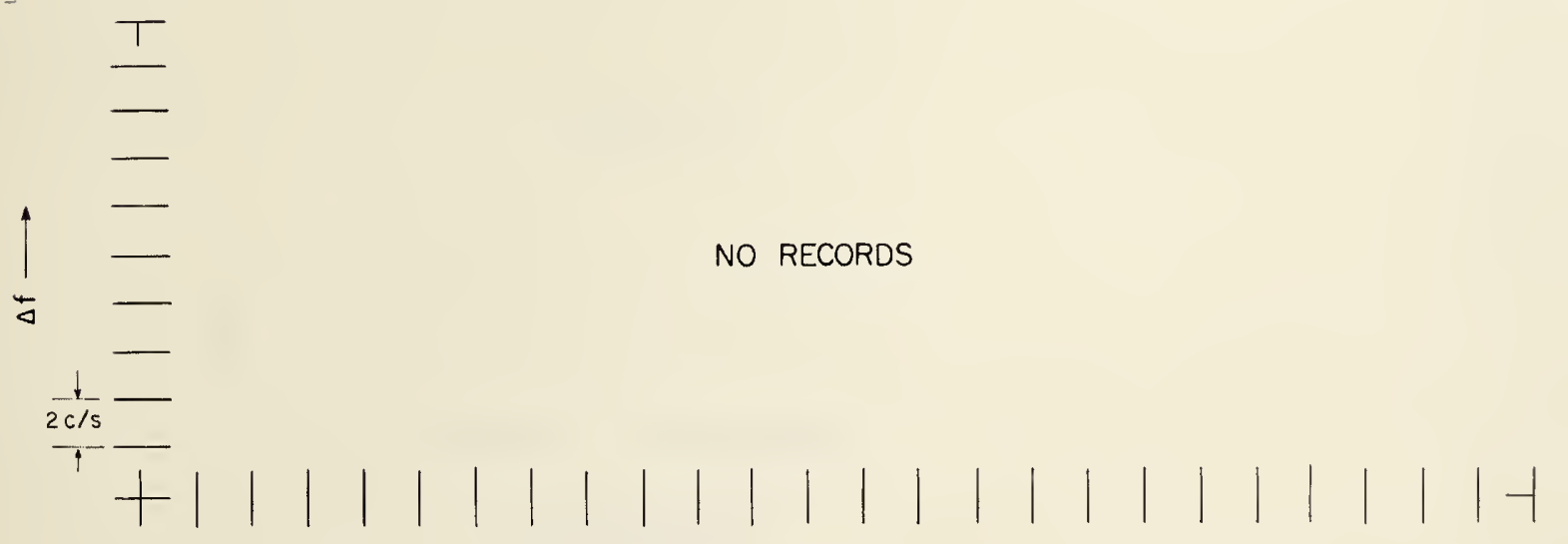

(e) $20 \mathrm{Mc} / \mathrm{s}$, WWV TO BOULDER

4 SEPTEMBER 1961

Figure 28

$-43-$ 



(a) $10 \mathrm{Mc} / \mathrm{s}, \mathrm{WWV}$ TO BOULDER

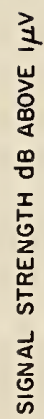

NO RECORDS

(b) $20 \mathrm{Mc} / \mathrm{s}$, WWV TO BOULDER

4 SEPTEMBER $196 \mid$

Figure 29 

OPTICAL FLARE, IMPORTANCE $1,1512-1520-1540 \mathrm{U}$

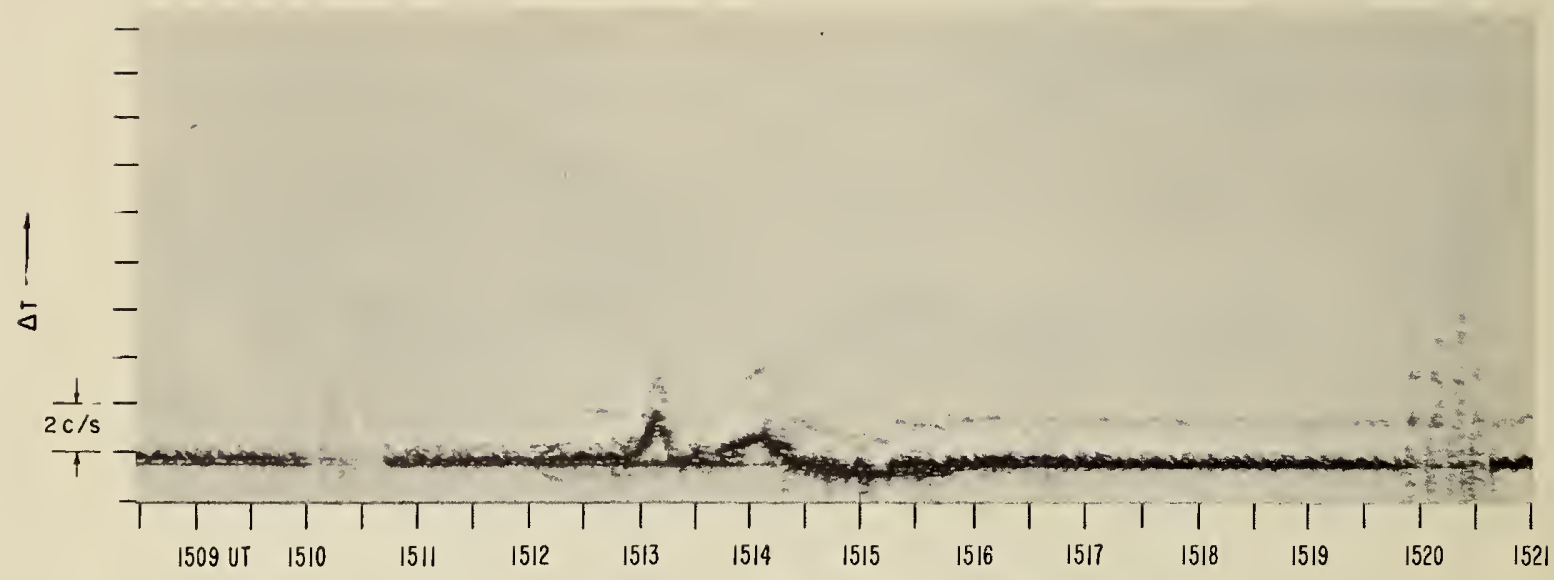

(a) $4.000 \mathrm{mc} / \mathrm{s}$, SUNSET TO BOULDER

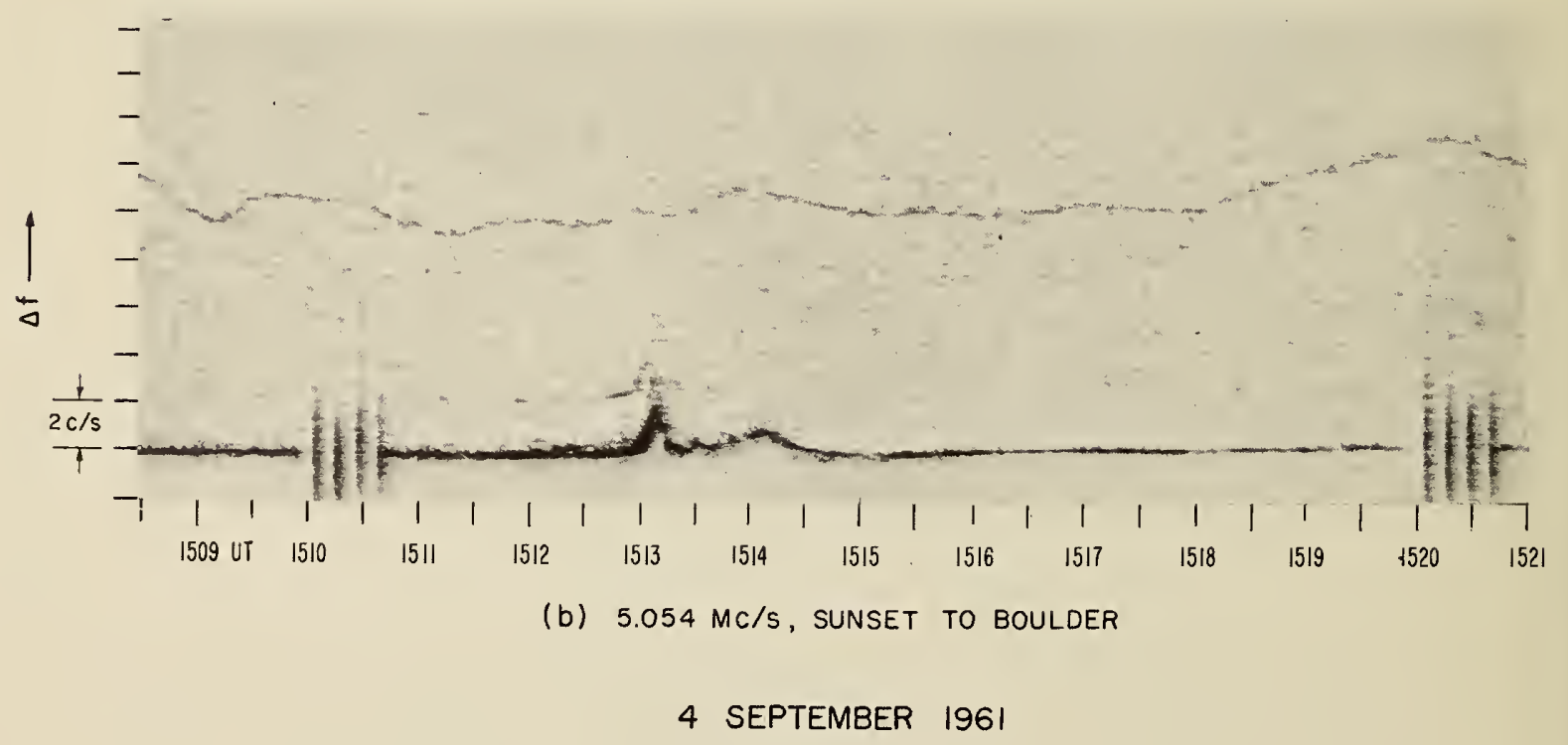

Figure 30 


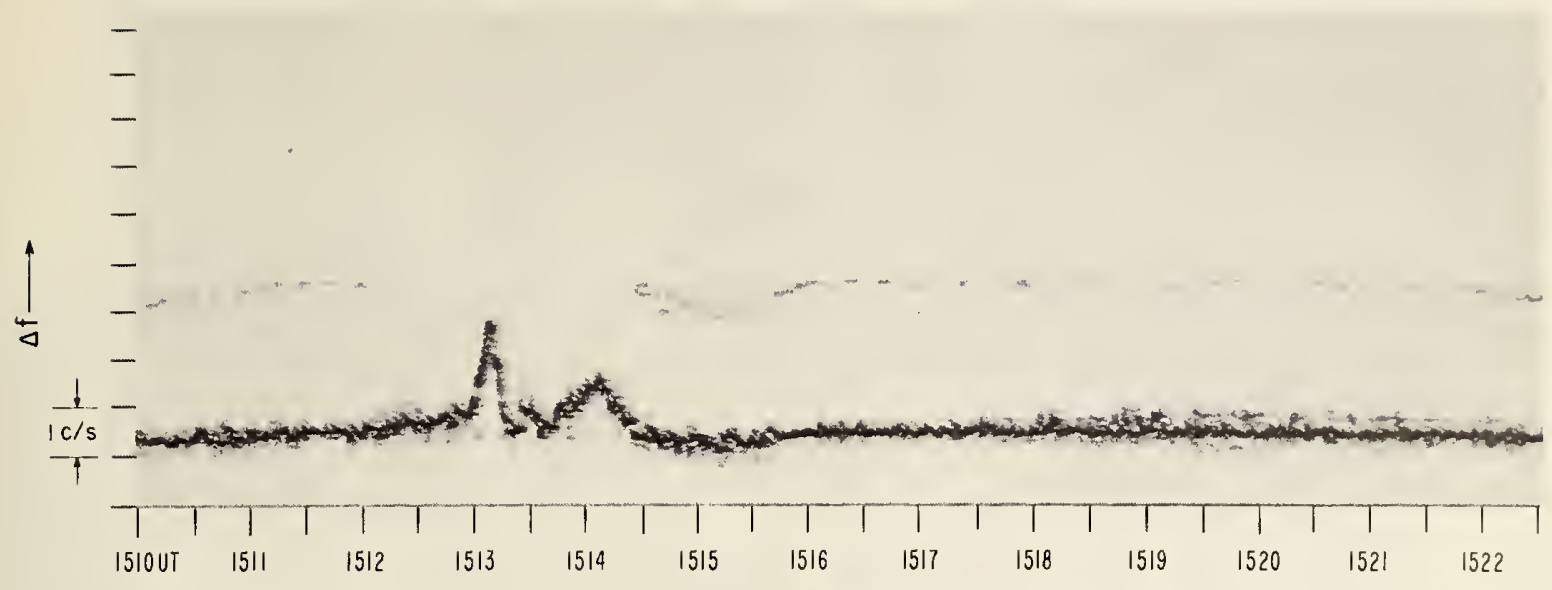

(c) $10 \mathrm{mc} / \mathrm{s}$, WWV TO SHICKLEY

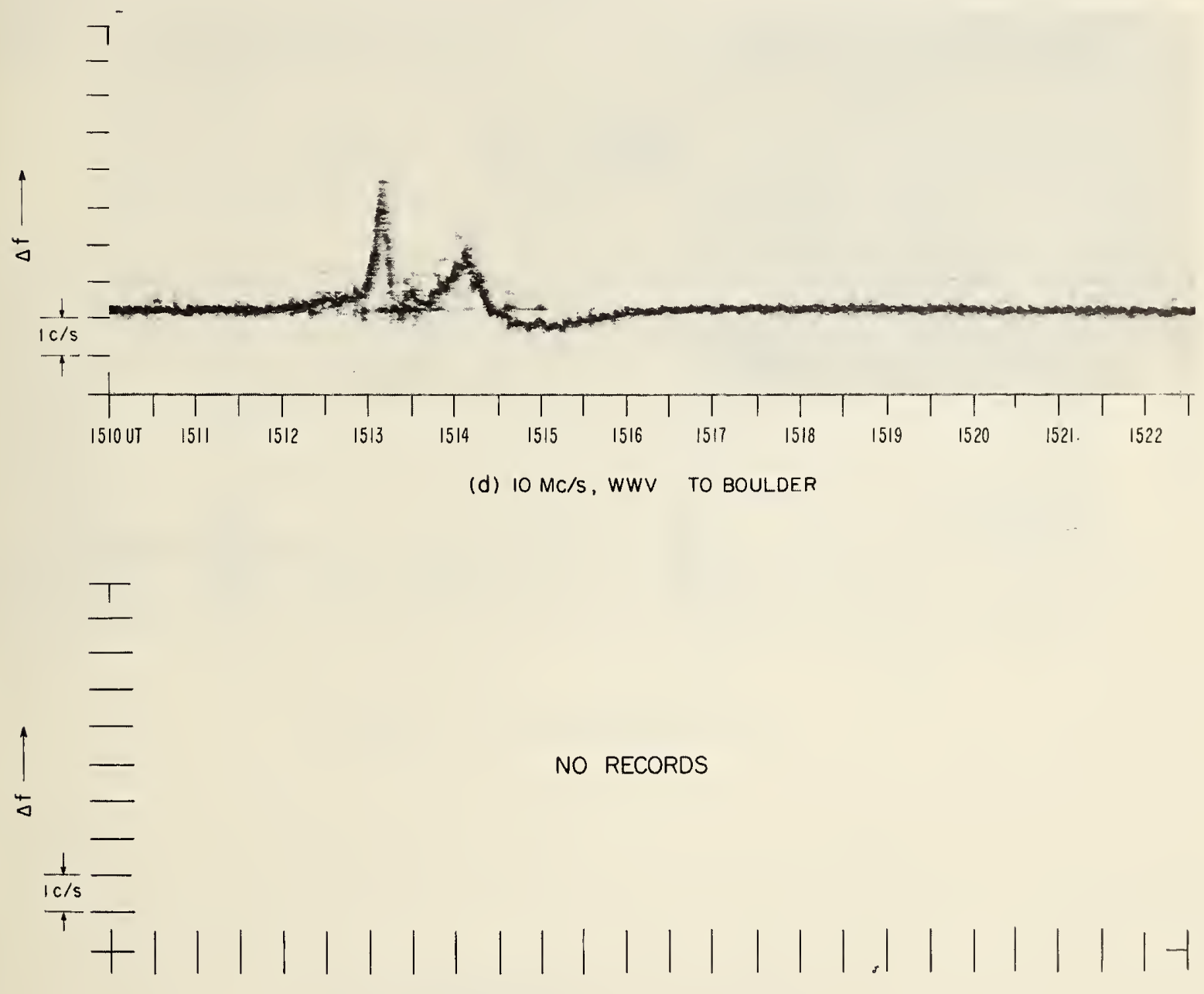

(e) $20 \mathrm{Mc} / \mathrm{s}$, WWV TO BOULDER

4 SEPTEMBER 1961

Figure 30

$-47-$ 


$$
\begin{aligned}
\text { OPTICAL FLARE, IMPORTANCE } 1,1902-1905-1919 U \\
2,1911-1924 U-2018
\end{aligned}
$$

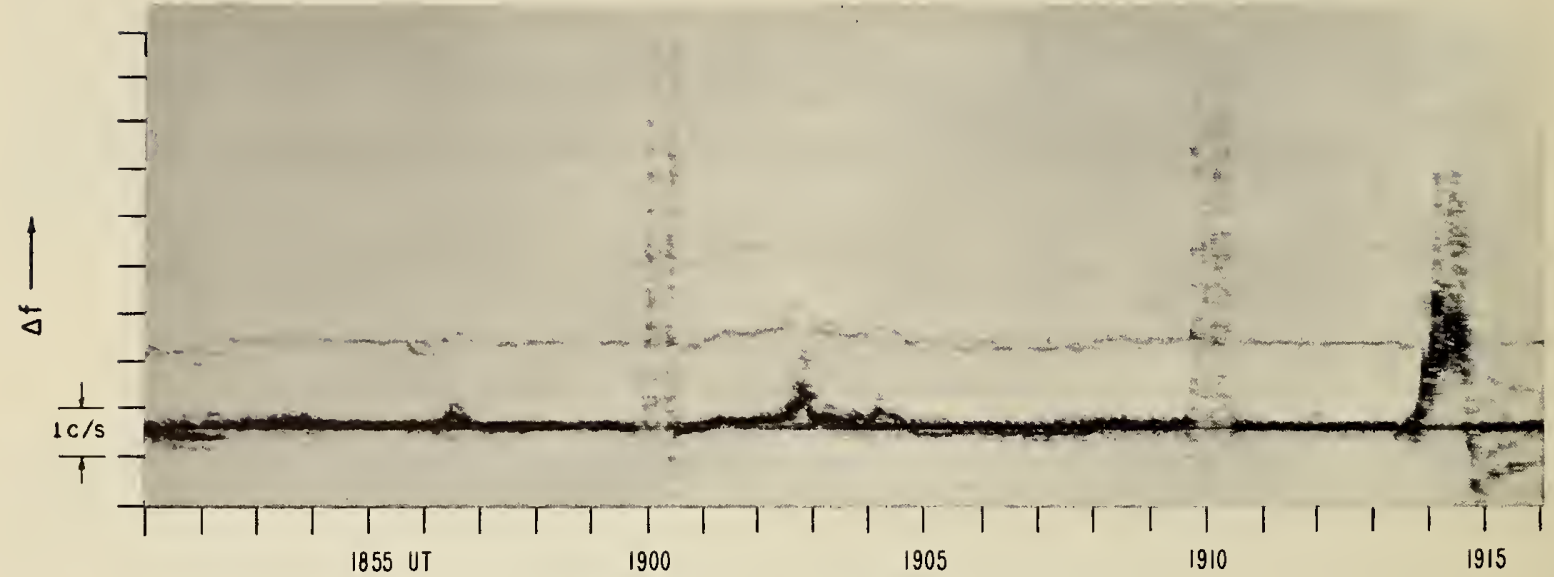

(a) $4.000 \mathrm{mc} / \mathrm{s}$, SUNSET TO BOULDER

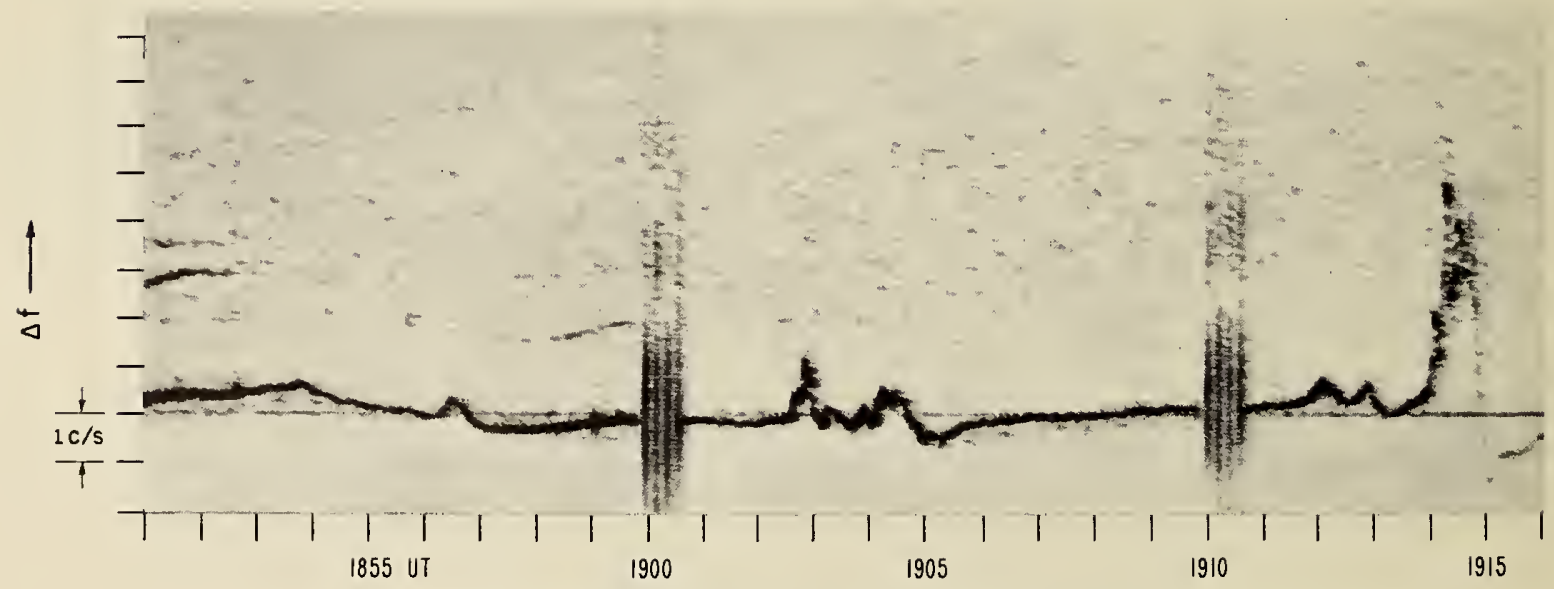

(b) $5.054 \mathrm{mc} / \mathrm{s}$, SUNSET TO BOULDER 
OPTICAL FLARE, IMPORTANCE I, 1902-1905-1919U

$2,1911-1924 U-2018$

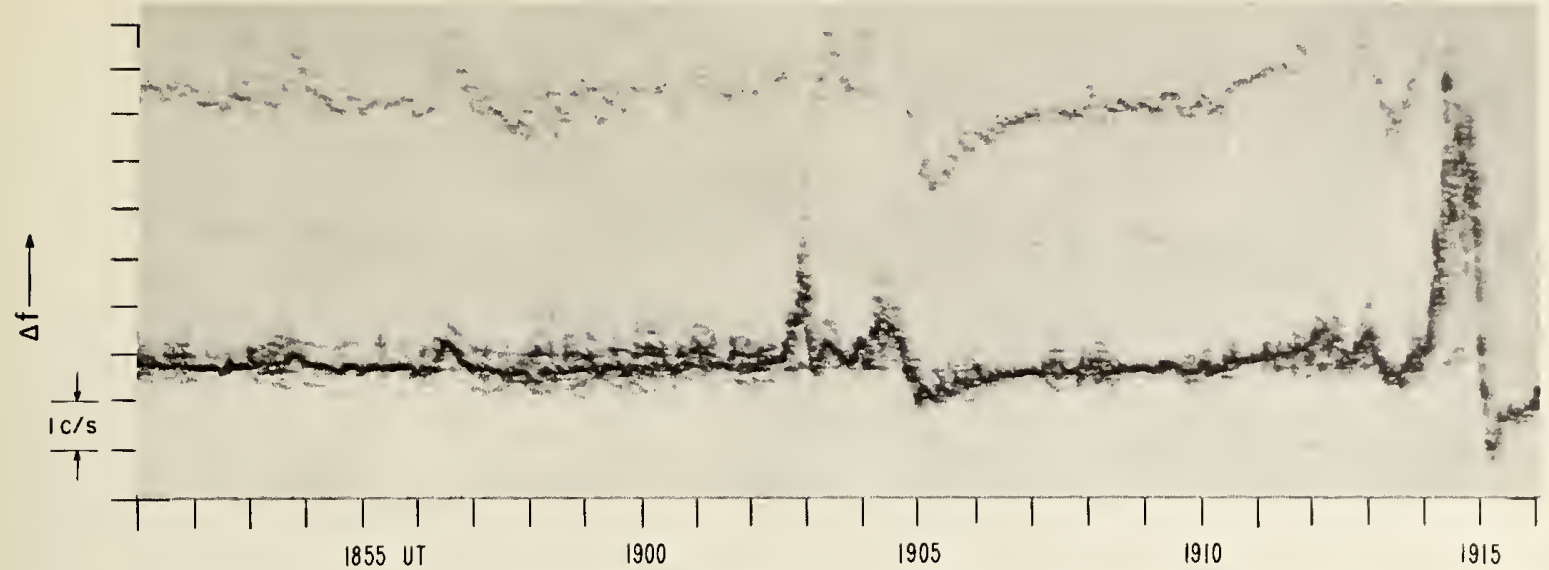

(c) $10 \mathrm{mc} / \mathrm{s}$, WWV TO SHICKLEY

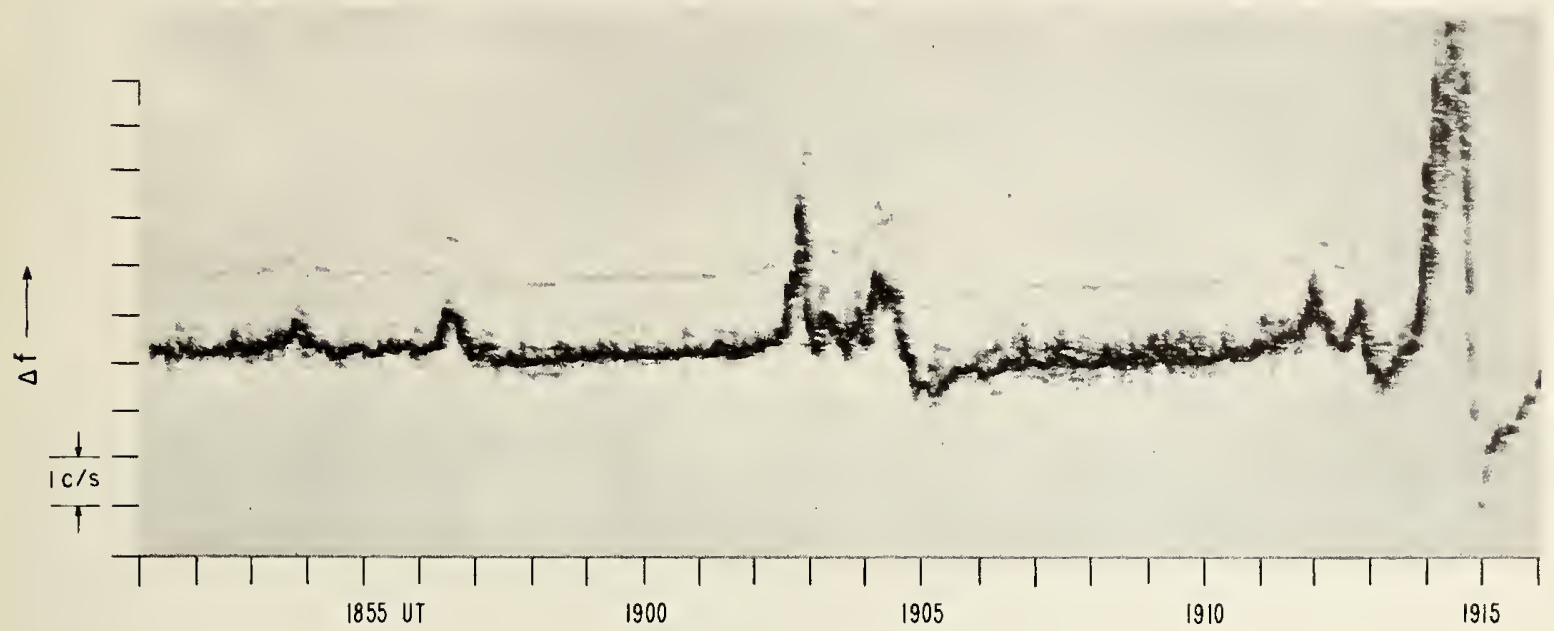

(d) $10 \mathrm{Mc} / \mathrm{s}$, WWV TO BOULDER

NO RECORDS

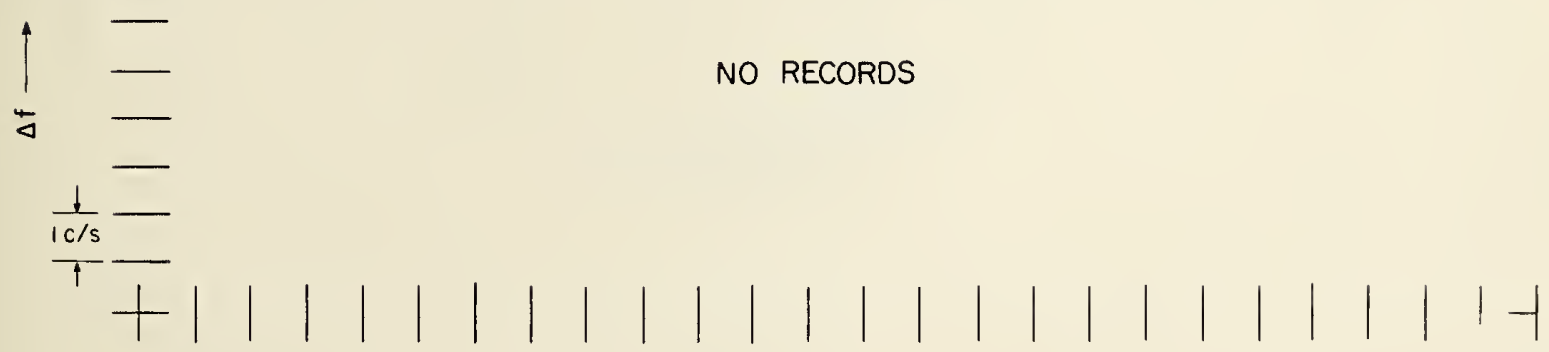

(e) $20 \mathrm{mC} / \mathrm{s}$, WWV TO BOULDER

4 SEPTEMBER 1961

Figure 31 
OPTICAL FLARE, IMPORTANCE $2,1911-1924 \mathrm{U}-2018$

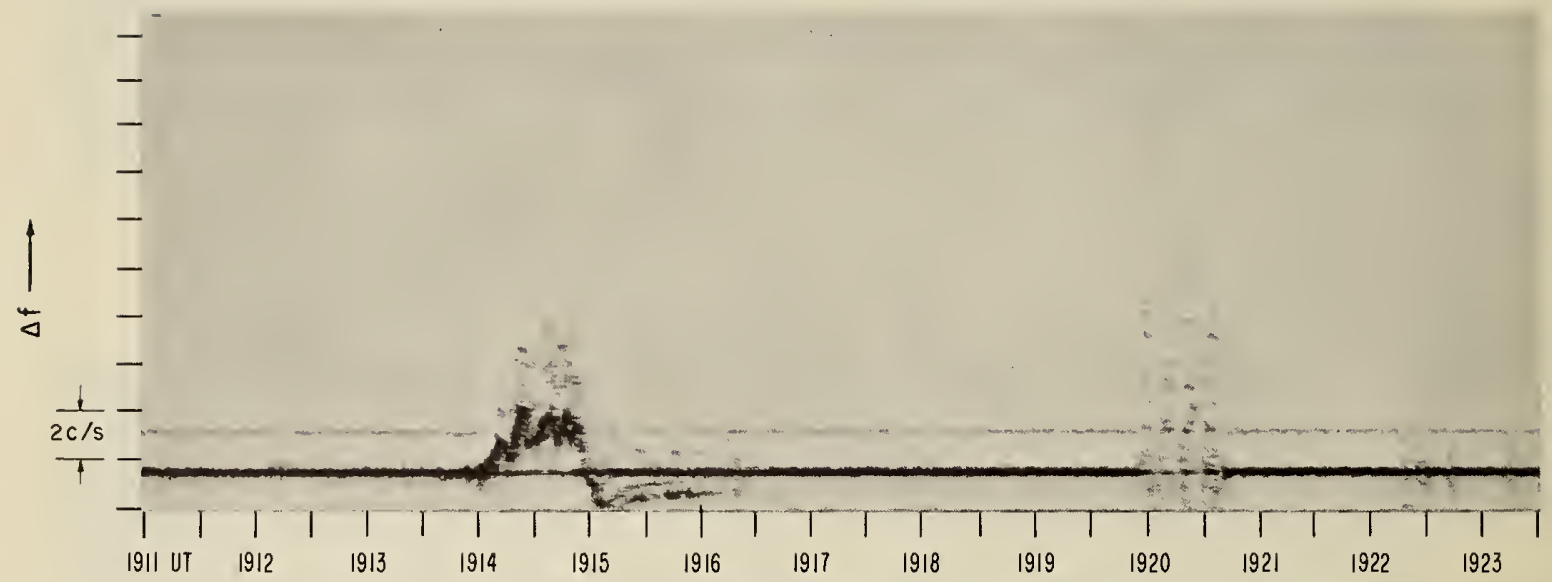

(a) $4.000 \mathrm{mc} / \mathrm{s}$, SUNSET TO BOULDER

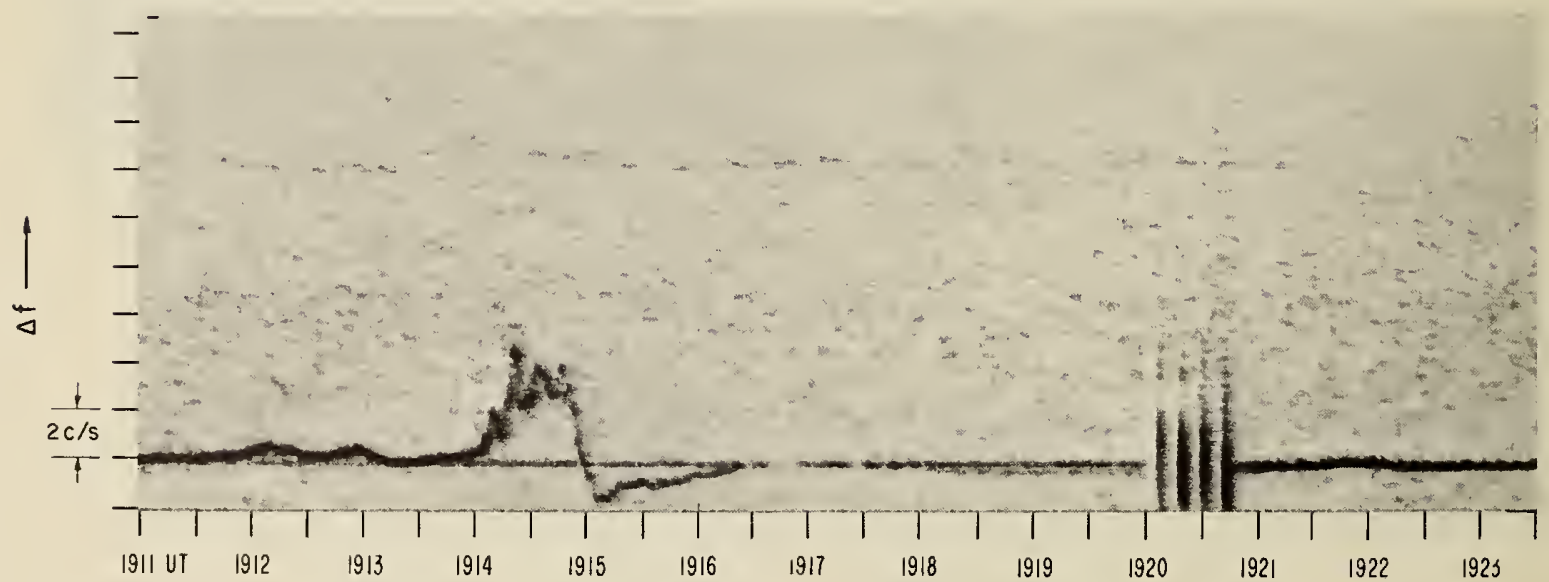

(b) $5.054 \mathrm{mc} / \mathrm{s}$, SUNSET TO BOULDER

4 SEPTEMBER 1961

Figure 32 

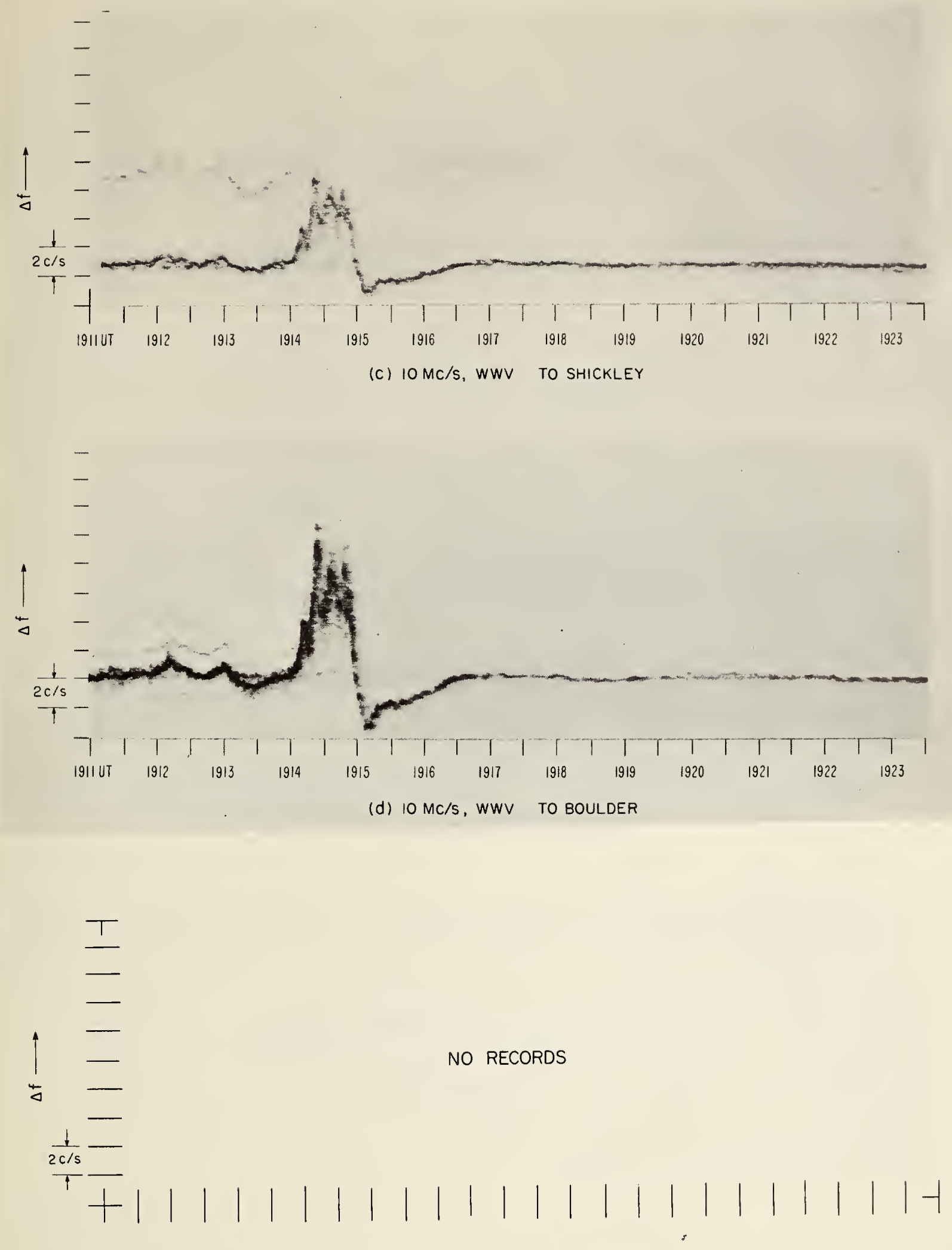

(e) $20 \mathrm{Mc} / \mathrm{s}$, WWV TO BOULDER

4 SEPTEMBER 1961
Figure 32

$-51-$ 
OPTICAL FLARE, IMPORTANCE I, 1950-2010-2052

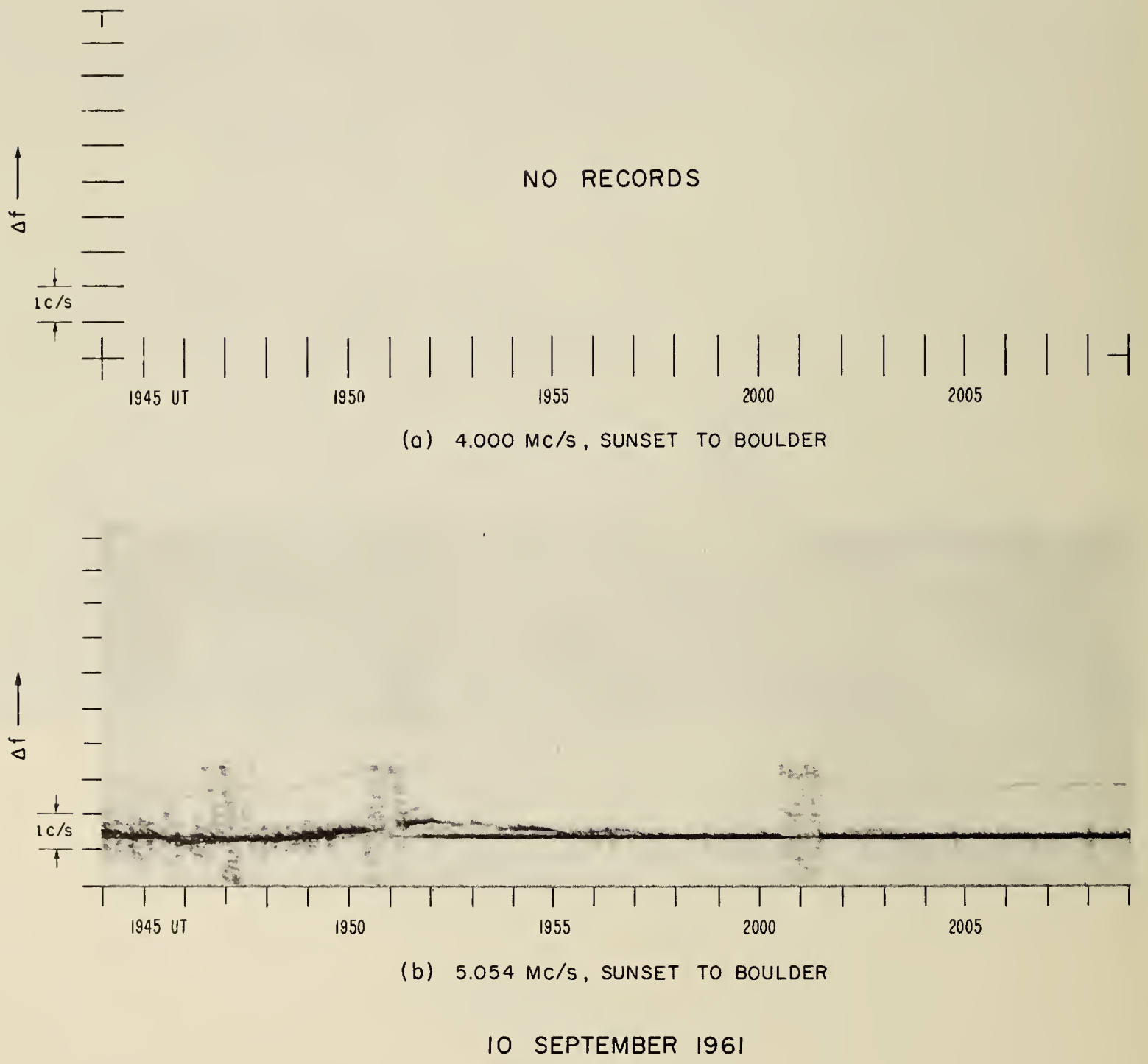

Figure 33 
OPTICAL FLARE, IMPORTANCE 1, 1950-2010-2052

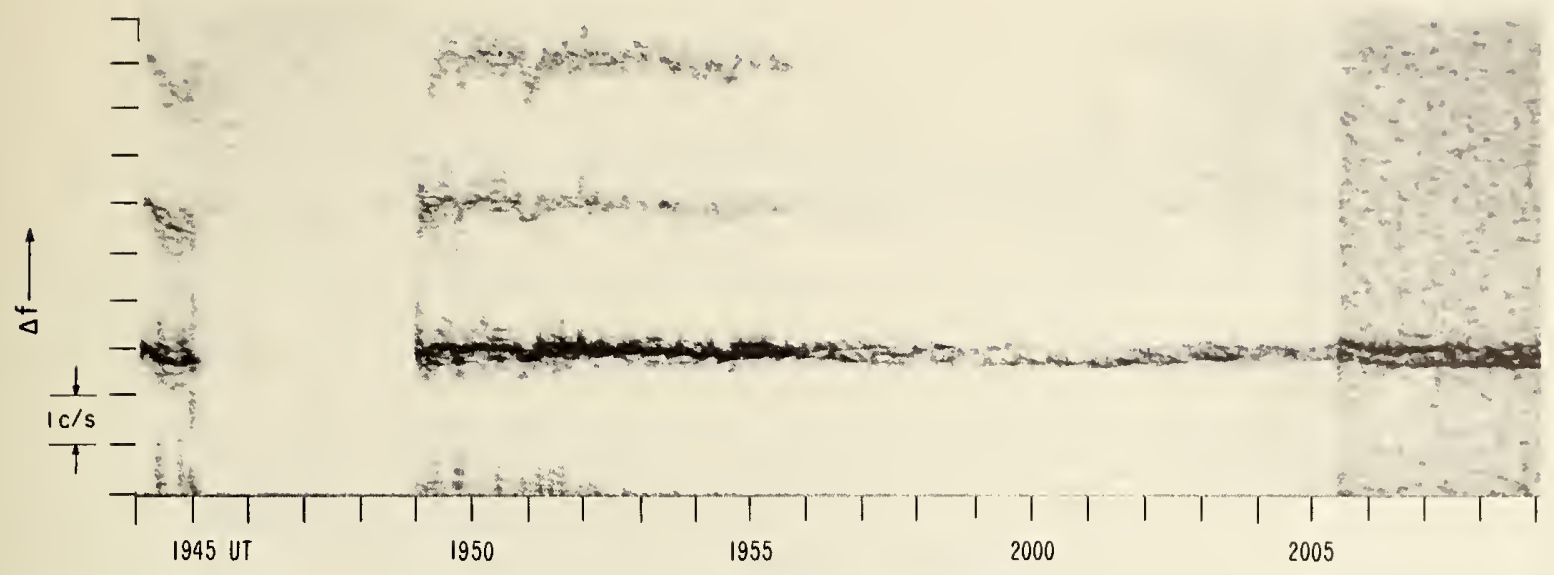

(c) $10 \mathrm{mc} / \mathrm{s}$, WWV TO SHICKLEY

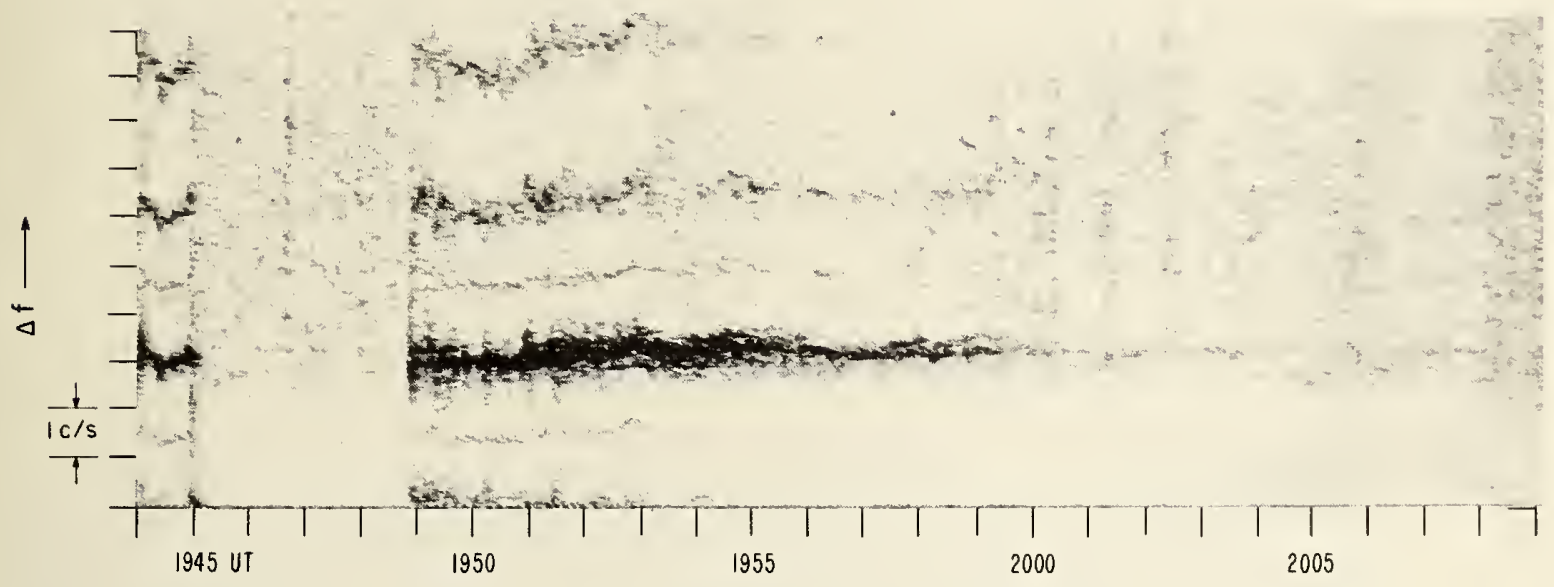

(d) $10 \mathrm{Mc} / \mathrm{s}$, WWV TO BOULDER

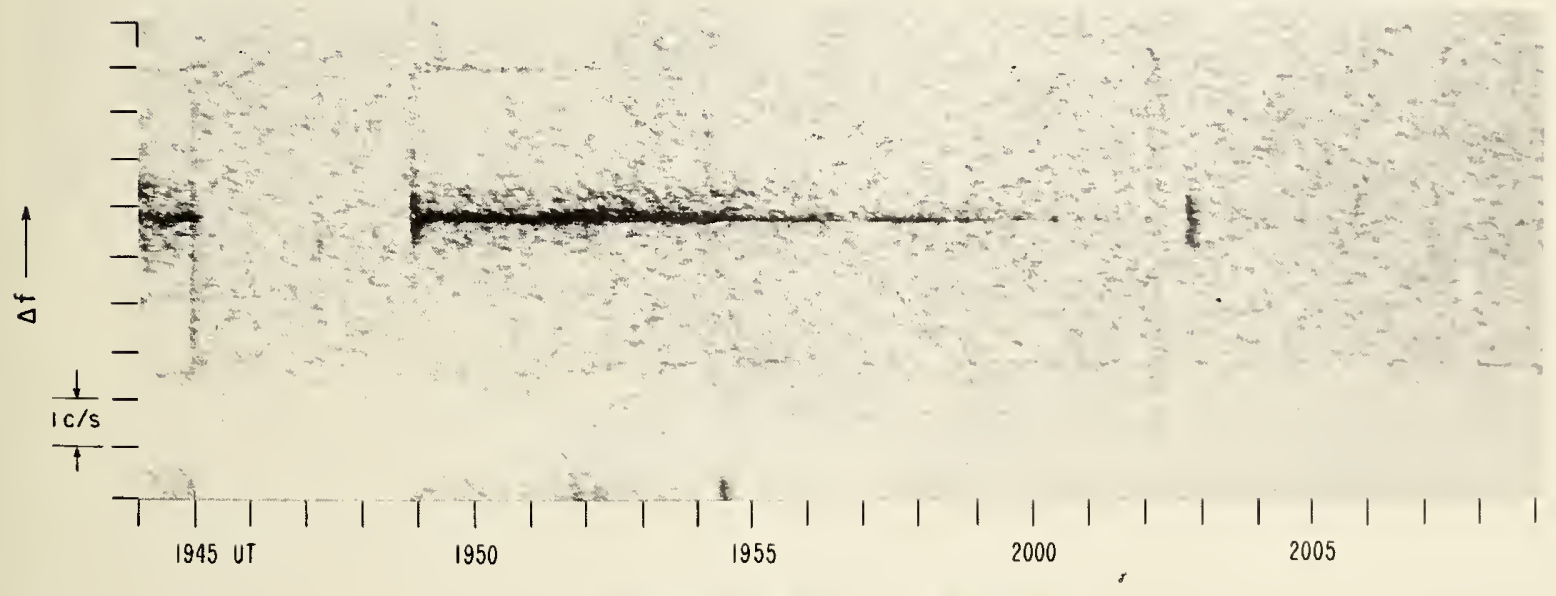

(e) $20 \mathrm{MC} / \mathrm{s}$, WWV TO BOULDER 
OPTICAL FLARE, IMPORTANCE 1, 1950-2010-2052

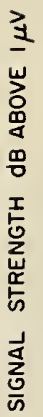

NO RECORDS

(a) $4.000 \mathrm{mC} / \mathrm{s}$, SUNSET TO BOULDER

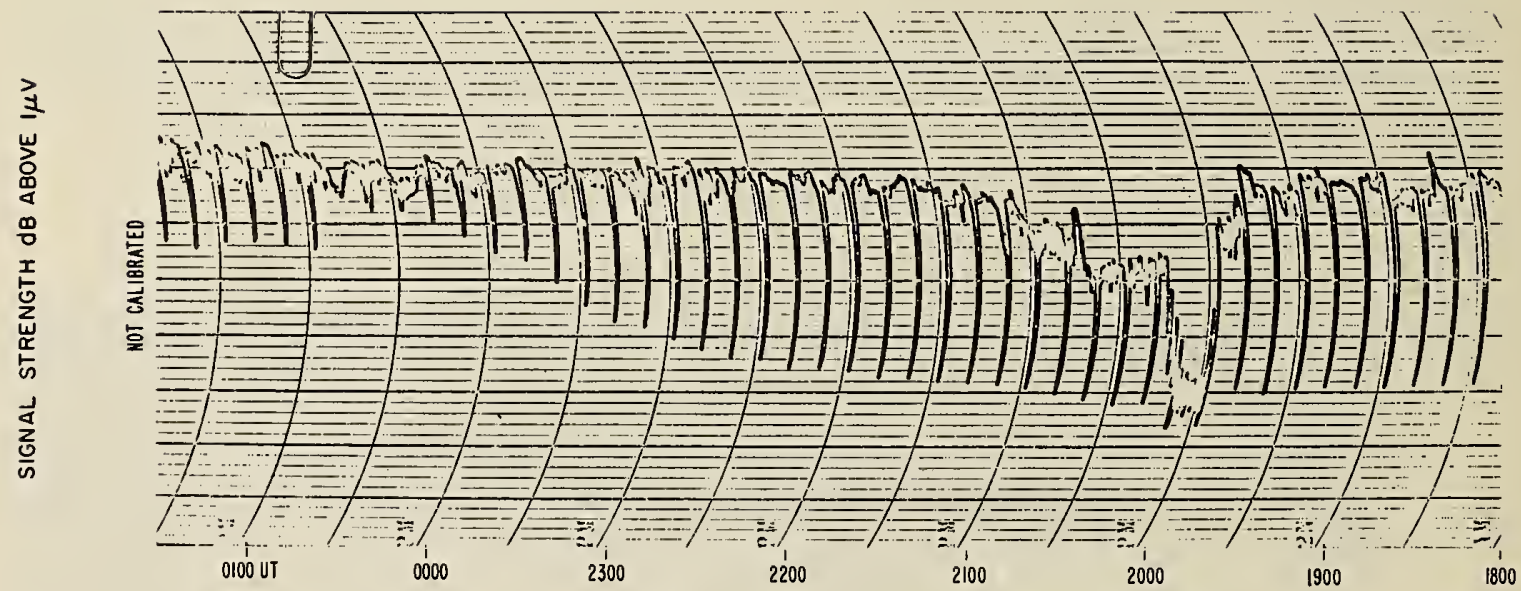

(b) $5.054 \mathrm{mc} / \mathrm{s}$, SUNSET TO BOULDER

10 SEPTEMBER 1961

Figure 34 
OPTICAL FLARE, IMPORTANCE $1,1950-2010-2052$

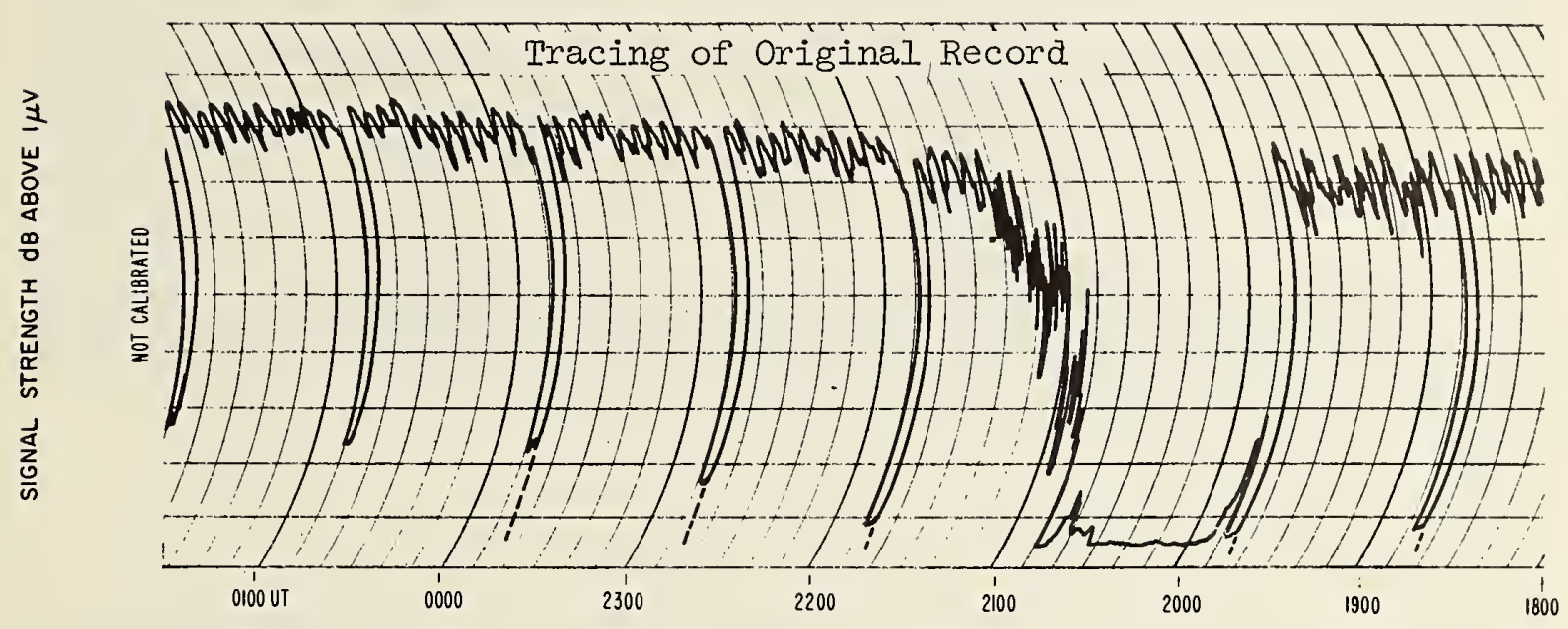

(c) $10 \mathrm{Mc} / \mathrm{s}$, WWV TO BOULDER

NO RECORDS

(d) $20 \mathrm{Mc} / \mathrm{s}$, WWV TO BOULDER

IO SEPTEMBER 196I

Figure 34 
OPTICAL FLARE, IMPORTANCE I, 1950-1958-2007

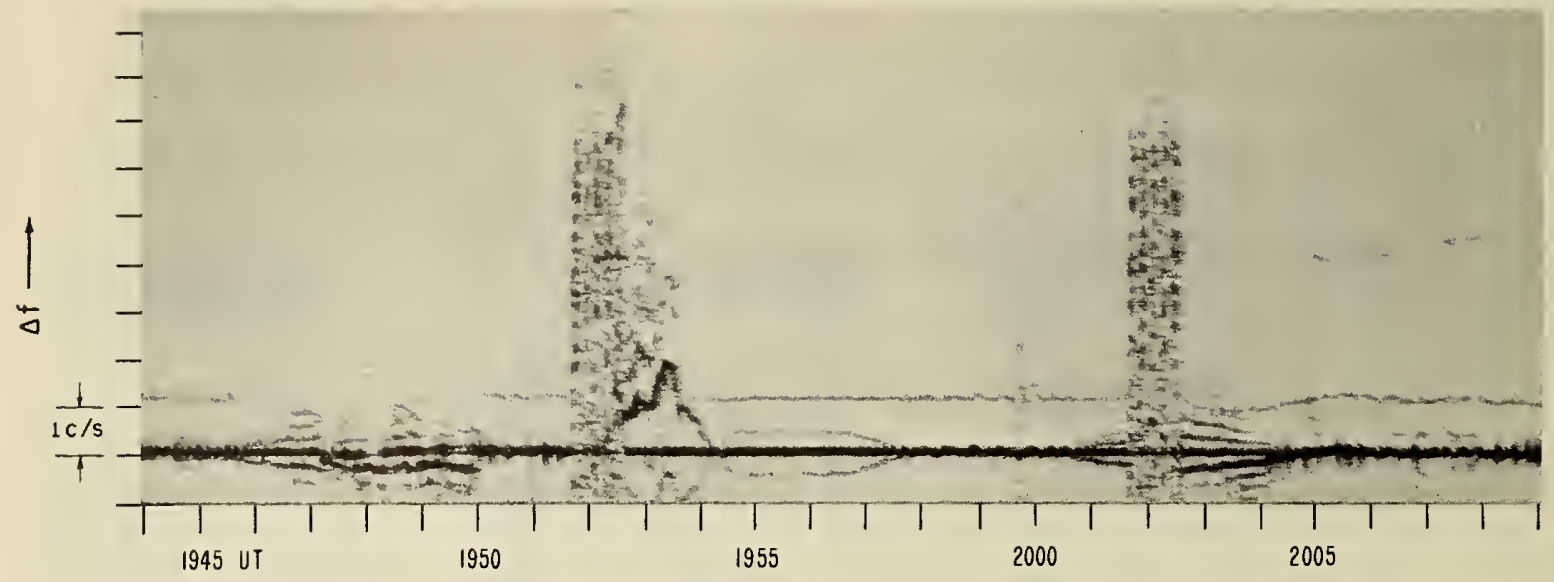

(a) $4.000 \mathrm{mc} / \mathrm{s}$, SUNSET TO BOULDER

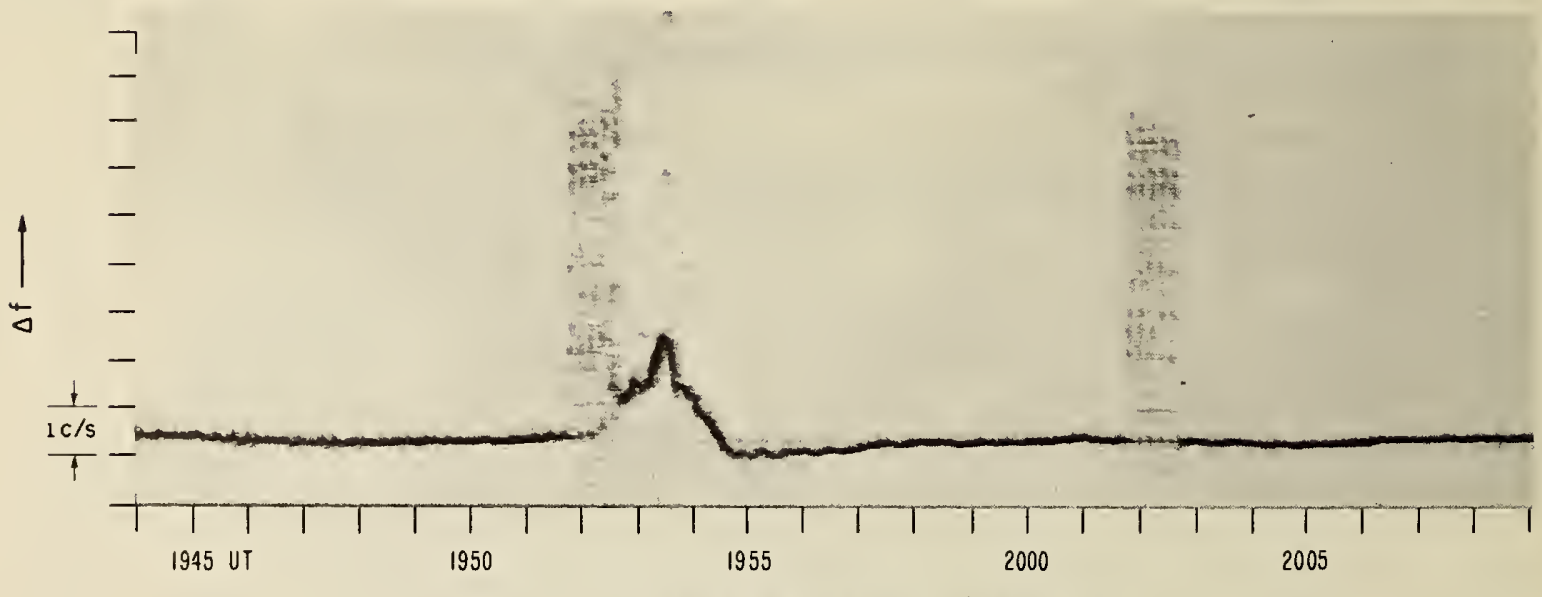

(b) $5.054 \mathrm{mc} / \mathrm{s}$, SUNSET TO BOULDER

27 SEPTEMBER $|96|$

Figure 35

$-56-$ 
OPTICAL FLARE, IMPORTANCE I, 1950-1958-2007

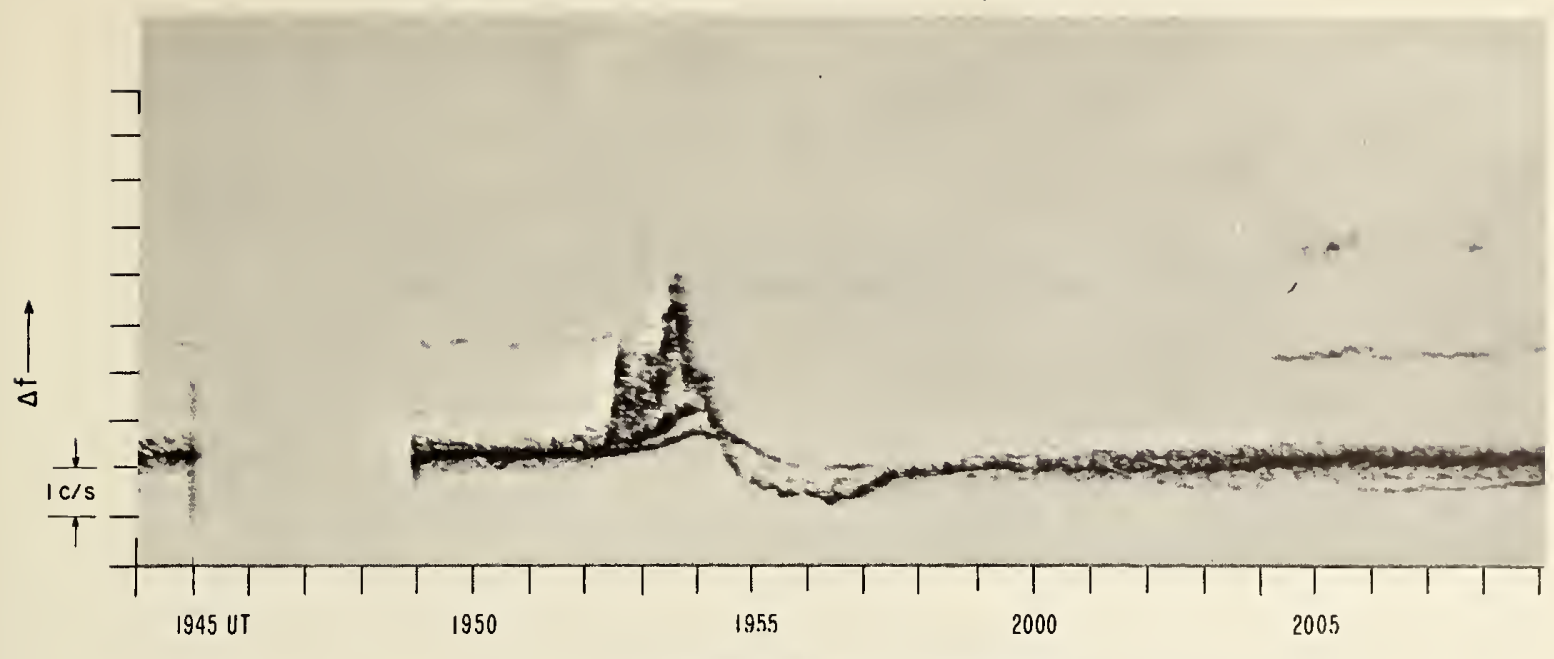

(c) $10 \mathrm{MC} / \mathrm{s}$, WWV TO SHICKLEY

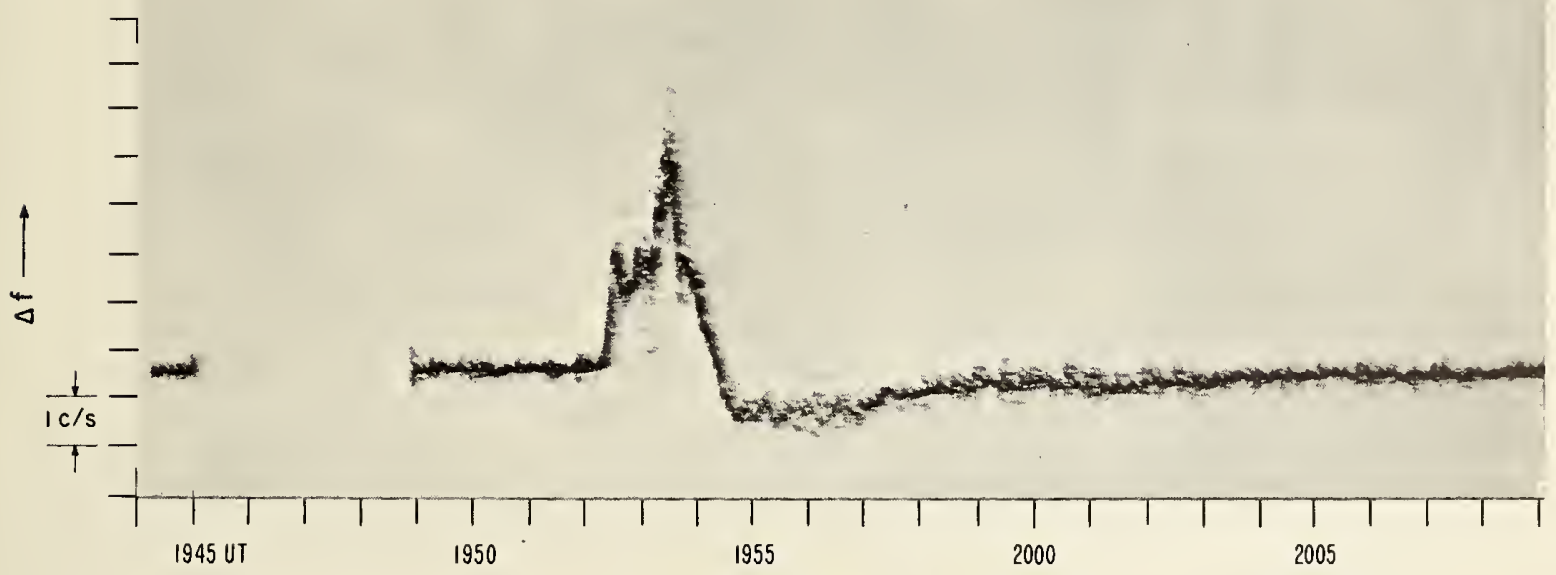

(d) $10 \mathrm{Mc} / \mathrm{s}, W W V$ TO BOULDER

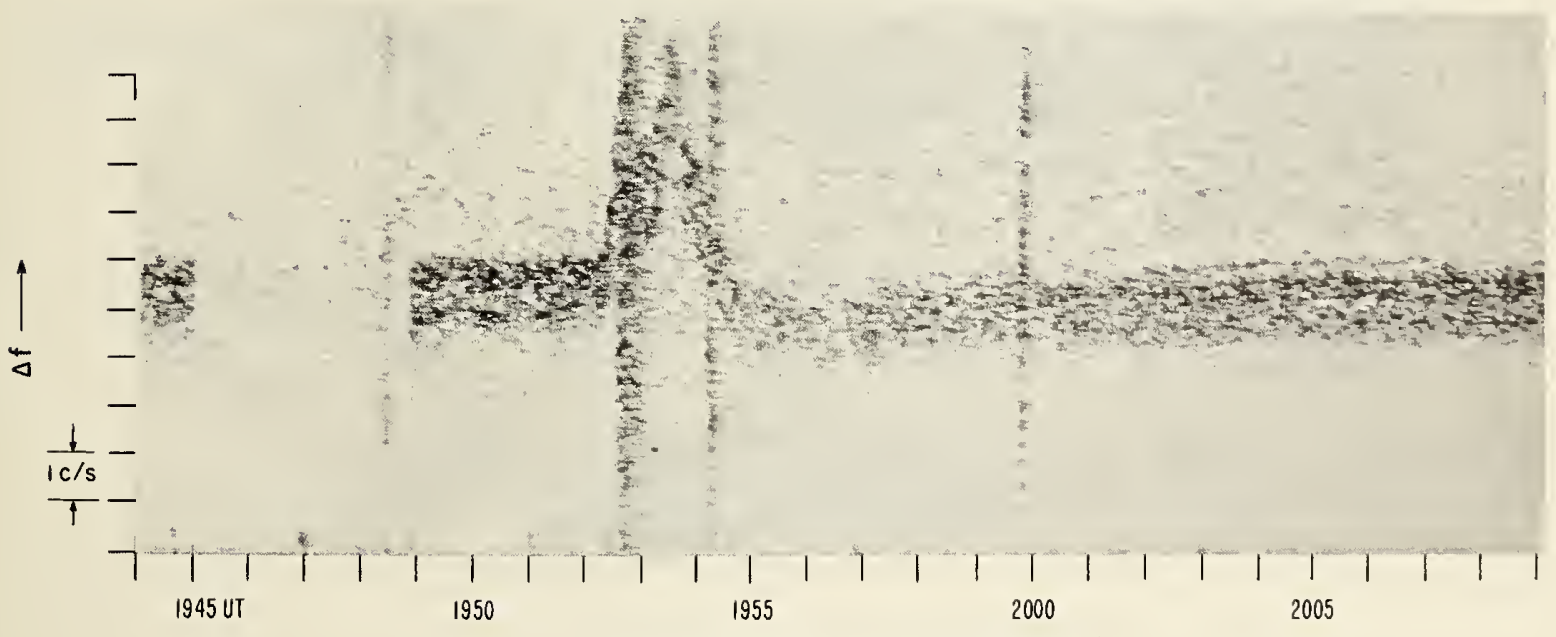

(e) $20 \mathrm{Mc} / \mathrm{s}$, WWV TO BOULDER 
OPTICAL FLARE, IMPORTANCE 1, 1950-1958-2007

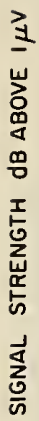

NO RECORDS

(a) $4.000 \mathrm{mC} / \mathrm{s}$, SUNSET TO BOULDER

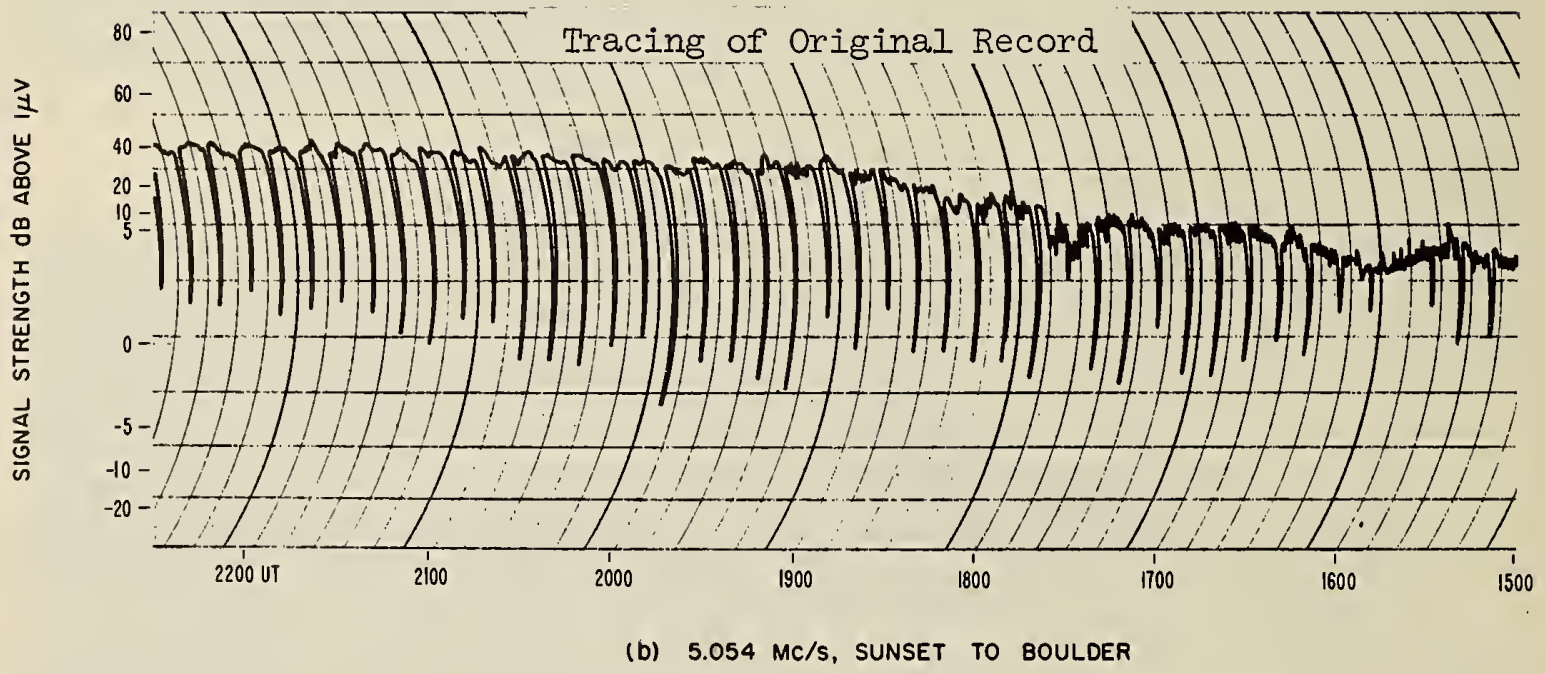

27 SEPTEMBER 1961

Figure 36 
OPTICAL FLARE, IMPORTANCE 1, 1950-1958-2007

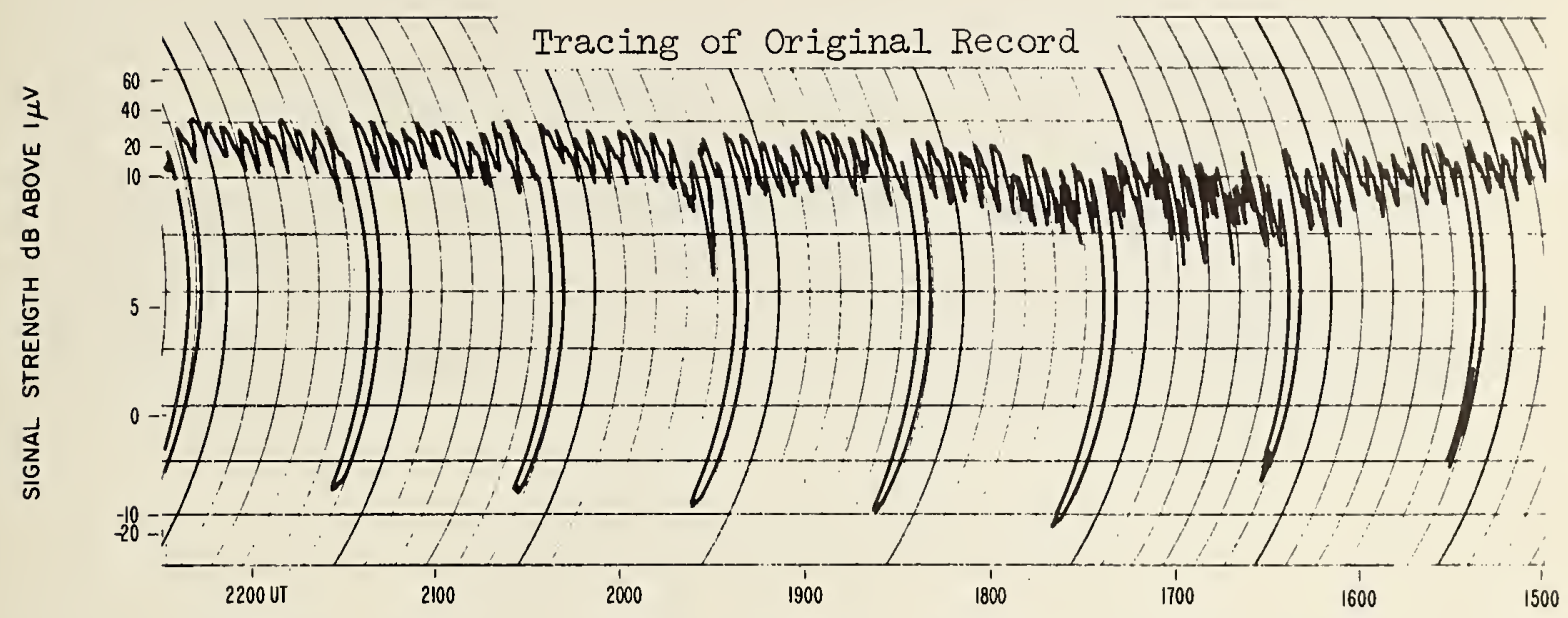

(c) $10 \mathrm{mc} / \mathrm{s}$, WWV TO BOULDER

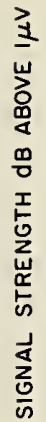

NO RECORDS

(d) $20 \mathrm{MC} / \mathrm{s}$, WWV TO BOULDER

27 SEPTEMBER 1961

Figure 36 
OPTICAL FLARE, IMPORTANCE $3,2202-2224-2530$

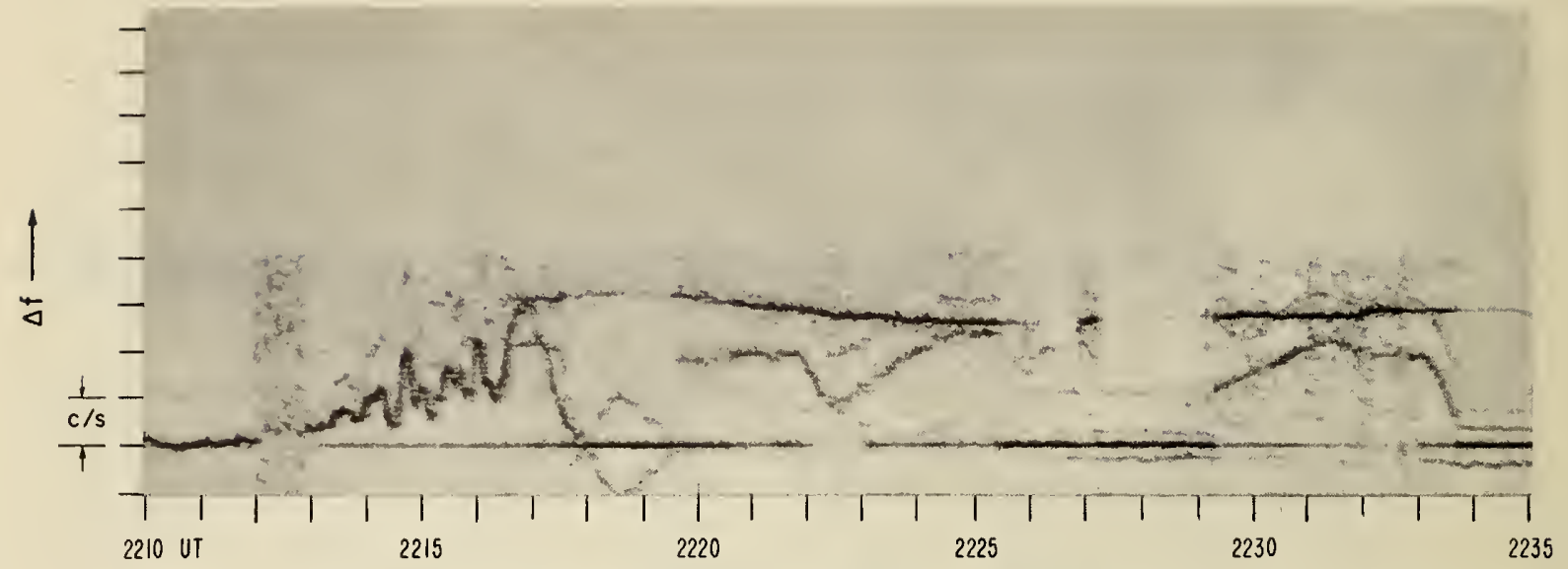

(a) $4.000 \mathrm{mc} / \mathrm{s}$, SUNSET TO BOULDER

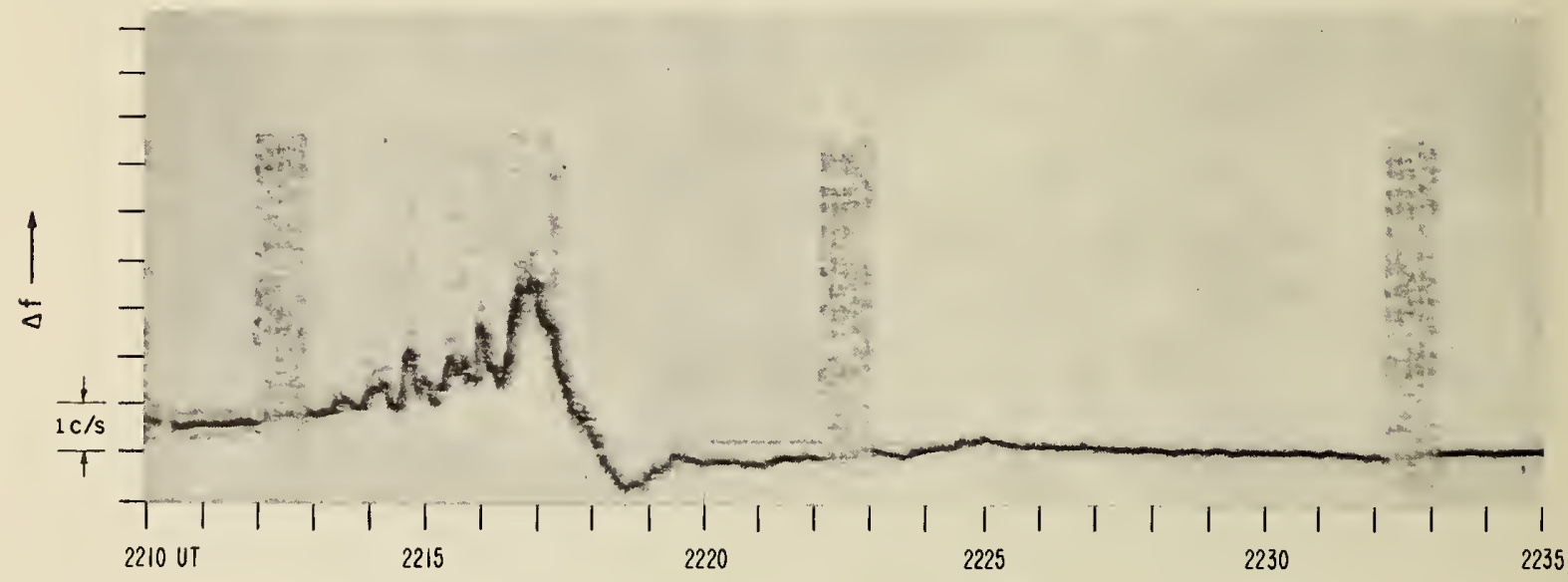

(b) $5.054 \mathrm{mc} / \mathrm{s}$, SUNSET TO BOULDER

\section{SEPTEMBER 1961}

Figure 37 
OPTICAL FLARE, IMPORTANCE 3, 2202-2224-2530

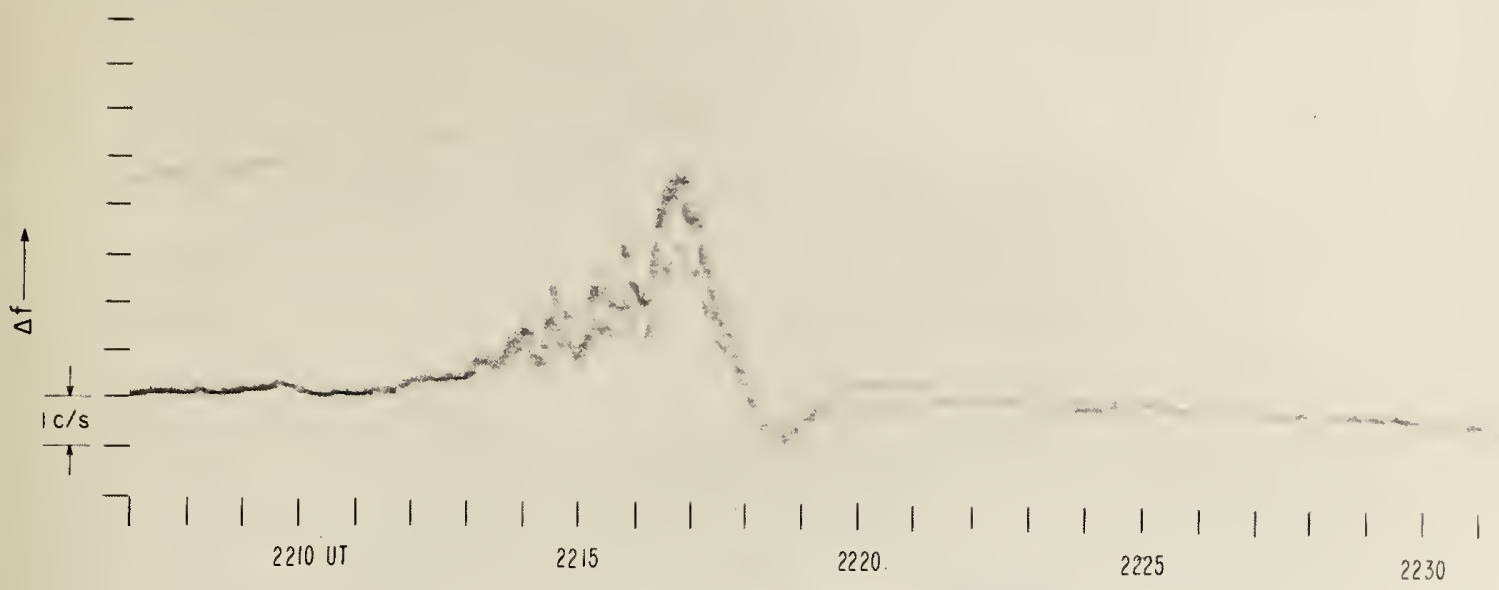

(c) $10 \mathrm{MC} / \mathrm{s}$, WWV TO SHICKLEY

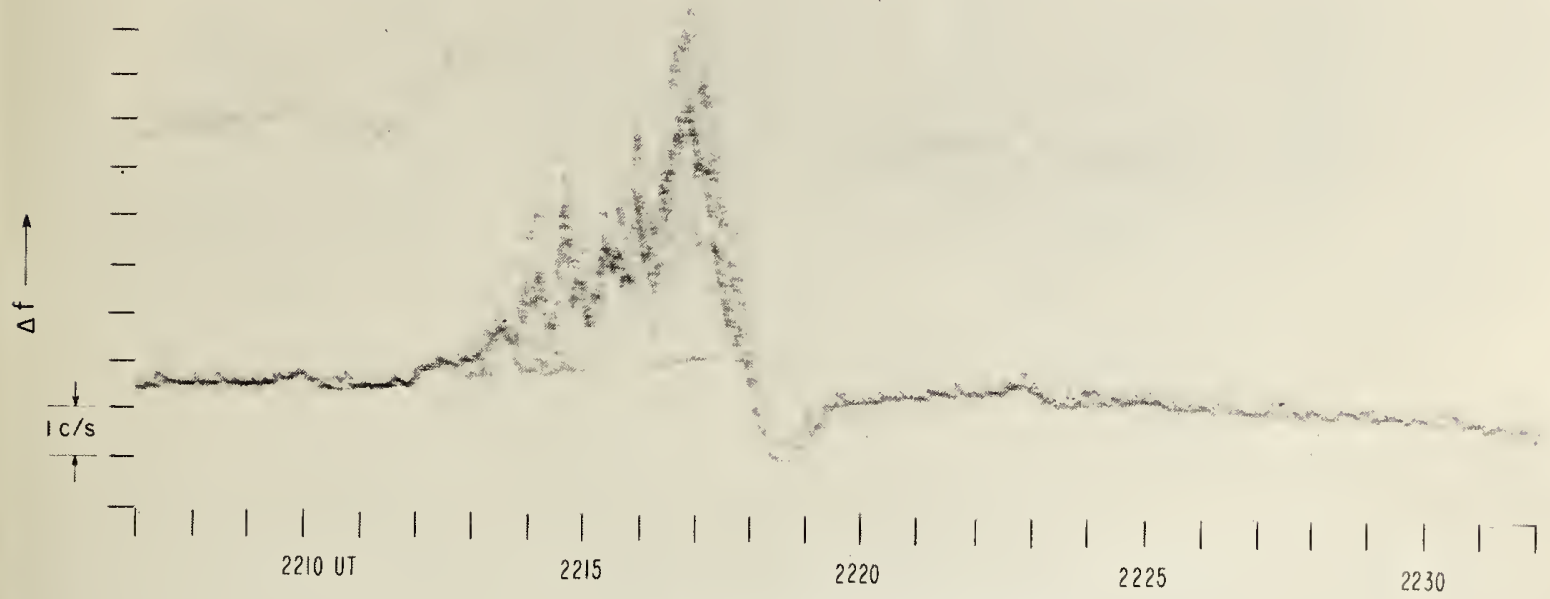

(d) $10 \mathrm{mc} / \mathrm{s}$, WWV TO BOULDER

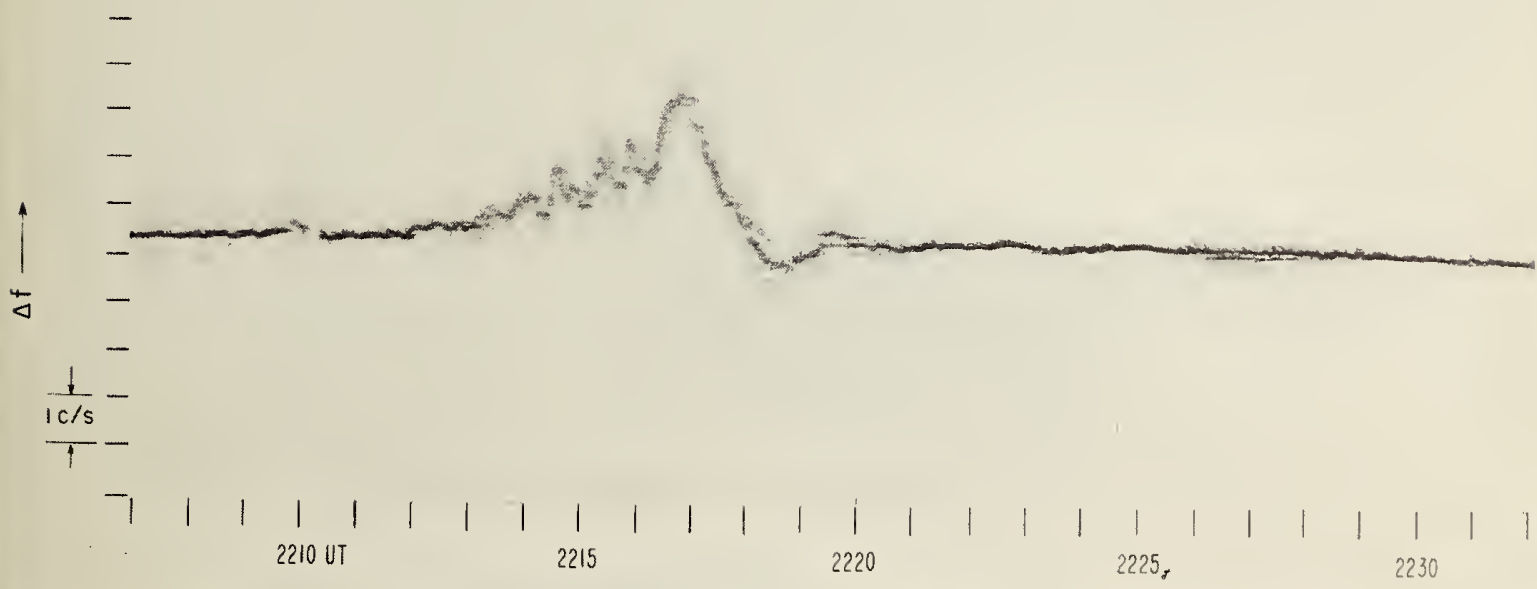

(e) $20 \mathrm{Mc} / \mathrm{s}$, WWV TO BOULDER 
OPTICAL FLARE, IMPORTANCE 3,2202-2224-2530

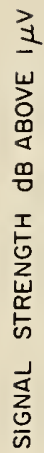

NO RECOROS

(a) $4.000 \mathrm{mC} / \mathrm{s}$, SUNSET TO BOULDER

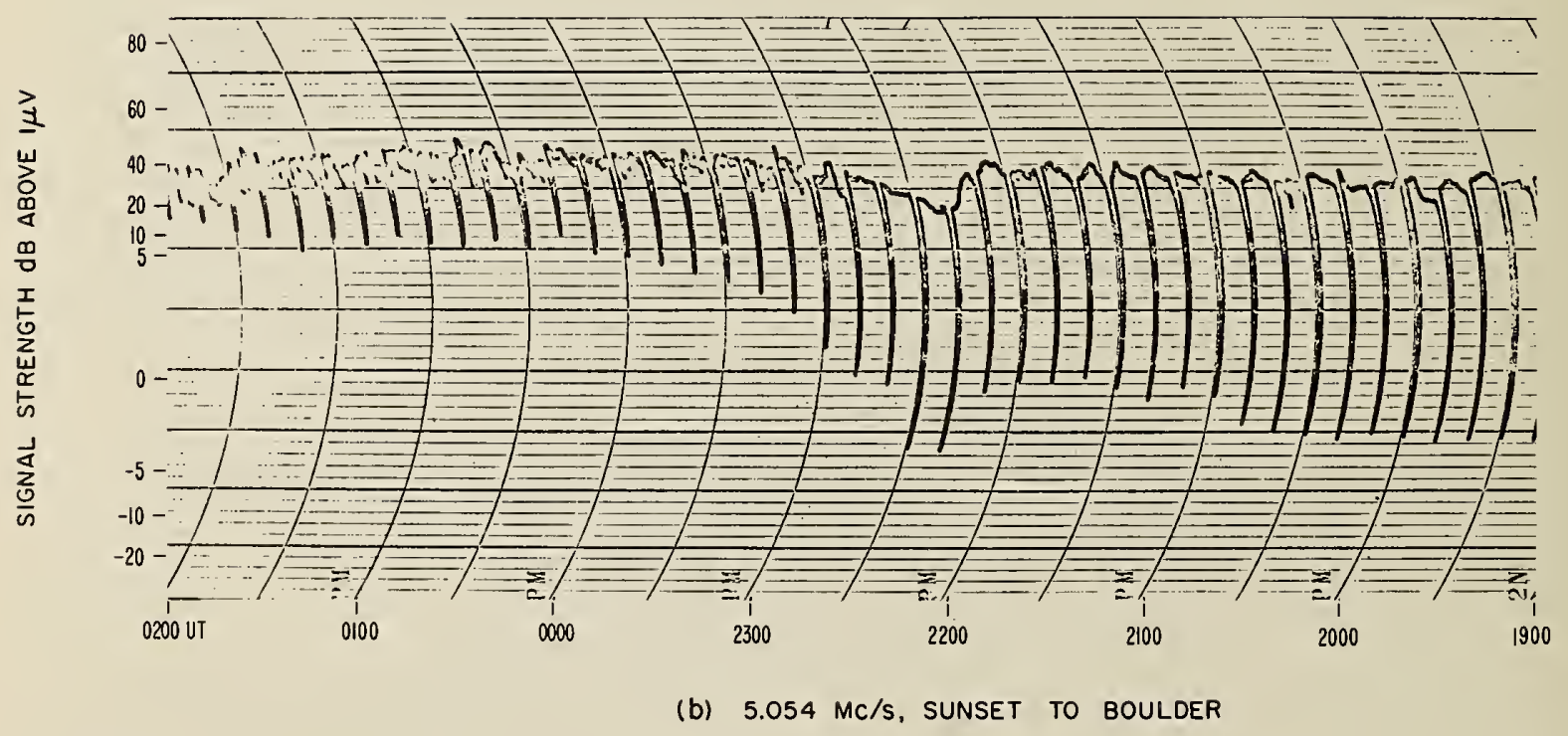

28 SEPTEMBER 1961

Figure 38

$-62-$ 
OPTICAL FLARE, IMPORTANCE 3, 2202-2224-2530

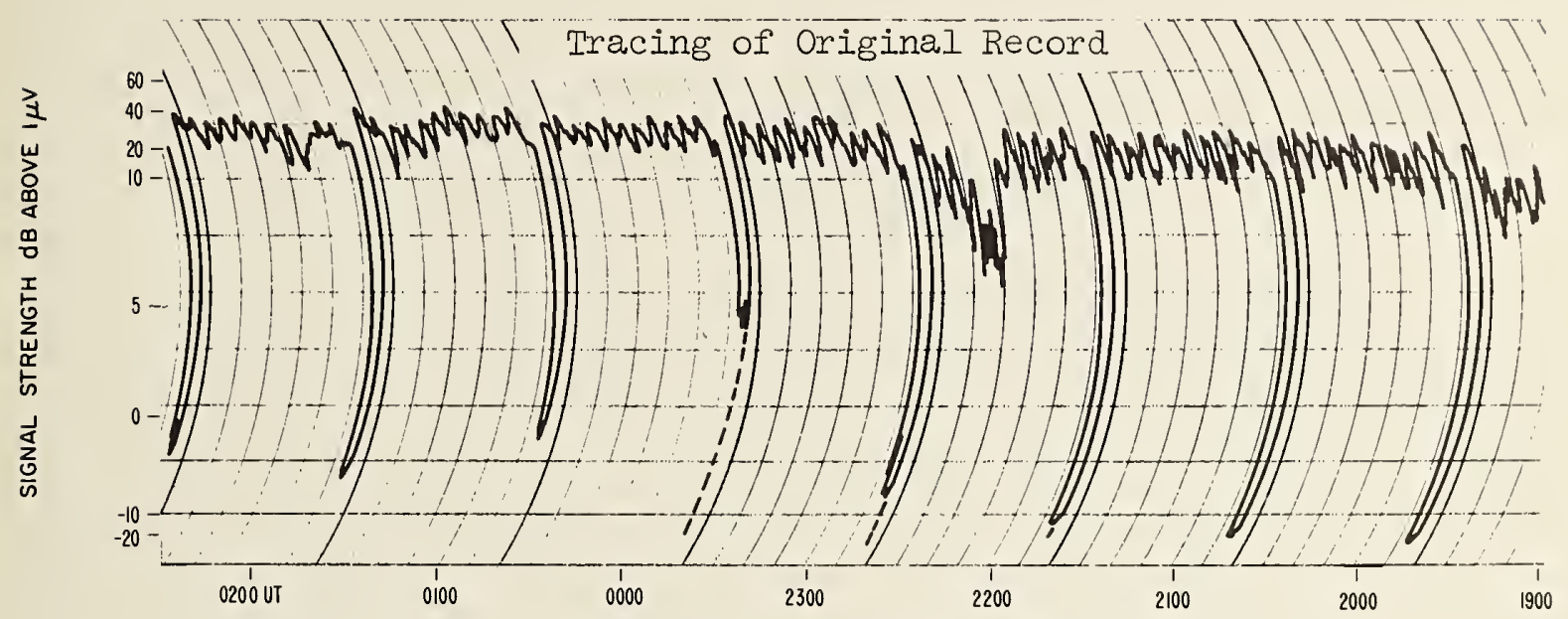

(c) $10 \mathrm{mc} / \mathrm{s}$, WWV TO BOULDER

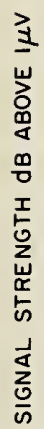

NO RECORDS

(d) $20 \mathrm{MC} / \mathrm{s}$, WWV TO BOULDER

28 SEPTEMBER 1961

Figure 38 
OPTICAL FLARE, IMPORTANCE 2, $2012-2016-2044$

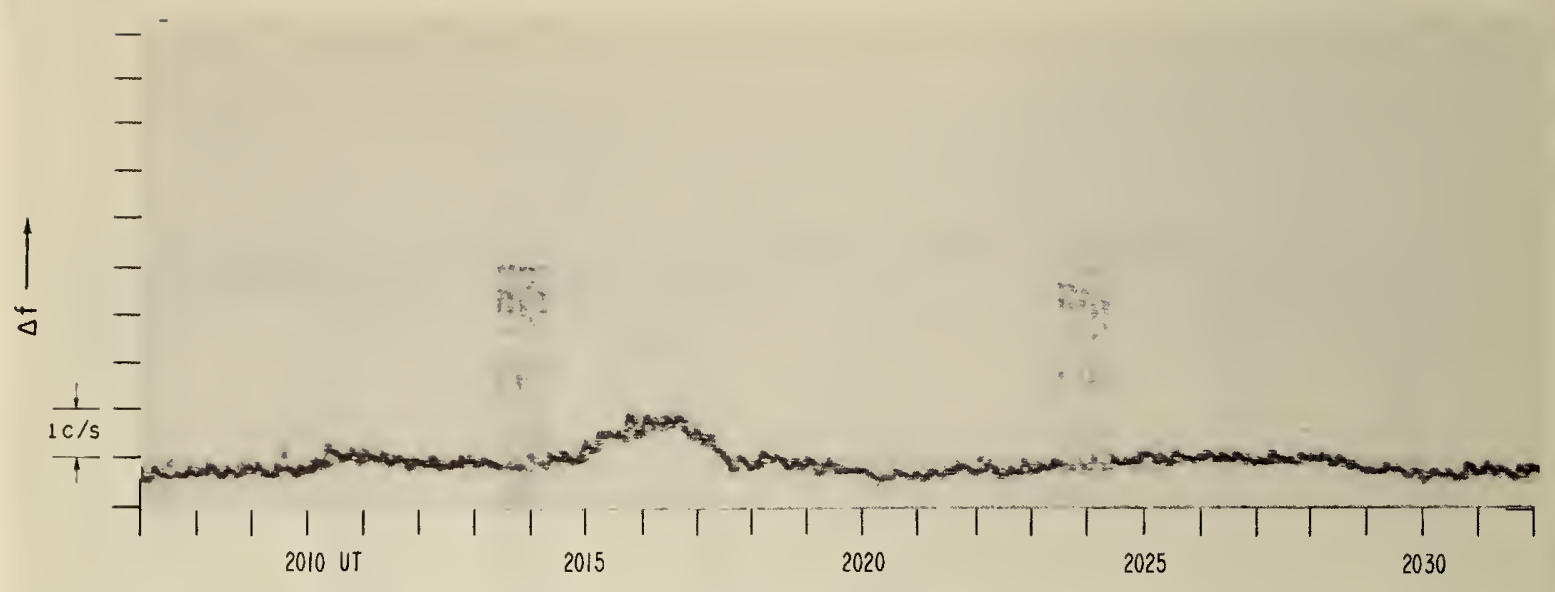

(a) $4.000 \mathrm{mc} / \mathrm{s}$, SUNSET TO BOULDER

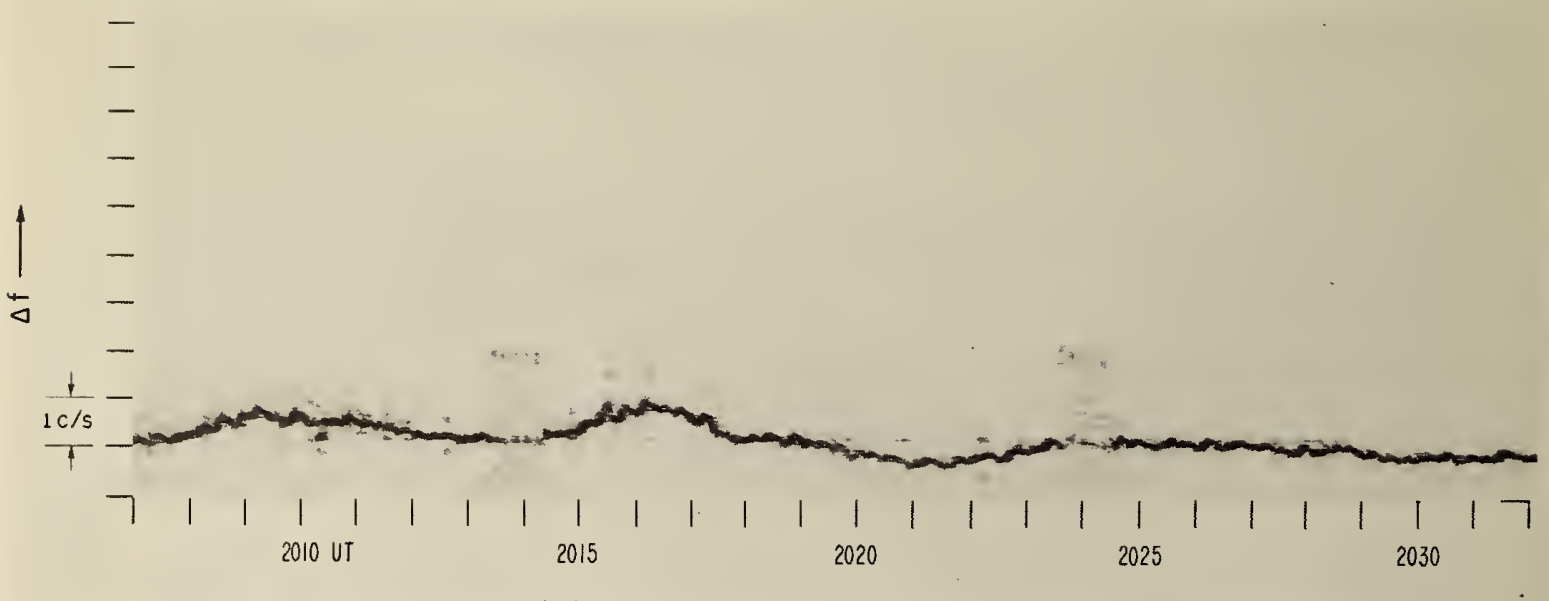

(b) $5.054 \mathrm{Mc} / \mathrm{s}$, SUNSET TO BOULDER

22 NOVEMBER 1961

Figure 39

$-64-$ 
OPTICAL FLARE, IMPORTANCE 2, 2012-2016-2044

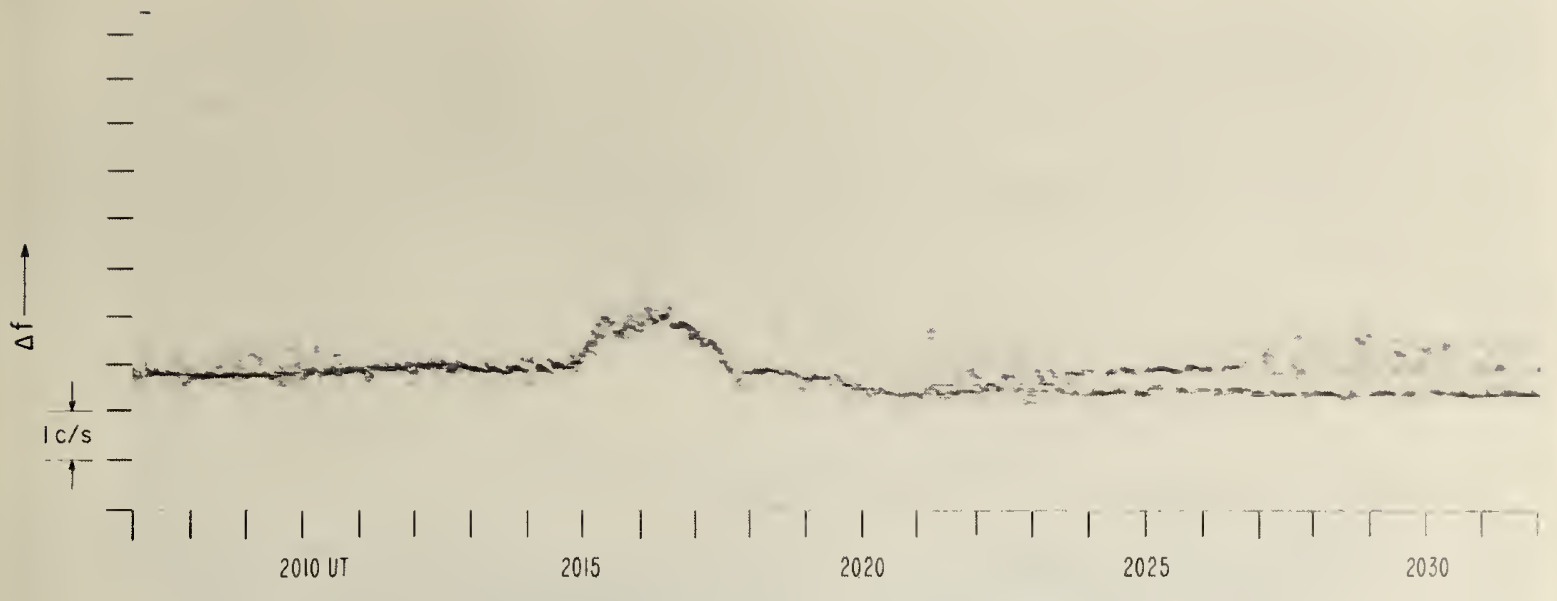

(c) $10 \mathrm{MC} / \mathrm{s}$, WWV TO SHICKLEY

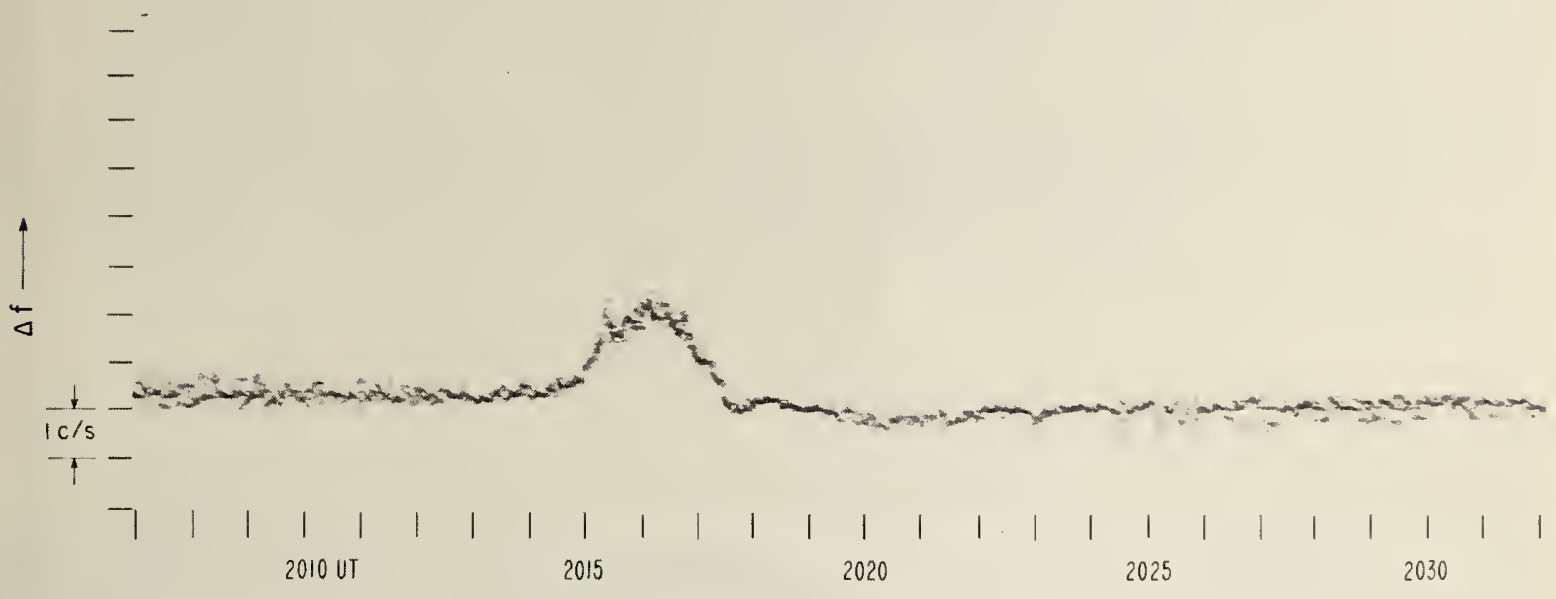

(d) $10 \mathrm{Mc} / \mathrm{s}$, WWV TO BOULDER

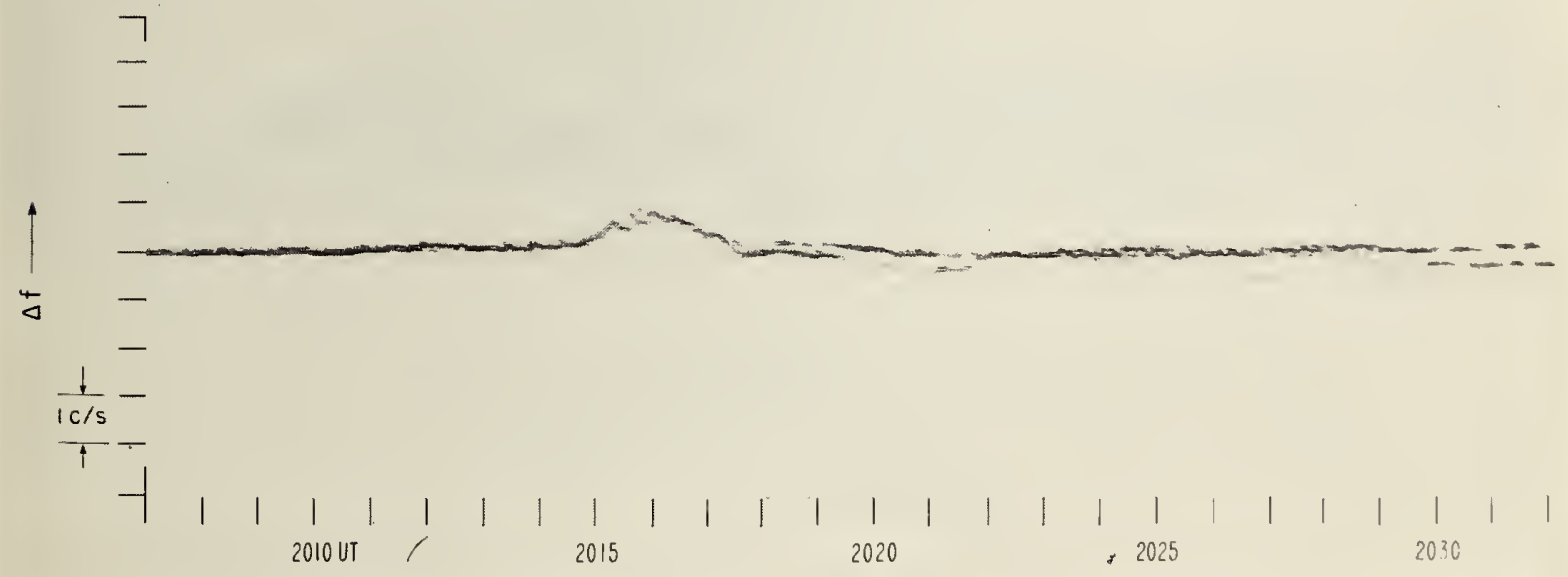

(e) $20 \mathrm{Mc} / \mathrm{s}$, WWV TO BOULDER 
OPTICAL FLARE, IMPORTANCE $2,2014-2016-2024$
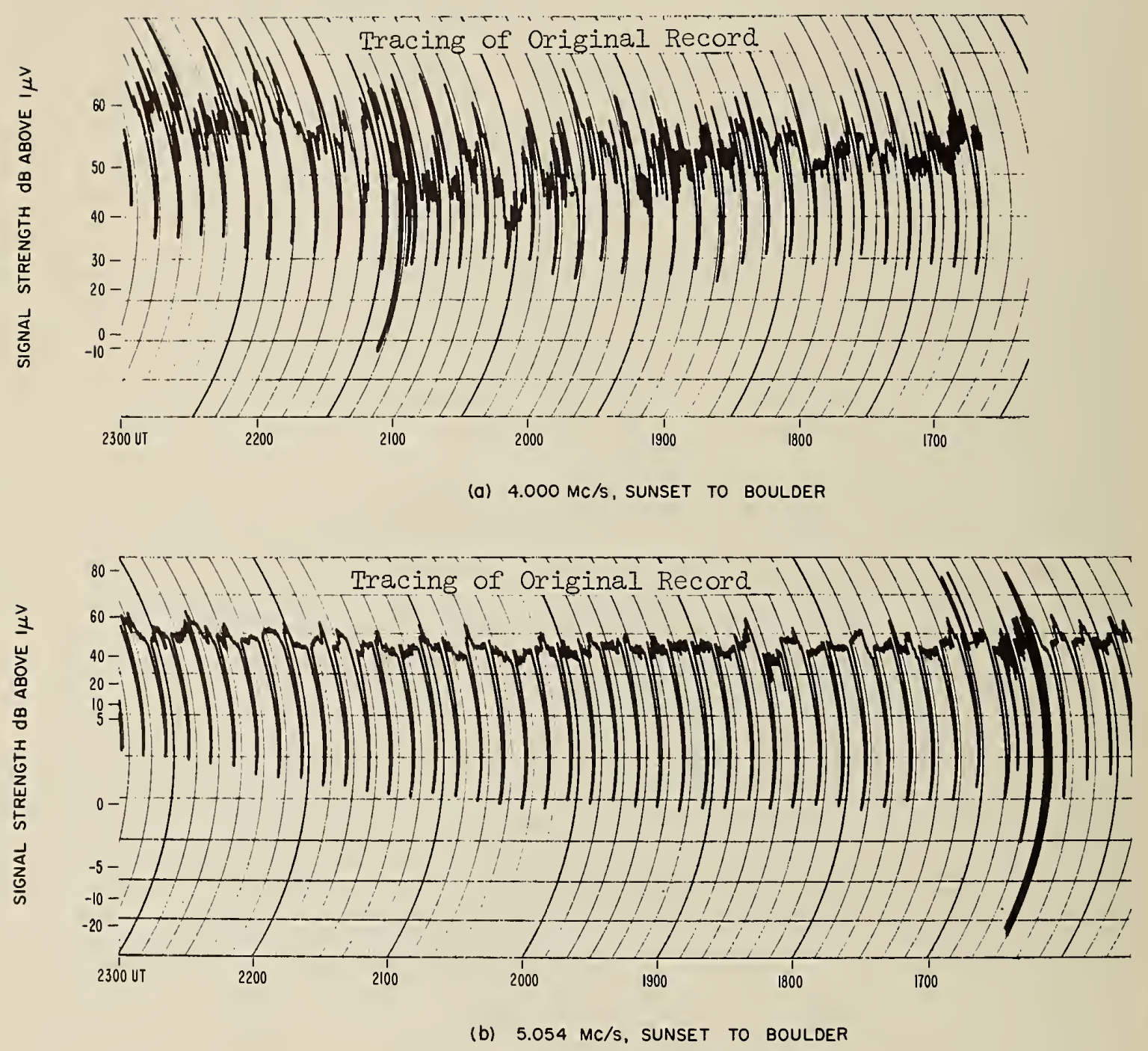

22 NOVEMBER 1961

Figure 40 
OPTICAL FLARE, IMPORTANCE 2, 2014-2016-2024

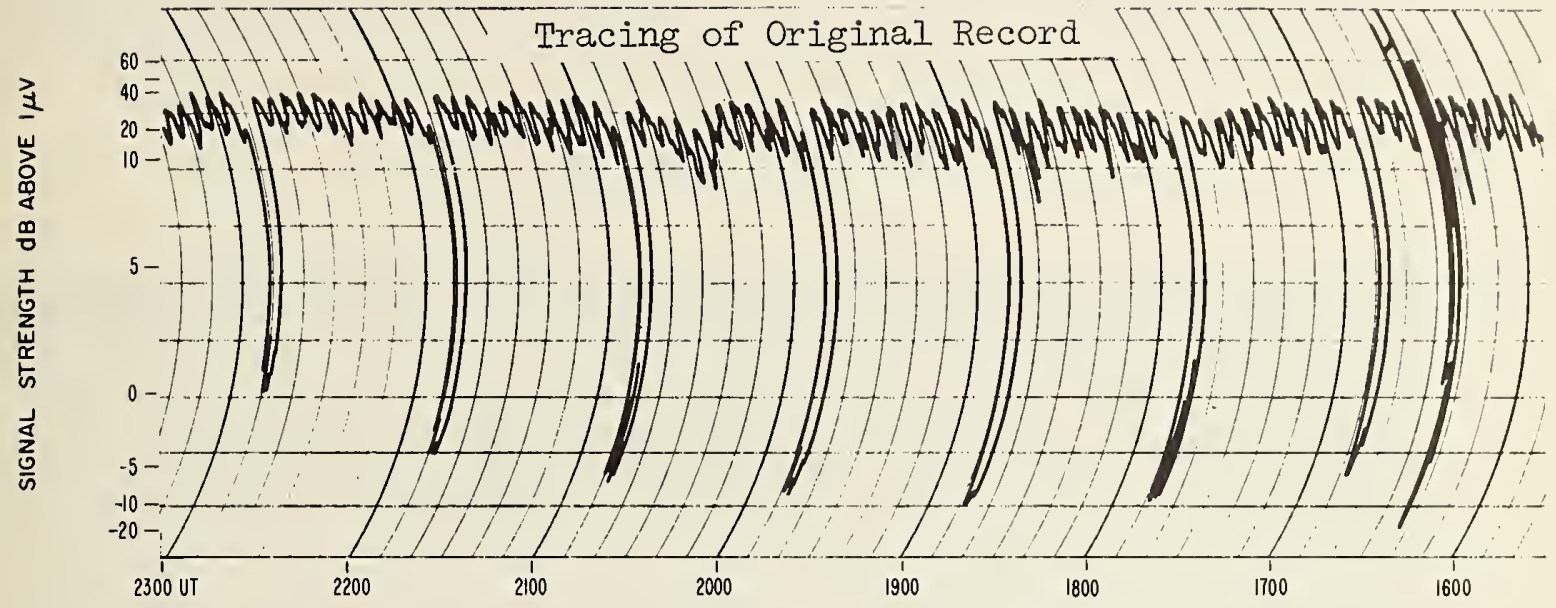

(c) $10 \mathrm{Mc} / \mathrm{s}$, WWV TO BOULDER

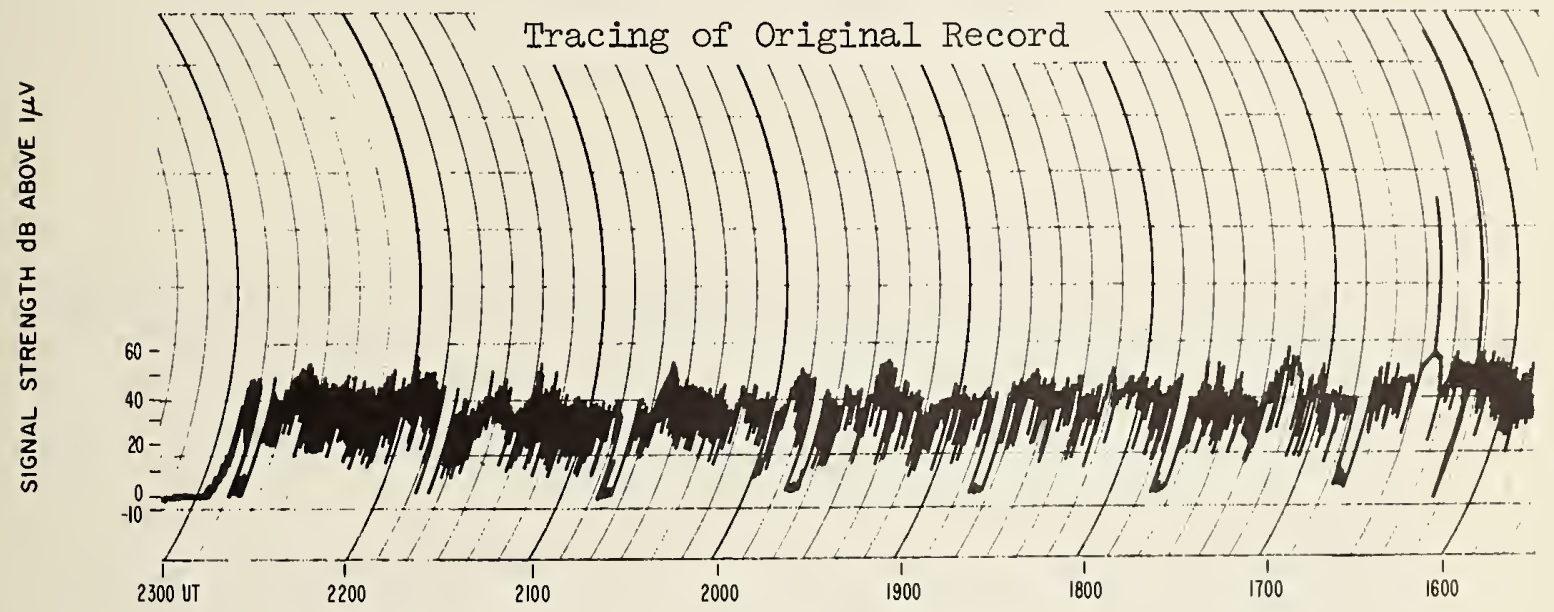

(d) $20 \mathrm{MC} / \mathrm{s}$, WWV TO BOULDER

22 NOVEMBER $196 \mid$ 


\section{OPTICAL FLARE, IMPORTANCE I-, I835E - 1835U-1855}

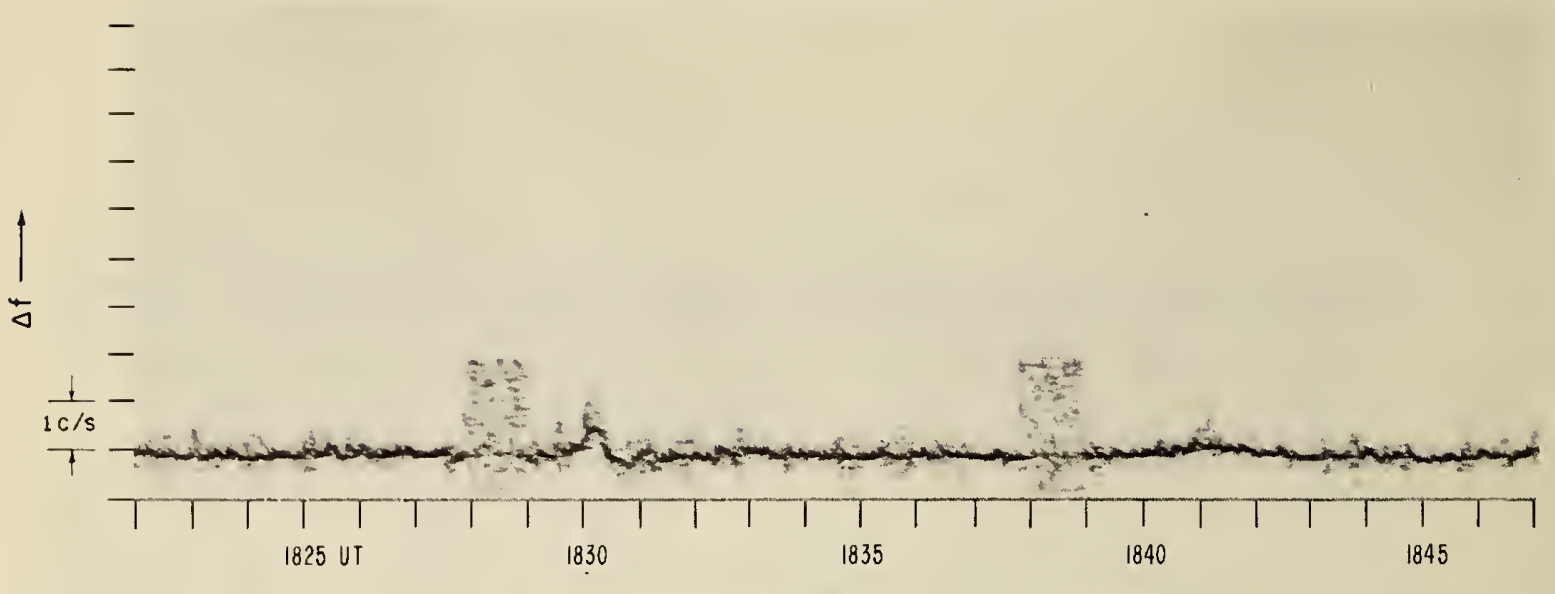

(a) $4.000 \mathrm{mc} / \mathrm{s}$, SUNSET TO BOULDER

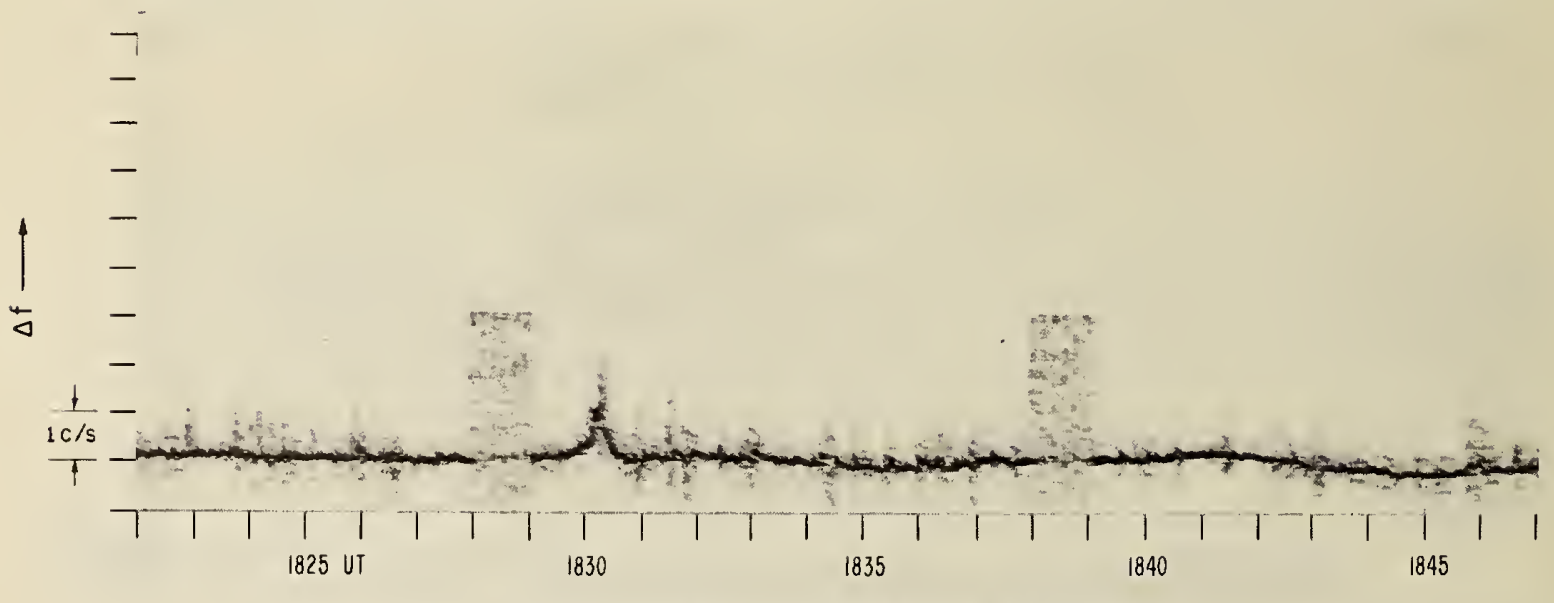

(b) $5.054 \mathrm{MC} / \mathrm{s}$, SUNSET TO BOULDER

21 FEBRUARY 1962

Figure 41 


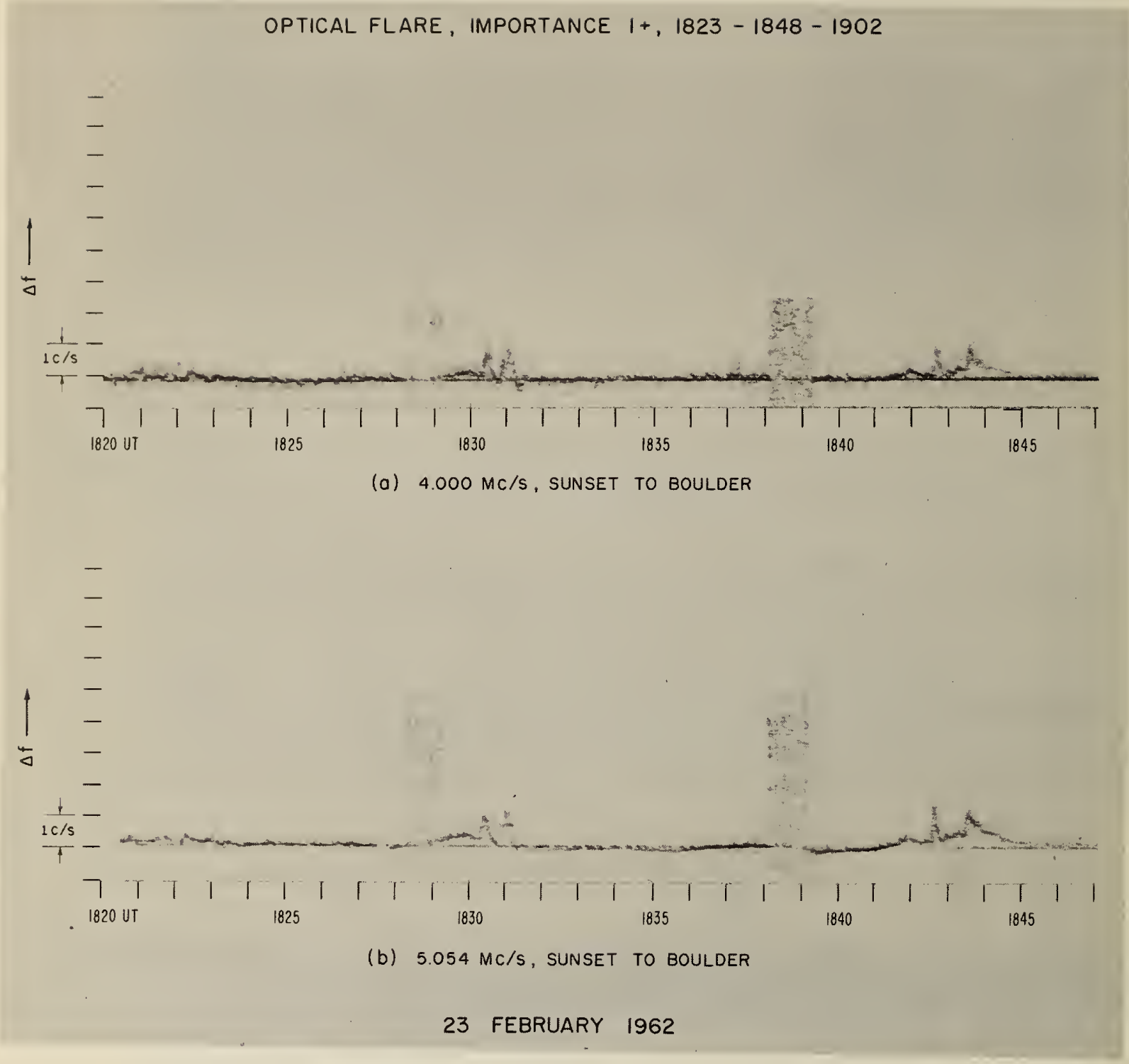

23 FEBRUARY 1962

Figure 42 


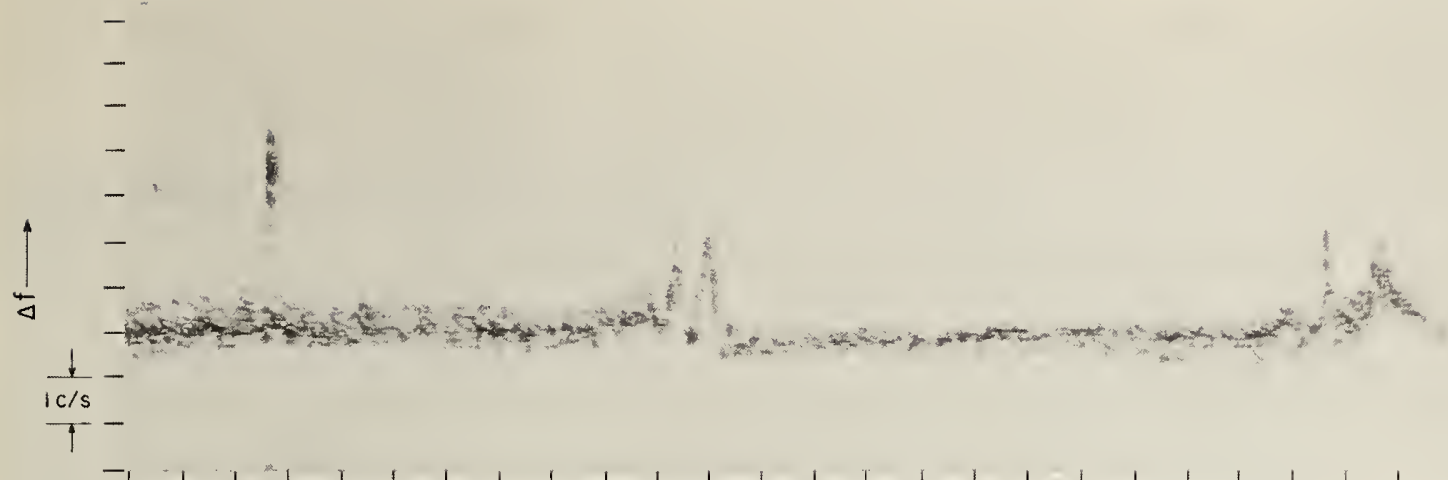

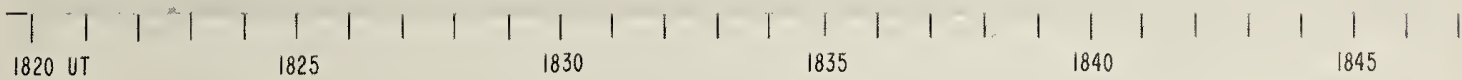

(C) $10 \mathrm{Mc} / \mathrm{s}$, WWV TO SHICKLEY

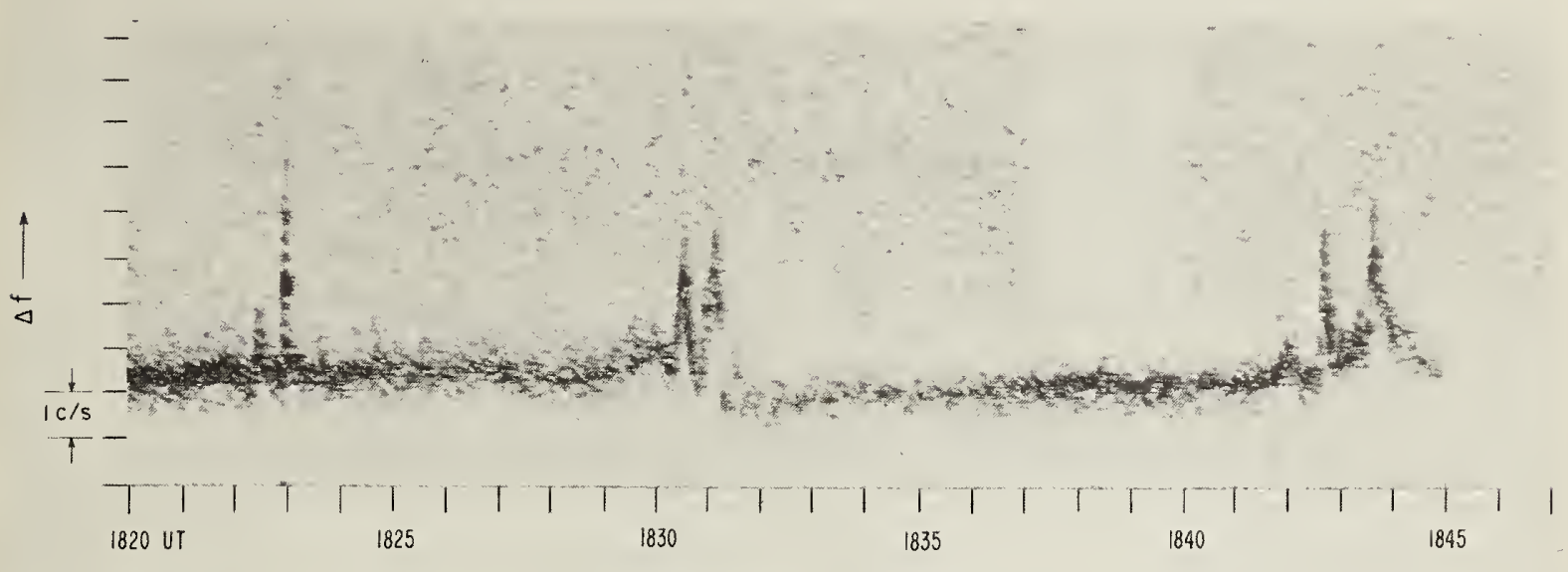

(d) $10 \mathrm{MC} / \mathrm{s}$, WWV TO BOULDER

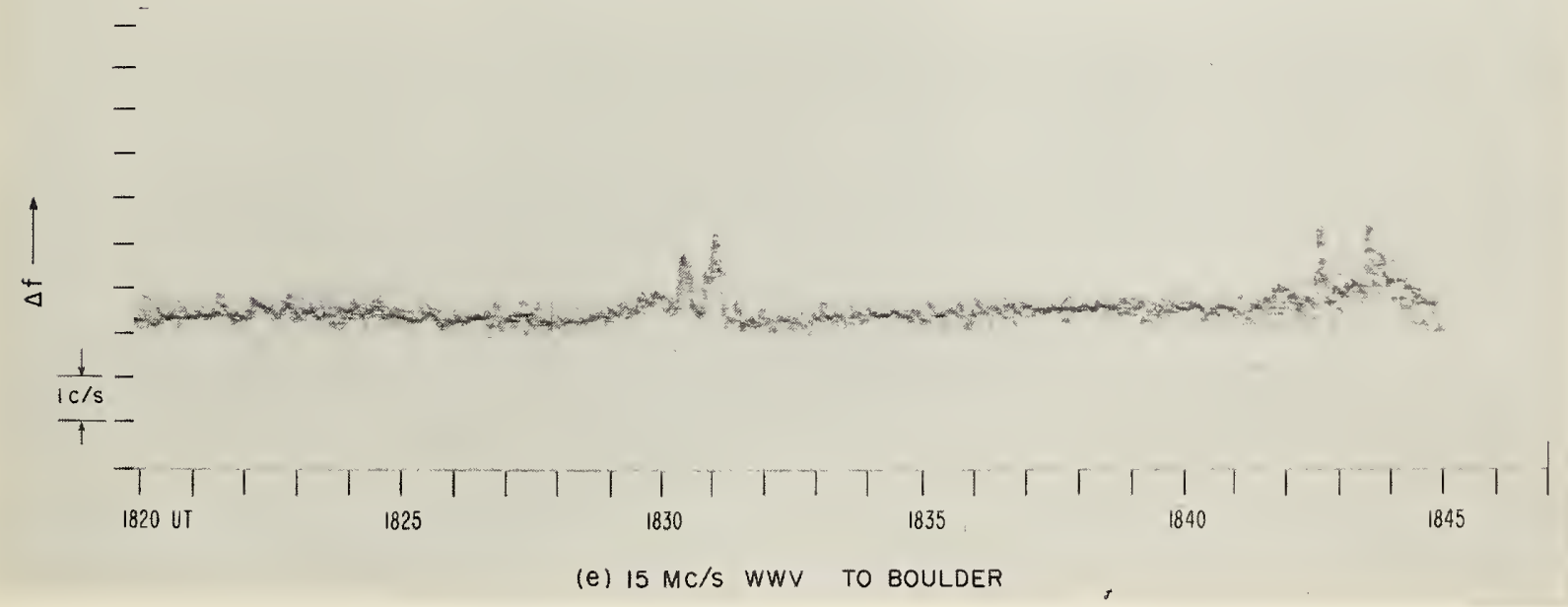

23 FEBRUARY 1962

Figure 42 
OPTICAL FLARE, IMPORTANCE I, 1934-1941-2028

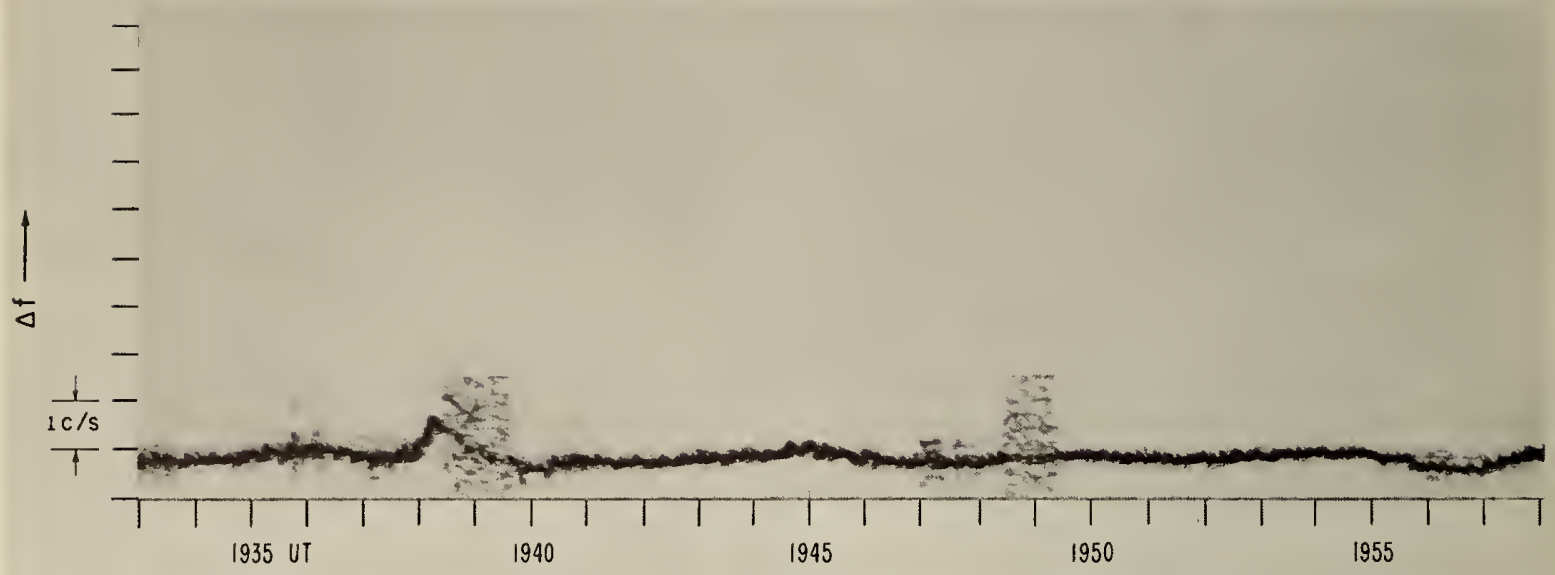

(a) $4.000 \mathrm{mc} / \mathrm{s}$, SUNSET TO BOULDER

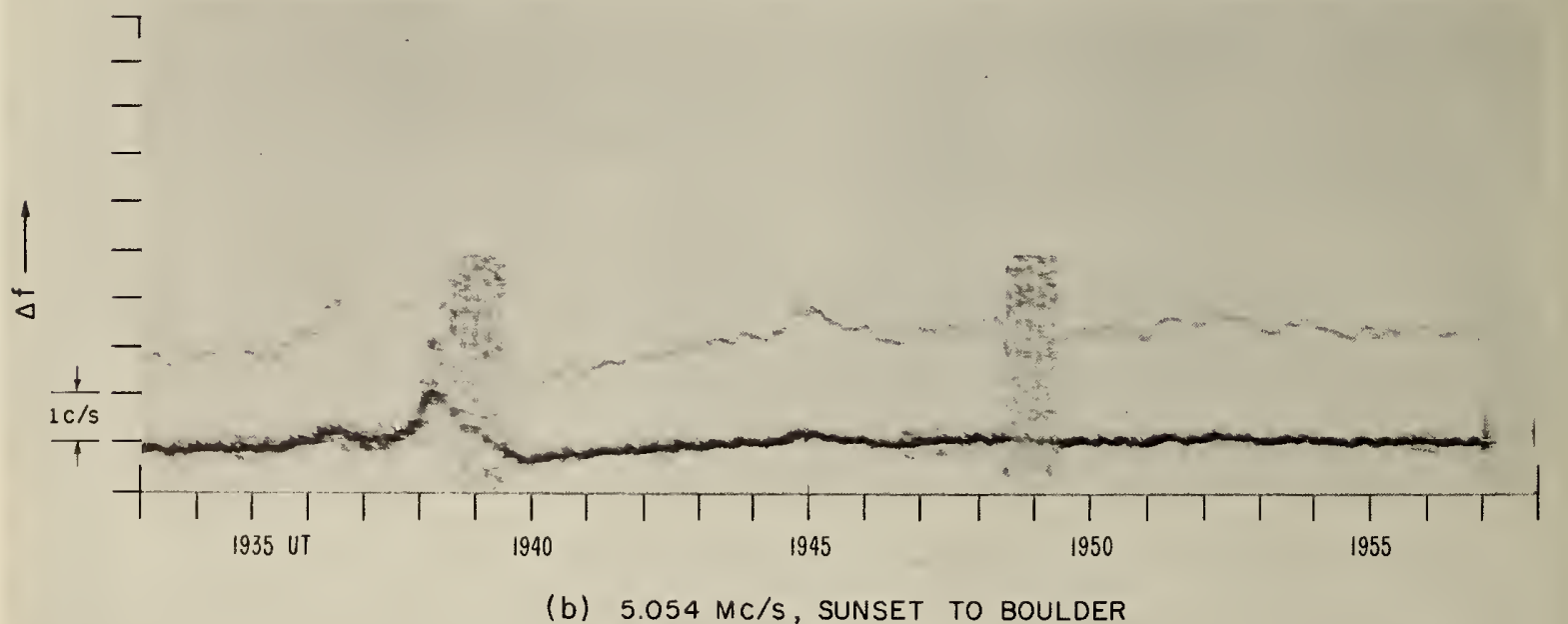

28 FEBRUARY 1962

Figure 43 


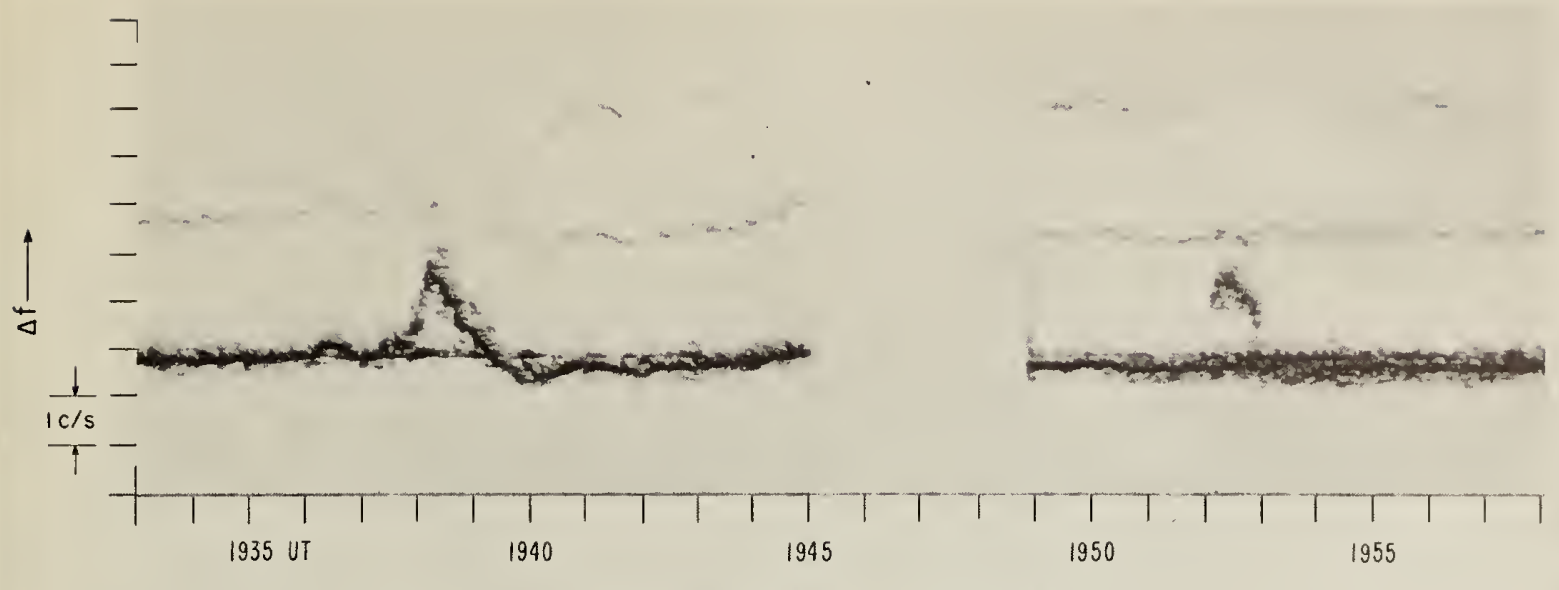

(c) $10 \mathrm{Mc} / \mathrm{s}$, WWV TO SHICKLEY

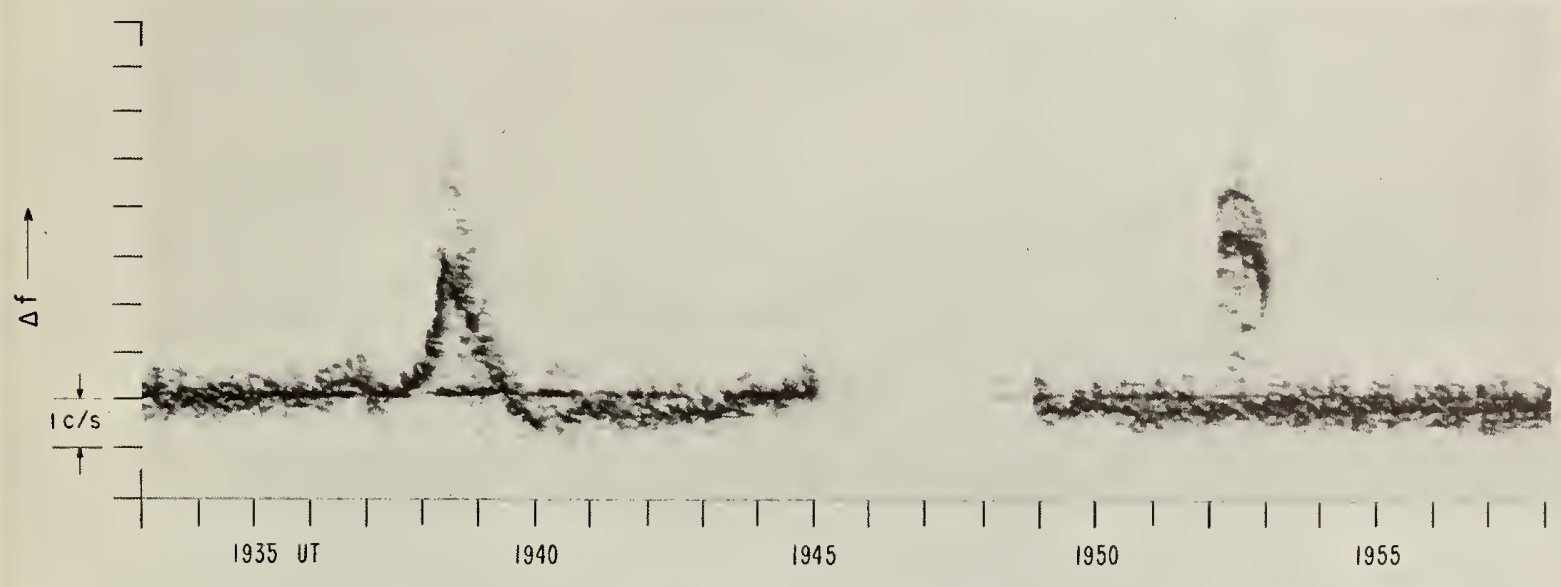

(d) $10 \mathrm{mc} / \mathrm{s}$, WWV TO BOULDER

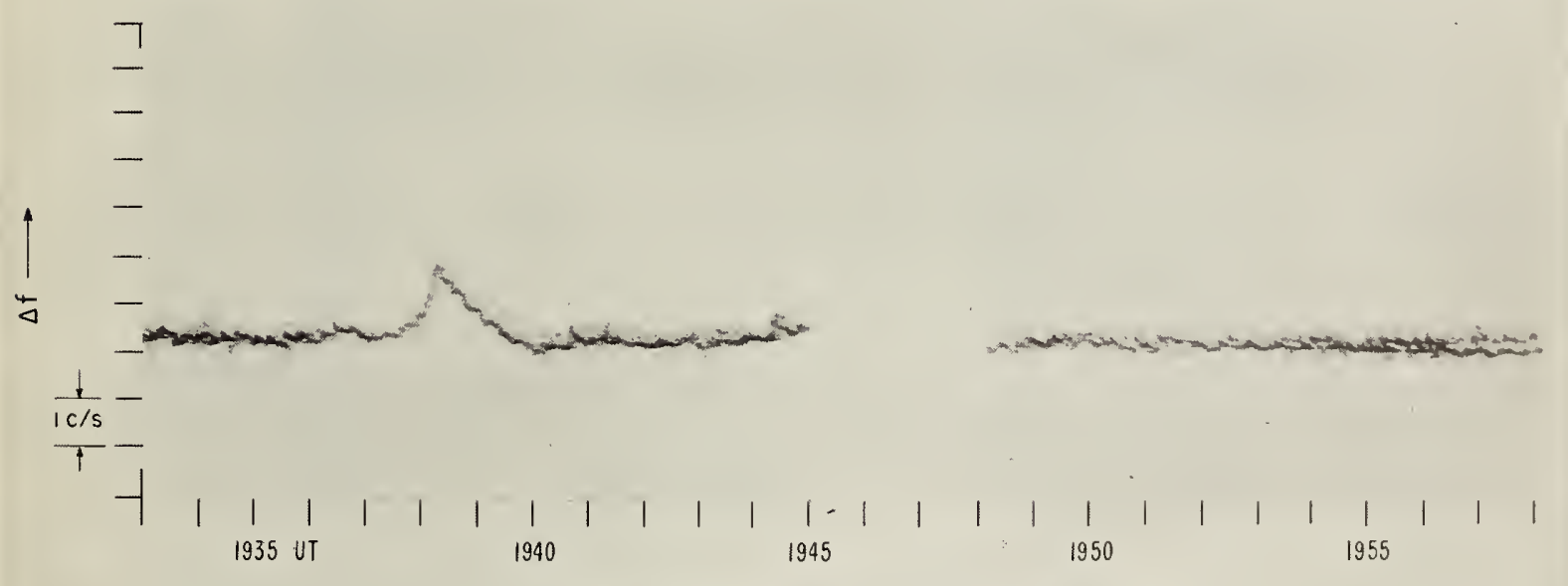

(e) $15 \mathrm{MC} / \mathrm{s}$, WWV TO BOULDER,

28 FEBRUARY 1962

Figure 43

$-73-$ 


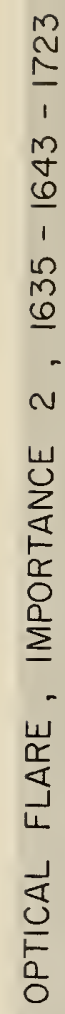
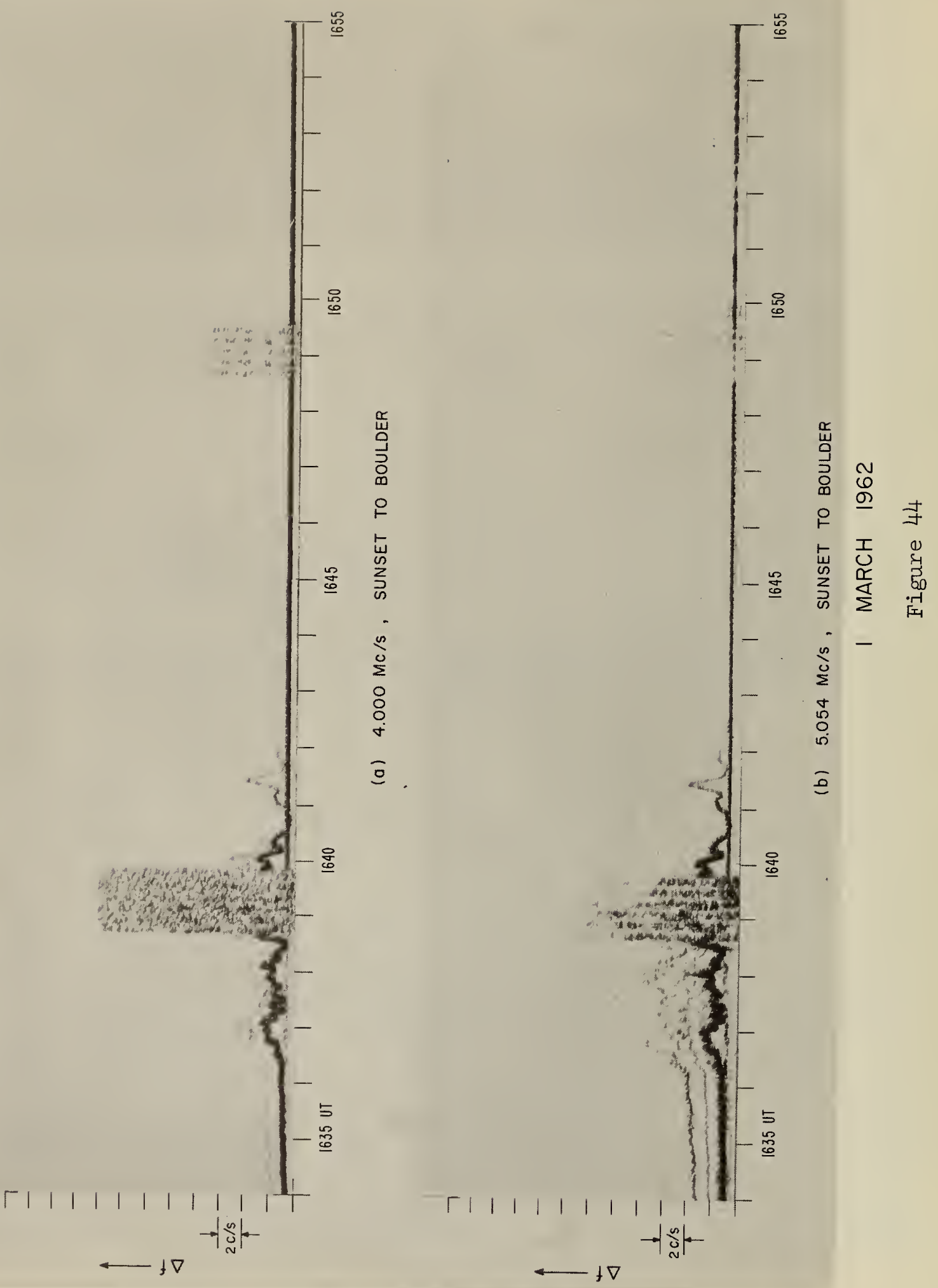
OPTICAL FLARE, IMPORTANCE 2, 1635-1643-1723

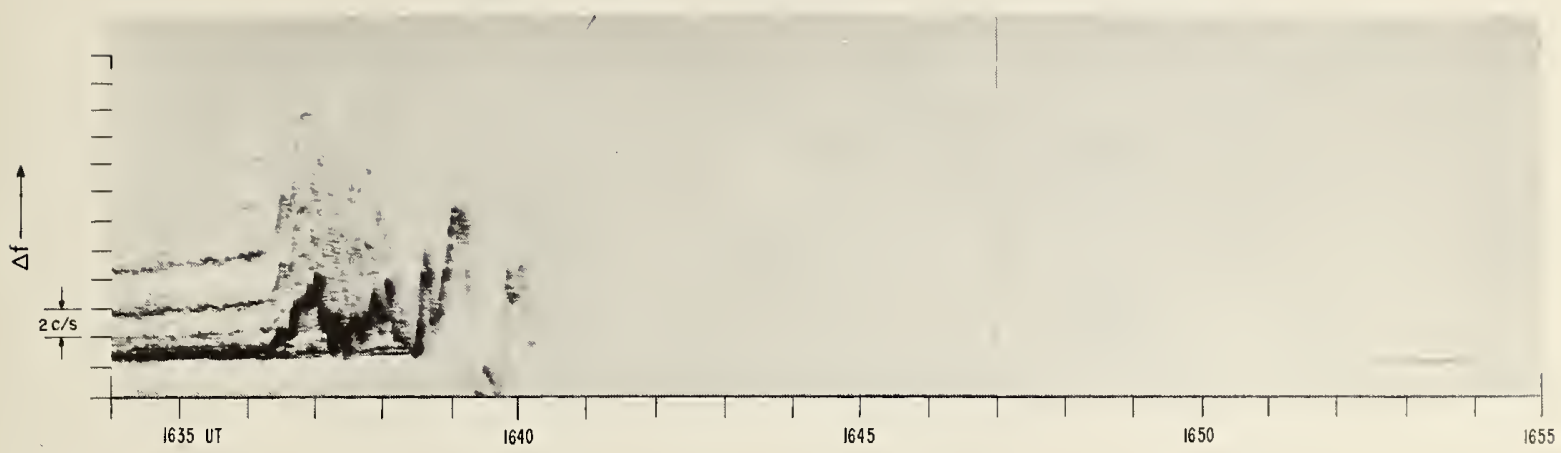

(c) $10 \mathrm{Mc} / \mathrm{s}$, WWV TO SHICKLEY

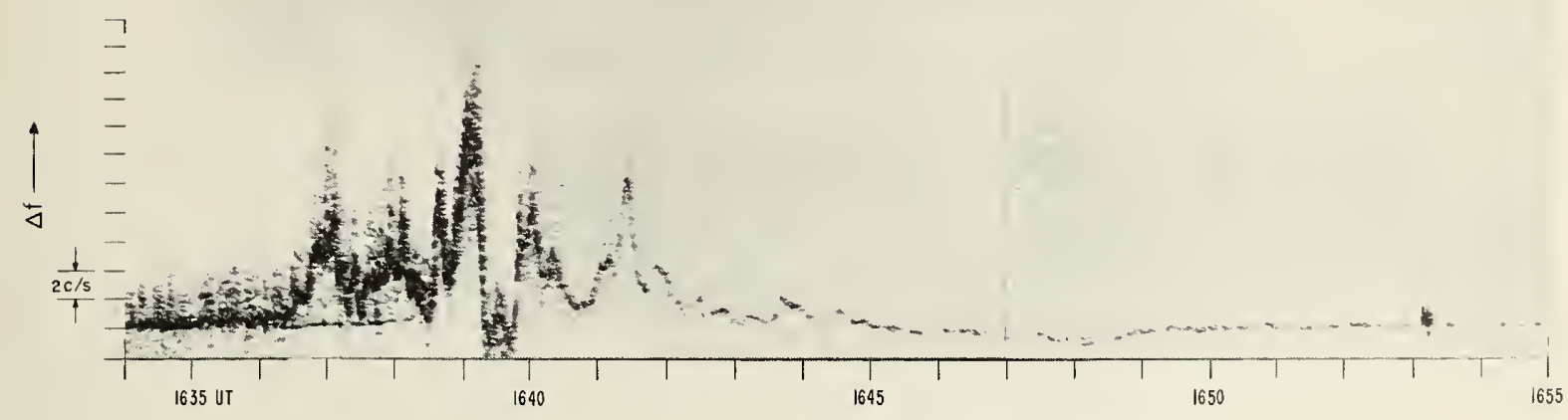

(d) $10 \mathrm{Mc} / \mathrm{s}$, WWV TO BOULDER

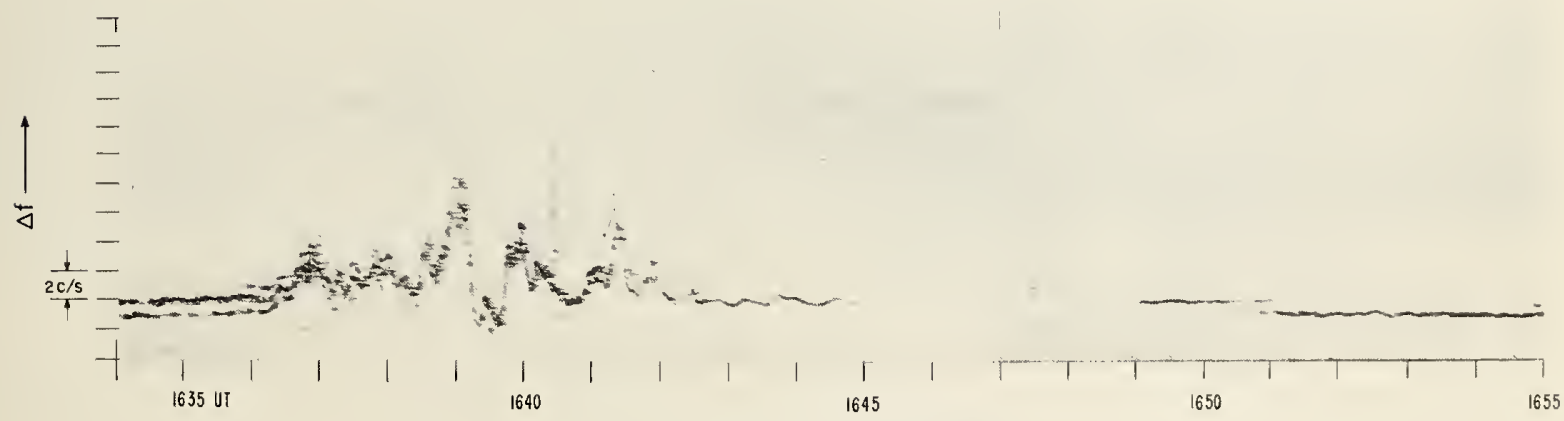

(e) $15 \mathrm{mc} / \mathrm{s}$, WWV TO BOULDER

I MARCH 1962

Figure 44 


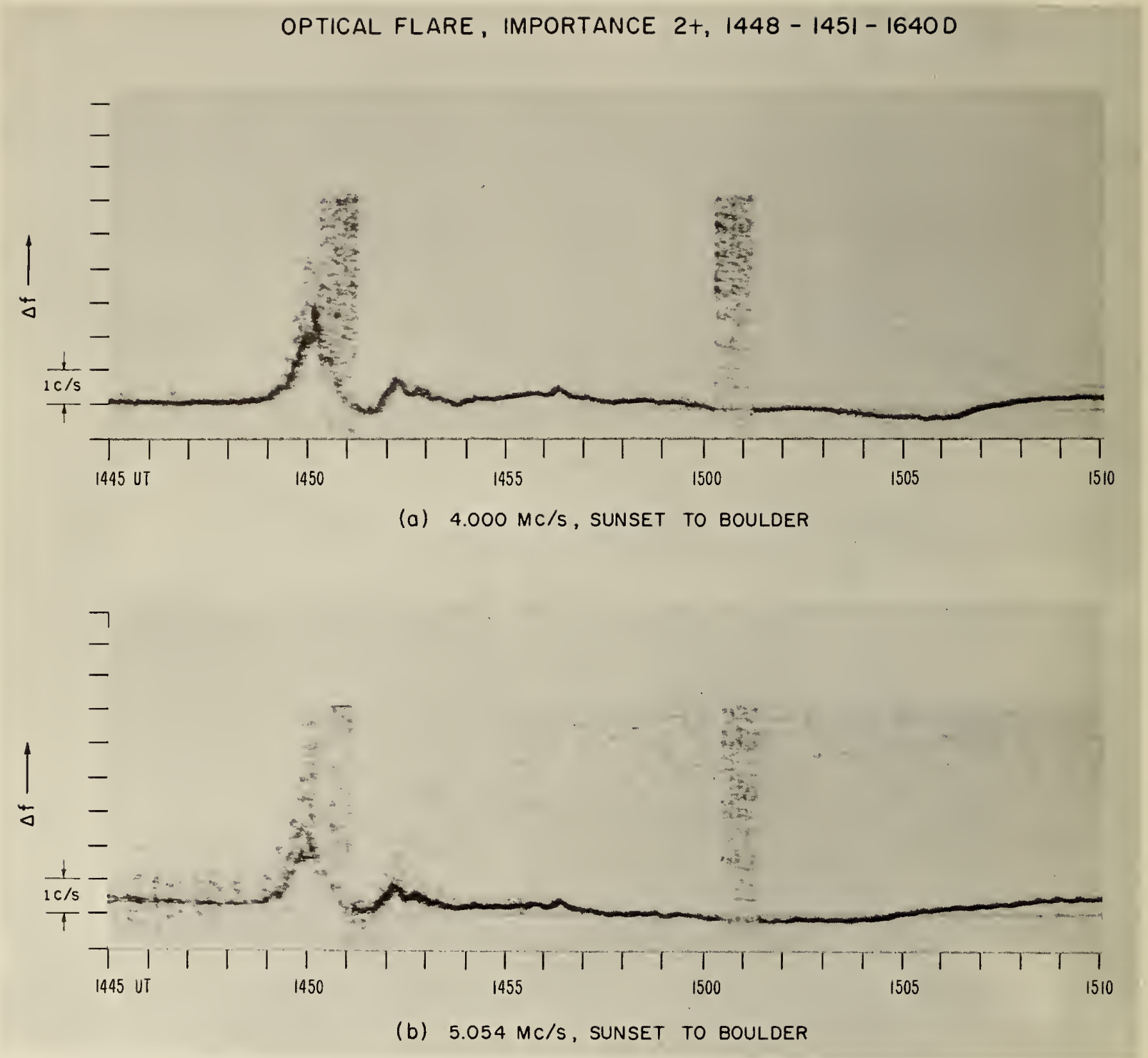

$13 \mathrm{MARCH} 1962$

Figure 45

$-76-$ 
OPTICAL FLARE, IMFORTANCE 2+, $1448-1451-16400$

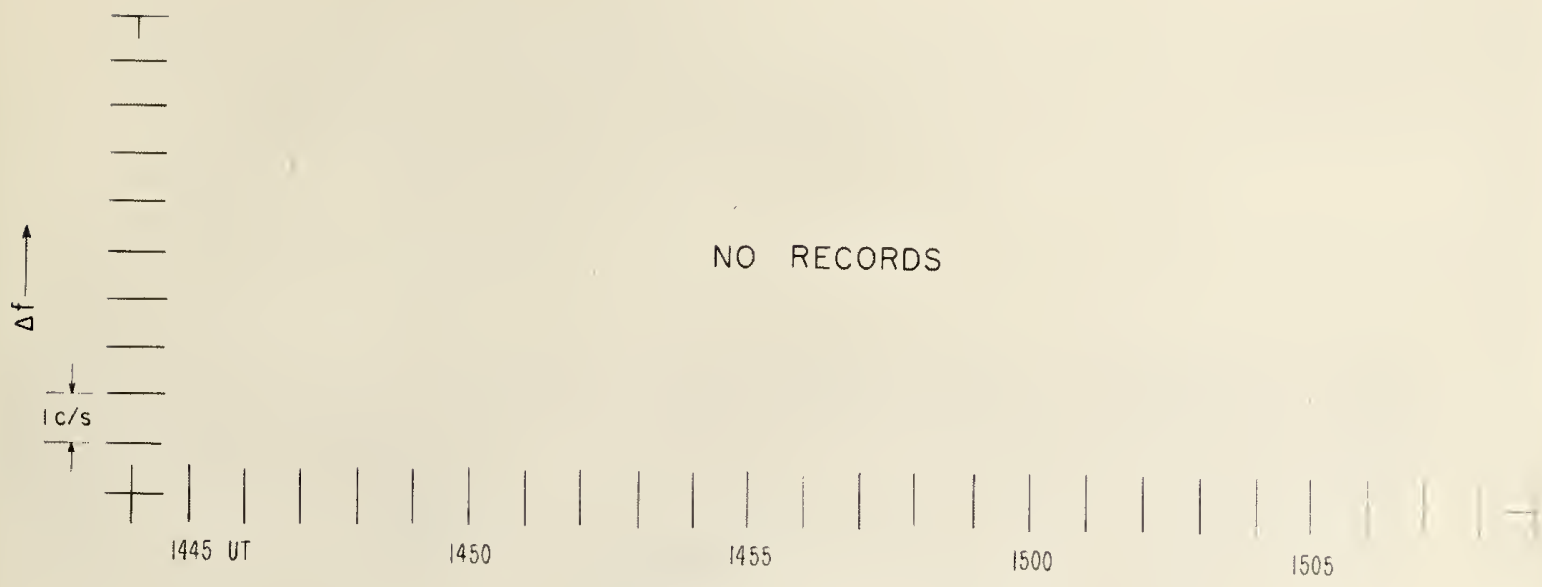

(c) $10 \mathrm{MC} / \mathrm{s}$, WWV TO SHICKLEY

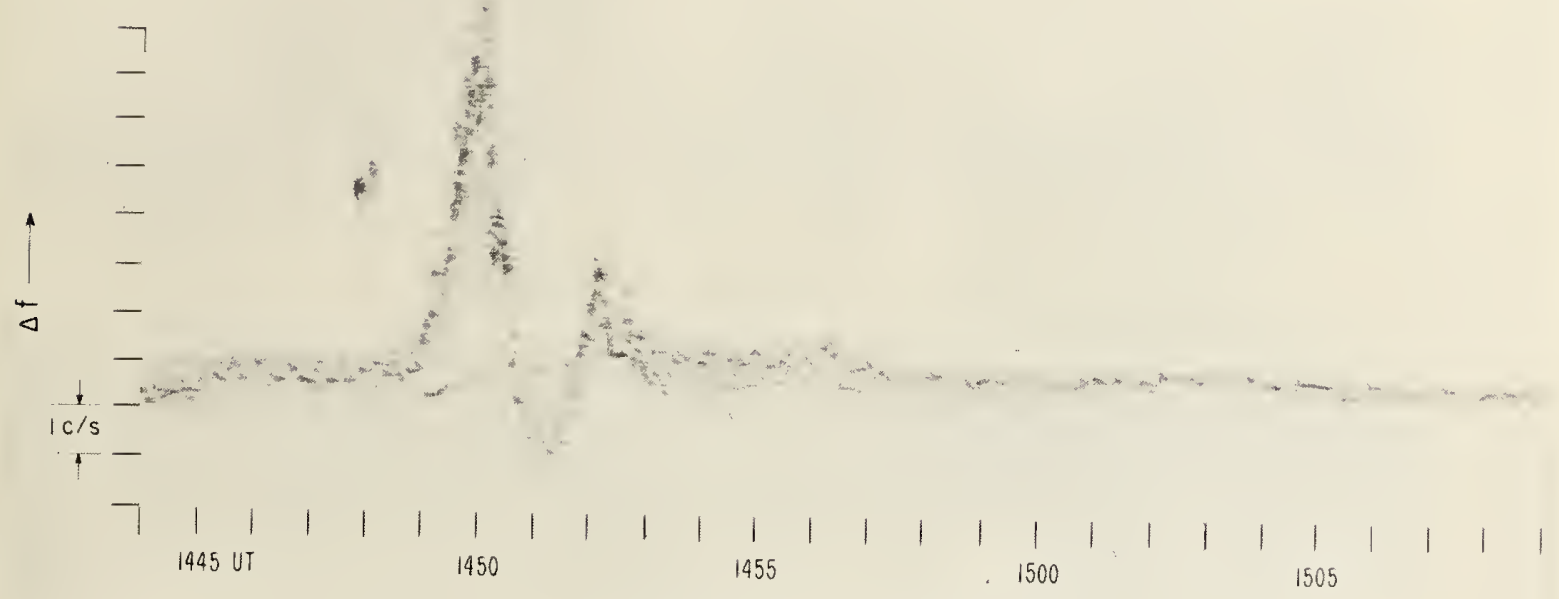

(d) $10 \mathrm{mC} / \mathrm{s}$, WWV TO BOULDER

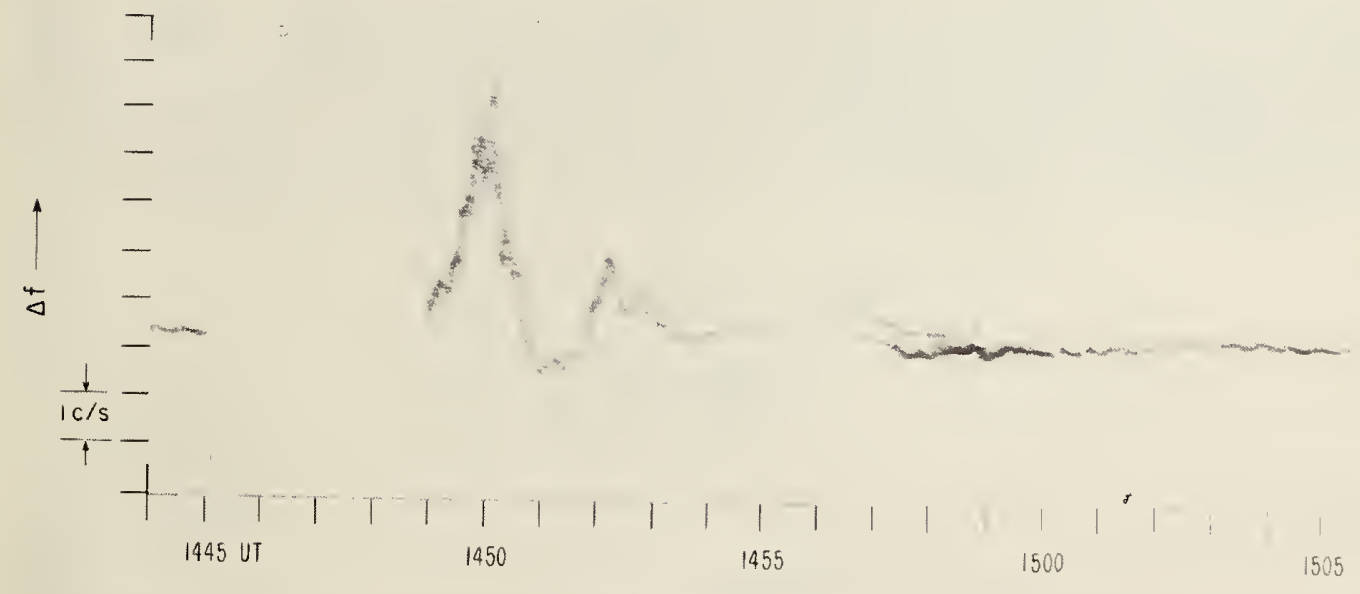

(e) $15 \mathrm{MC} / \mathrm{s}$, wWV TO BOULDER 
OPTICAL FLARE, IMPORTANCE $2+, 1448-1451-16400$

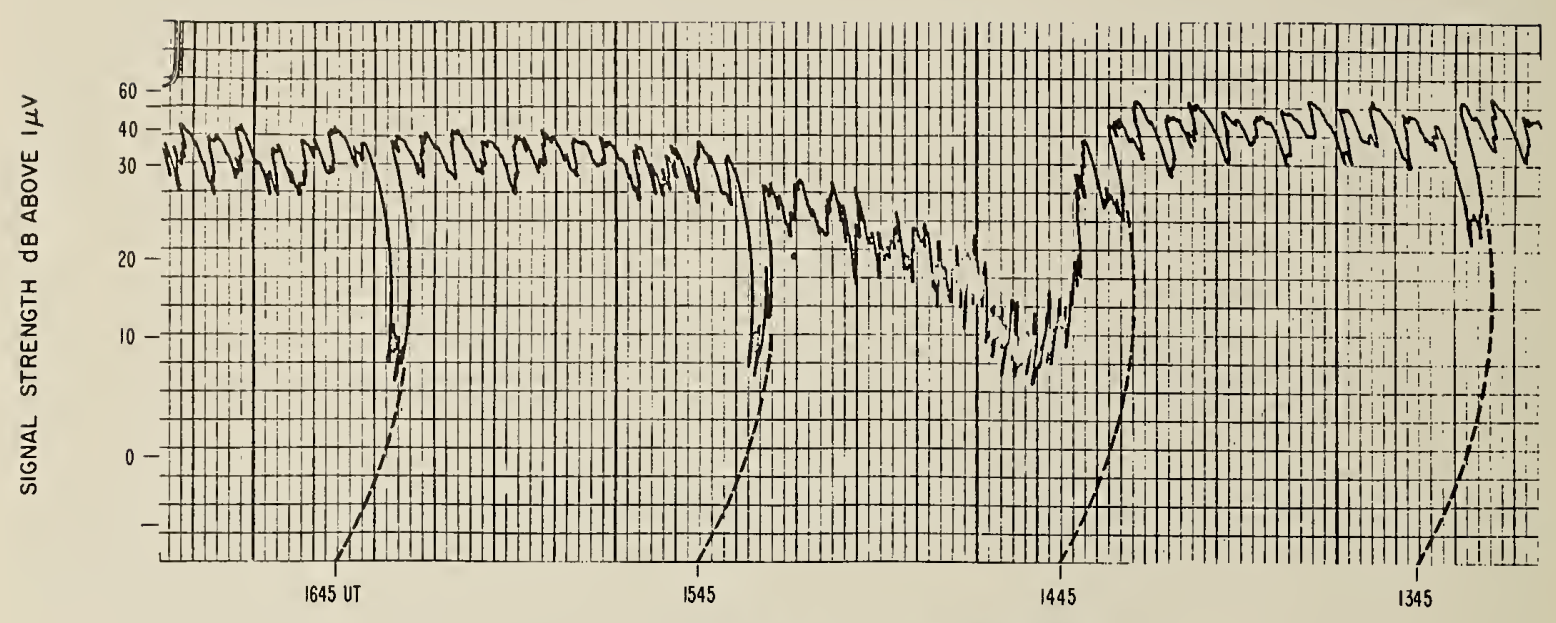

(a) $10 \mathrm{Mc} / \mathrm{s}$, WWV TO BOULDER

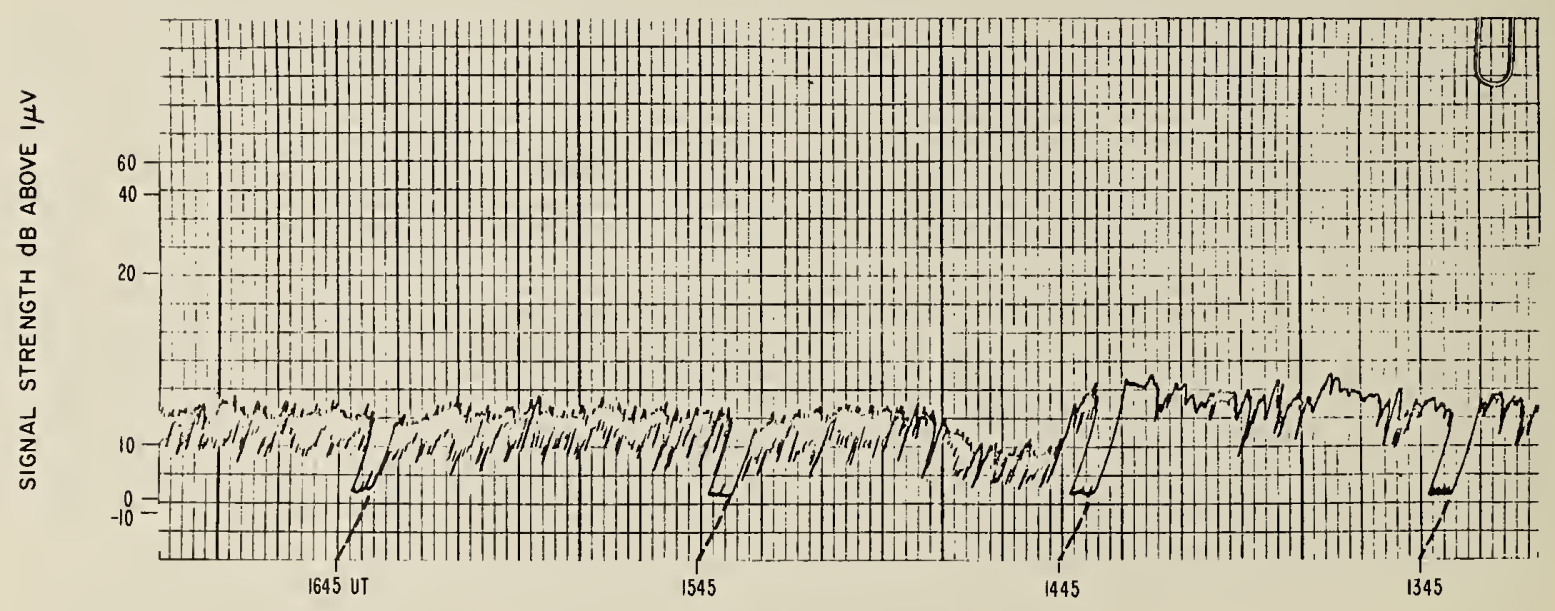

(b) $15 \mathrm{Mc} / \mathrm{s}$, WWV TO BOULDER

13 MARCH 1962

Figure 46 

OPTICAL FLARE, IMPORTANCE 1-, 1300E-1307-1320

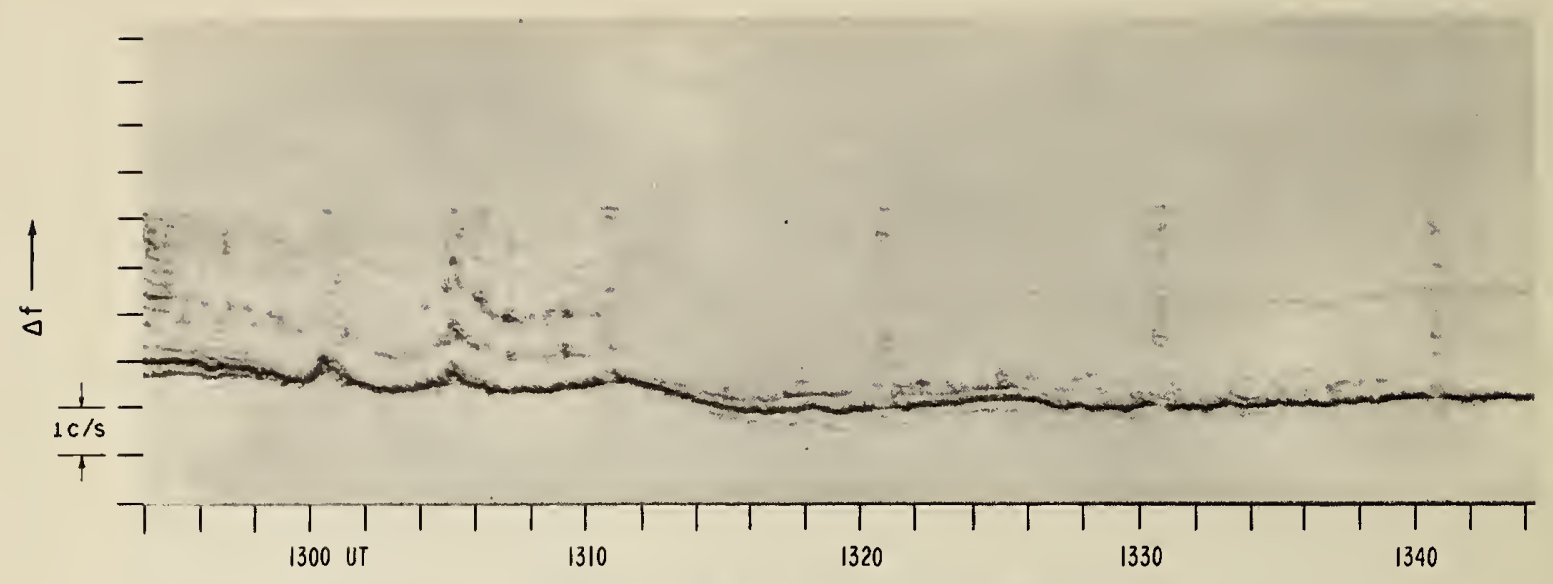

(a) $4.000 \mathrm{mC} / \mathrm{s}$, SUNSET TO BOULDER

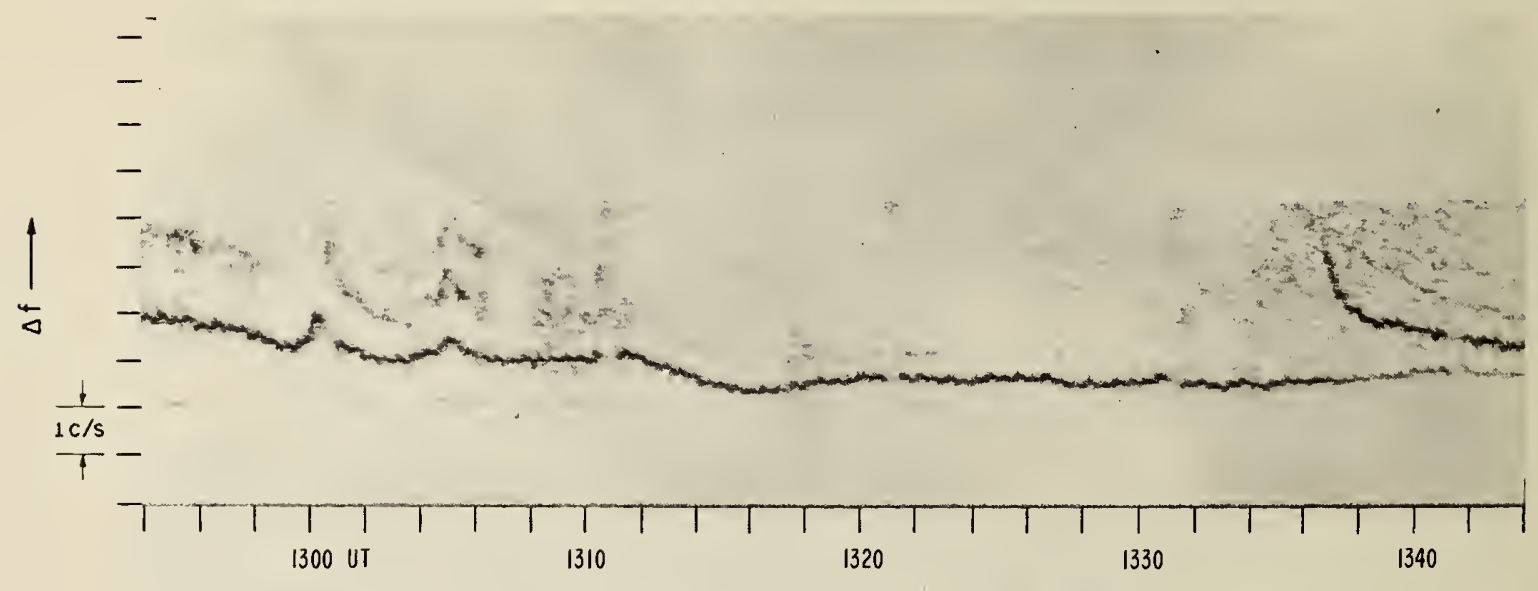

(b) $5.054 \mathrm{Mc} / \mathrm{s}$, SUNSET TO BOULDER

14 APRIL 1962

Figure 47

$-80-$ 
OPTICAL FLARE, IMPORTANCE 1-, 1300-1307-1320

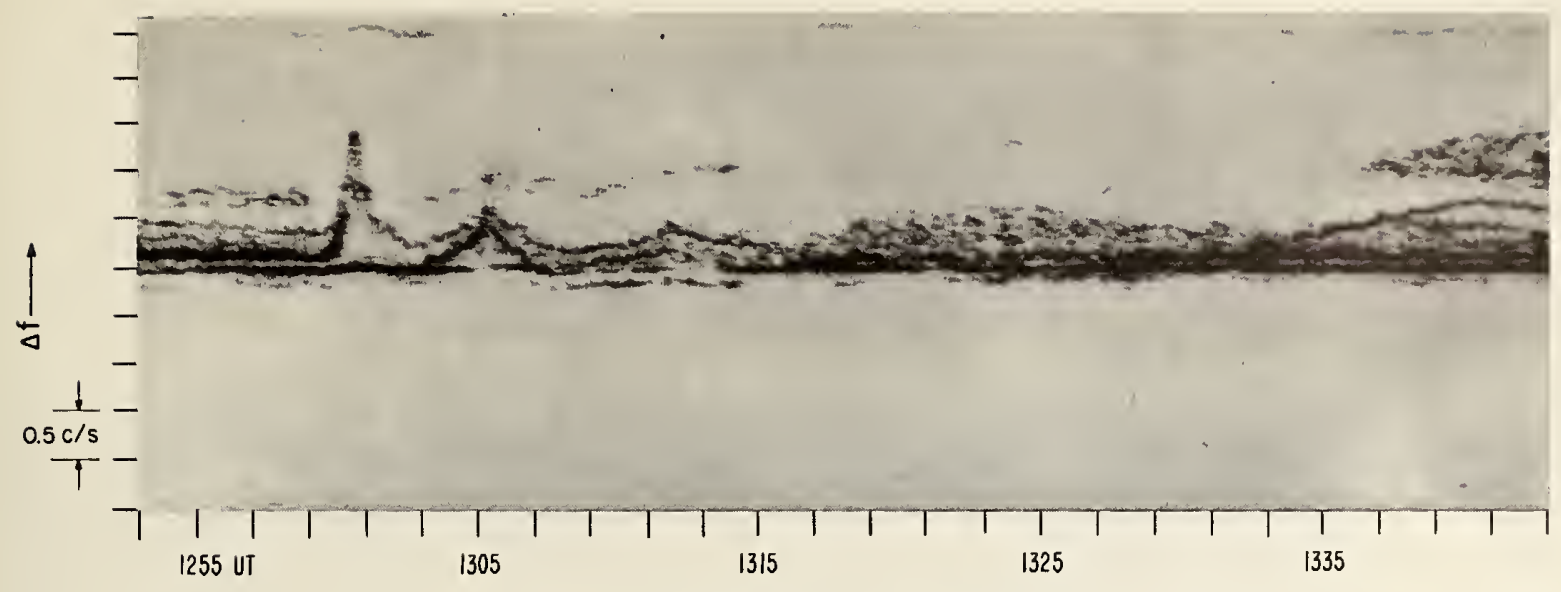

(C) $10 \mathrm{MC} / \mathrm{s}$, WWV TO SHICKLEY

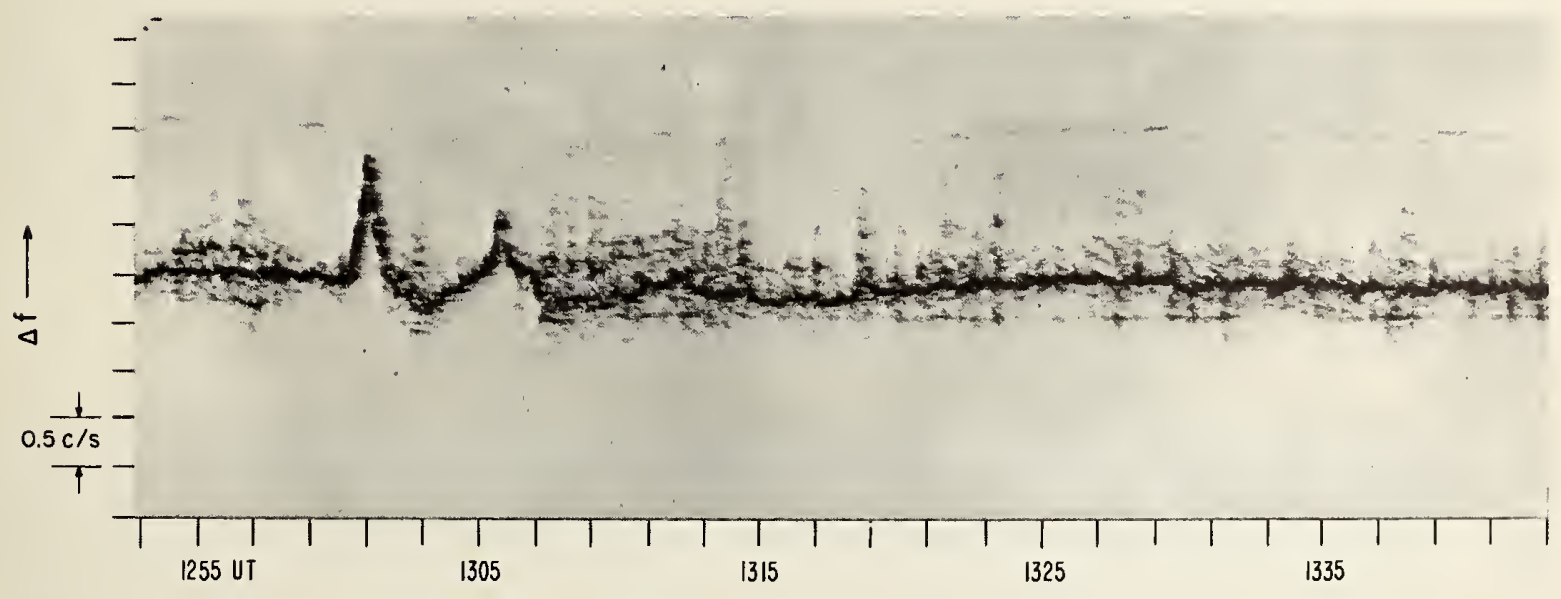

(d) $10 \mathrm{Mc} / \mathrm{s}$, WWV TO BOULDER

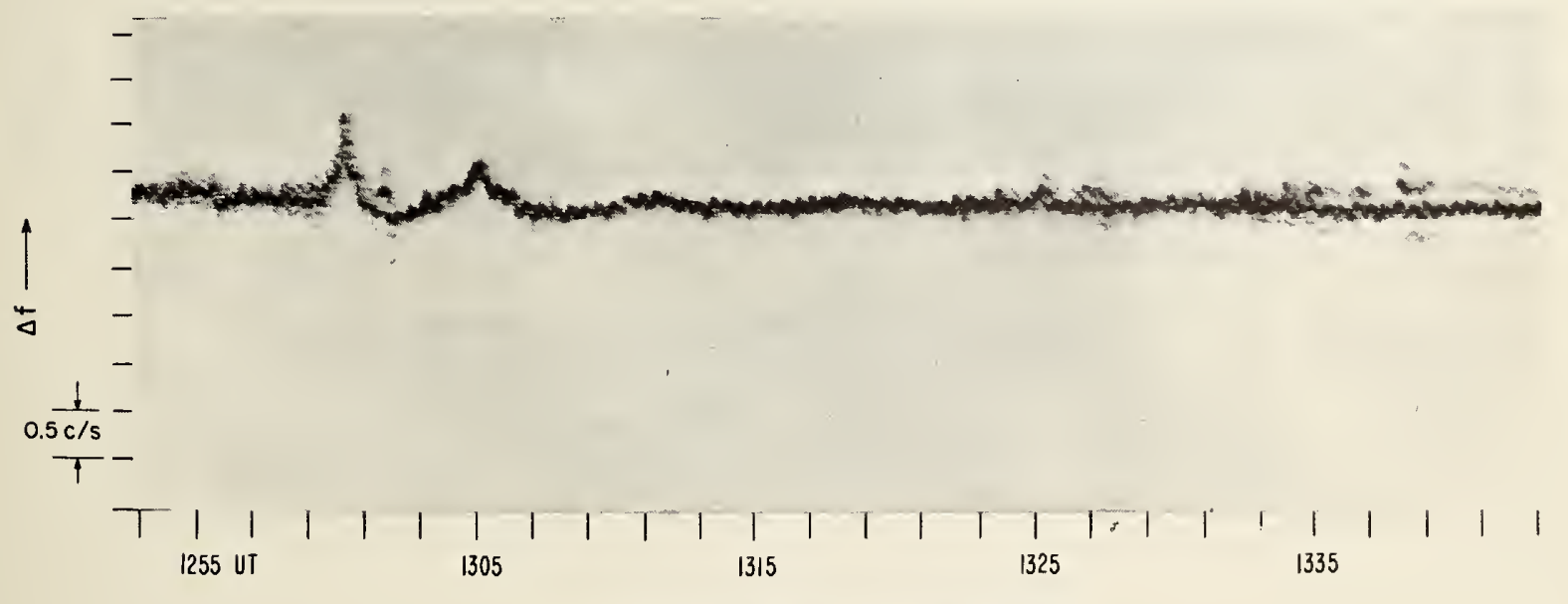

(e) $15 \mathrm{MC} / \mathrm{s}$ WWV TO BOULDER

14 APRIL 1962

Figure 47

$-81-$ 
OPTICAL FLARE, IMPORTANCE $1-, 1300 E-1302-1320$

$1-, 1300 E-1307-1320$

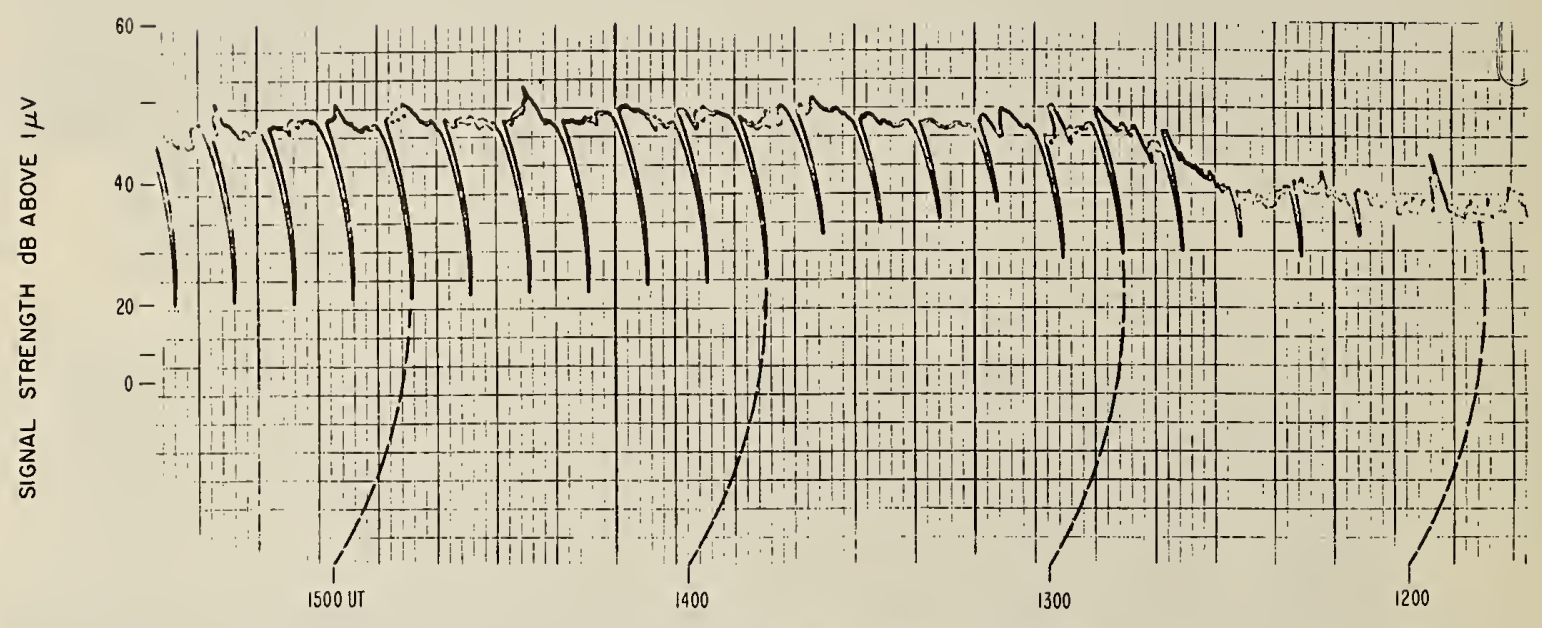

(a) $4.000 \mathrm{mc} / \mathrm{s}$, SUNSET TO BOULOER

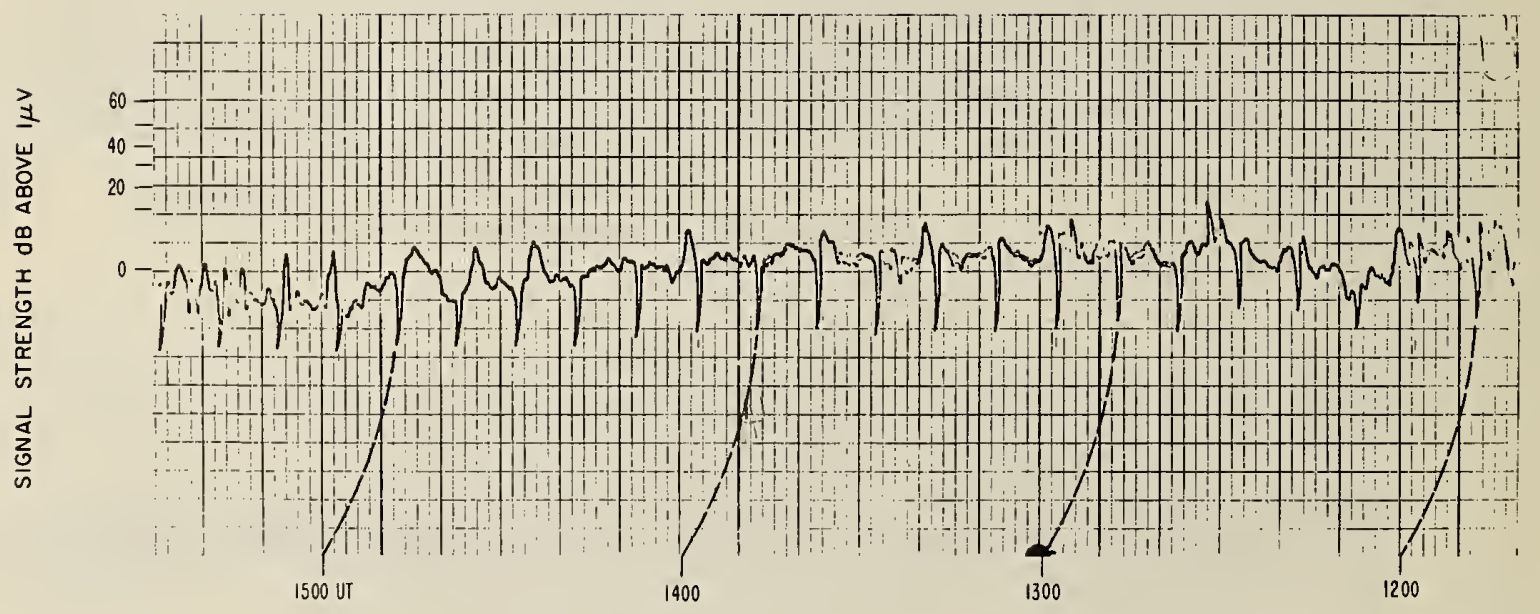

(b) $5.054 \mathrm{MC} / \mathrm{s}$, SUNSET TO BOULDER

14 APRIL 1962 
OPTICAL FLARE, IMPORTANCE I-, 1300E-1302-1320

$1-, 1300 E-1307-1320$

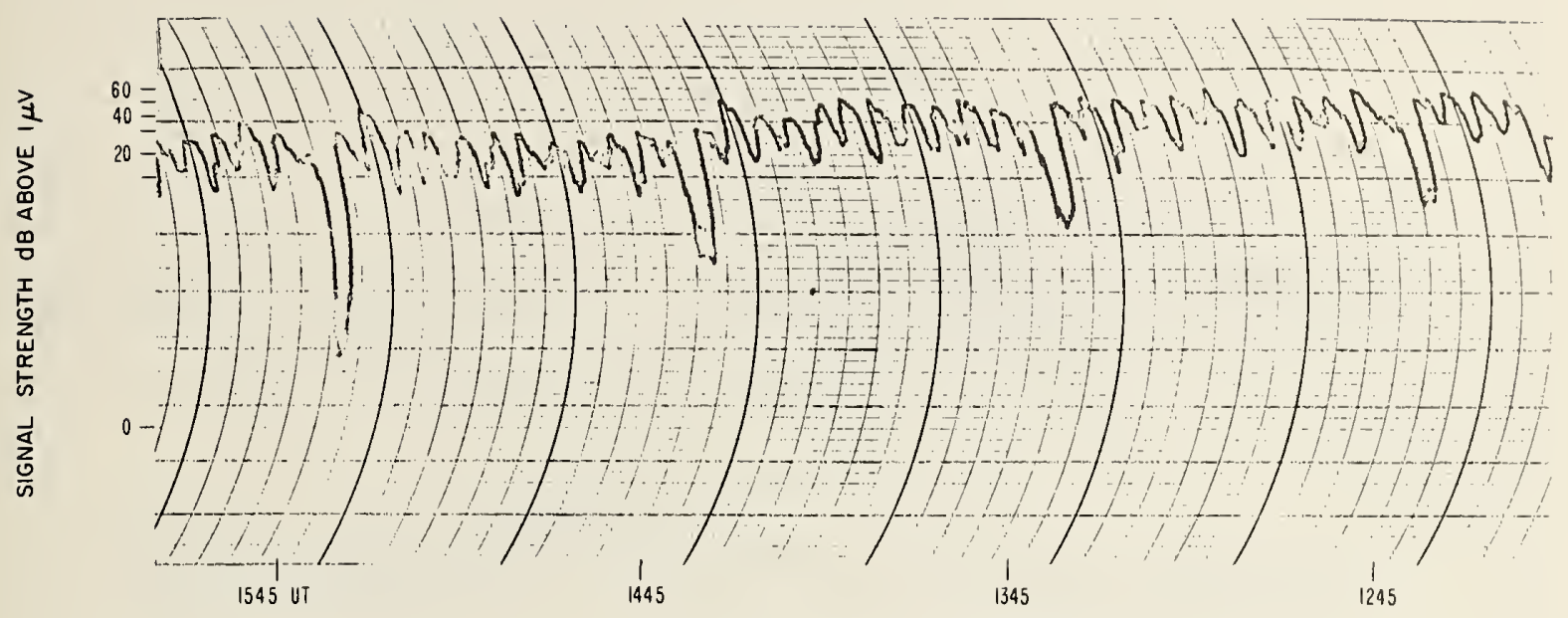

(c) $10 \mathrm{mc} / \mathrm{s}$, WWV TO BOULDER

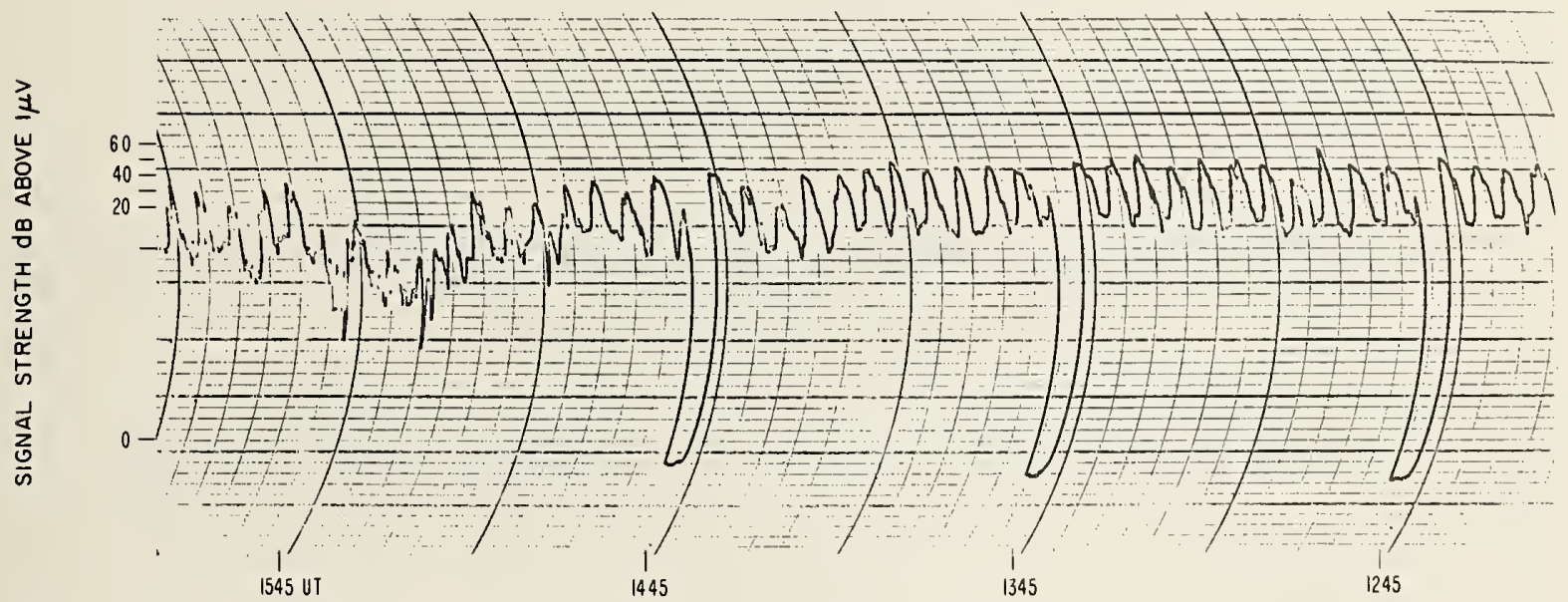

(d) $15^{\circ} \mathrm{Mc} / \mathrm{s}$, WWV TO BOULDER

14 APRIL 1962

Figure 48 
OPTICAL FLARE, IMPORTANCE I, I9IOE - 1924-2005

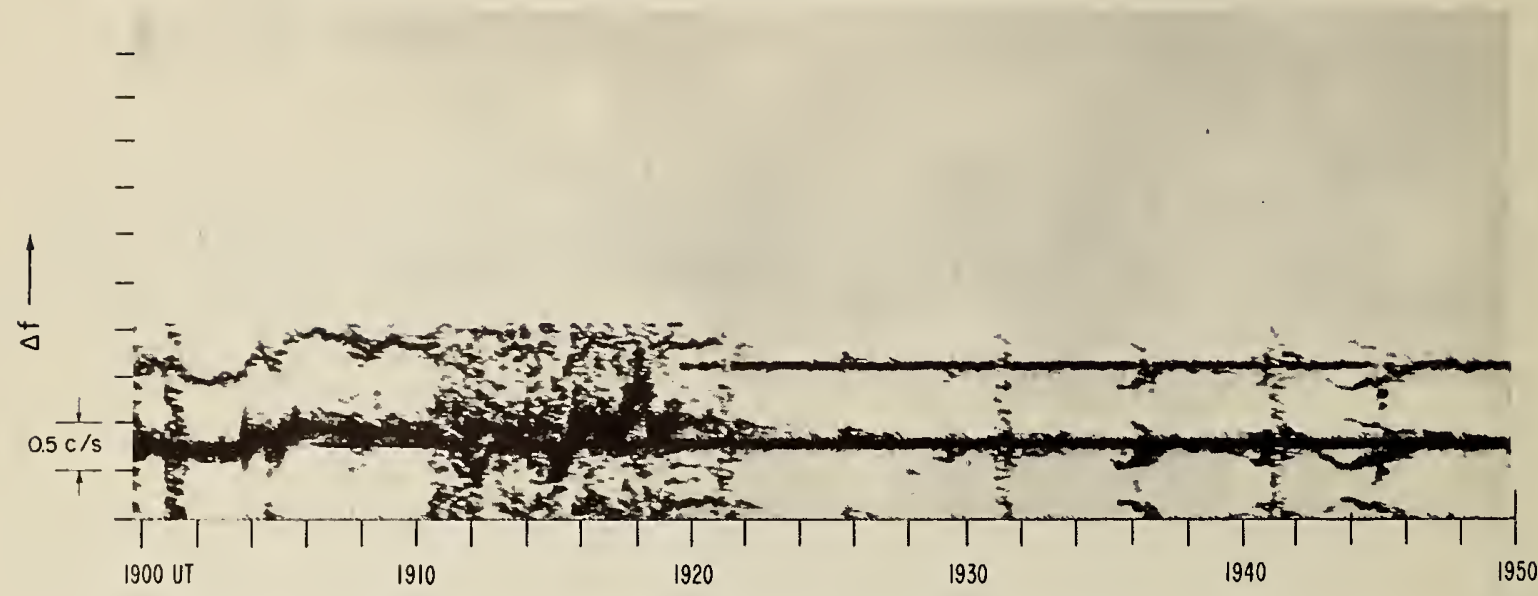

(a) $4.000 \mathrm{mc} / \mathrm{s}$, SUNSET TO BOULDER

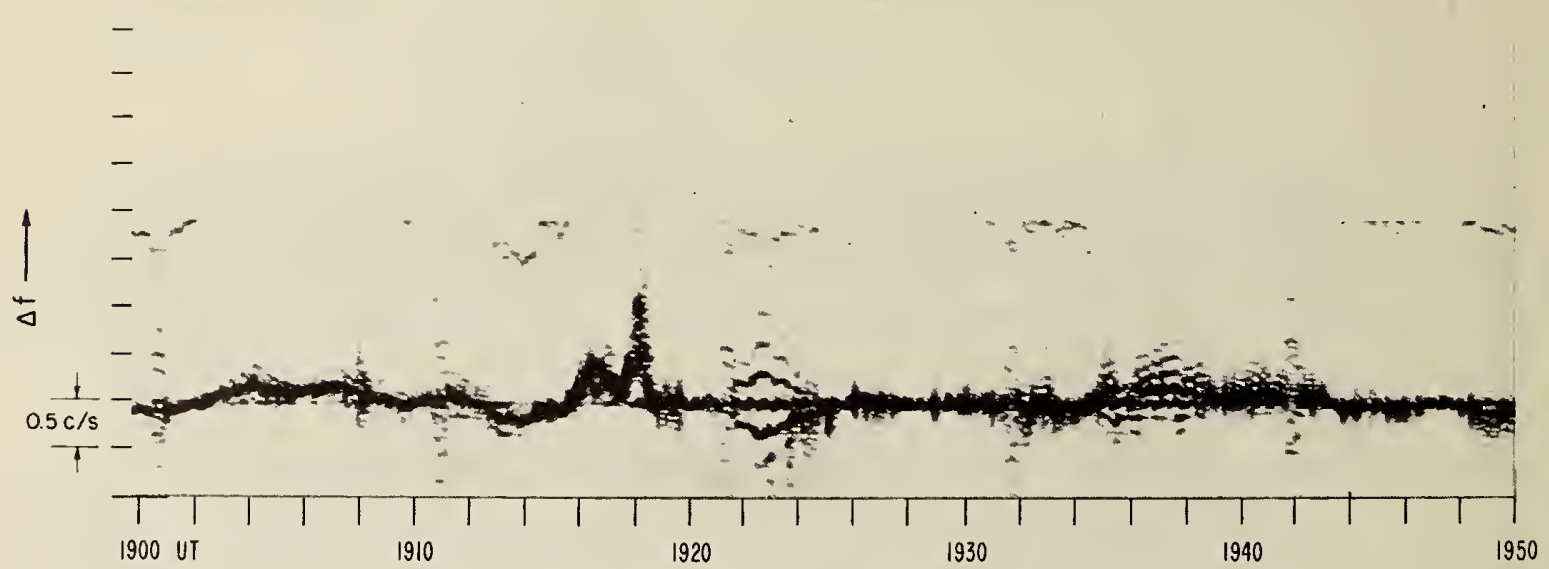

(b) $5.054 \mathrm{Mc} / \mathrm{s}$, SUNSET TO BOULDER

14 APRIL 1962 


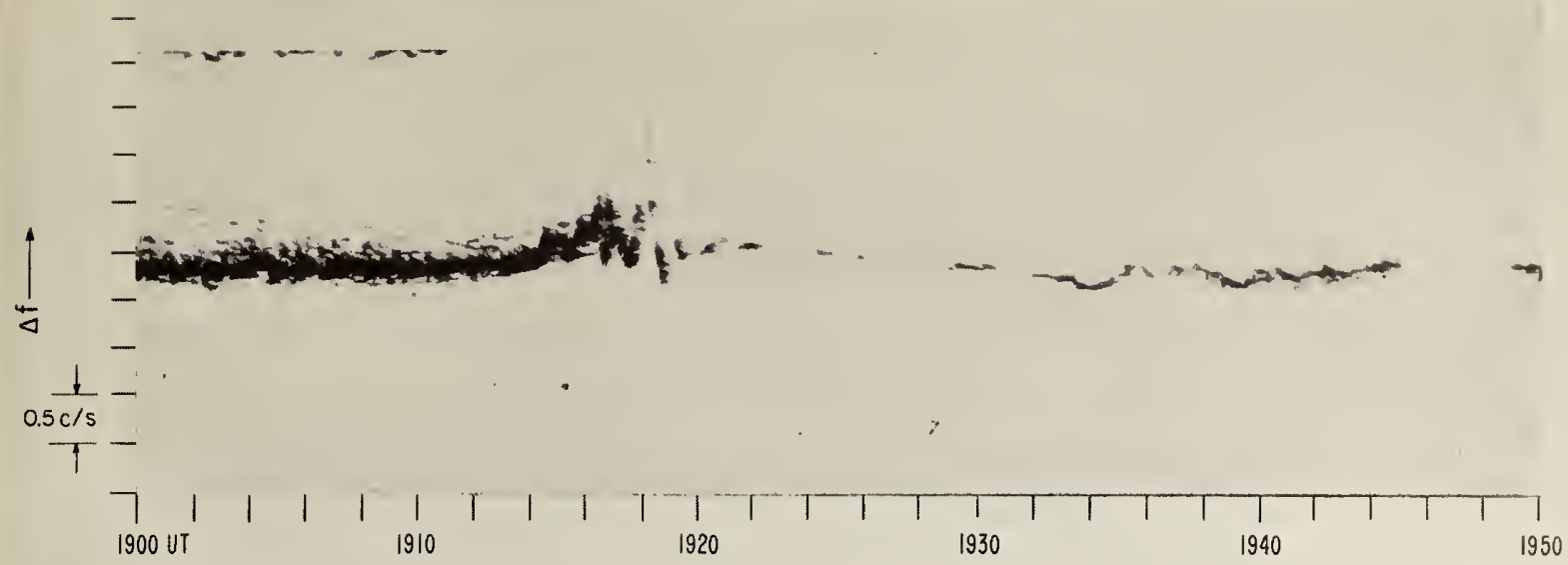

(c) $10 \mathrm{Mc} / \mathrm{s}$, WWV TO SHICKLEY

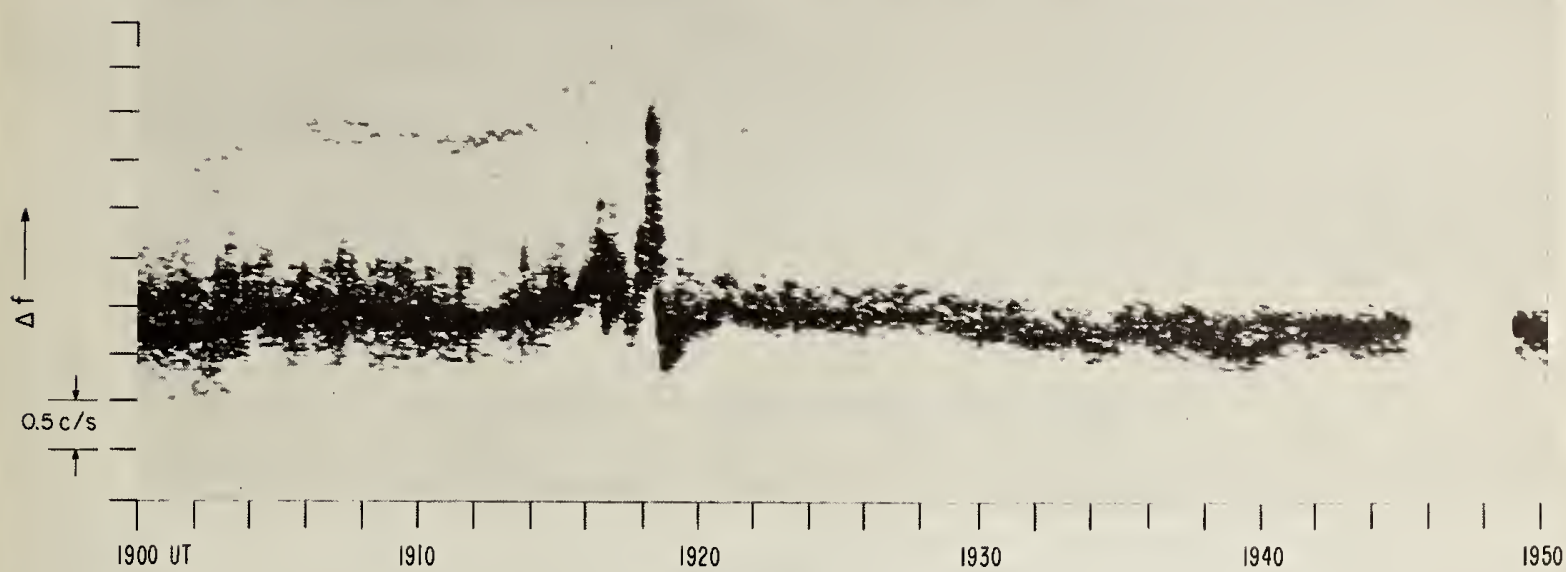

(d) $10 \mathrm{Mc} / \mathrm{s}$, WWV TO BOULDER

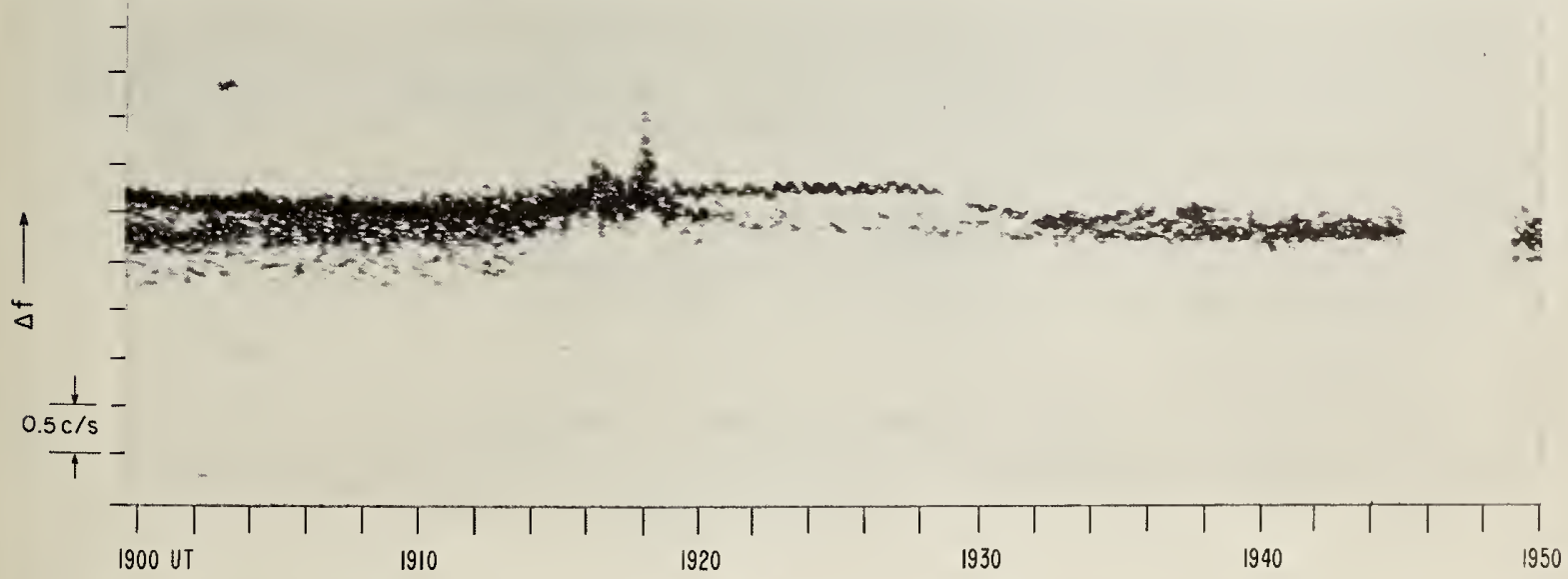

(e) $15 \mathrm{MC} / \mathrm{s}$ WWV TO BOULDER, 
OPTICAL FLARE, IMPORTANCE 1, 1910E-1924-2005
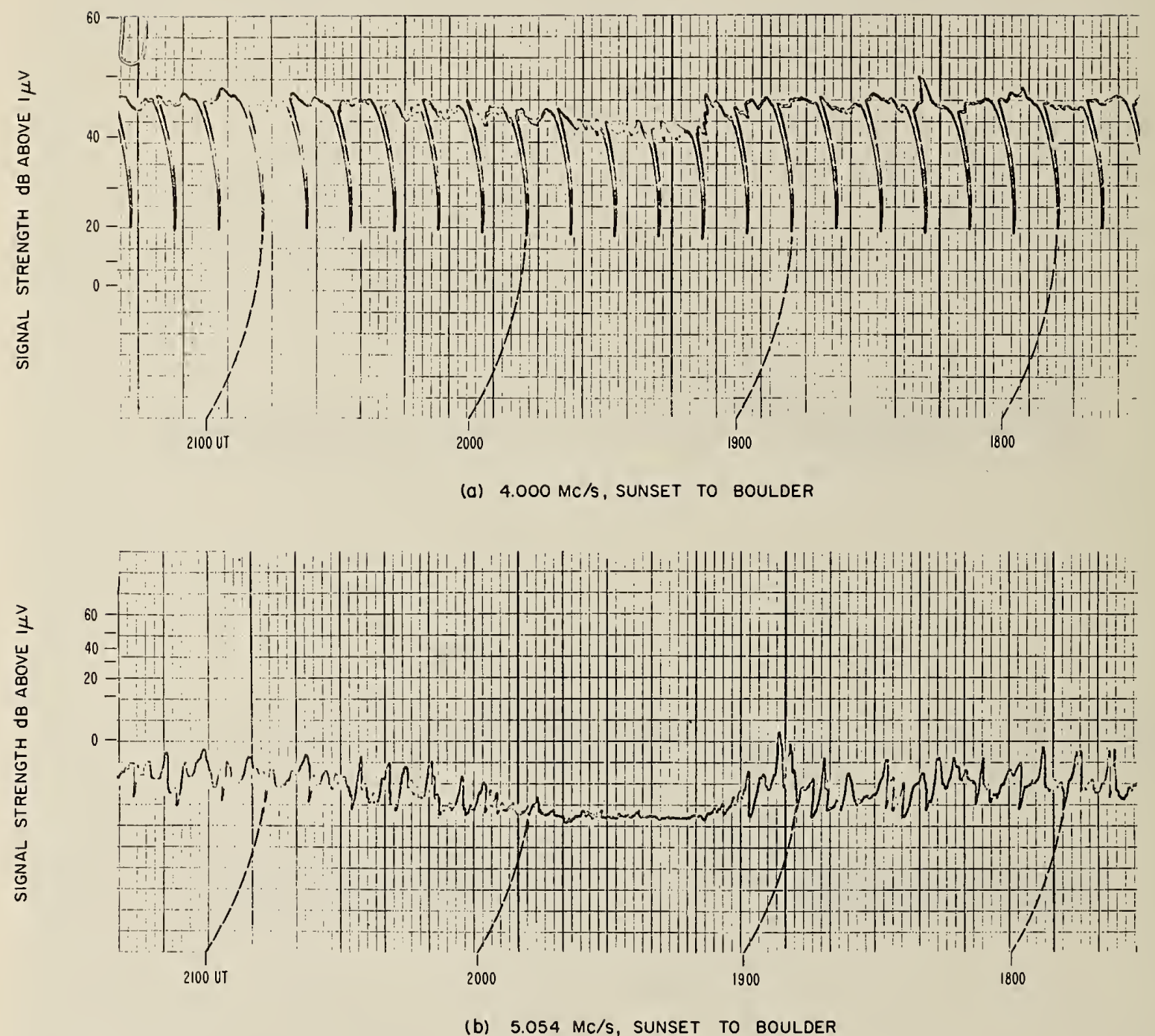

14 APRIL 1962 
OPTICAL FLARE, IMPORTANCE 1, I9IOE-1924-2005

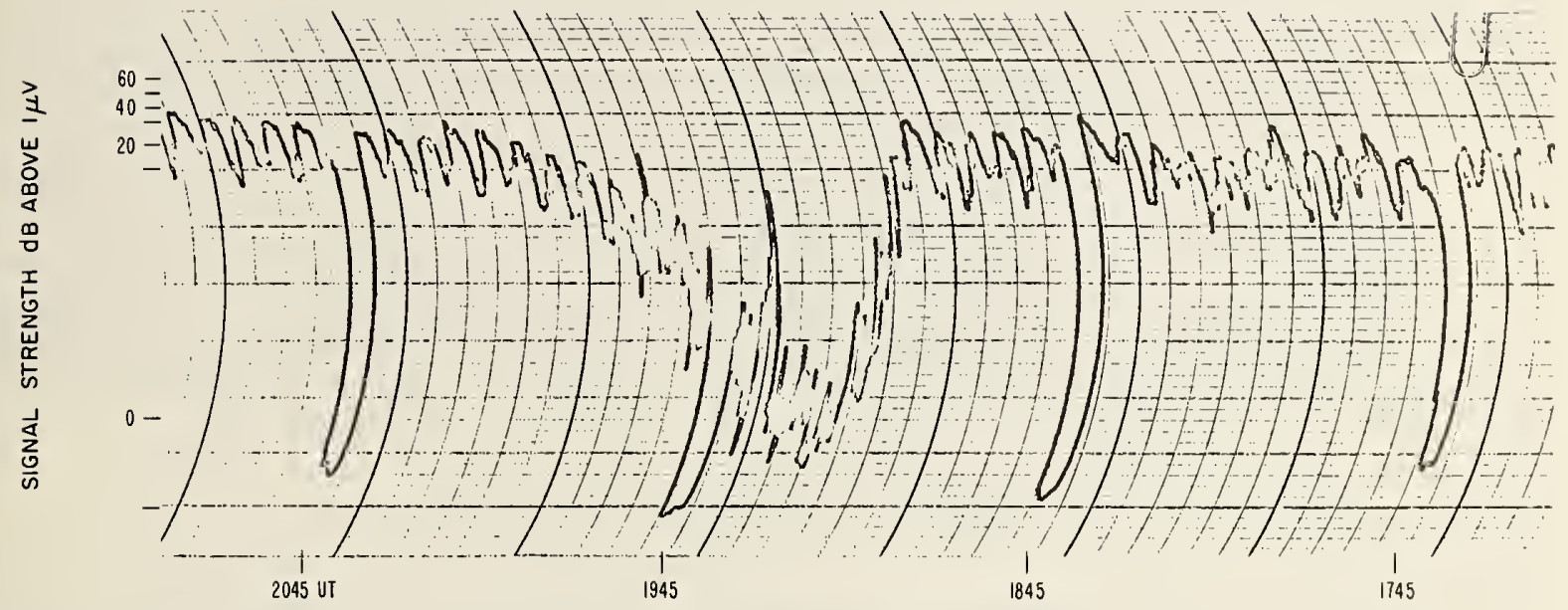

(c) $10 \mathrm{mc} / \mathrm{s}$, WWV TO BOULDER

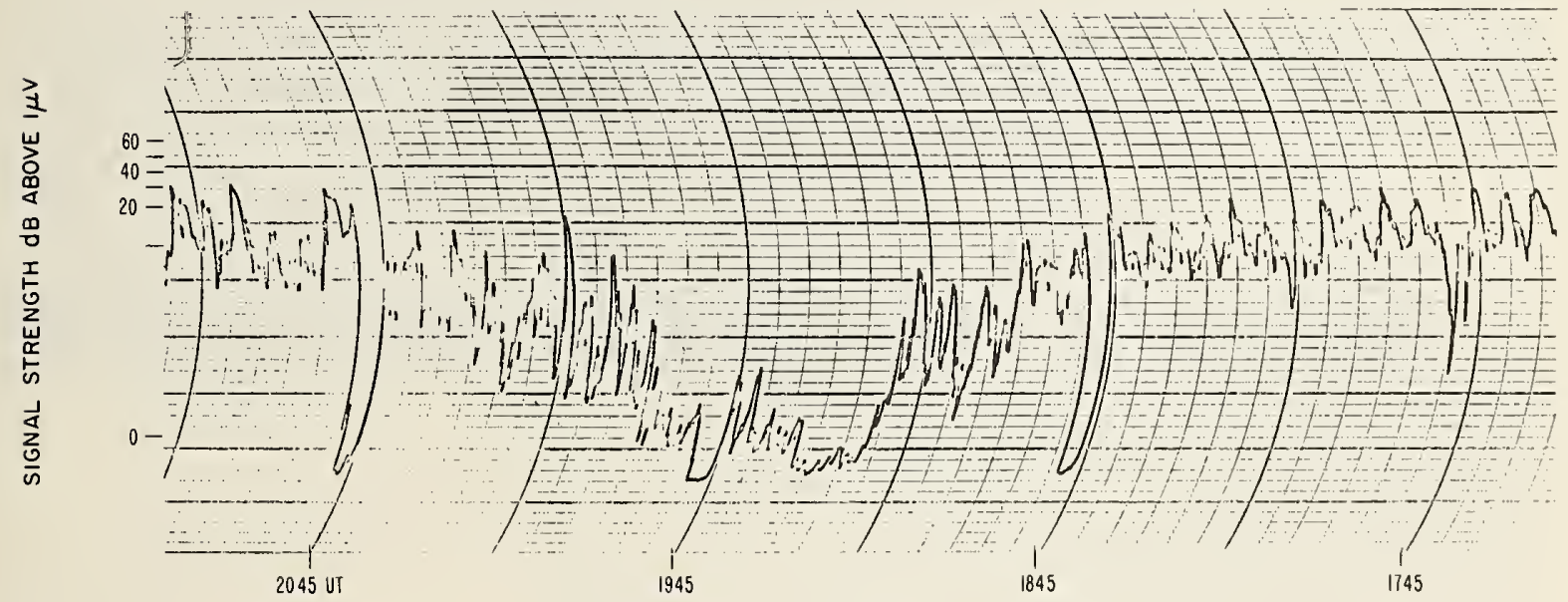

(d) $15 \mathrm{Mc} / \mathrm{s}$, WWV TO BOULDER

14 APRIL 1962 
OPTICAL FLARE, IMPORTANCE I-, 2051-2053-2058

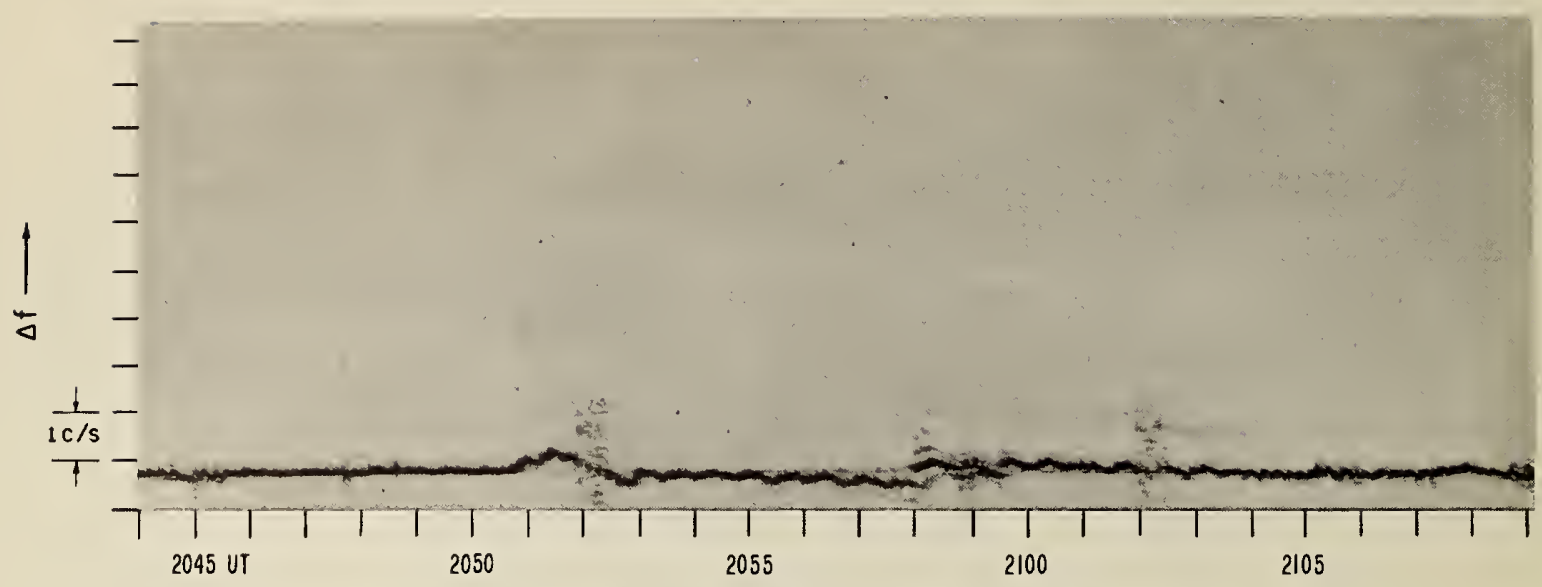

(a) $4.000 \mathrm{mc} / \mathrm{s}$, SUNSET TO BOULDER

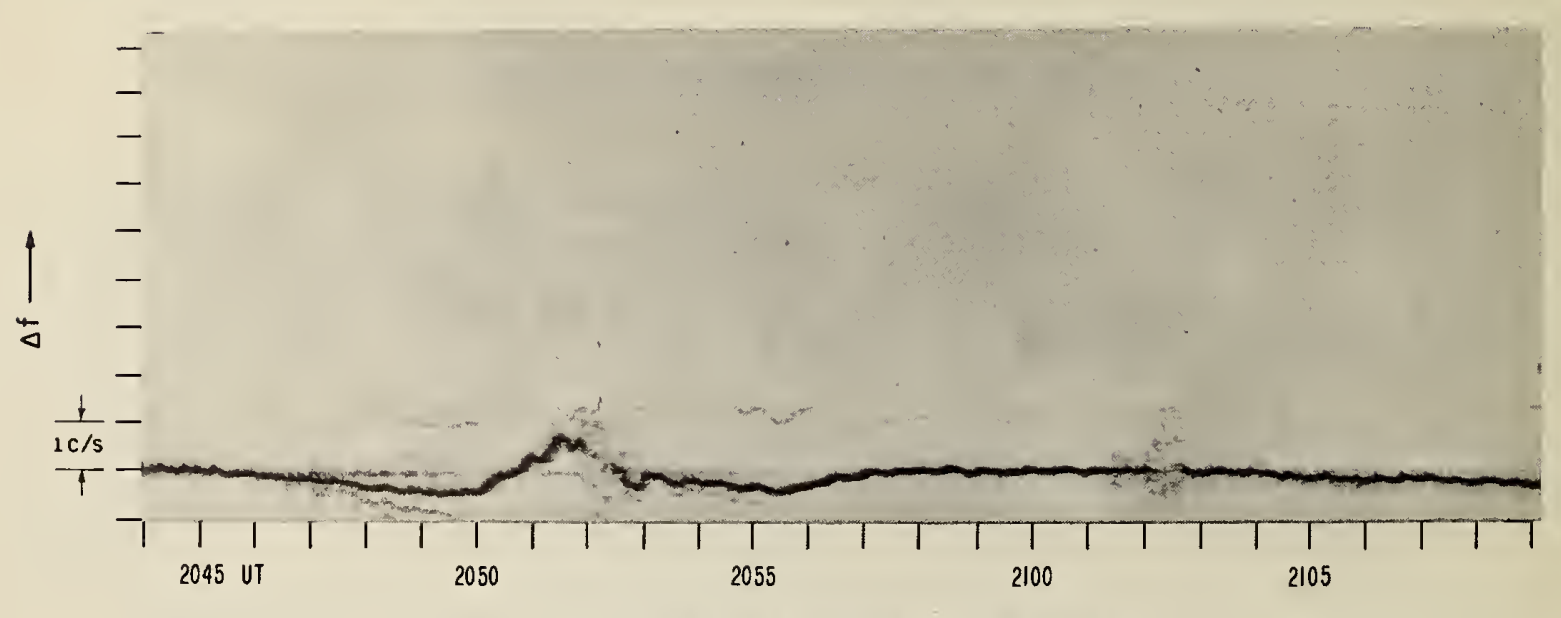

(b) $5.054 \mathrm{Mc} / \mathrm{s}$, SUNSET TO BOULDER

15 APRIL 1962

Figure 51 
OPTICAL FLARE, IMPORTANCE 1-, $2051-2053-2058$

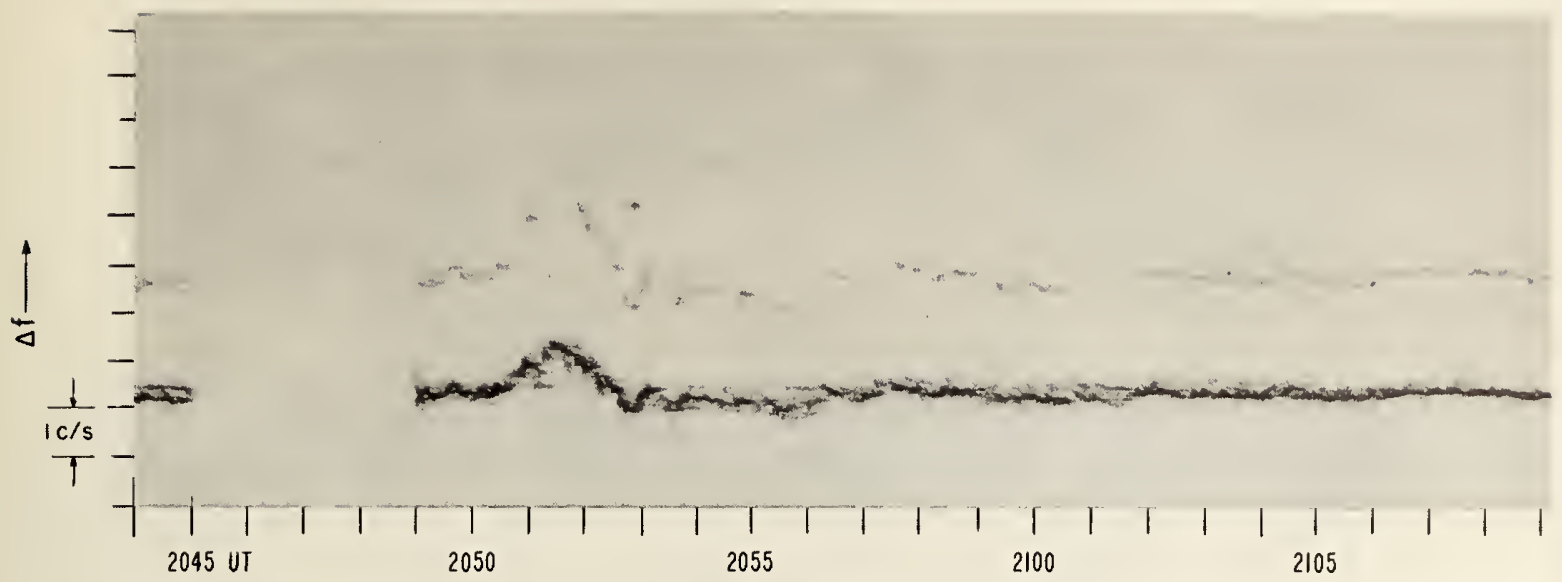

(c) $10 \mathrm{Mc} / \mathrm{s}$, WWV TO SHICKLEY

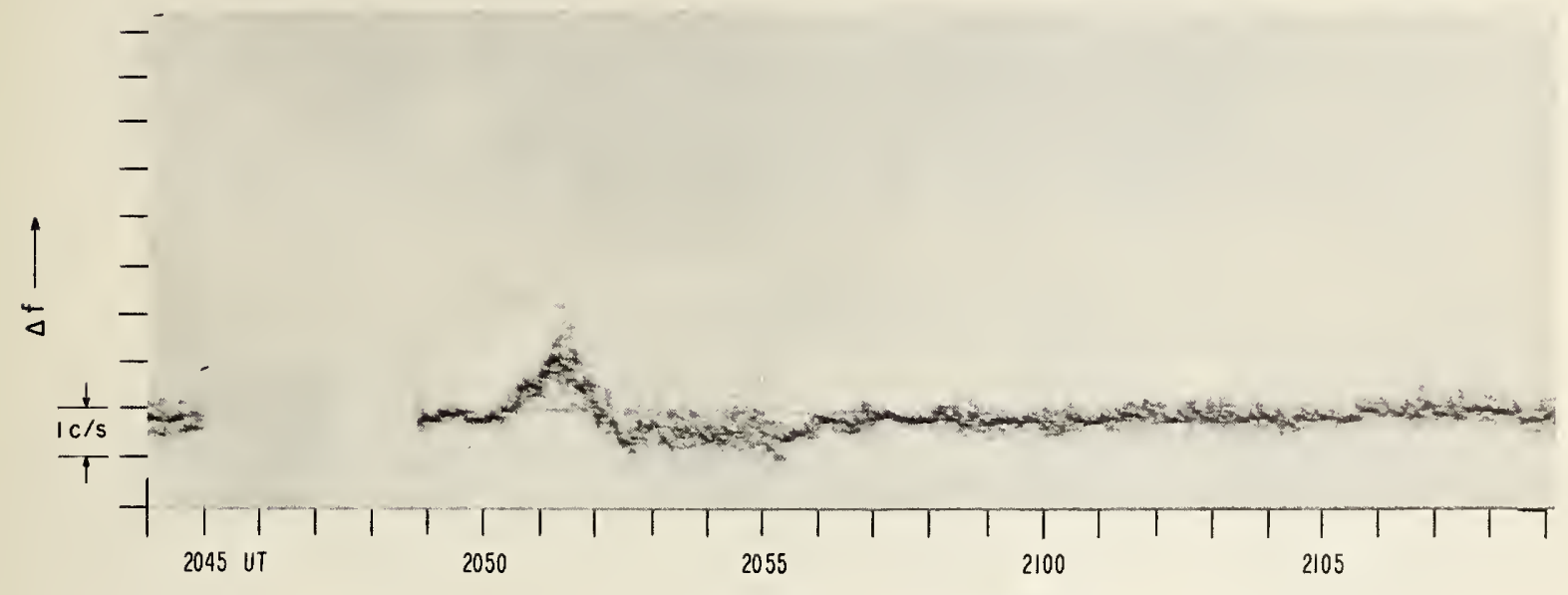

(d) $10 \mathrm{Mc} / \mathrm{s}$, WWV TO BOULDER

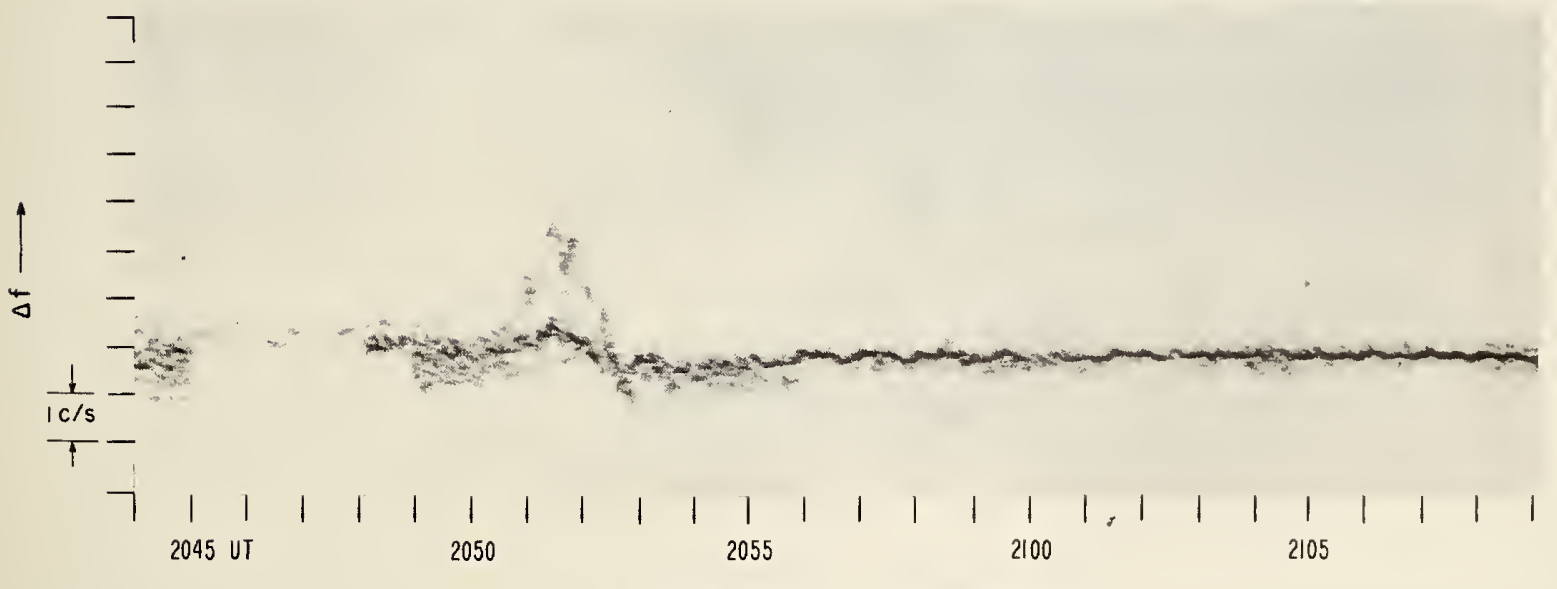

(e) $15 \mathrm{MC} / \mathrm{s}$ WWV TO BOULDER 

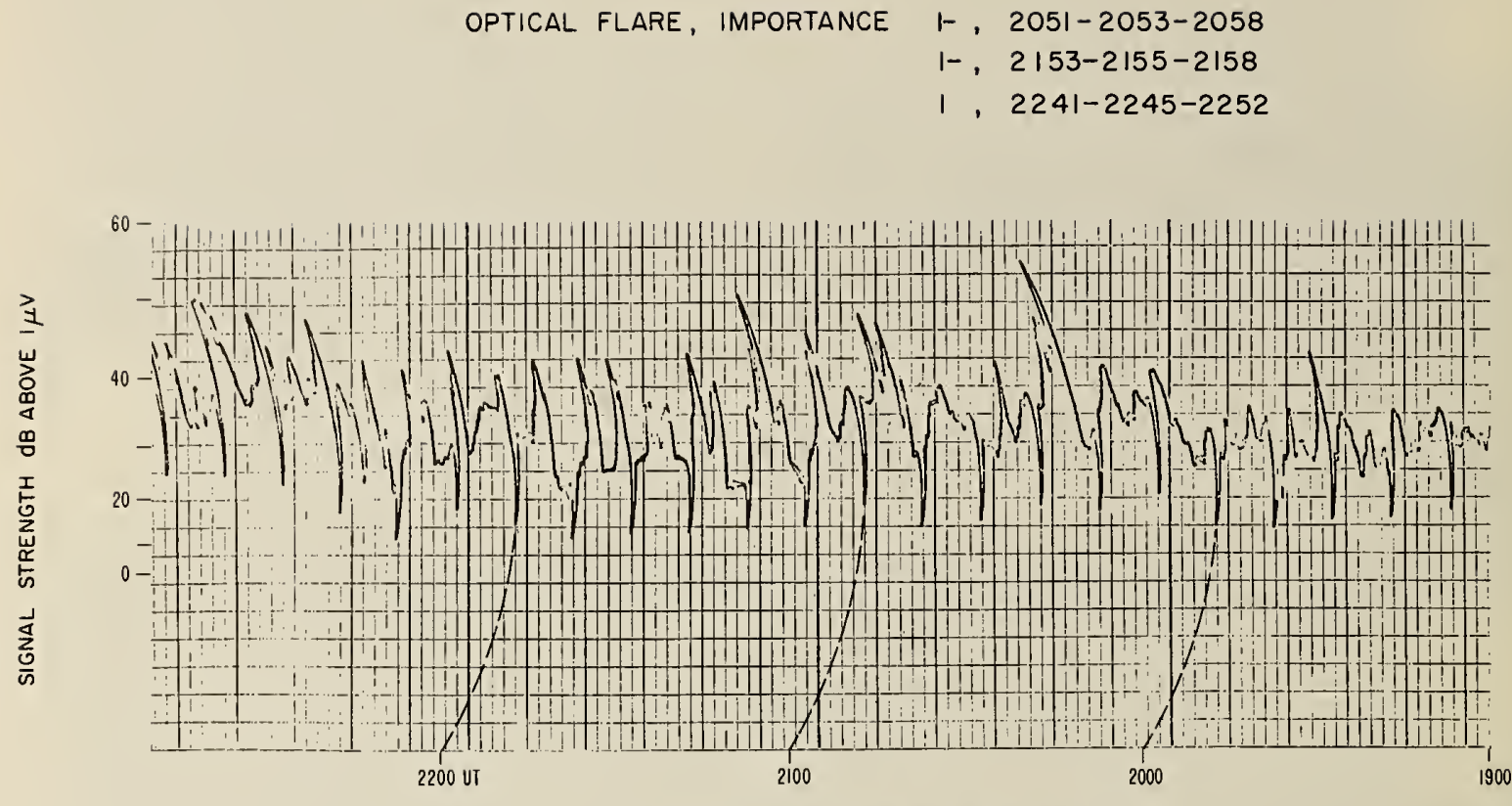

(a) $4.000 \mathrm{mc} / \mathrm{s}$, SUNSET TO BOULDER

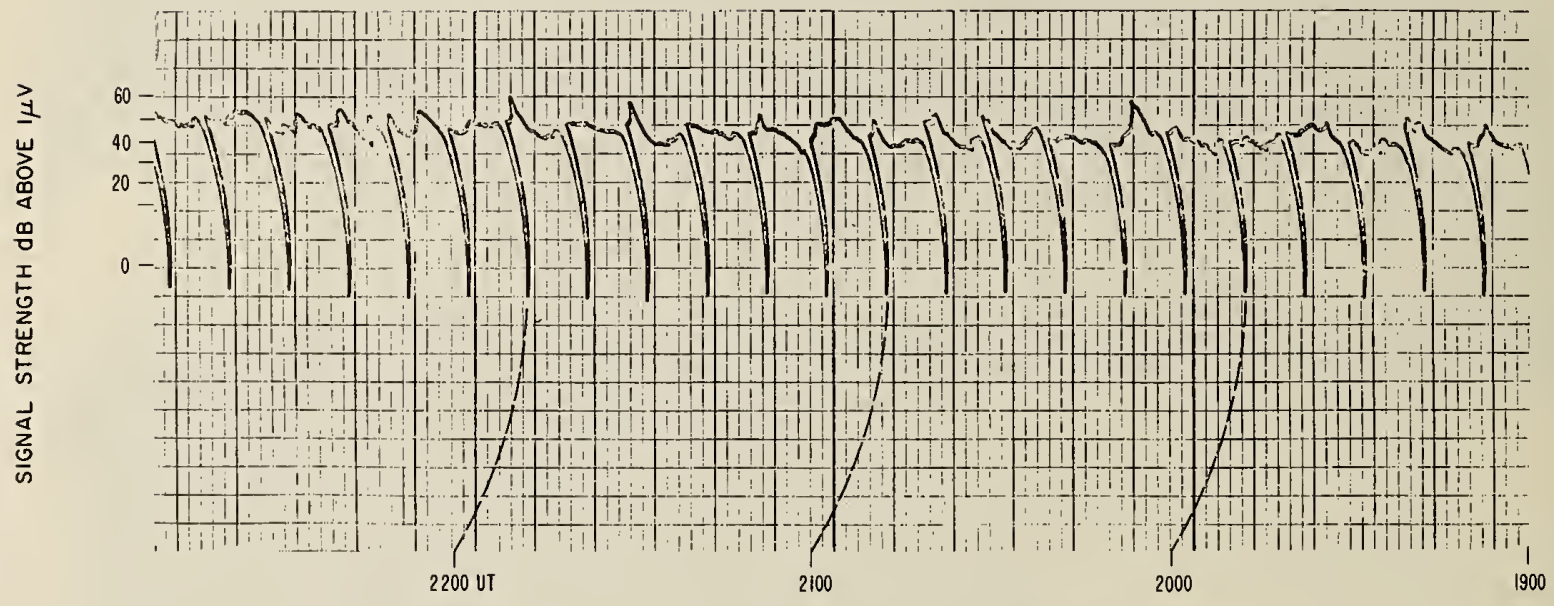

(b) $5.054 \mathrm{mc} / \mathrm{s}$, SUNSET TO BOULDER

15 APRIL 1962 
OPTICAL FLARE, IMPORTANCE 1- , 2051-2053-2058

$1-, 2153-2155-2158$

$1,2241-2245-2252$

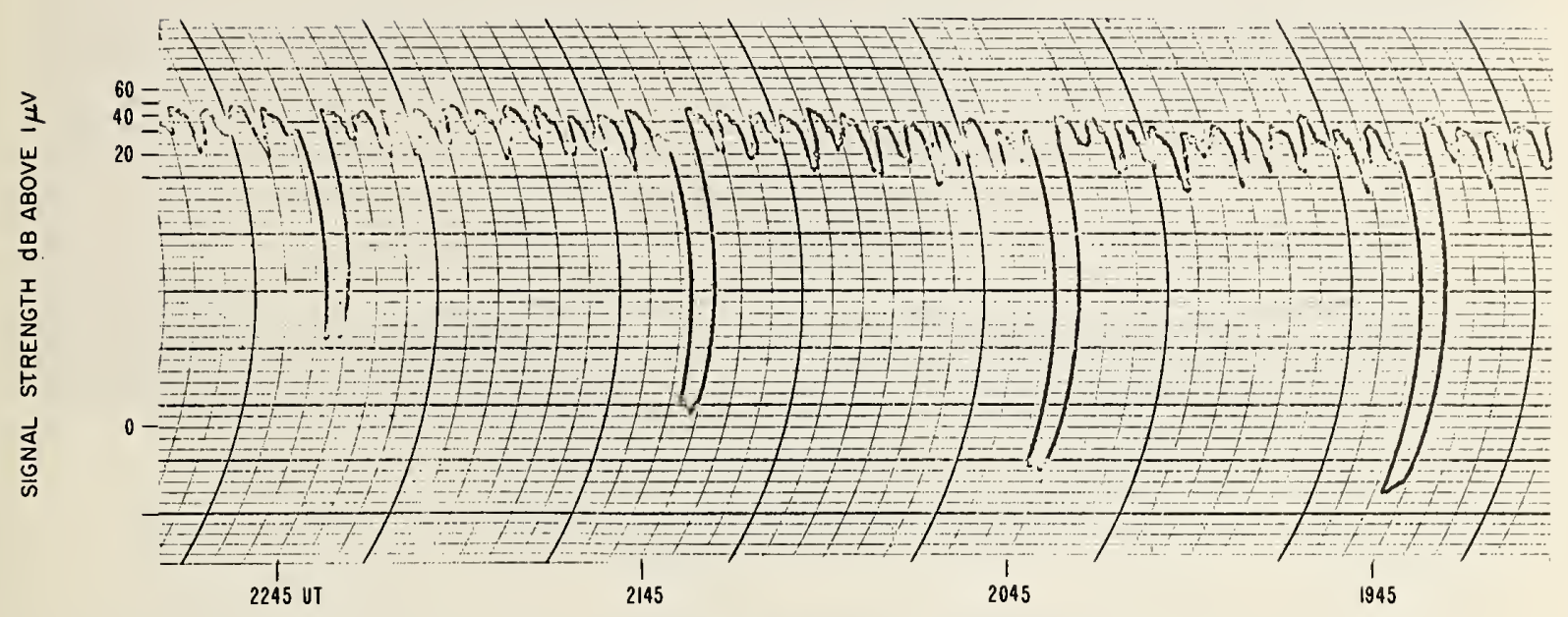

(c) $10 \mathrm{mc} / \mathrm{s}$, WWV TO BOULDER

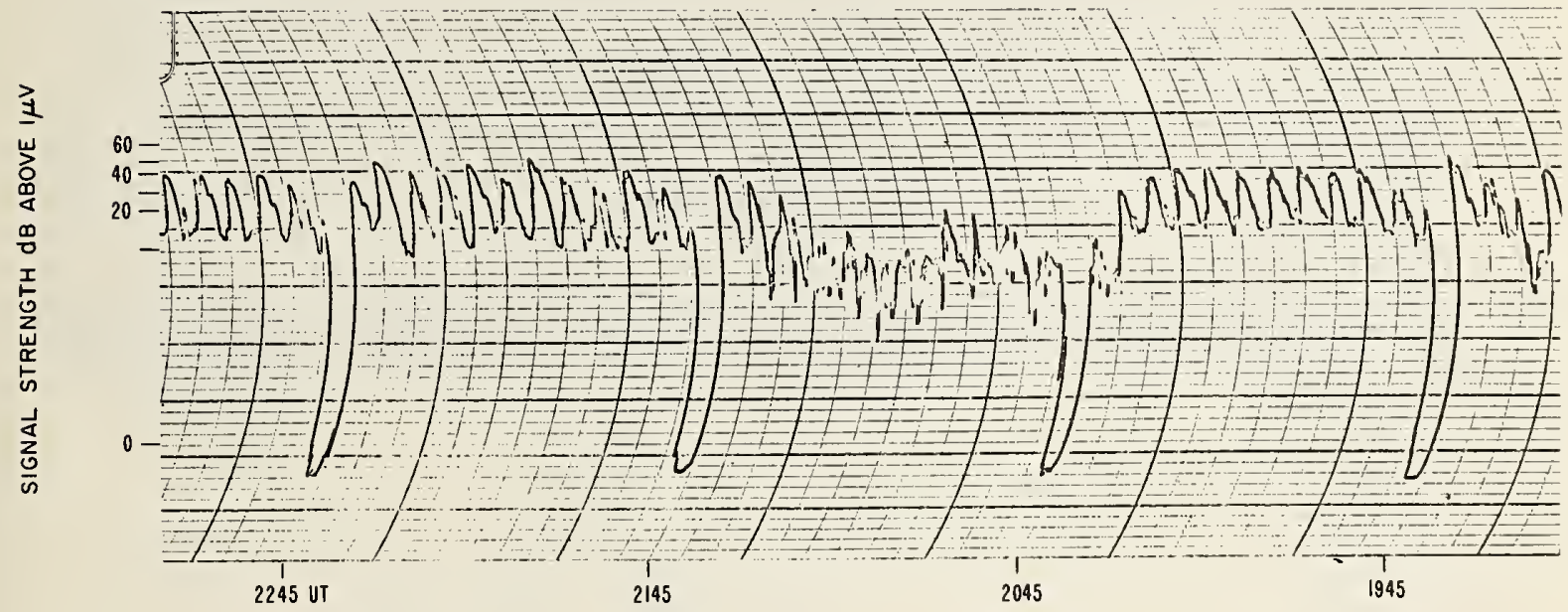

(d) $15 \mathrm{Mc} / \mathrm{s}$, WWV TO BOULDER

15 APRIL 1962

Figure 52 
OPTICAL FLARE, IMPORTANCE I-, 2252-2256-2313

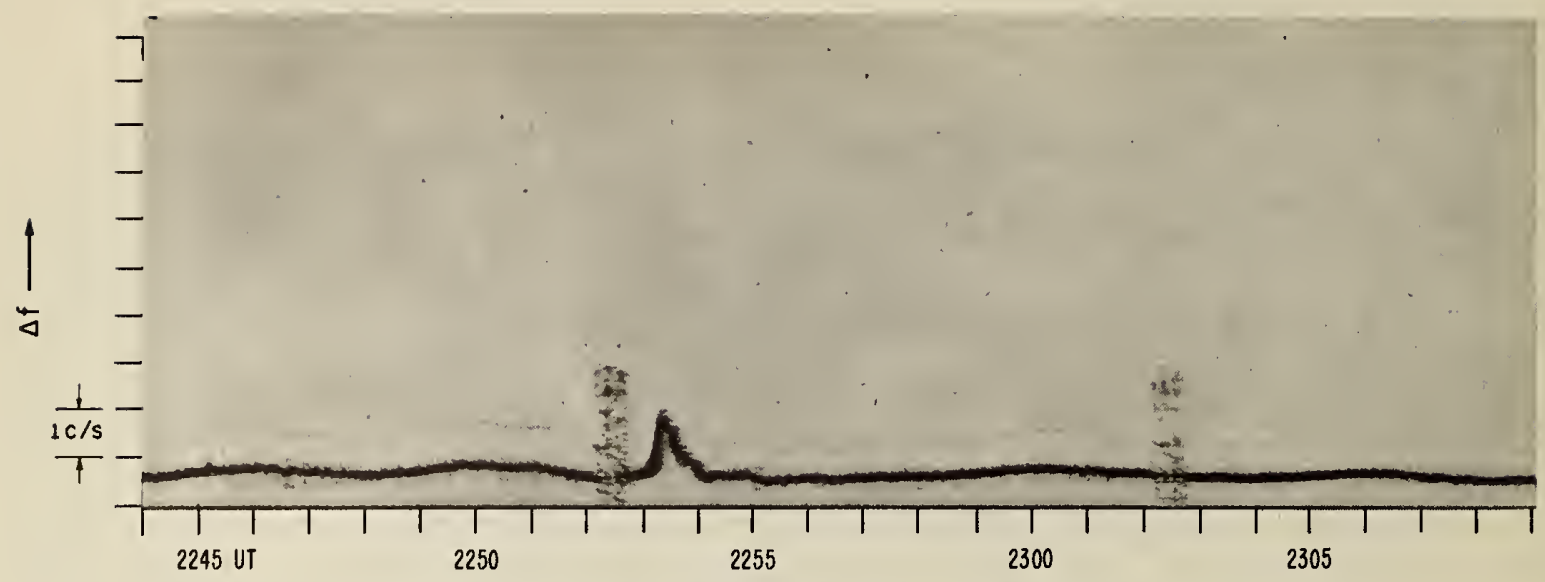

(a) $4.000 \mathrm{mc} / \mathrm{s}$, SUNSET TO BOULDER

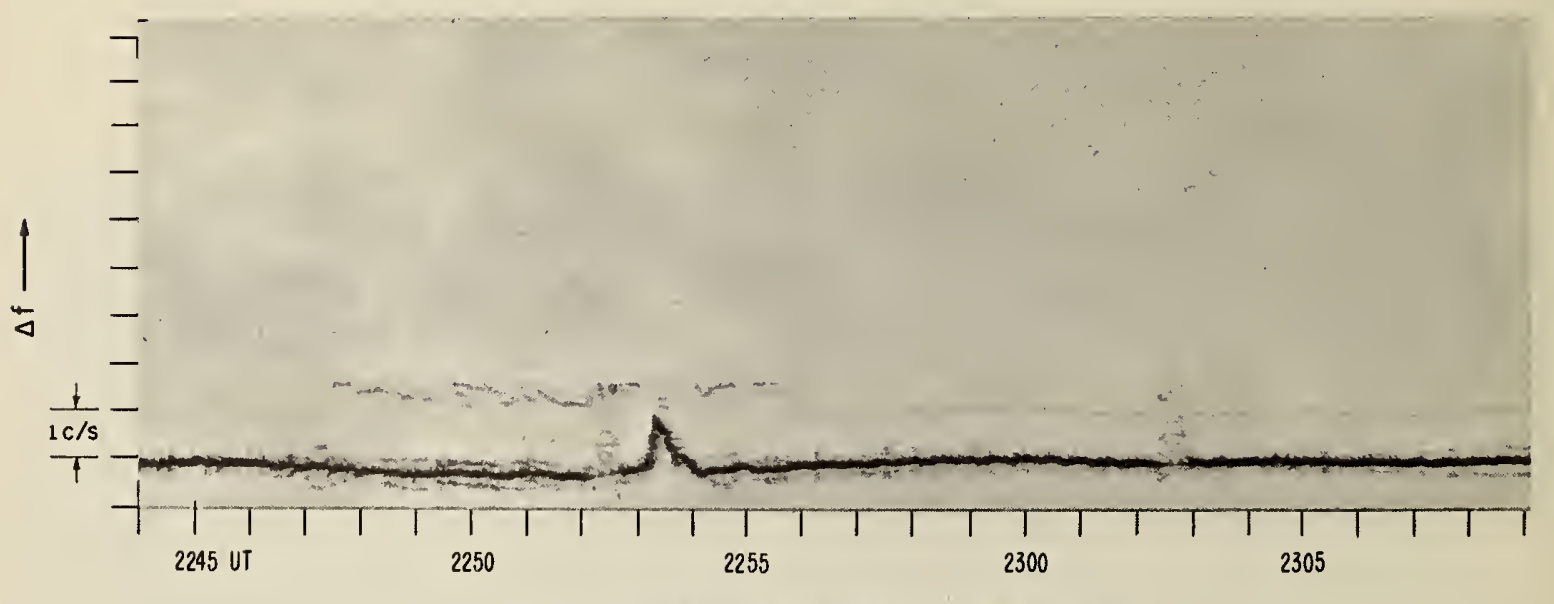

(b) $5.054 \mathrm{Mc} / \mathrm{s}$, SUNSET TO BOULDER

17 APRIL 1962

Figure 53 
OPTICAL FLARE, IMPORTANCE $1-, 2252-2256-2313$

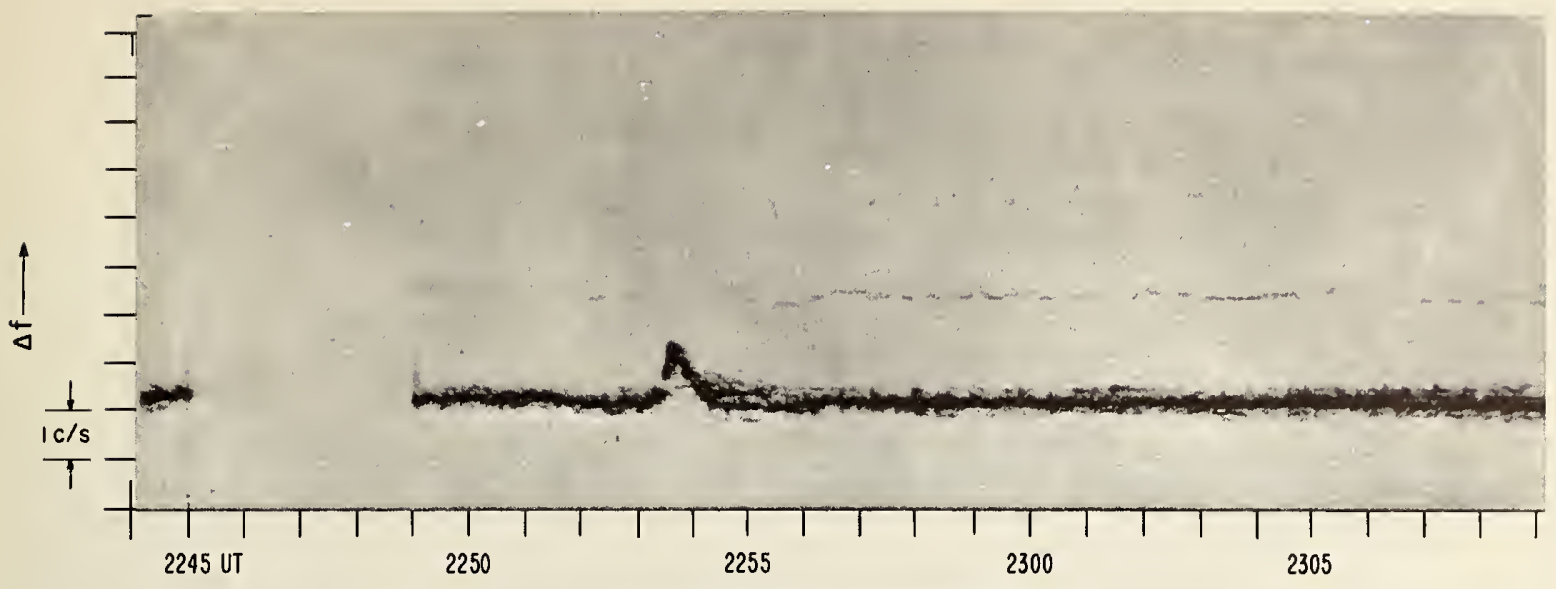

(c) $10 \mathrm{Mc} / \mathrm{s}$, WWV TO SHICKLEY

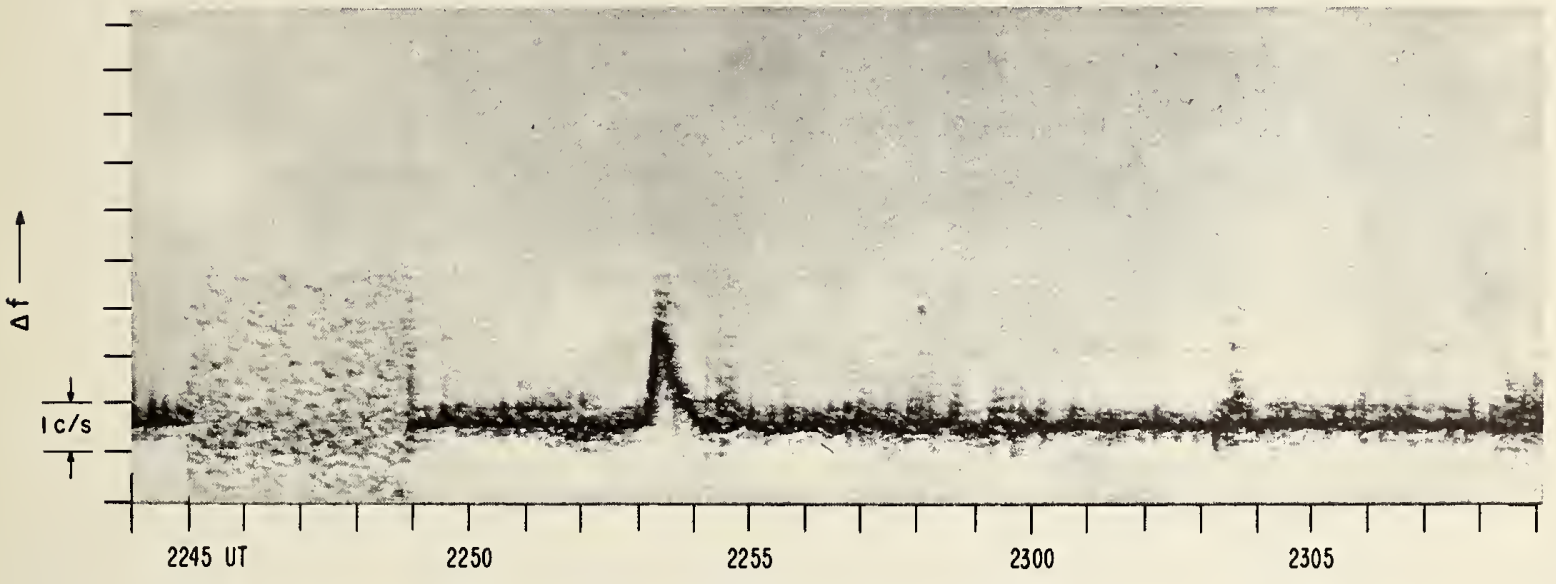

(d) $10 \mathrm{MC} / \mathrm{s}$, WWV TO BOULDER

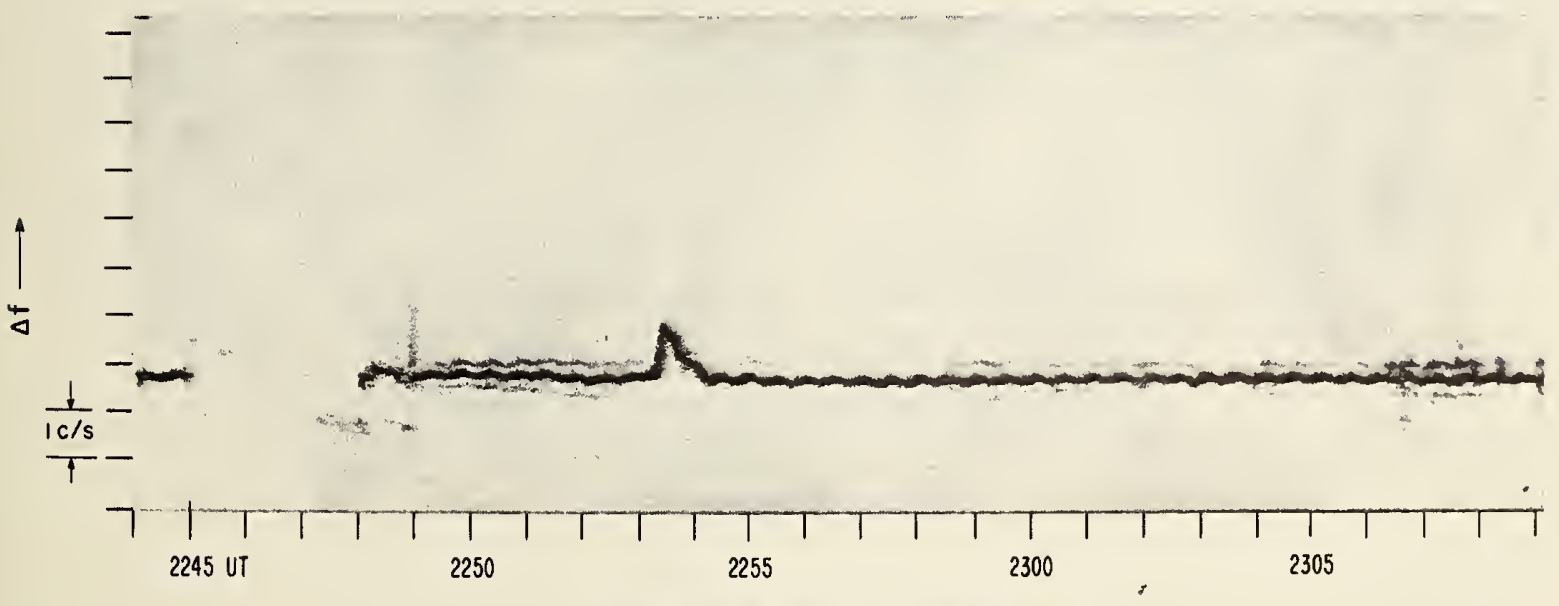

(e) $15 \mathrm{MC} / \mathrm{s}$ WWV TO BOULDER 
OPTICAL FLARE, IMPORTANCE I-, 2252-2256-2313
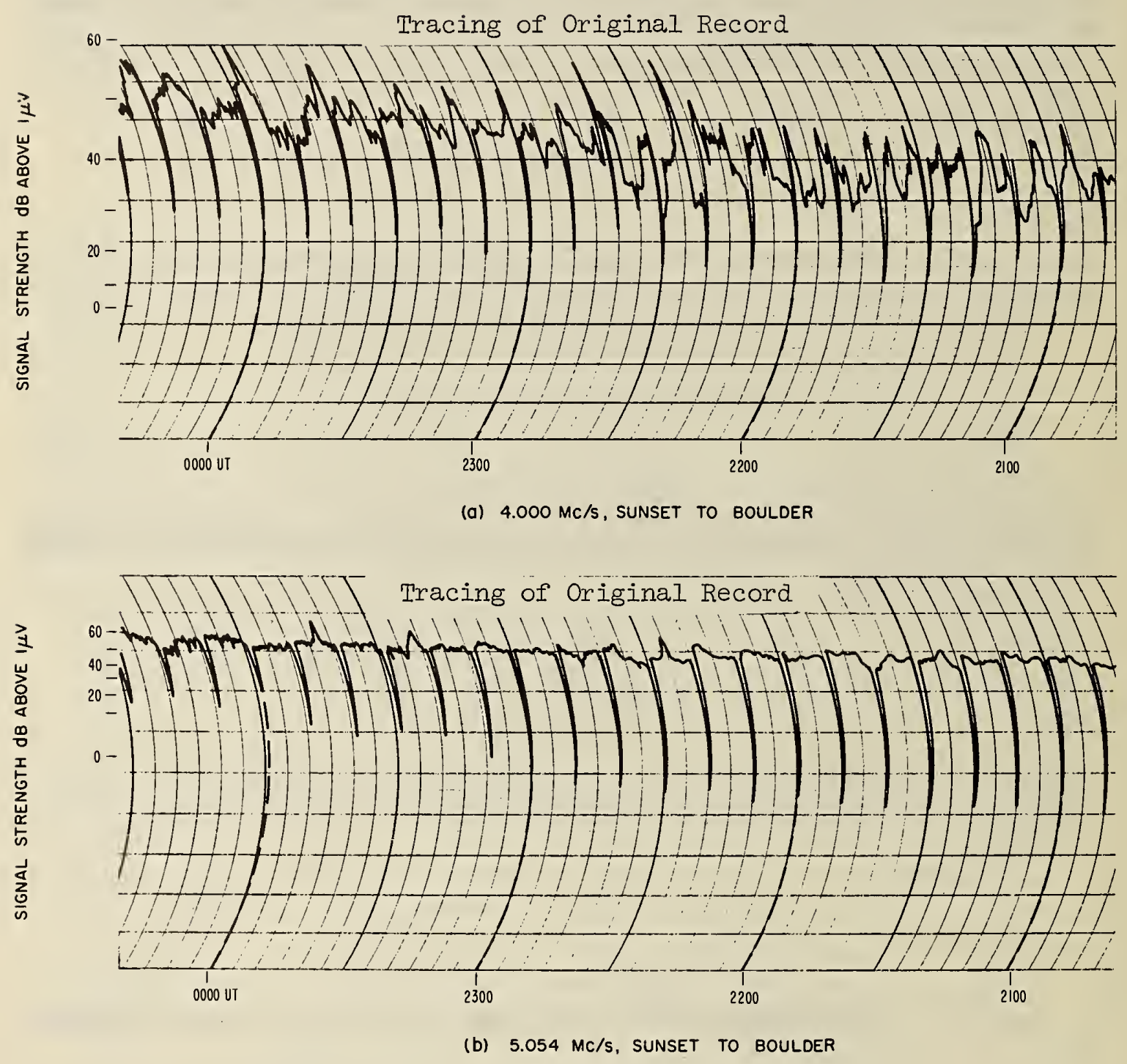

17 APRIL 1962 
OPTICAL FLARE, IMPORTANCE 1-, 2252-2256-2313

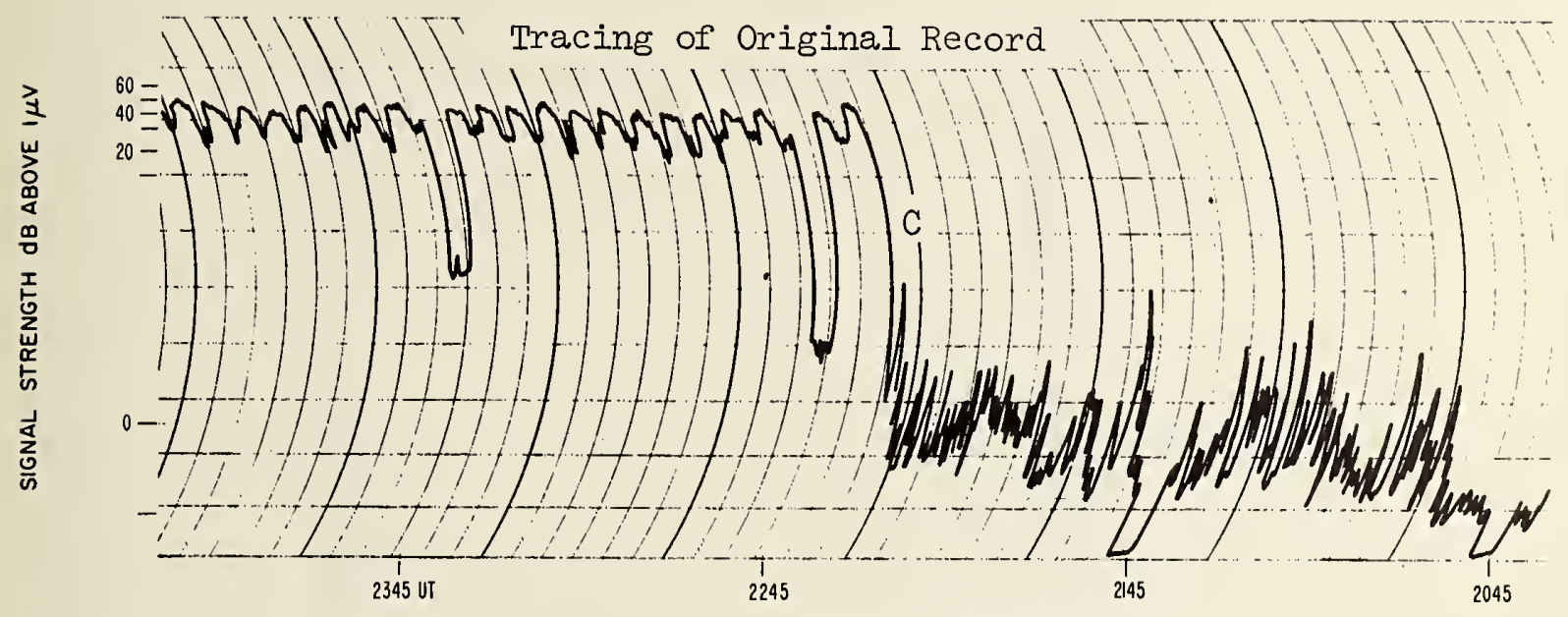

(c) $10 \mathrm{Mc} / \mathrm{s}$, WWV TO BOULDER

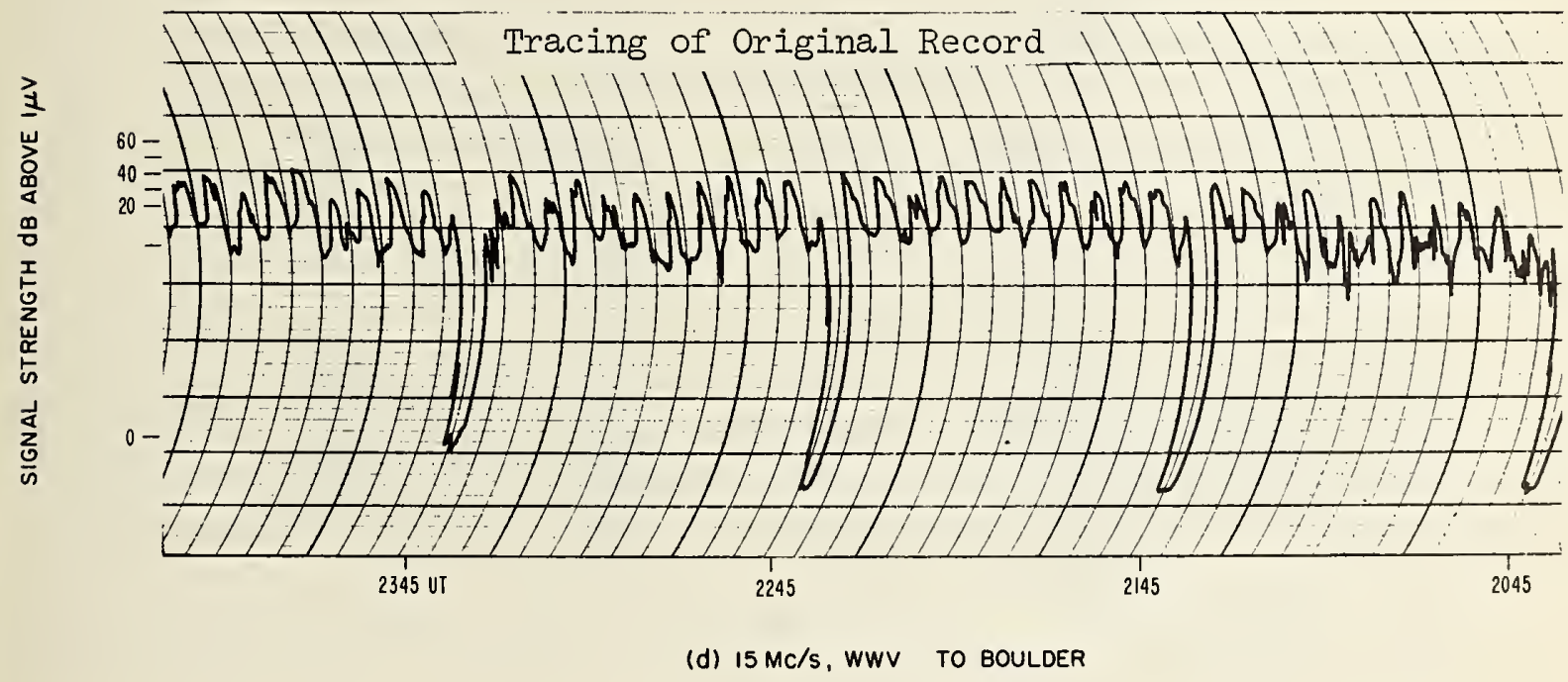

17 APRIL 1962

Figure 54 

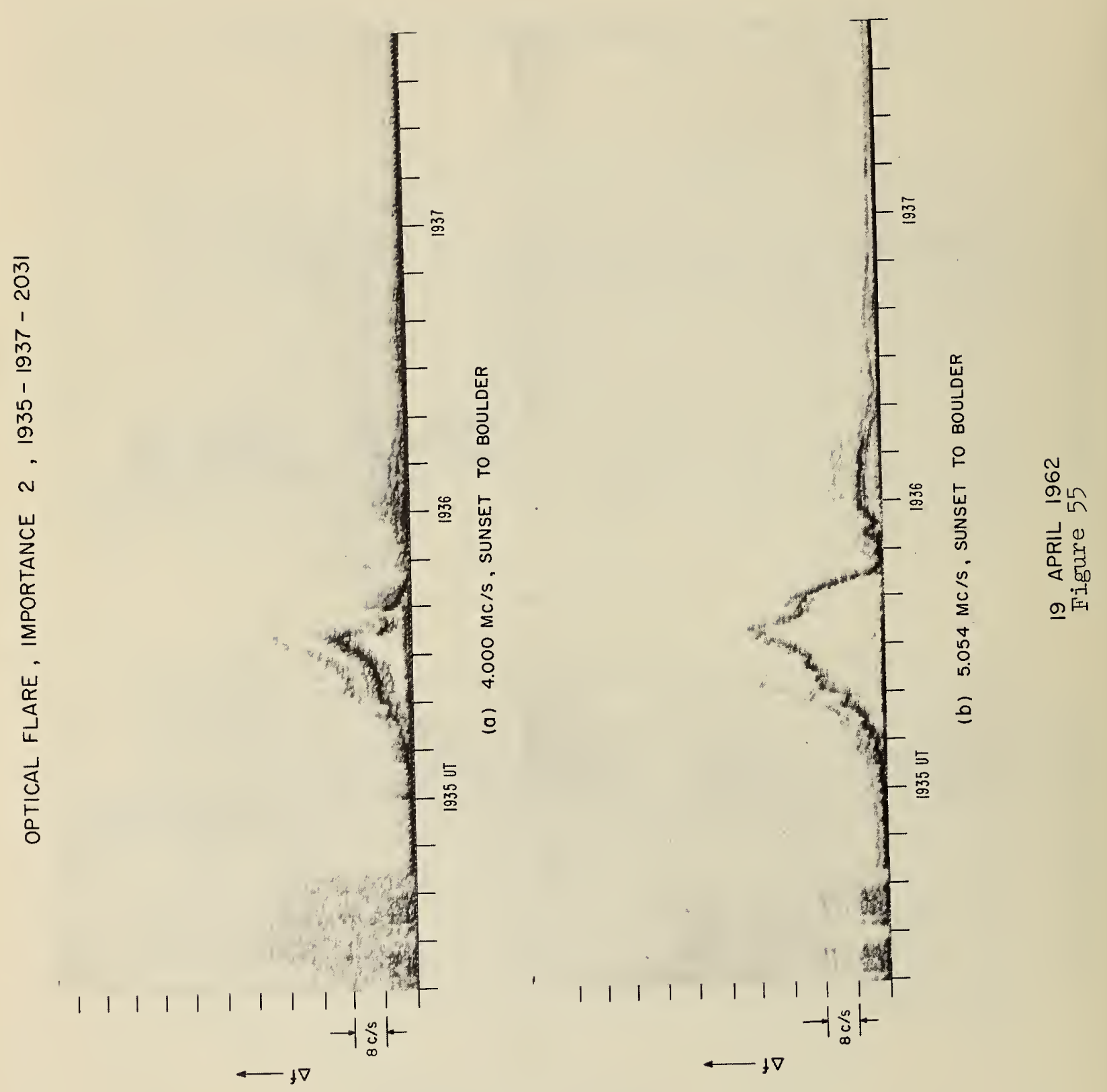


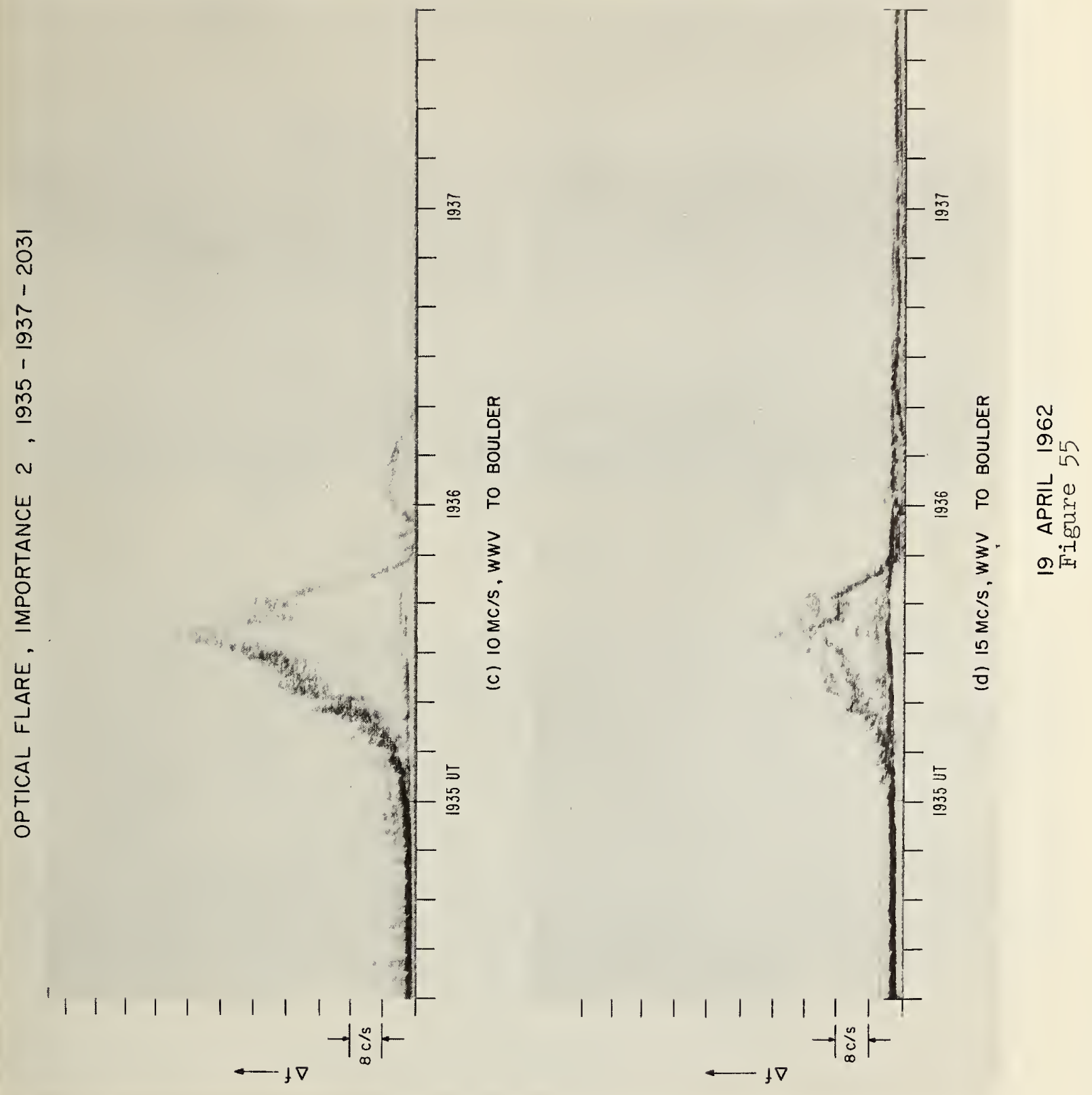


OPTICAL FLARE, IMPORTANCE 2 , 1935-1937-2031

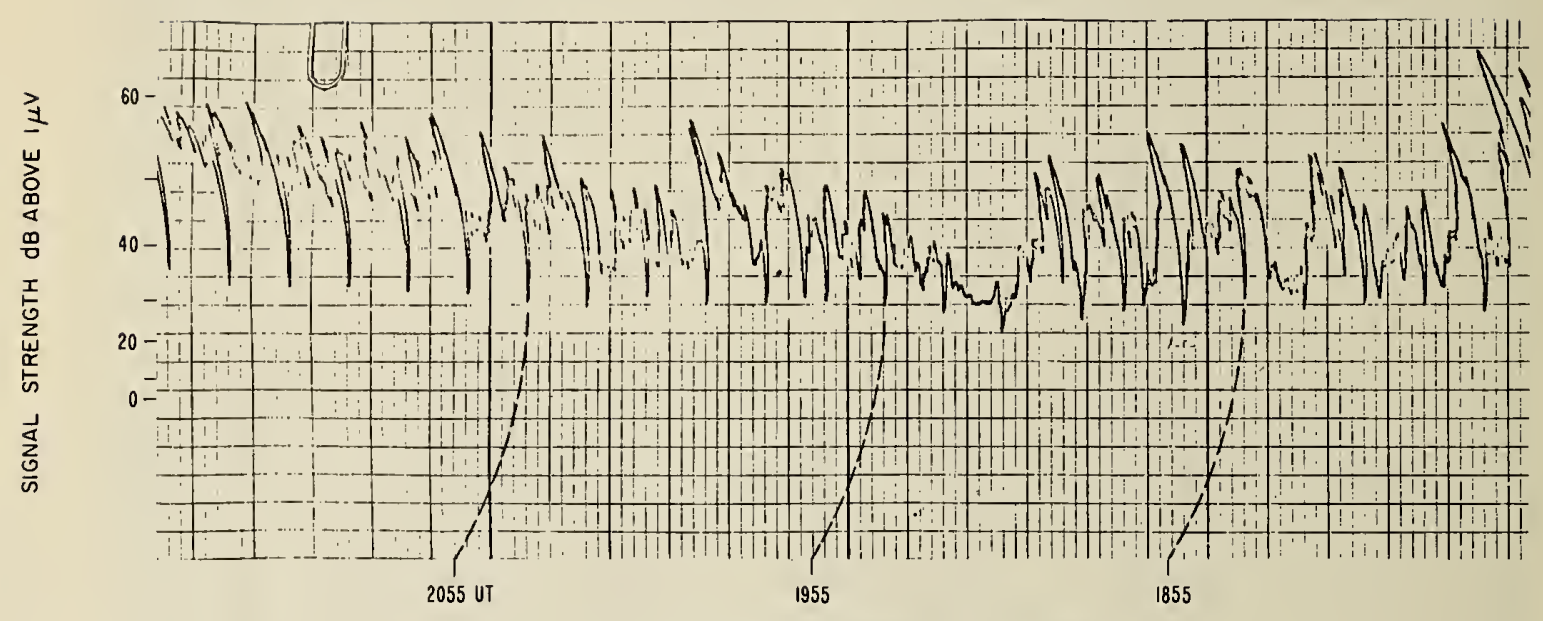

(a) $4.000 \mathrm{mc} / \mathrm{s}$, SUNSET TO BOULDER

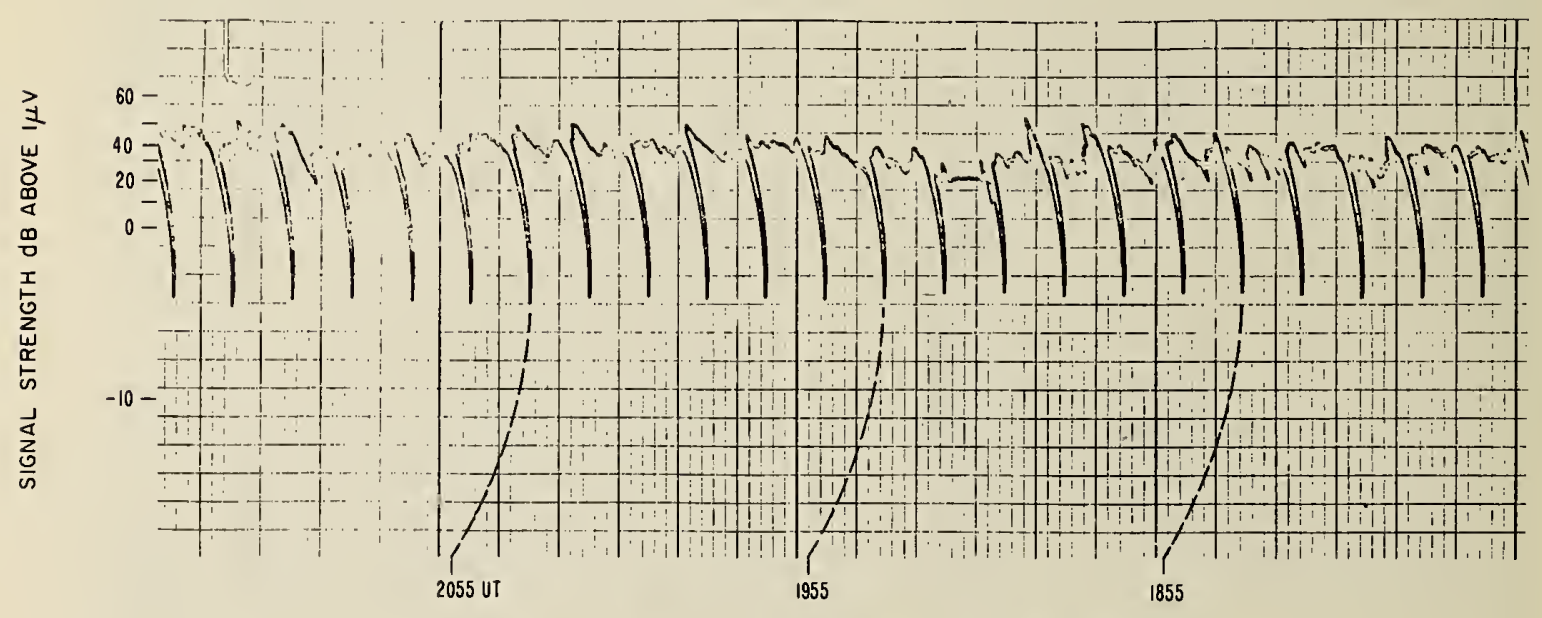

(b) $5.054 \mathrm{MC} / \mathrm{s}$, SUNSET TO BOULDER

19 APRIL 1962 
OPTICAL FLARE, IMPORTANCE 2, 1935-1937-2031

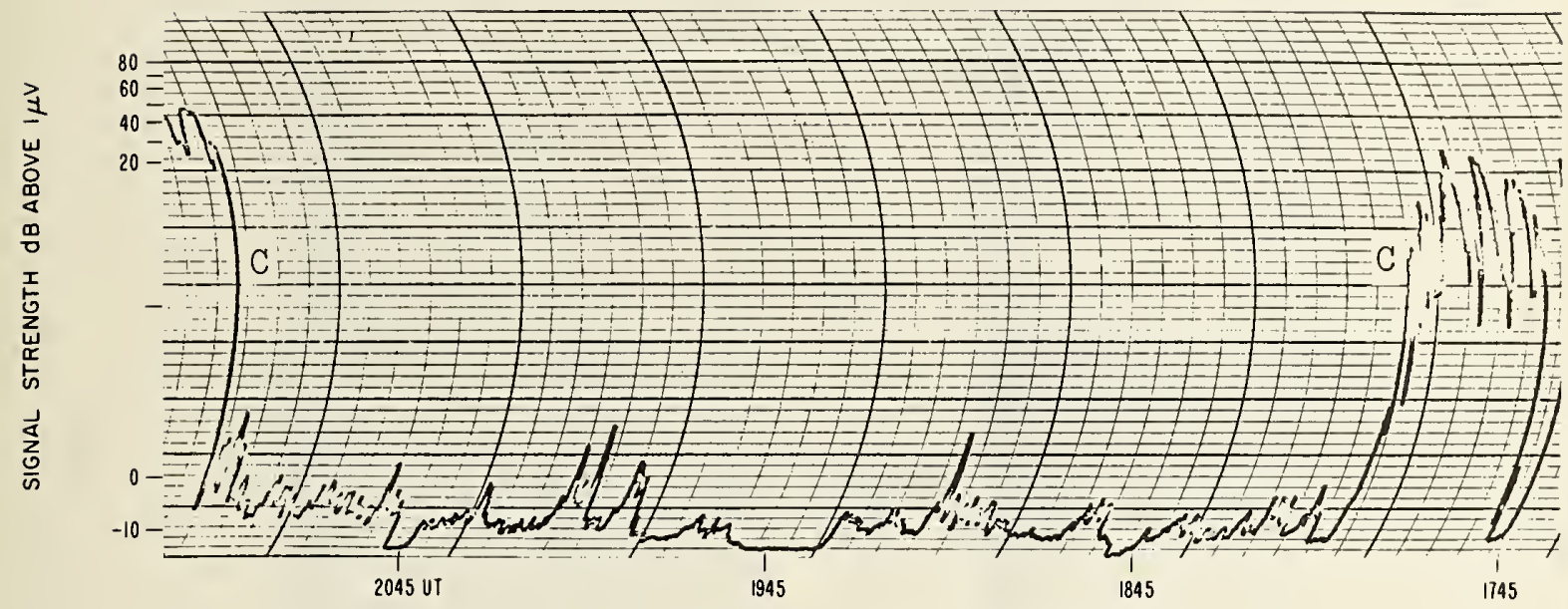

(c) $10 \mathrm{mc} / \mathrm{s}$, WWV TO BOULDER

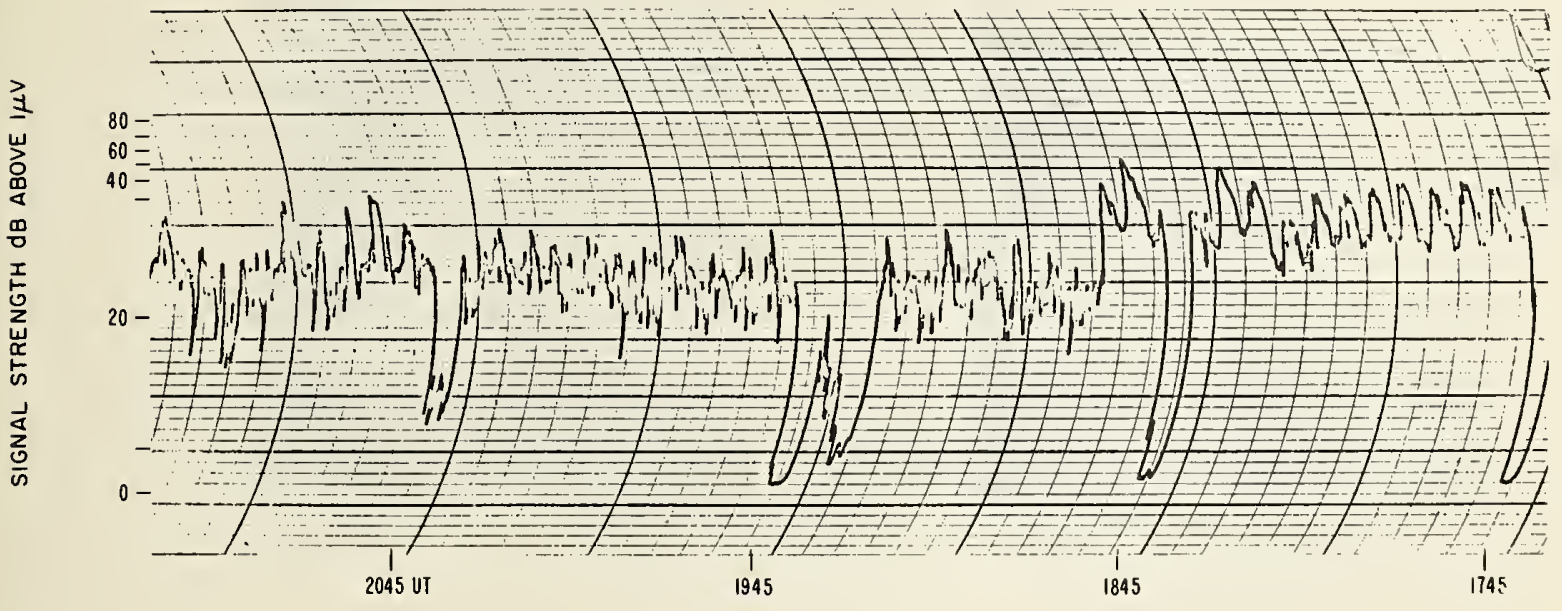

(d) $15 \mathrm{mc} / \mathrm{s}$, WWV TO BOULDER

19 APRIL 1962 

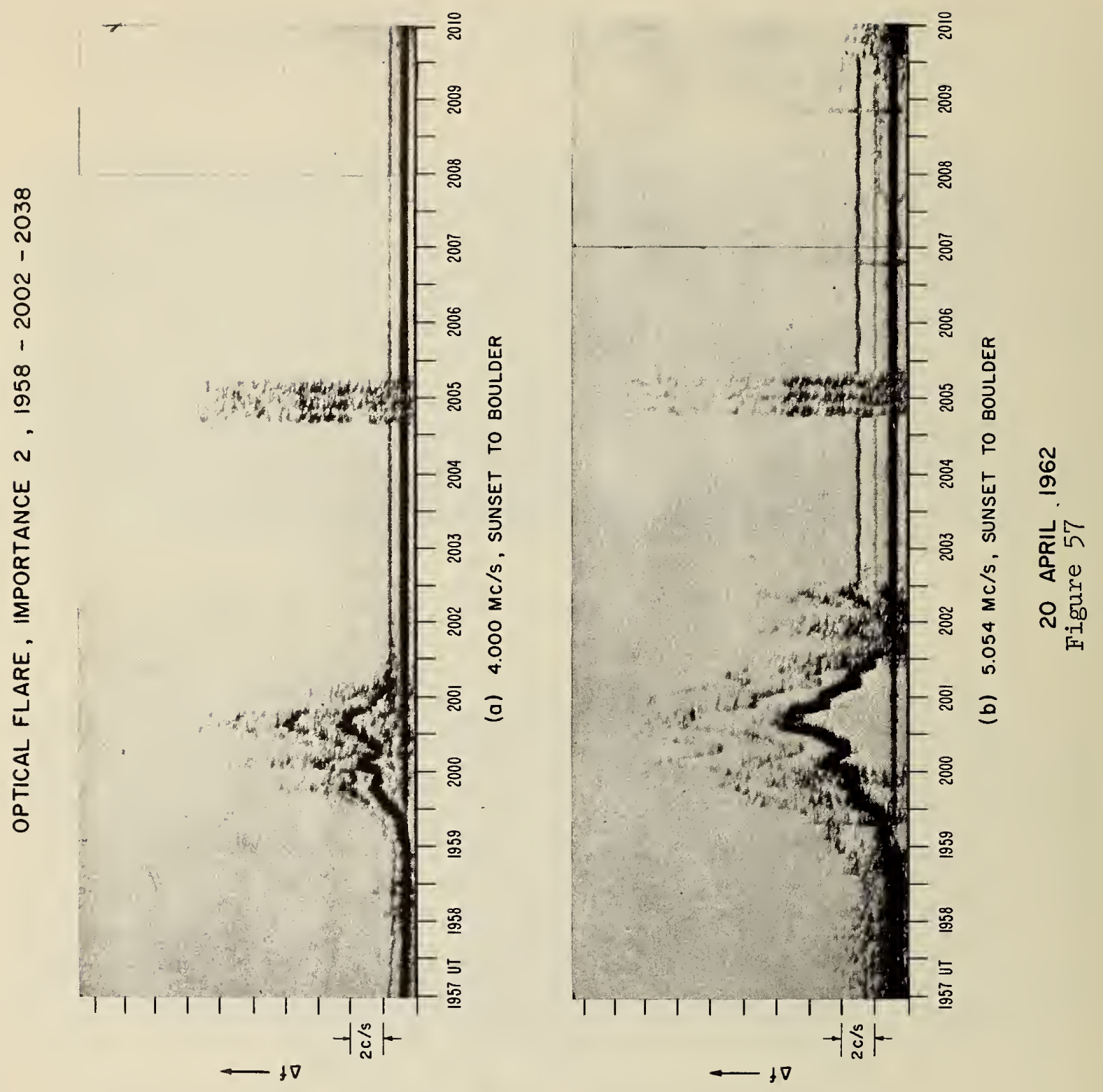

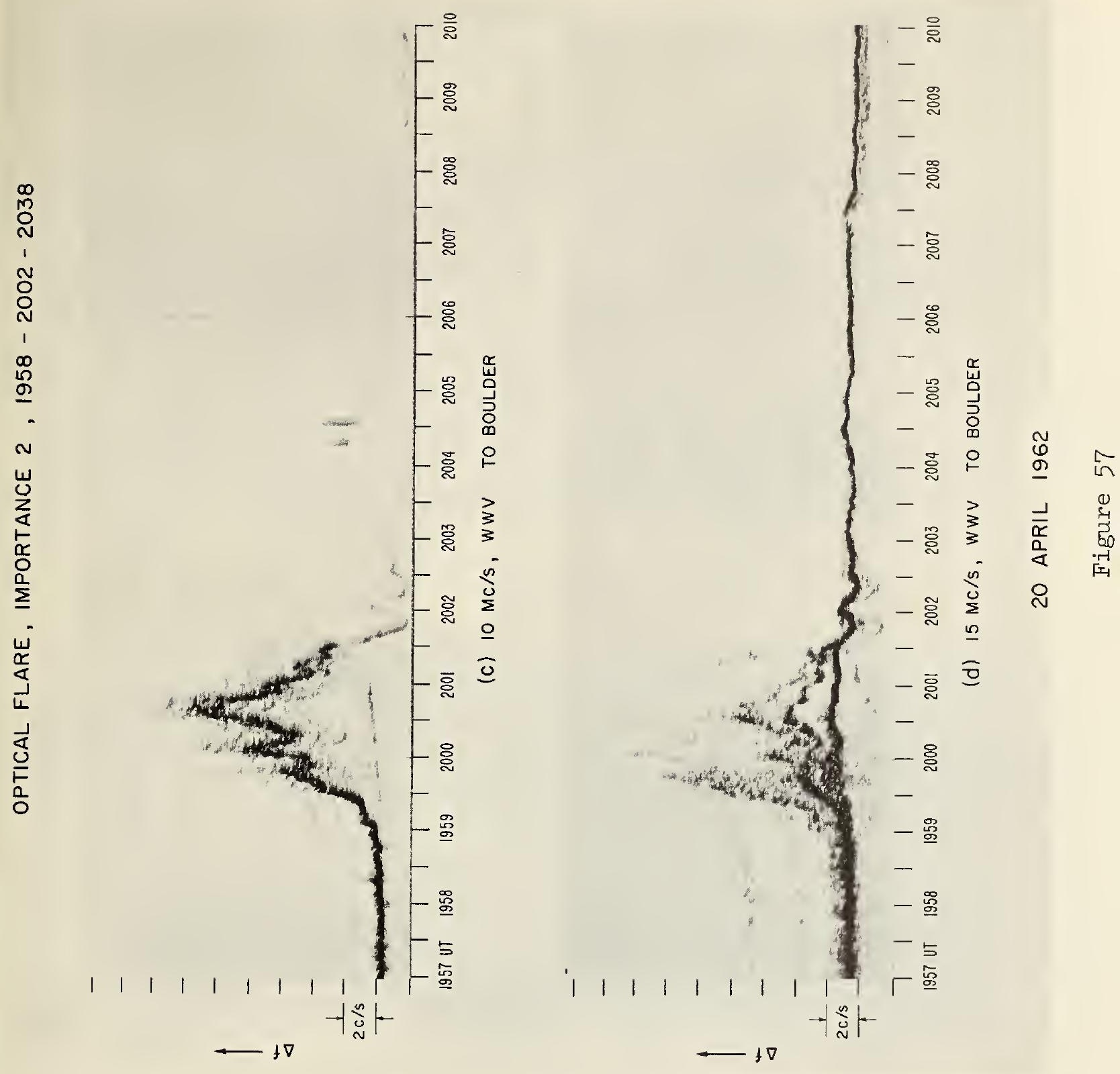
OPTICAL FLARE, IMPORTANCE $2,1958-2002-2038$

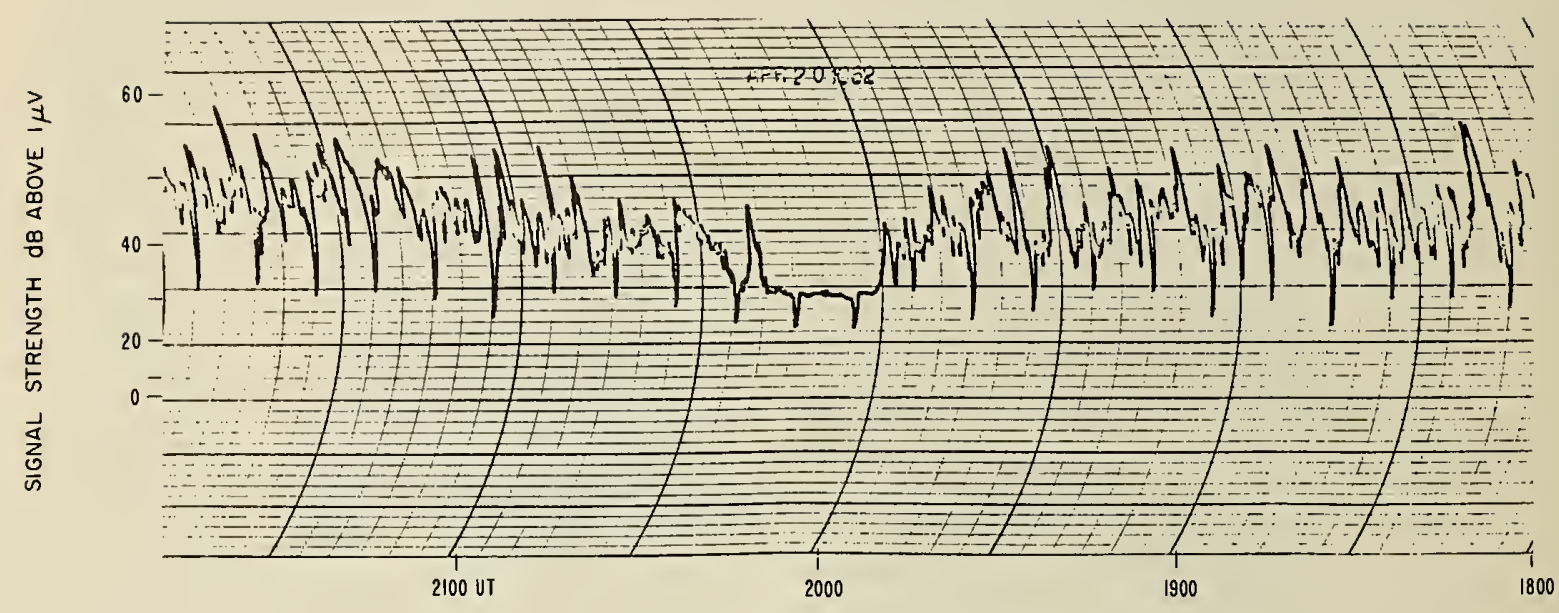

(a) $4.000 \mathrm{mC} / \mathrm{s}$, SUNSET TO BOULDER

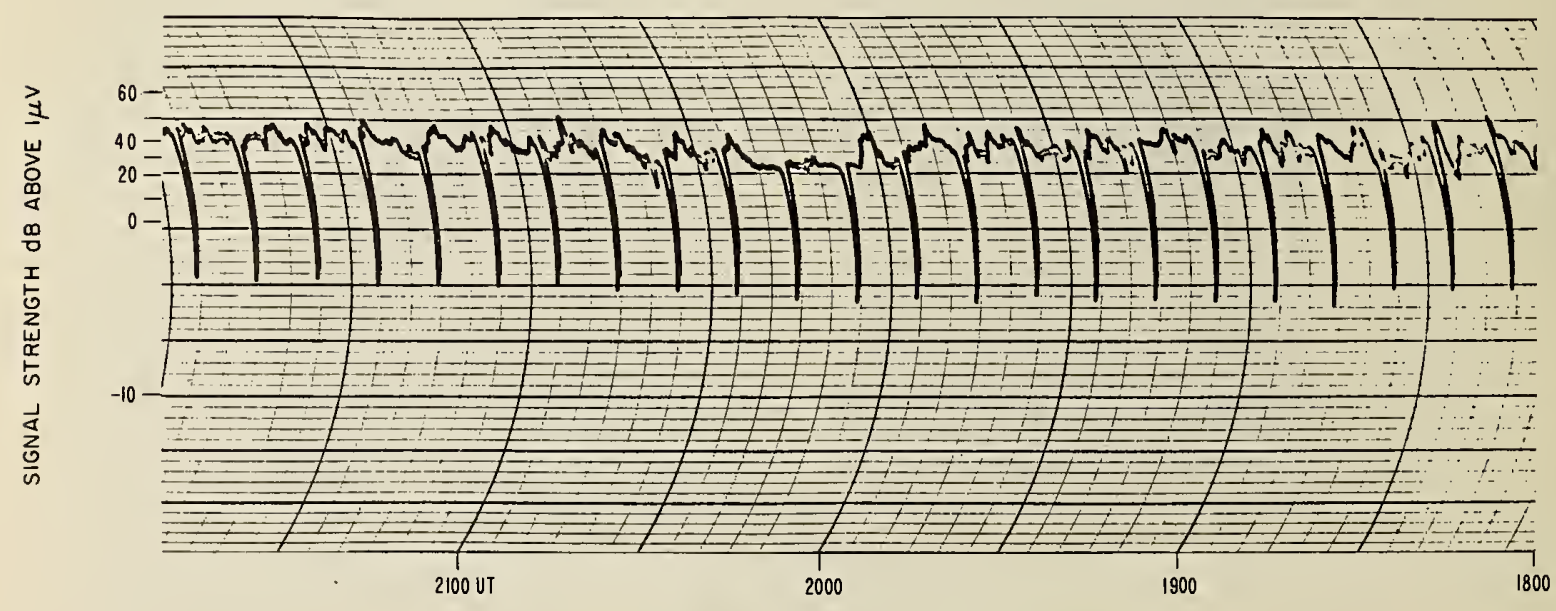

(b) $5.054 \mathrm{mC} / \mathrm{s}$, SUNSET TO BOULDER

20 APRIL 1962

Figure 58 
OPTICAL FLARE, IMPORTANCE $2,1958-2002-2038$

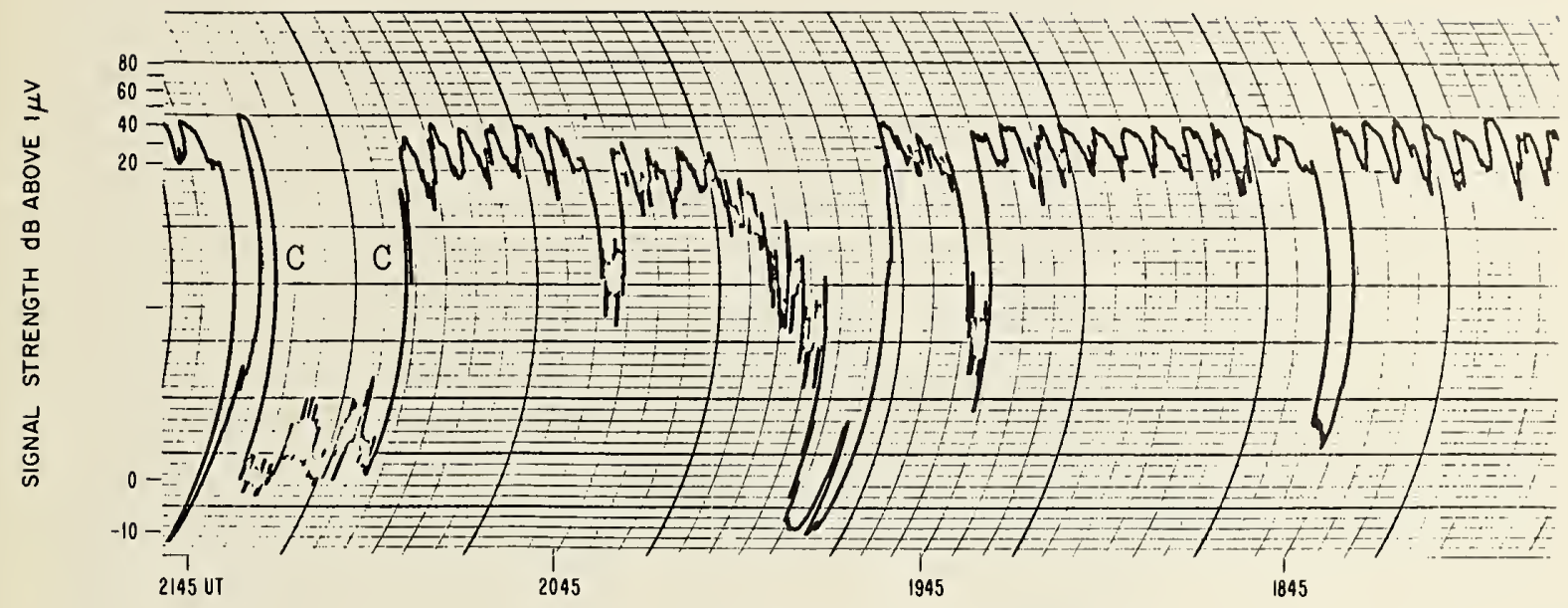

(c) $10 \mathrm{mc} / \mathrm{s}$, WWV TO BOULDER

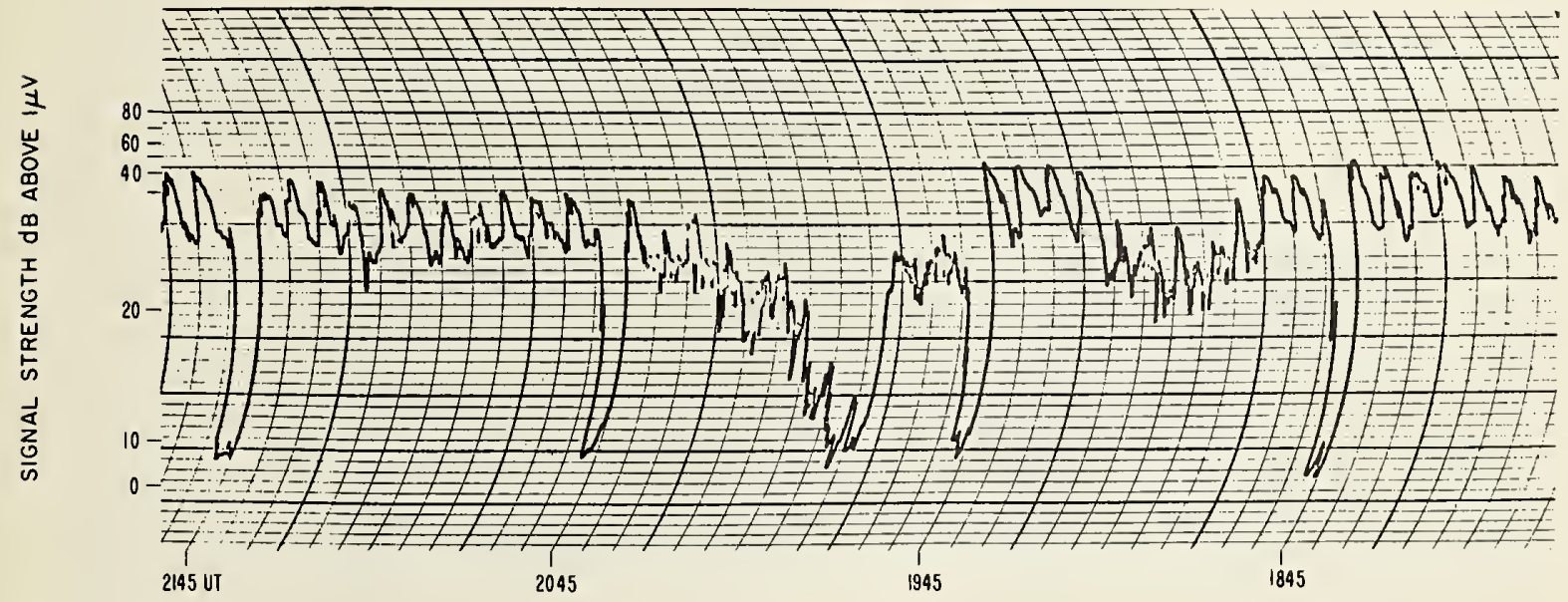

(d) $15 \mathrm{Mc} / \mathrm{s}$, WWV TO BOULDER

20 APRIL 1962

Figure 58 


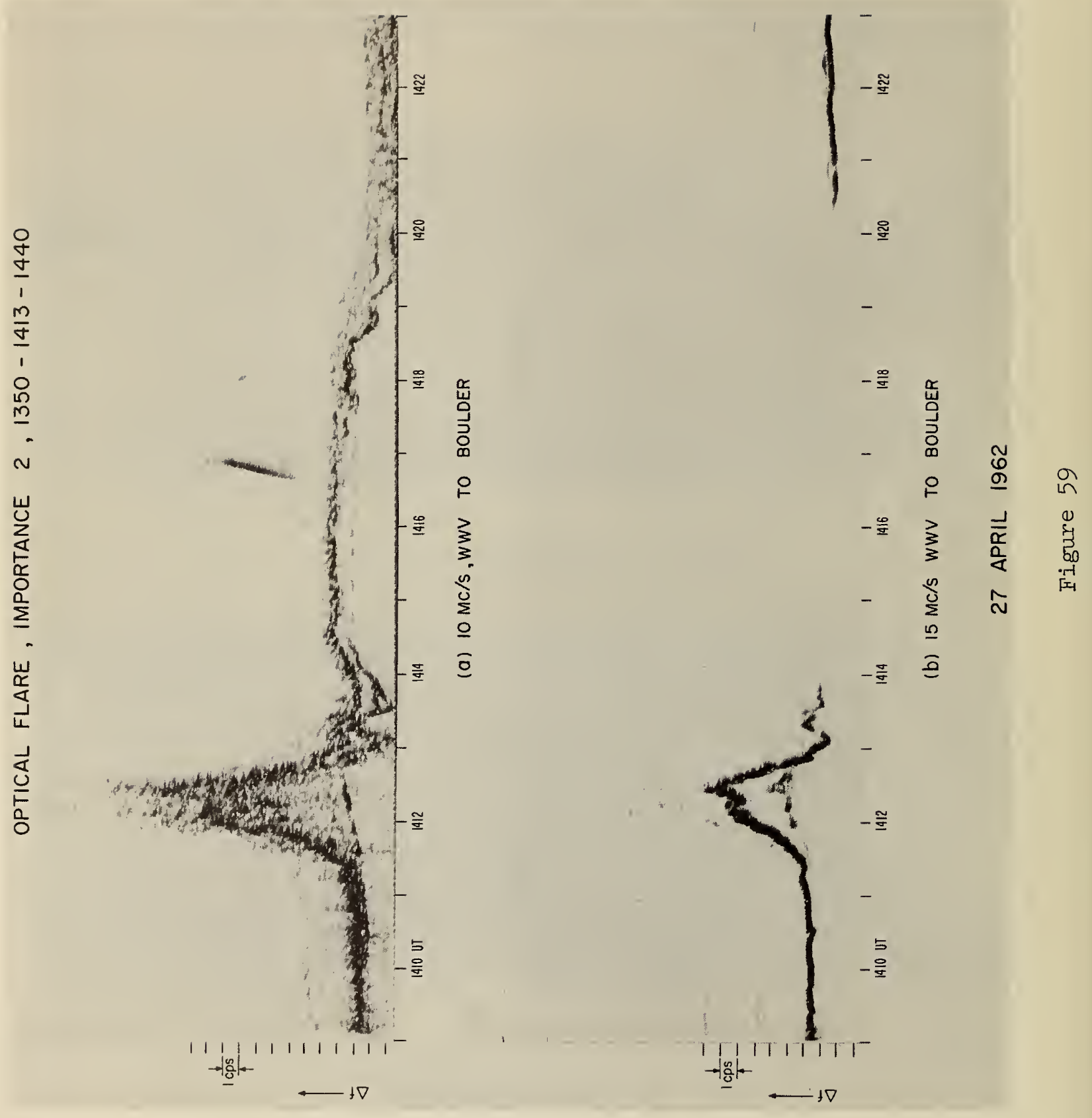


OPTICAL FLARE, IMPORTANCE $2,1350-1413-1440$

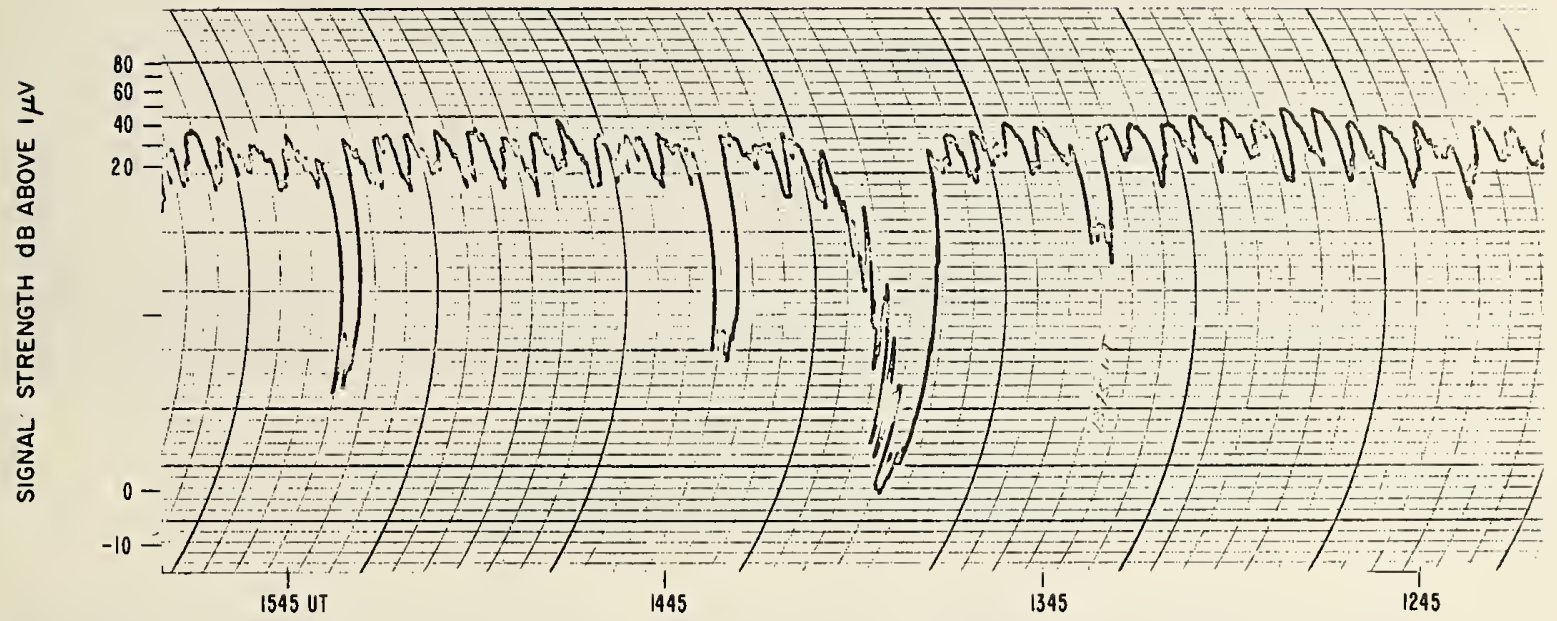

(a) $10 \mathrm{Mc} / \mathrm{s}$, WWV TO BOULDER

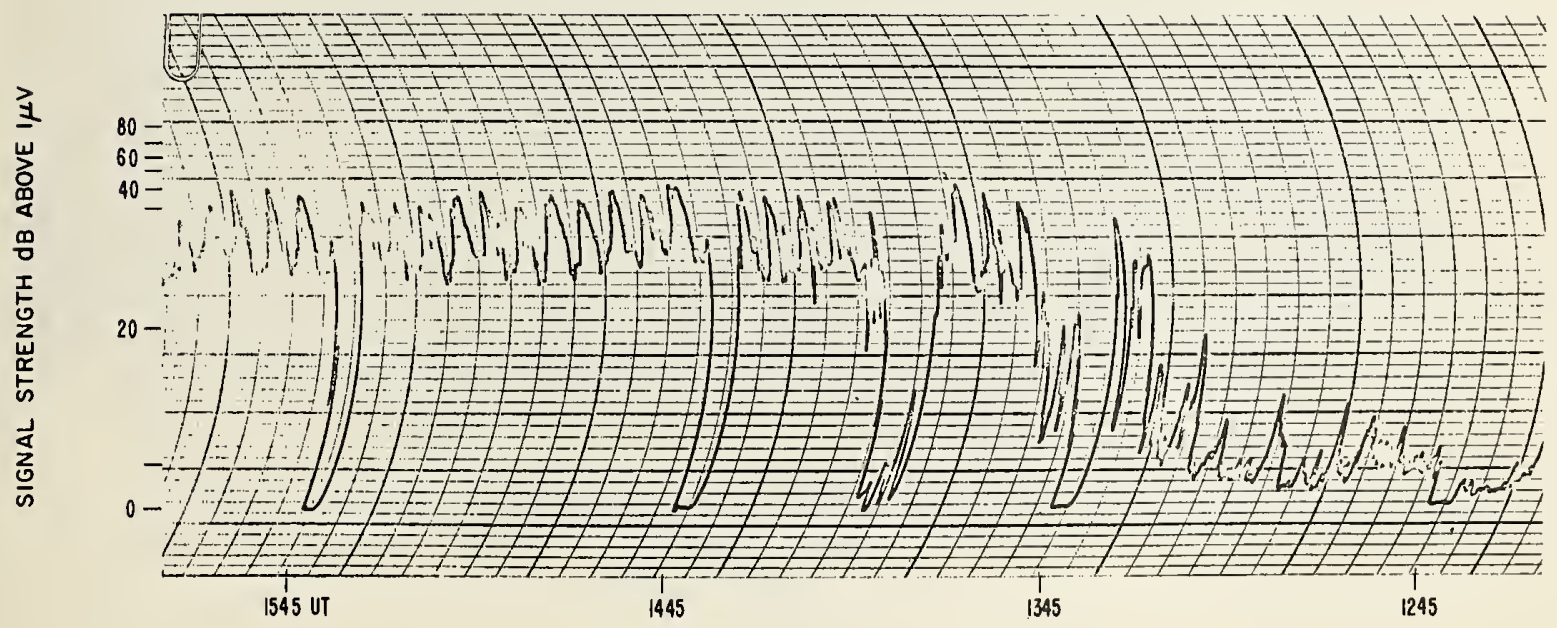

(b) $15 \mathrm{Mc} / \mathrm{s}$, WWV TO BOULDER 
OPTICAL FLARE, IMPORTANCE I, 1915-1920-1928

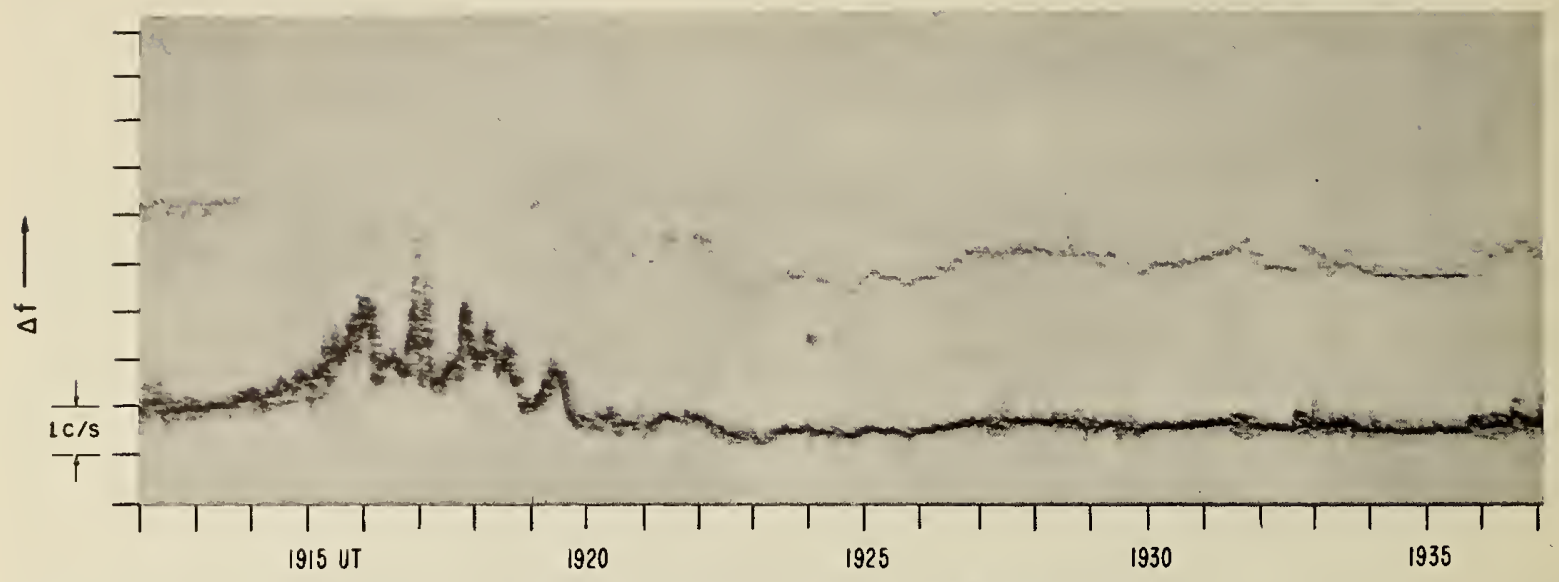

(a) $10 \mathrm{mc} / \mathrm{s}$, WWV TO BOULDER

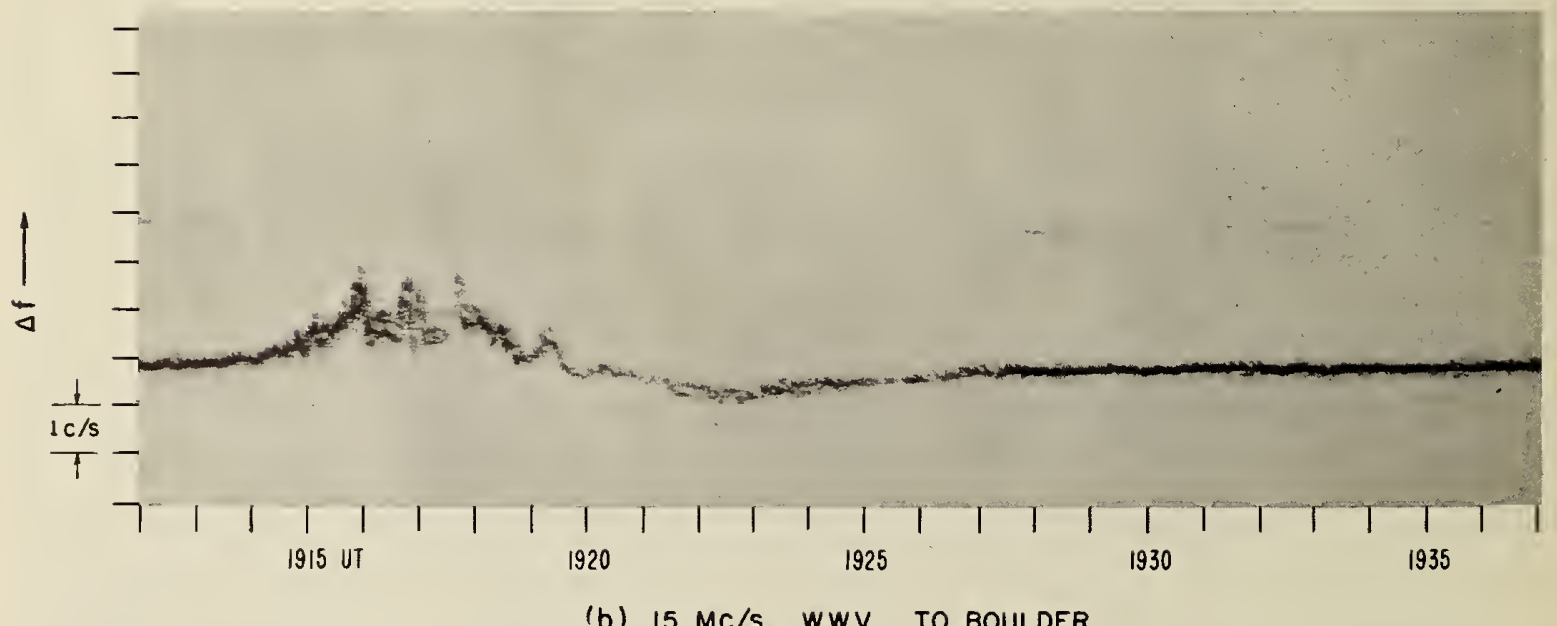

(b) $15 \mathrm{mc} / \mathrm{s}$, WWV TO BOULDER

I MAY 1962

Figure 61 
OPTICAL FLARE, IMPORTANCE $1,1908-1916-1934$

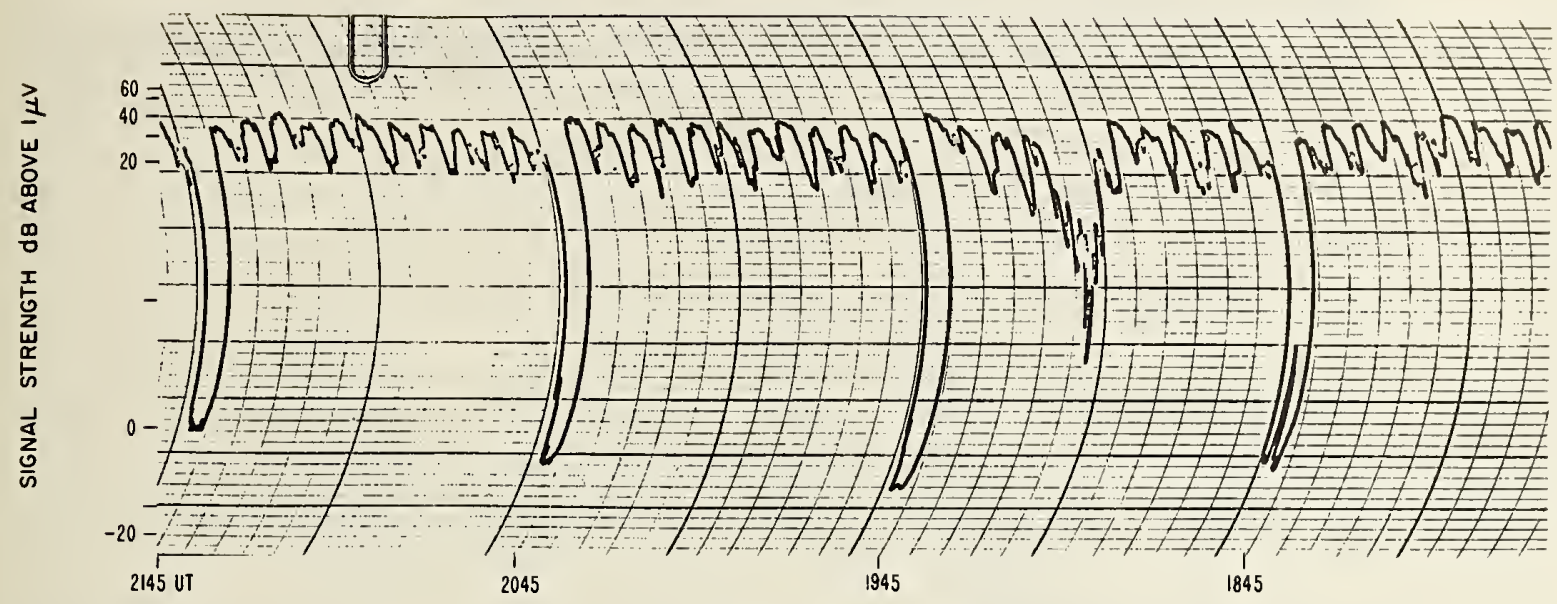

(a) $10 \mathrm{mc} / \mathrm{s}$, WWV TO BOULDER

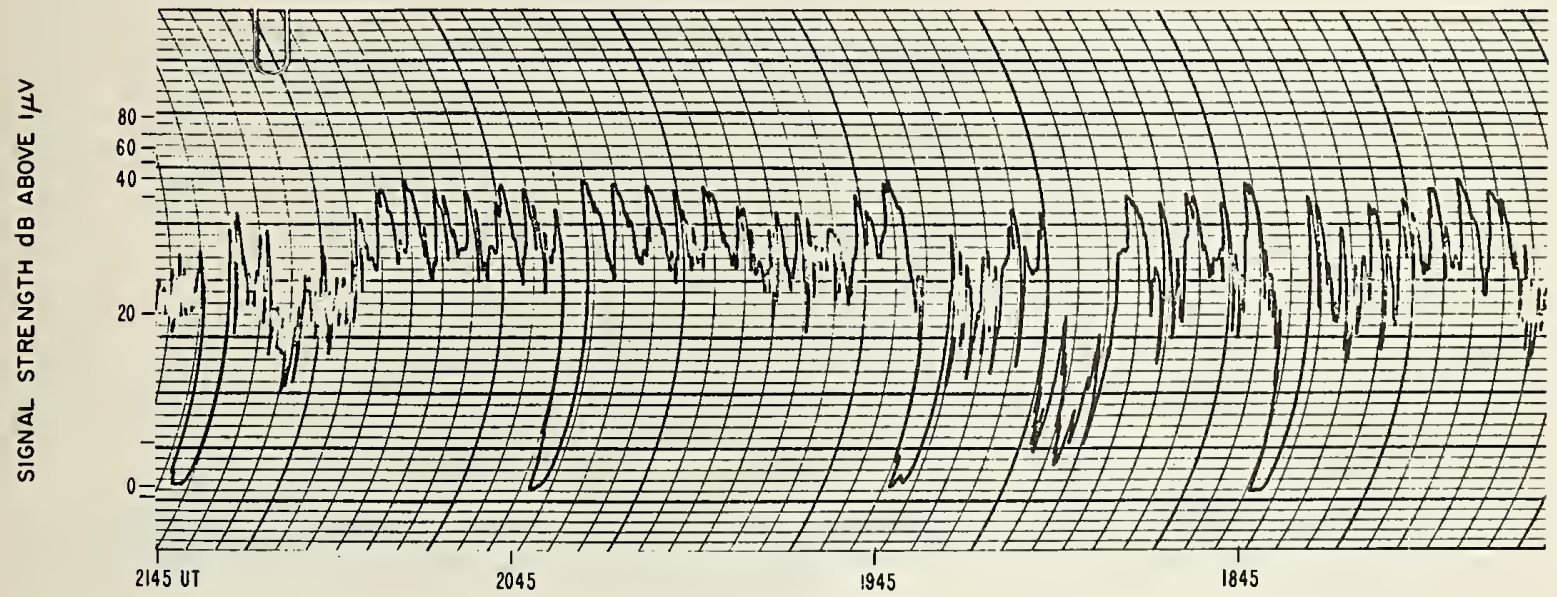

(b) $15 \mathrm{MC} / \mathrm{s}$, WWV TO BOULDER

I MAY 1962 


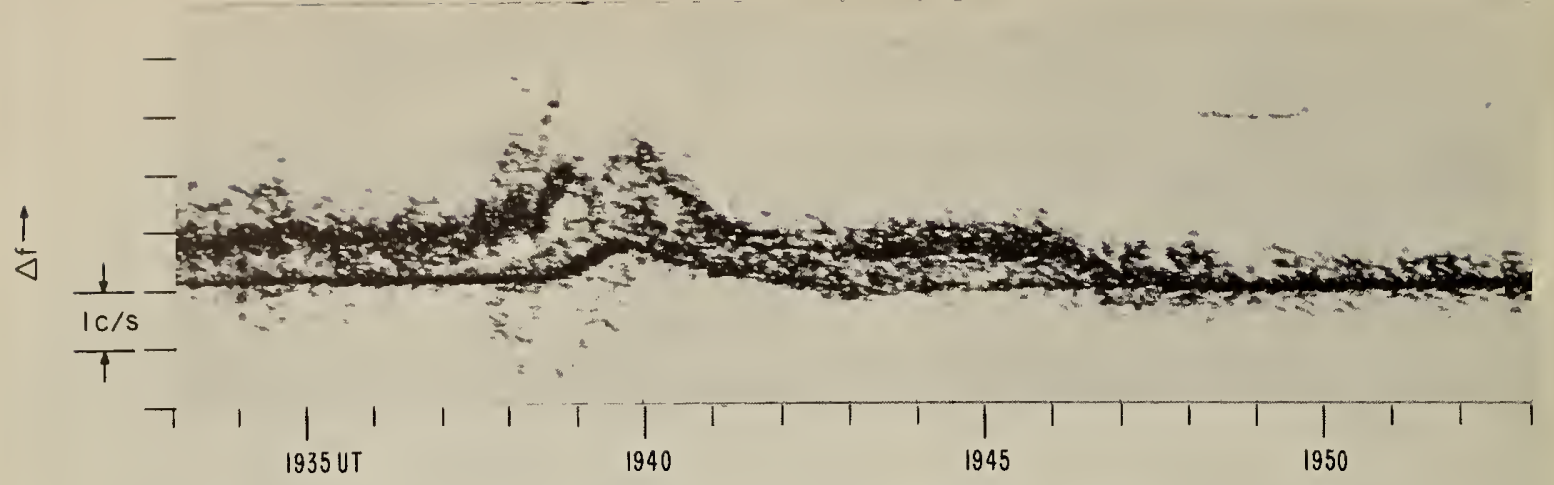

(c) WWVH- $10 \mathrm{Mc} / \mathrm{s}$ TO MIDWAY ISLAND

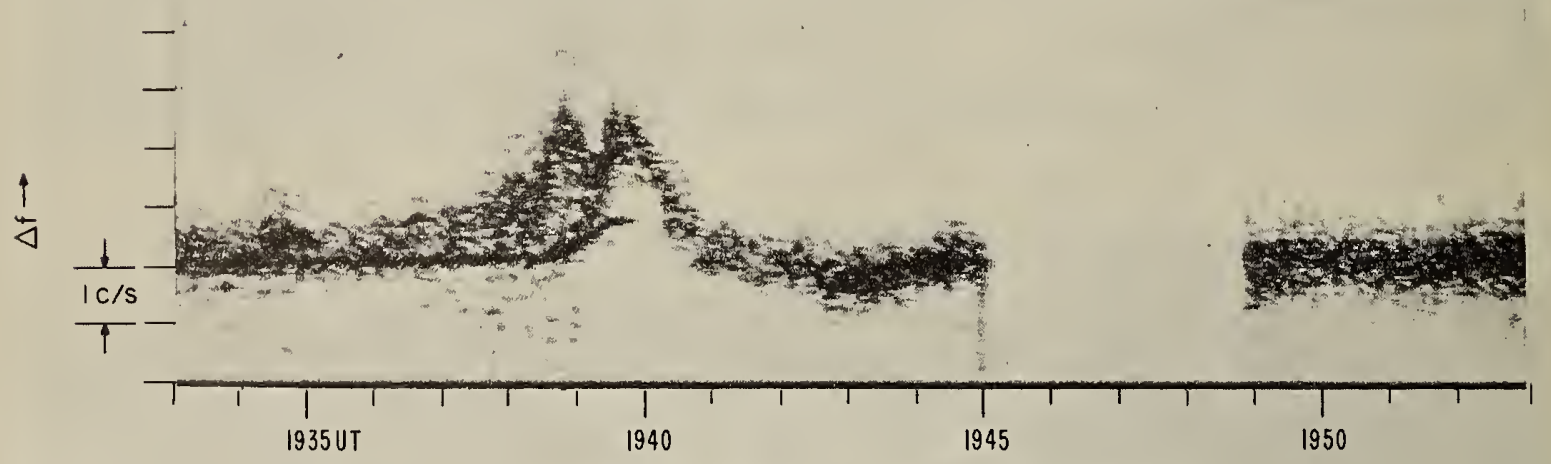

(d) $W W V-10 \mathrm{Mc} / \mathrm{s}$ TO BOULDER, COLORADO

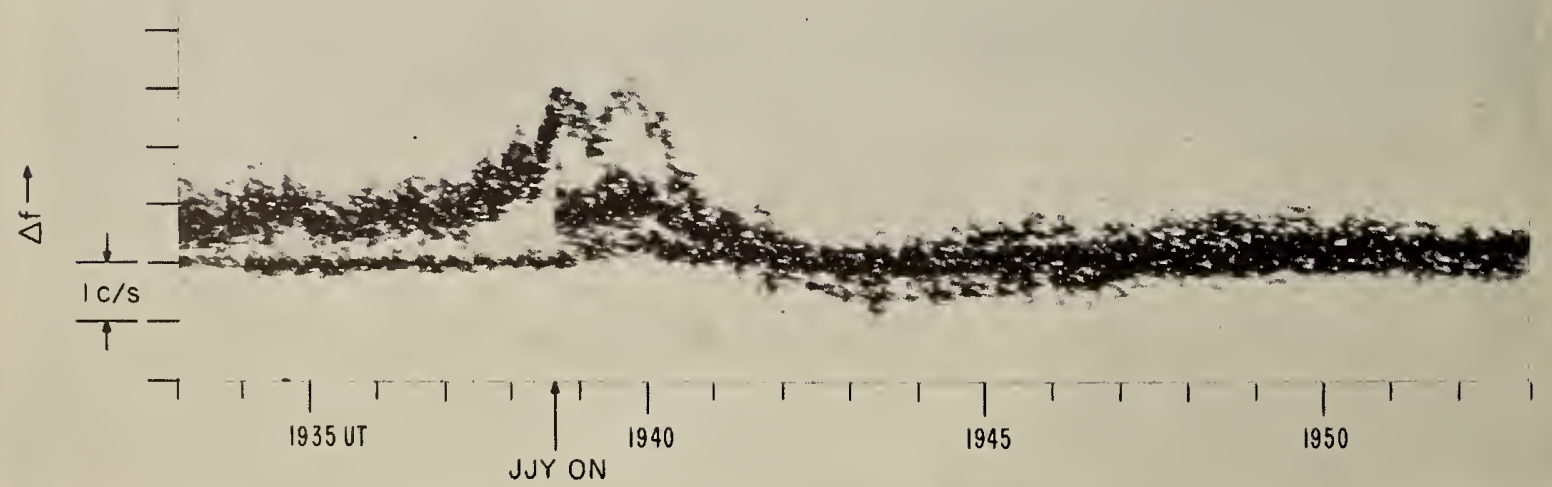

(e) WWVH AND JJY $-10 \mathrm{MC} / \mathrm{S}$ TO WAKE ISLAND

JULY 5, 1962

Figure 63 


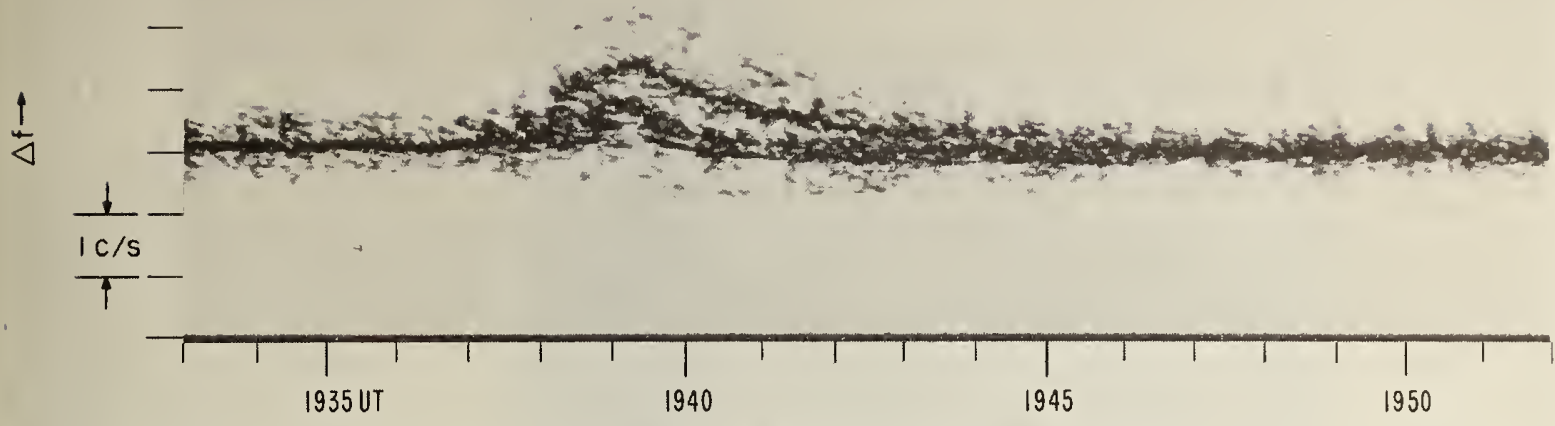

(f) WWVH - $15 \mathrm{MC} / \mathrm{S}$ TO MIDWAY ISLAND

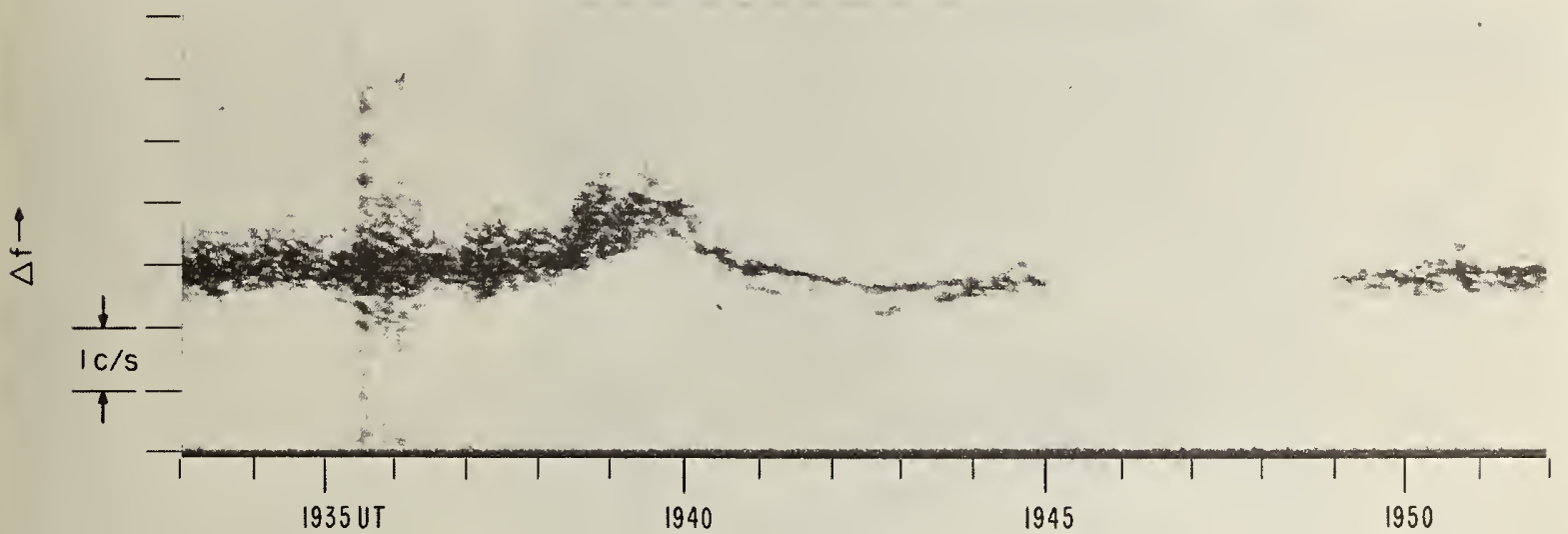

(g) WWV - $15 \mathrm{MC} / \mathrm{s}$ TO BOULDER, COLORADO

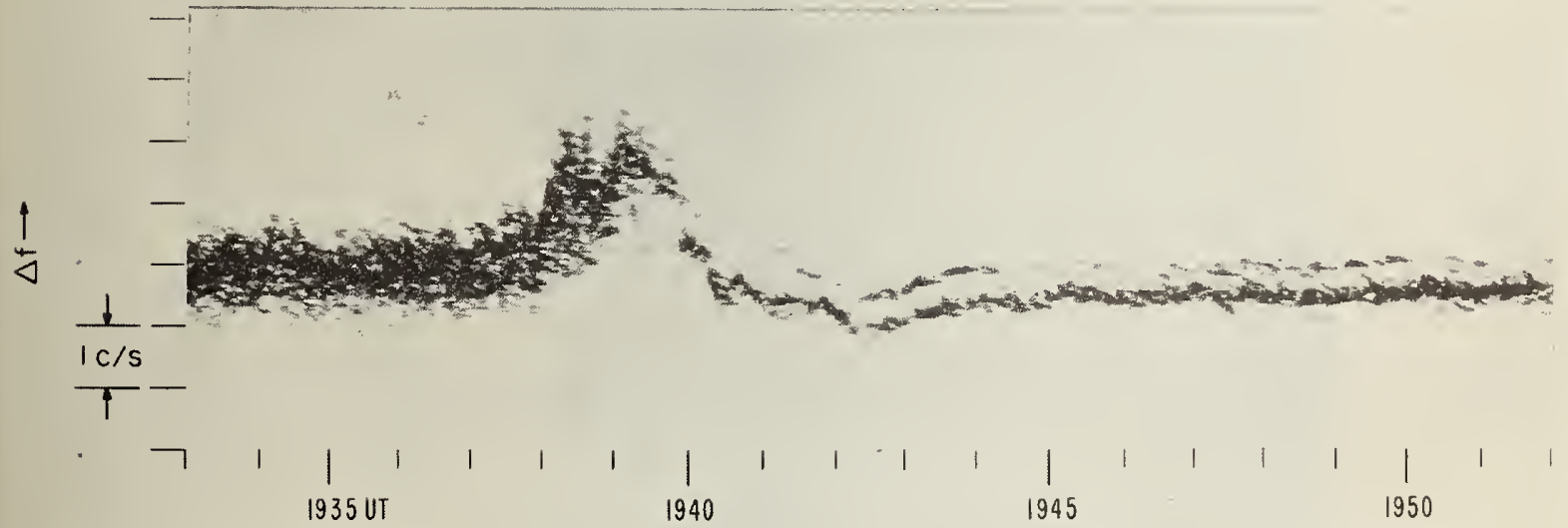

(h) $W W V H-15 \mathrm{Mc} / \mathrm{s}$ TO ANCHORAGE, ALASKA 


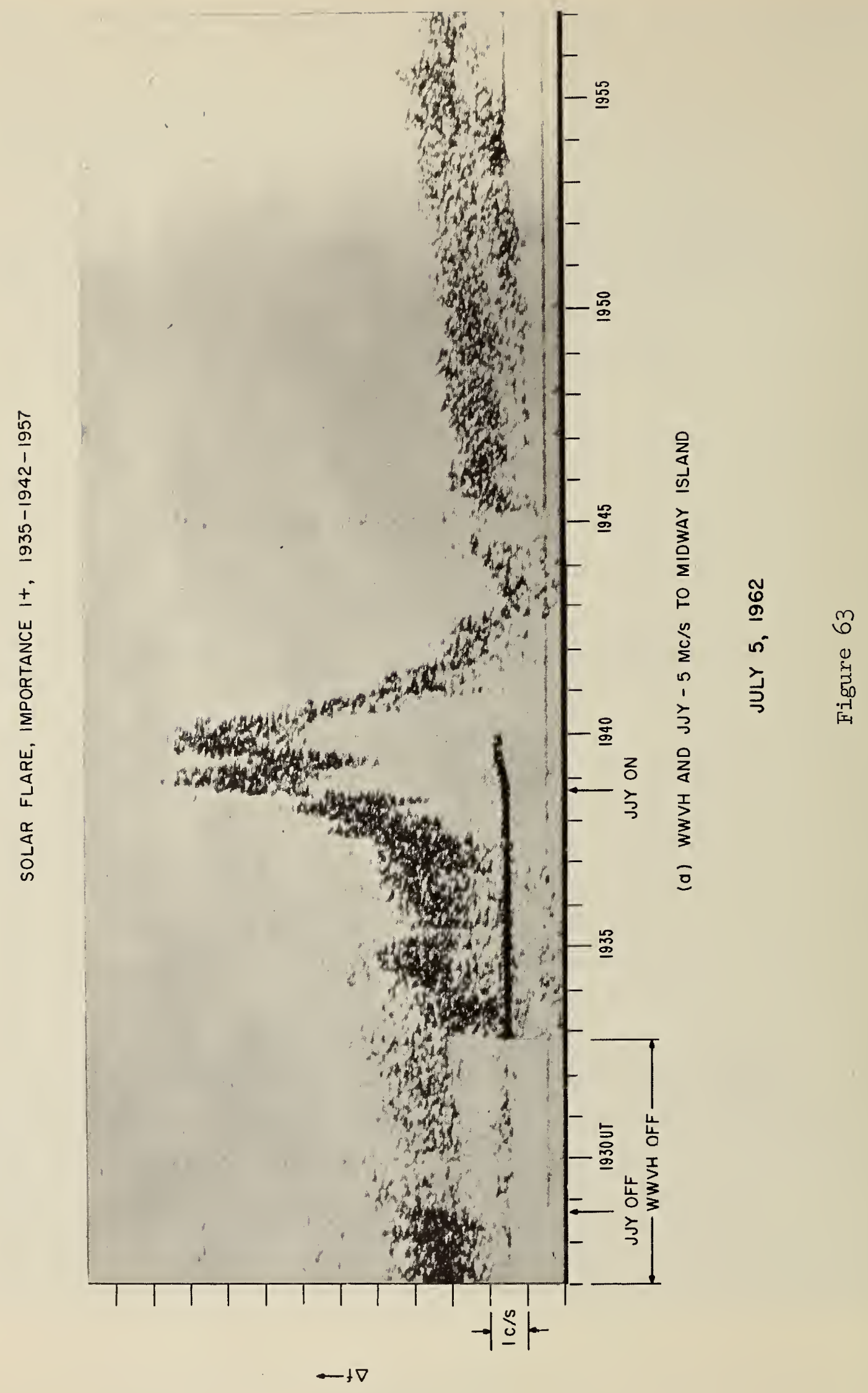


OPTICAL FLARE, IMPORTANCE I+, 1935-1942-1957

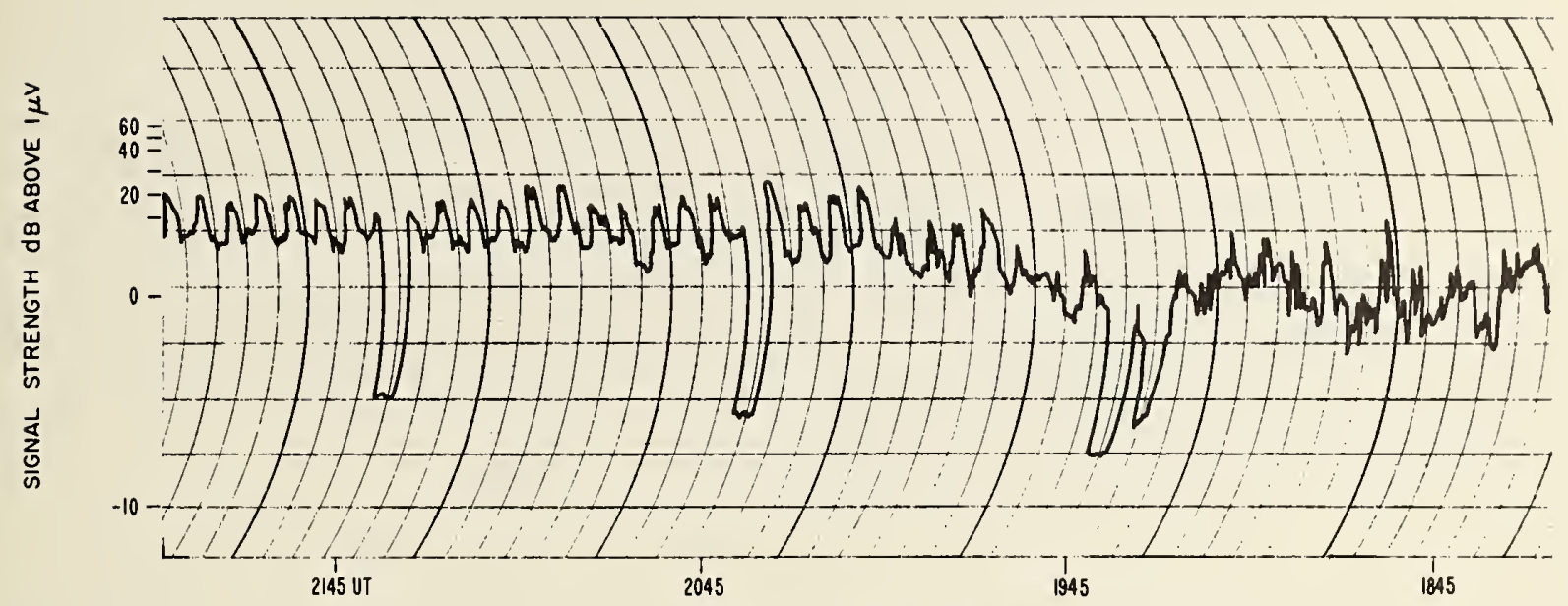

(a) $10 \mathrm{Mc} / \mathrm{s}$, WWV TO BOULDER

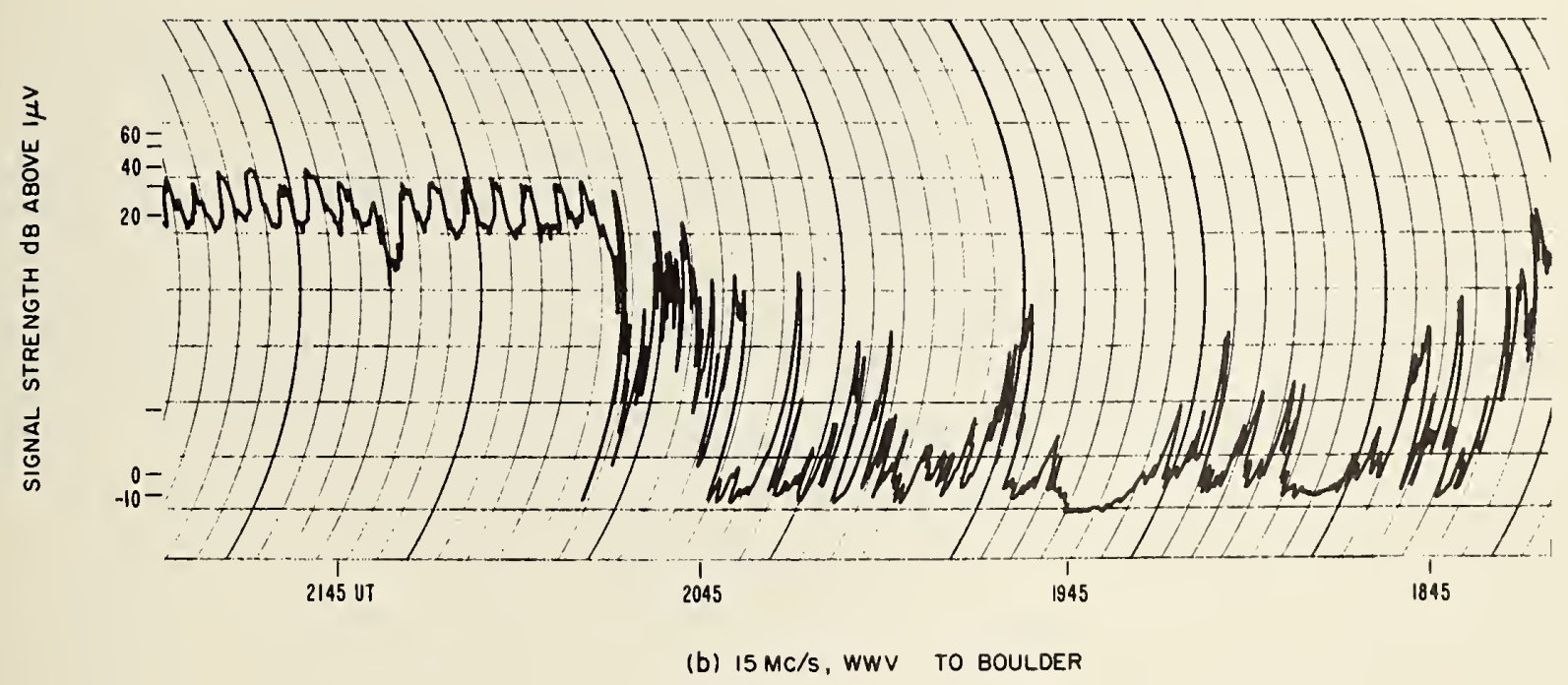

5 JULY 1962

Figure 64 
OPTICAL FLARE, IMPORTANCE I-, 2037-2045-2118

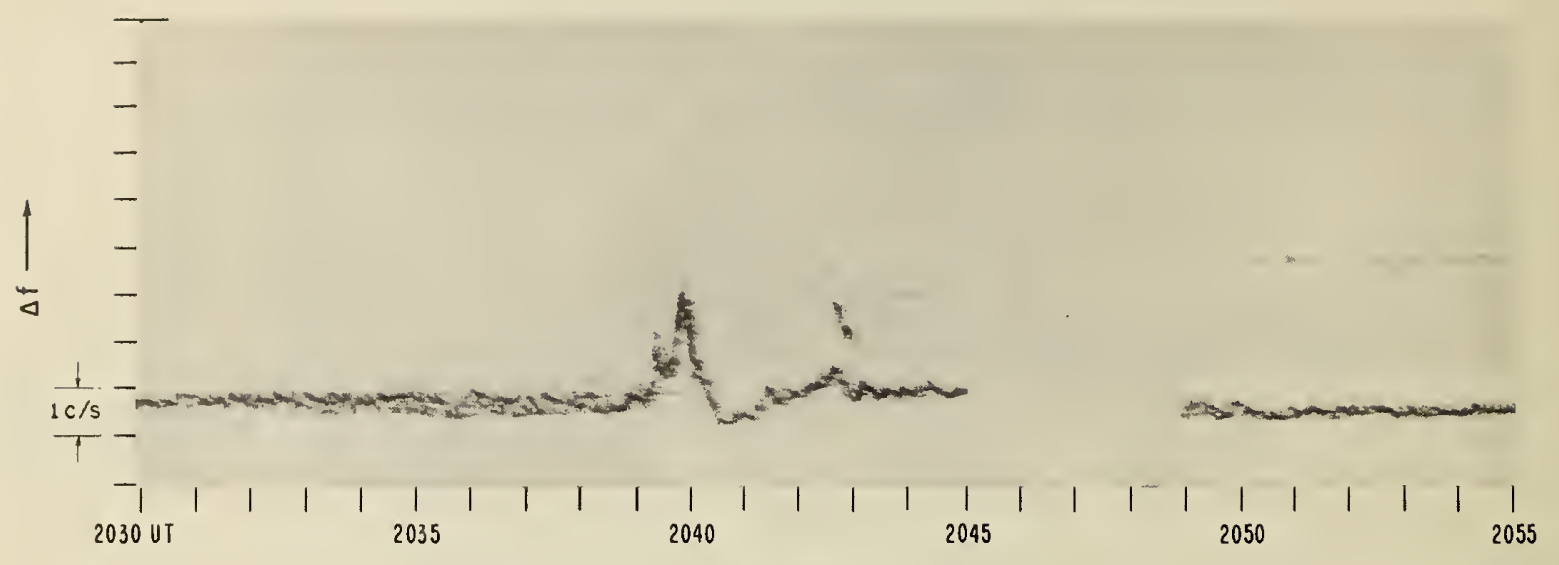

(c) $10 \mathrm{mc} / \mathrm{s}$, WWV TO BOULDER

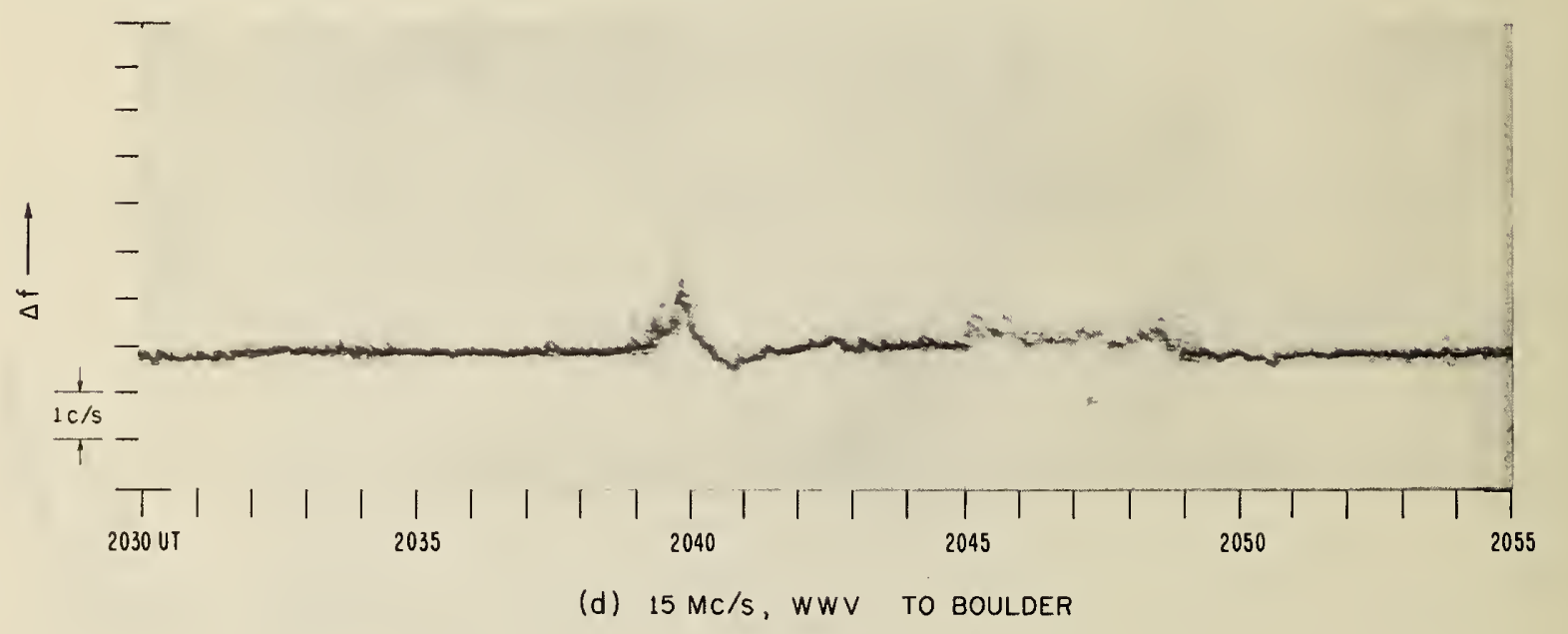

13 AUGUST 1962

Figure 65 
OPTICAL FLARE, IMPORTANCE I-, 2037-2045-2118

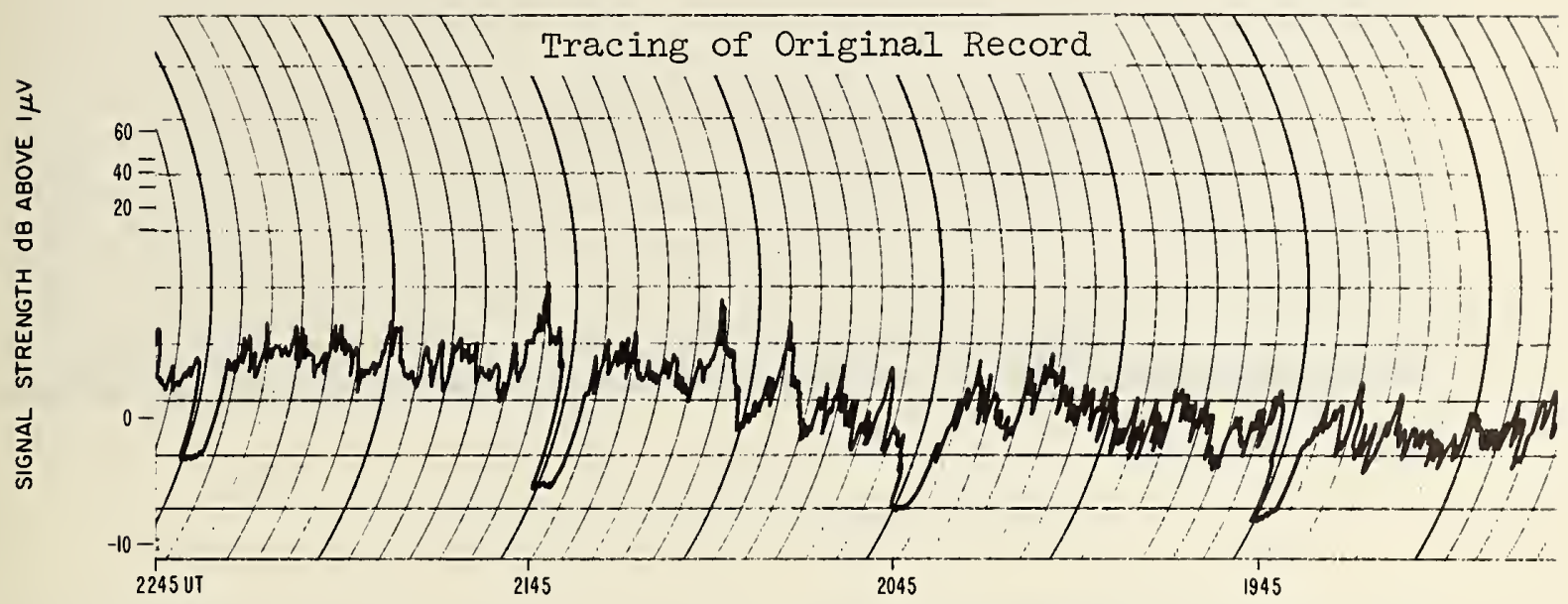

(a) $10 \mathrm{Mc} / \mathrm{s}$, WWV TO BOULDER

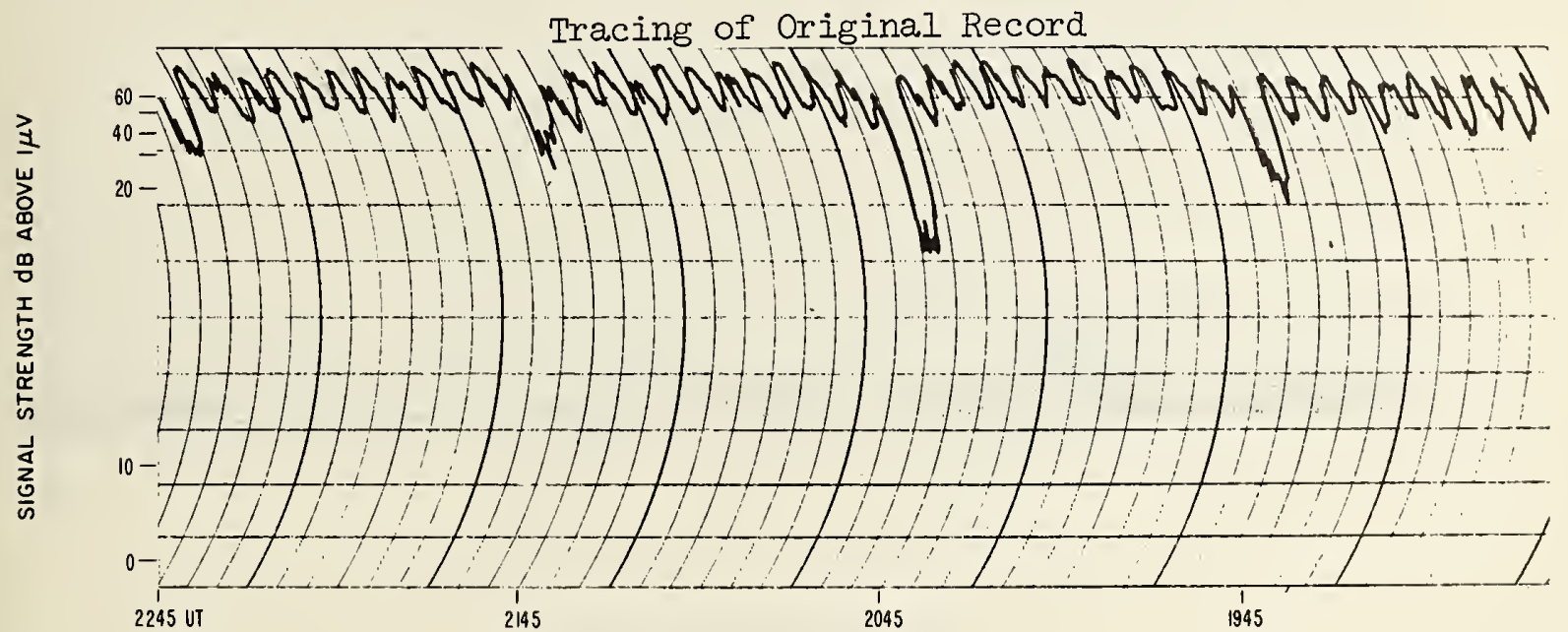

(b) $15 \mathrm{Mc} / \mathrm{s}$, WWV TO BOULOER

I3 AUGUST 1962 
OPTICAL FLARE, IMPORTANCE 1-, 1805-1808-1825

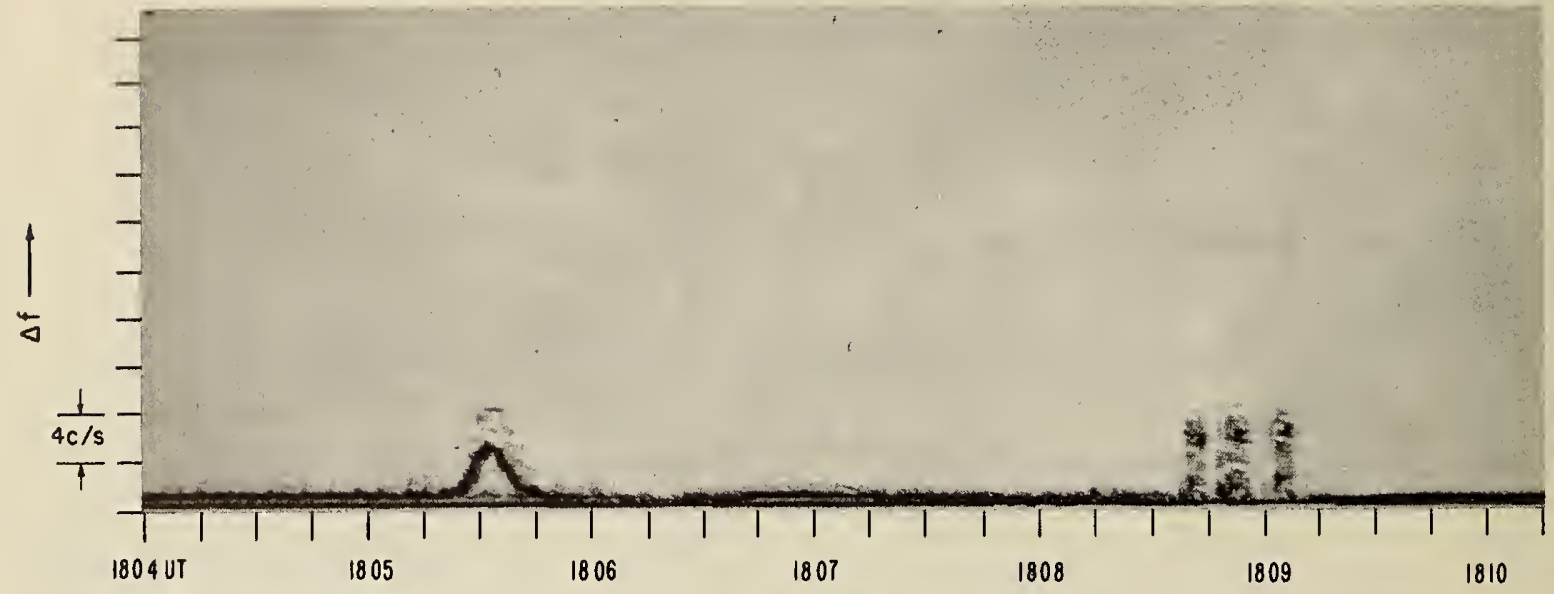

(a) $4.000 \mathrm{mc} / \mathrm{s}$, SUNSET TO BOULDER

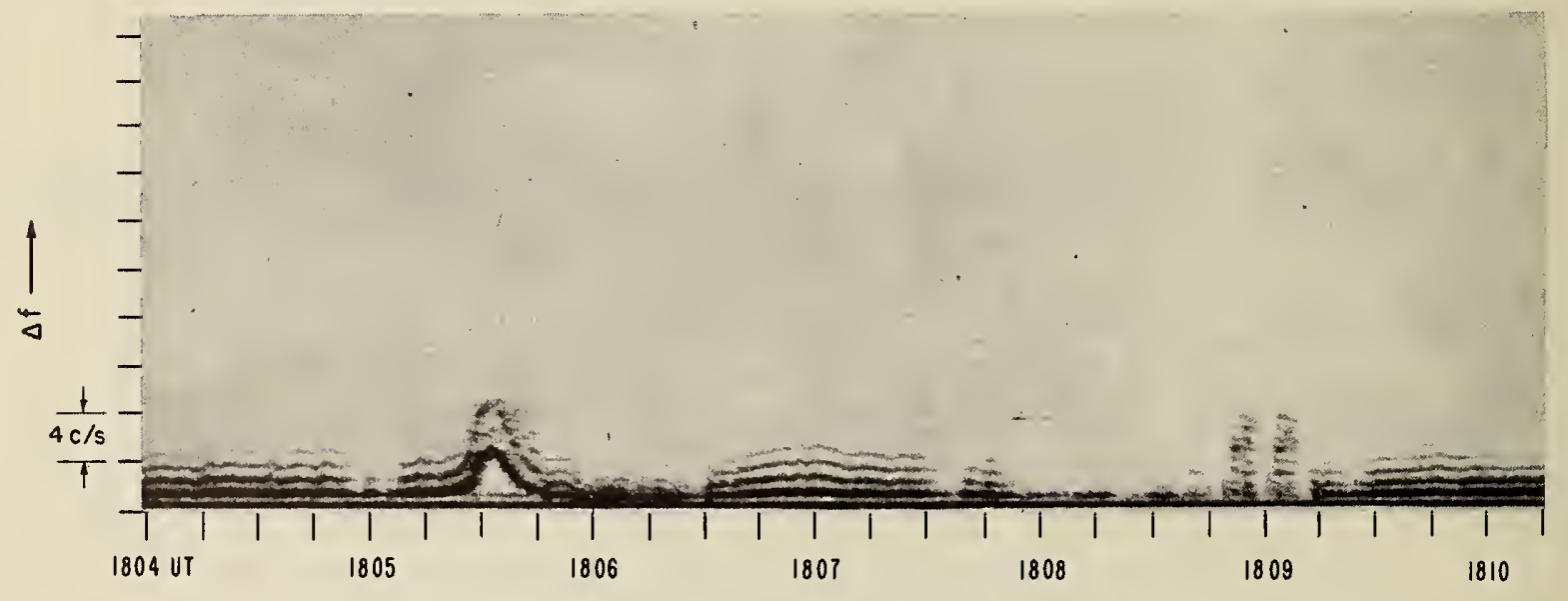

(b) $5.054 \mathrm{MC} / \mathrm{s}$, SUNSET TO BOULDER

13 OCTOBER 1962

Figure 67 
OPTICAL FLARE, IMPORTANCE 1-, 1805-1808-1825

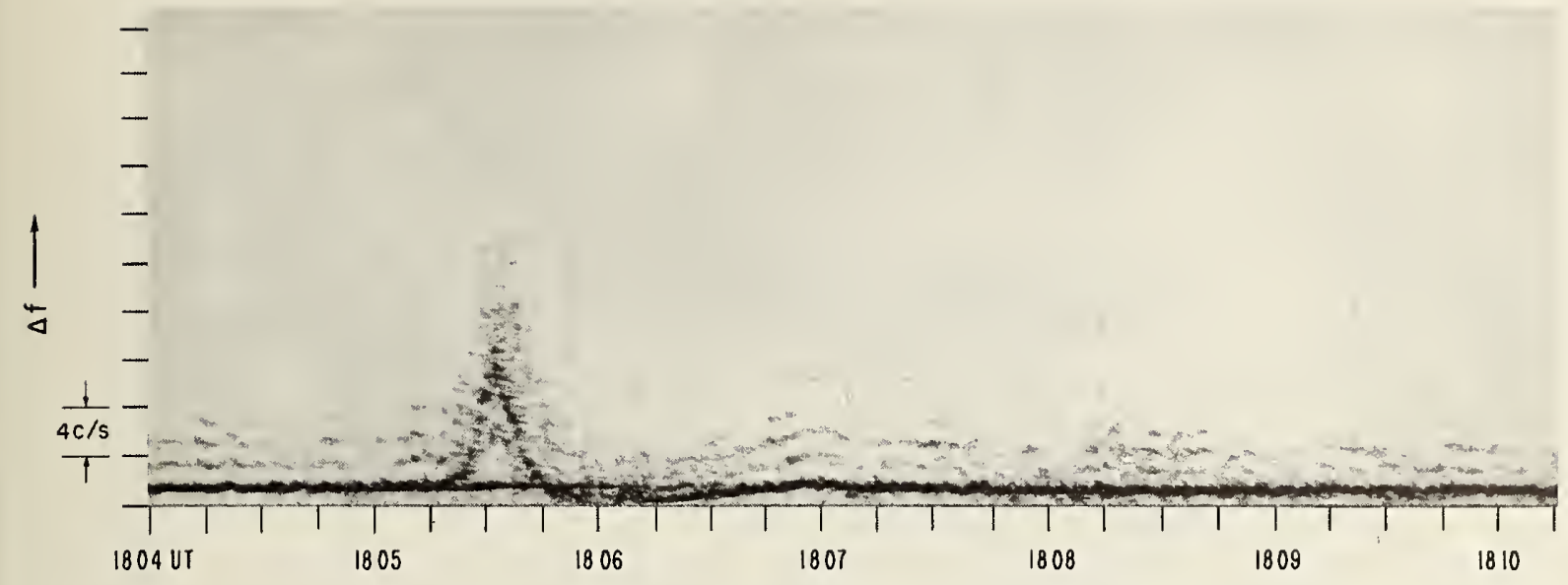

(c) $10 \mathrm{mc} / \mathrm{s}$, WWV TO BOULDER

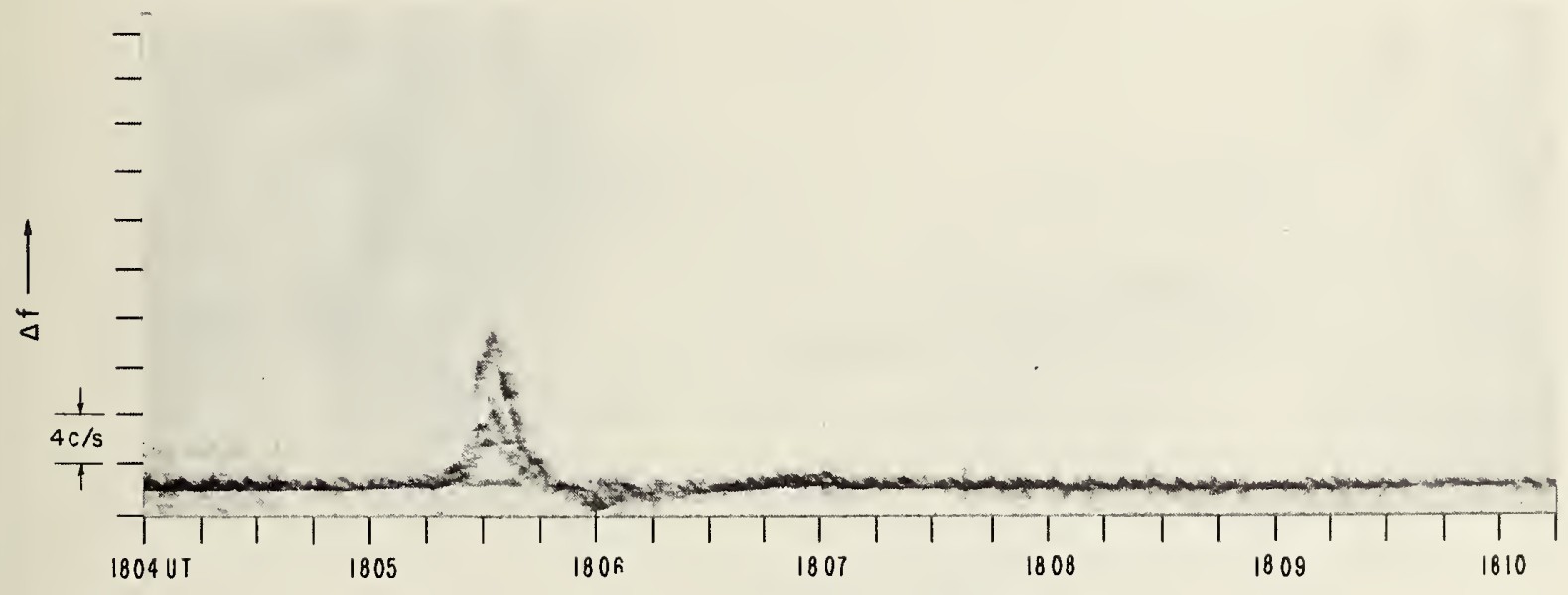

(d) $15 \mathrm{MC} / \mathrm{s}$, WWV TO BOULDER

13 OCTOBER 1962

Figure 67 
OPTICAL FLARE, IMPORTANCE I-, 1805-1808-1825

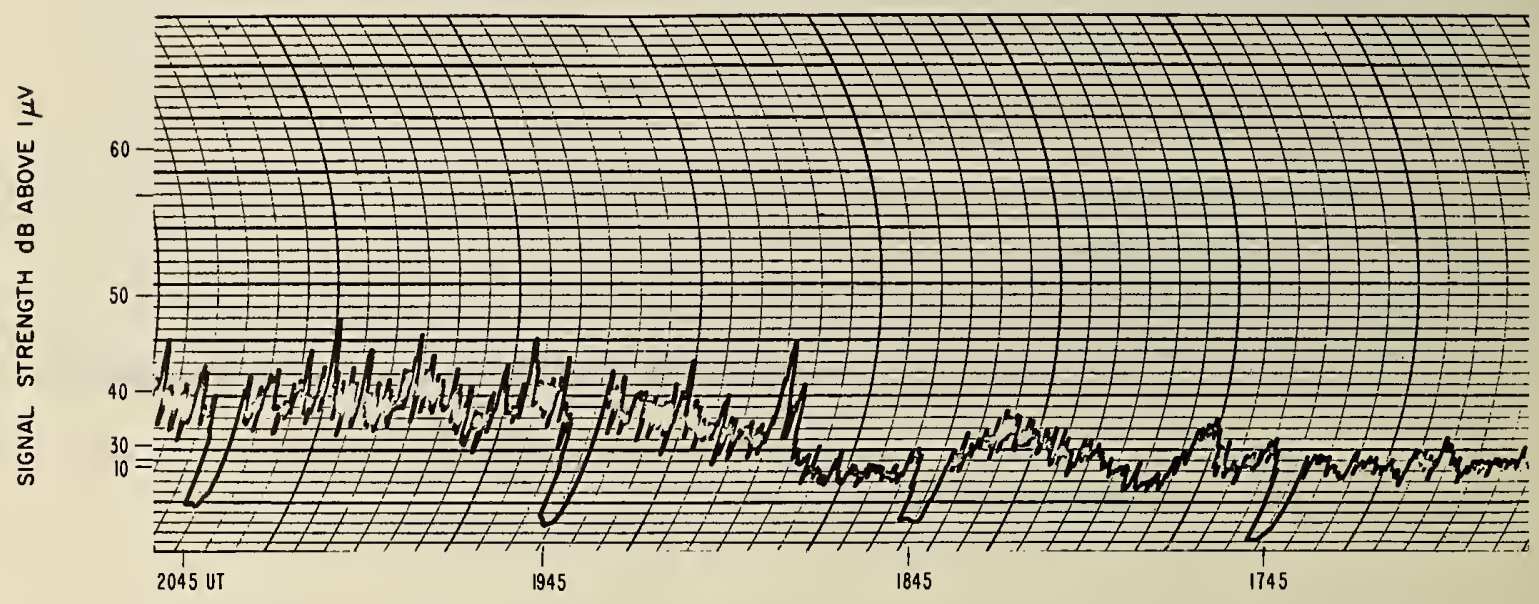

(a) $10 \mathrm{Mc} / \mathrm{s}$, WWV TO BOULDER

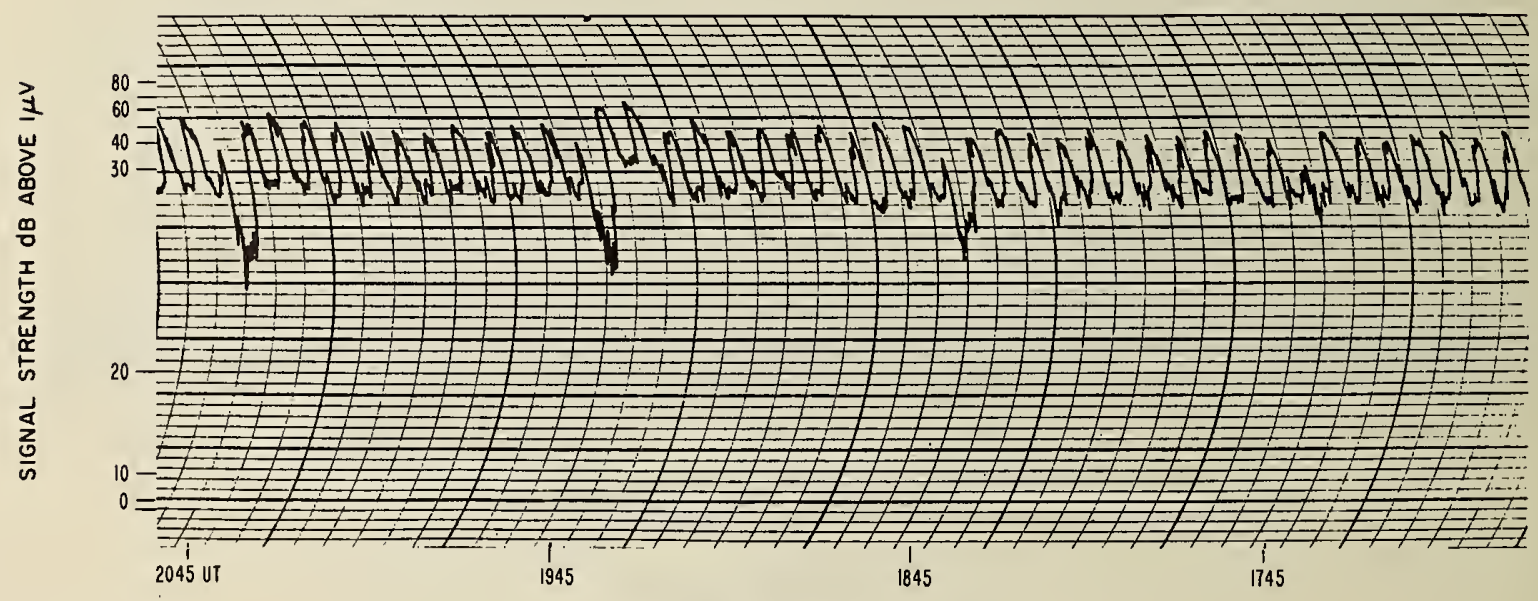

(b) $15 \mathrm{MC} / \mathrm{s}$, WWV TO BOULDER

13 OCTOBER 1962

Figure 68 

U.S. DEPARTMENT OF COMMERCE

WASHINGTON, D.C. 20230

OFFICIAL BUSINESS
POSTAGE AND FEES PAID

U.S. DEPARTMENT OF COMMERC 